UNIVERSIDADE DE SÃO PAULO

FACULDADE DE ECONOMIA, ADMINISTRAÇÃO E CONTABILIDADE PROGRAMA DE PÓS-GRADUAÇÃO EM ADMINISTRAÇÃO

\title{
A HIERARQUIA DE PREFERÊNCIA DO CONSUMIDOR EM DECISÕES DE INVESTIMENTO FINANCEIRO
}

Hudson Antunes Bessa Orientador: Prof. Dr. José Afonso Mazzon

\author{
SÃo PAULO
}


Prof. Dr. Marco Antonio Zago

Reitor da Universidade de São Paulo

Prof. Dr. Adalberto Américo Fischmann

Diretor da Faculdade de Economia, Administração e Contabilidade

Prof. Dr. Roberto Sbragia

Chefe do Departamento de Administração

Prof. Dr. Moacir de Miranda Oliveira Junior

Coordenador do Programa de Pós-Graduação em Administração 
HUDSON ANTUNES BESSA

\section{A HIERARQUIA DE PREFERÊNCIA DO CONSUMIDOR EM DECISÕES DE INVESTIMENTO FINANCEIRO}

Tese apresentada ao Departamento de Administração da Faculdade de Economia, Administração e Contabilidade da Universidade de São Paulo, como parte dos requisitos para obtenção do título de Doutor em Ciências.

Área de Concentração: Administração

Orientador: Prof. Dr. José Afonso Mazzon Versão Corrigida

São Paulo 
FICHA CATALOGRÁFICA

Elaborada pela Seção de Processamento Técnico do SBD/FEA/USP

Bessa, Hudson Antunes

A hierarquia de preferência do consumidor em decisões de investimento financeiro / Hudson Antunes Bessa. - São Paulo, 2016. $202 \mathrm{p}$.

Tese (Doutorado) - Universidade de São Paulo, 2016.

Orientador: José Afonso Mazzon.

1. Teoria da decisão 2. Investimento financeiro 3. Percepção de risco 4. Comportamento do consumidor 5. Estilo cognitivo I. Universidade de São Paulo. Faculdade de Economia, Administração e Contabilidade. II. Título. 
DEDICATÓRIA

Ao meu filho, João Henrique, que torna a minha vida mais alegre.

À minha esposa, Tereza Cristina, pelo amor, carinho e compreensão.

Ao meu pai, Lourenço, pelo exemplo de vida.

À minha mãe, Julia (in memorian), que sempre me incentivou a estudar. 



\section{AGRADECIMENTOS}

Inicio agradecendo ao meu orientador, o professor José Afonso Mazzon. Muito obrigado pelo aprendizado, por sempre abrir minha mente a novas ideias, pela confiança, pela paciência, enfim, pelo prazer da convivência.

Ao professor Riccardo Rocha, que me incentivou a cursar o doutorado em marketing e, desde o início, tem colaborado com comentários e sugestões para esta tese.

Ao professor Geraldo Toledo que me ajudou a construir uma visão integrada entre marketing e estratégia.

À ANBIMA que forneceu todas as condições necessárias para que pudesse compatibilizar a minha rotina profissional com a participação no programa de doutorado.

Aos meus companheiros da Gerência de Informações, uma equipe de alto desempenho, cujo apoio foi fundamental para que pudesse levar empresa e doutorado em paralelo. Trabalhar com vocês é muito bom! Vocês são a prova de que é possível aliar produtividade e diversão!

Aos meus amigos e amigas do mercado de financeiro que me ajudaram com conversas, dicas, indicações e que atenderam prontamente aos meus pedidos de entrevista.

Ao Daniel Infante e ao Luis Pilli pela valiosa colaboração no planejamento e execução da conjoint analysis.

Aos meus familiares e amigos, pela compreensão por minha ausência, pelo apoio e pela paciência. 



\section{RESUMO}

A literatura acadêmica sobre o comportamento do investidor financeiro é bastante escassa. A pesquisa sobre o processo de decisão, em geral, aborda tradeoffs na aquisição de produtos e pouco se discute o processo de decisão de investimento. Esta tese pretende contribuir para a redução deste gap ao discutir fatores determinantes para a tomada de decisão do investidor pessoal em produtos financeiros. A decisão de investimento é complexa, envolve, entre outros, o tradeoff entre renunciar o consumo presente pela possibilidade de maior bem estar no futuro. Adicionalmente, em muitas situações, existe possibilidade real de perda dos recursos financeiros investidos. Para investigar os percursos desta decisão foram realizadas entrevistas em profundidade com executivos ligados ao setor de fundos de investimento e ao de distribuição de produtos de investimento dos maiores bancos brasileiros atuantes no segmento de varejo. Os conhecimentos recolhidos e a revisão de literatura efetuada subsidiaram a elaboração do questionário de pesquisa aplicado em plataforma web junto a potenciais investidores. Os atributos rentabilidade, possibilidade de perda (proxy de risco), liquidez, taxa de administração e recomendação do gerente foram identificados como os mais relevantes para a decisão do investidor. Para construção dos estímulos e decomposição da utilidade da decisão foi utilizada a técnica conjoint based choice (CBC) que simula uma decisão real. Os resultados apontaram ser a recomendação do gerente o atributo mais importante para a formação da preferência por uma alternativa de investimento, resultado que, por si só, indica que fatores não racionais exercem influência na decisão. Estudou-se, então, o impacto da aversão ao risco e do estilo cognitivo do investidor. Os resultados denotam que os mais avessos e os mais intuitivos são mais suscetíveis à recomendação do gerente, mas que seus efeitos são independentes entre si. As evidências sugerem que os mais intuitivos utilizam o gerente para alcançar conforto cognitivo na decisão e que os mais avessos para mitigar a sensação de risco associada ao produto. Uma análise de cluster indicou ser possível segmentar a amostra em dois grupos, um mais propenso à recomendação do gerente e outro aos atributos do produto. A recomendação do gerente mostrou ser o atributo mais forte na distinção dos grupos. Os resultados indicam que uma segmentação de mercado baseada na propensão à recomendação do gerente pode ser efetiva para direcionar a construção de uma estratégia de relacionamento que busque incrementar os resultados de longo prazo.

Palavras Chaves: teoria da decisão, percepção de risco, comportamento do consumidor, estilo cognitivo. 


\begin{abstract}
The academic literature on the financial investor behavior is rather scarce. Research on decision generally discusses tradeoffs when purchasing products and little is discussed the investment decision process. This thesis aims to contribute to the reduction of this gap when discussing determining factors for decision making personnel investor in financial products. The investment decision is complex, involving, among others, the tradeoff between forgo present consumption by the possibility of greater well-being in the future. Additionally, in many situations, there is real possibility of loss of funds invested. To investigate the pathways of this decision were conducted in-depth interviews with executives linked to the investment fund industry and the distribution of investment products of the largest Brazilian banks operating in the retail segment. The collected knowledge and performed literature review supported the development of the survey questionnaire applied to web platform to potential investors. Attributes profitability, possible loss (risk proxy), liquidity, management fees and manager's recommendation have been identified as the most relevant for the investor's decision. Construction of stimuli and decomposition of the decision utility was based on the technique named conjoint based choice $(C B C)$ that simulates a real decision. The results showed to be the manager's recommendation the most important attribute for the formation of preference for an alternative investment, a result which, in itself, indicates that non-rational factors influence the decision. It was studied, then the impact of risk aversion and investor cognitive style. The results show that the more averse and more intuitive are more susceptible to the manager's recommendation but their effects are independent of each other. Evidence suggests that the most intuitive use the manager to achieve cognitive comfort in the decision and the most averse to mitigate the feeling of risk associated with the product. A cluster analysis indicated to be possible to segment the sample into two groups, one more prone to the manager's recommendation and the other more prone to product attributes. The manager's recommendation proved to be the strongest attribute distinguishing the groups. The results indicate that a segmentation of the market based on the propensity to manager's recommendation can be effective to direct the building of a relationship strategy that seeks to increase the long-term results.
\end{abstract}

Keywords: Decision theory, risk perception, consumer behavior, cognitive style. 


\section{Sumário}

1. Introdução

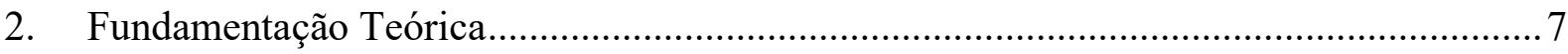

2.1 A Atividade de Gestão de Recursos de Terceiros (Asset Management) ....................... 7

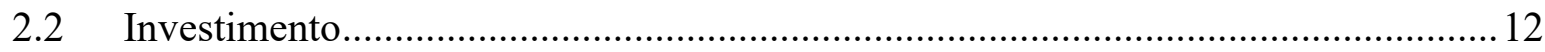

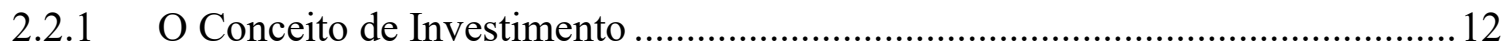

2.2.2 O Conceito de Risco na Teoria de Finanças...................................................... 14

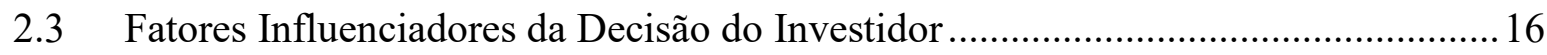

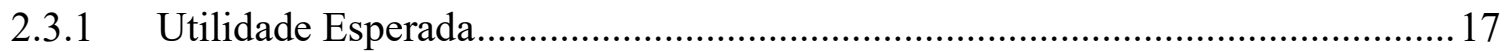

2.3.2 Análise Racional da Decisão do Consumidor ou Investidor. .............................21

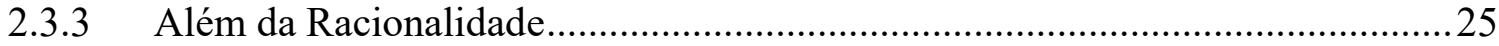

2.3.4 Prospect Theory (Teoria do Prospecto)..........................................................29

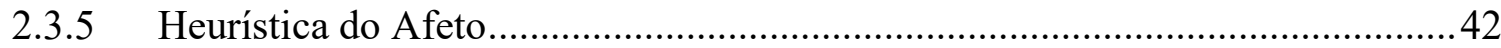

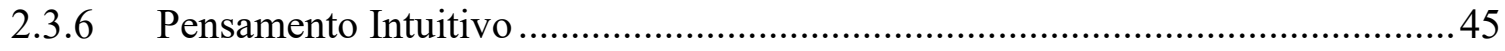

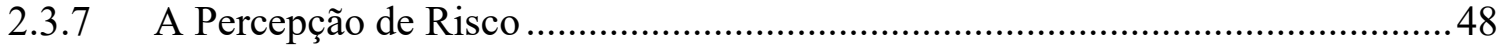

2.3.8 A importância do Gerente na Decisão de Investimento ......................................58

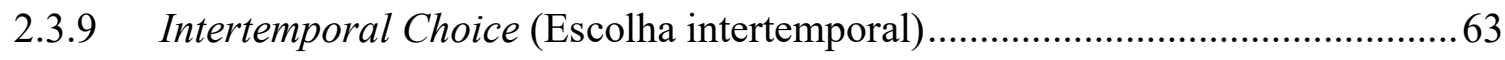

3. Contextualização e Problema da Pesquisa......................................................................... 65

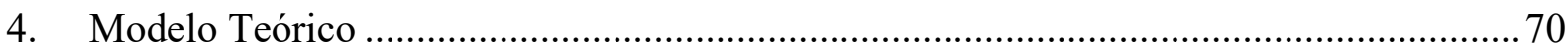

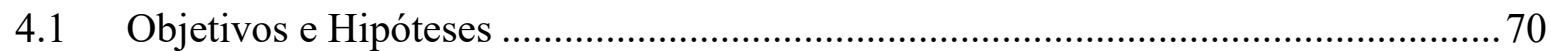

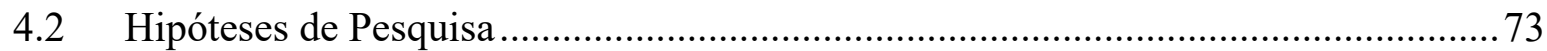

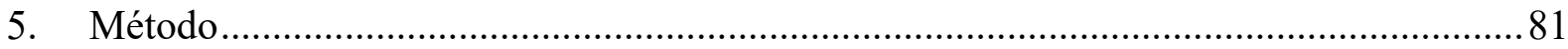

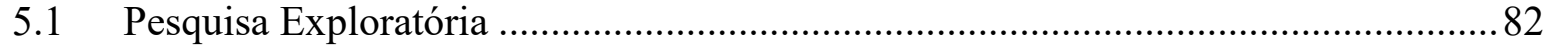

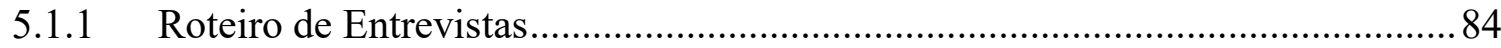

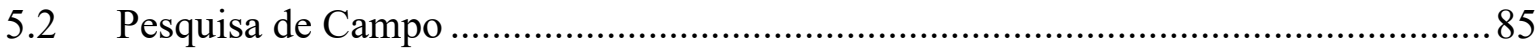

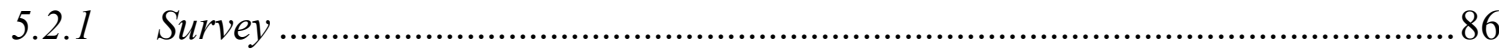

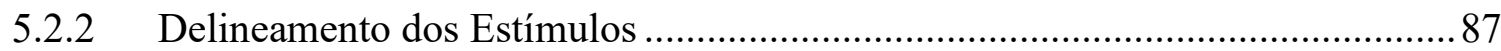




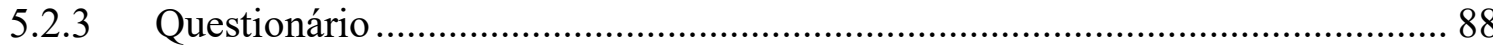

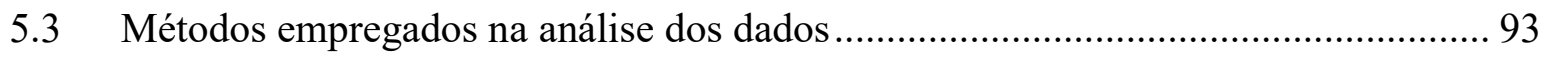

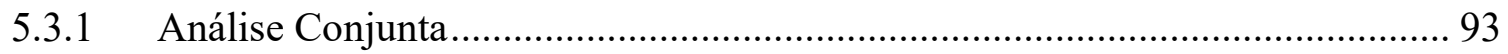

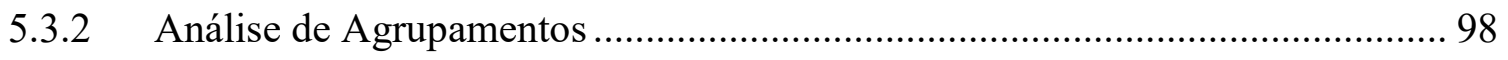

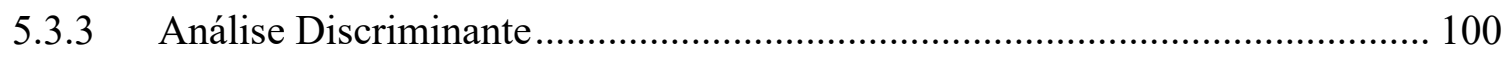

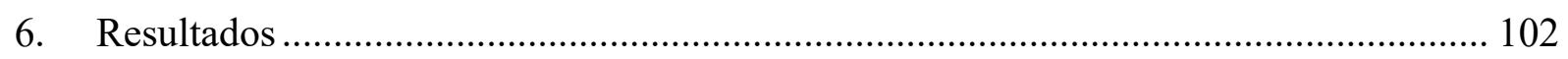

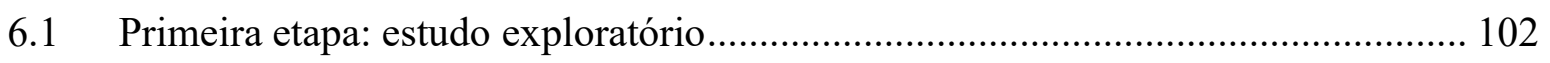

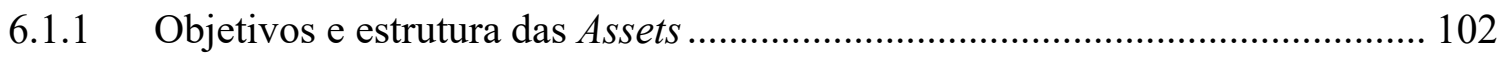

6.1.2 Bloco II - Esforços de Marketing e Propaganda ........................................... 103

6.1.3 Bloco III - Desenvolvimento de Produtos e Venda......................................... 104

6.1.4 Bloco IV - Fatores que Influenciam a Decisão do Investidor .......................... 107

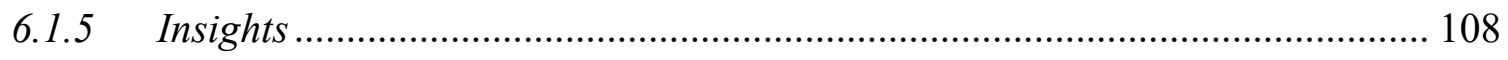

6.2 Segunda Etapa: Estudo Quantitativo............................................................. 111

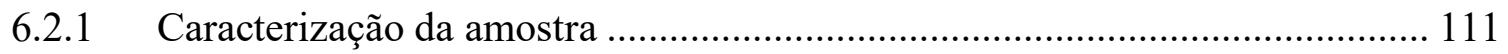

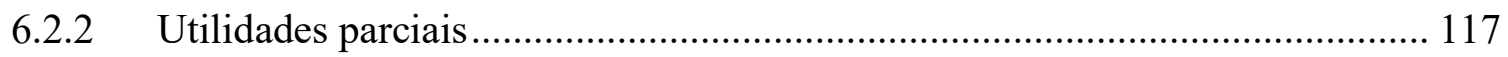

6.2.3 A importância relativa dos fatores na decisão ............................................ 123

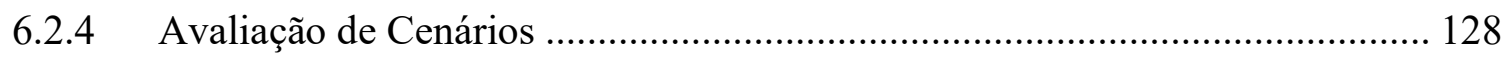

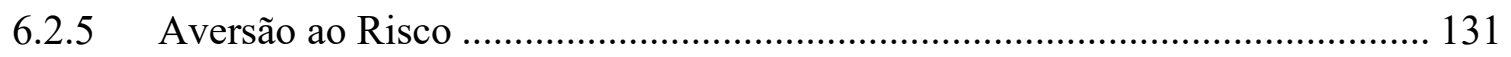

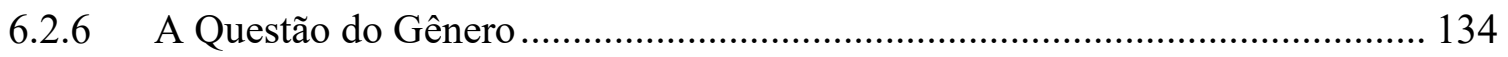

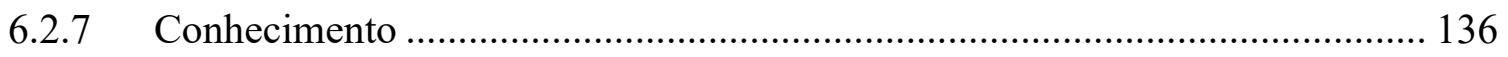

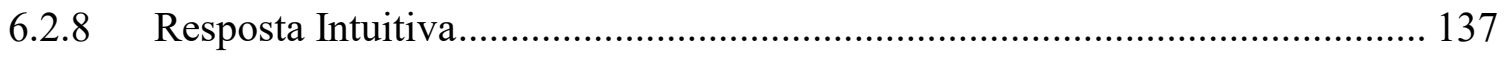

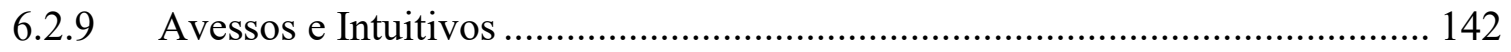

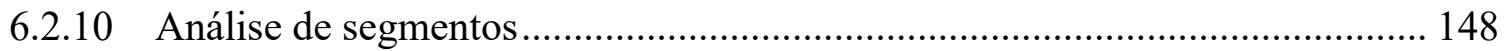

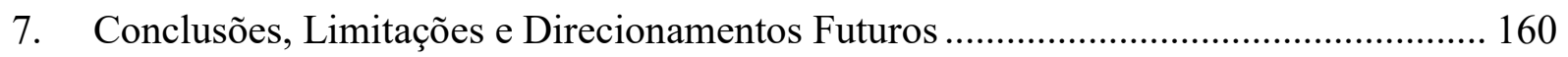

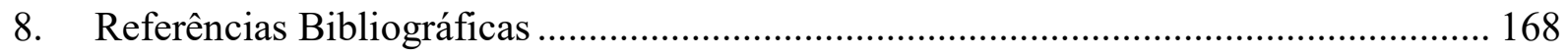

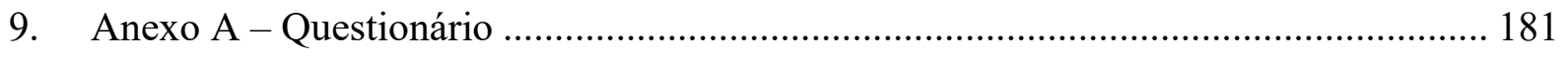




\section{LISTA DE FIGURAS}

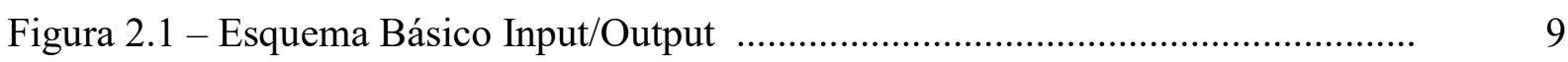

Figura 2.2 - Serviços Envolvidos na Gestão ............................................................. 10

Figura 2.3 - Curva de Utilidade de Bernoulli ................................................................ 19

Figura 2.4 - Esquema de Análise de Decisão de Louviere (1988) ................................ 22

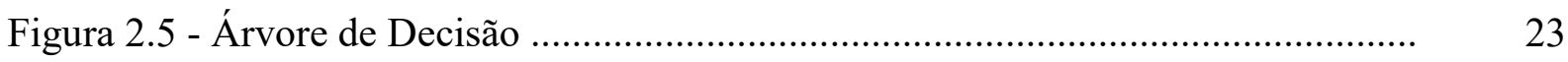

Figura 2.6 - Função Valor da Teoria do Prospecto ...................................................... 33

Figura 2.7 - Função Transformação de Probabilidades ............................................... 34

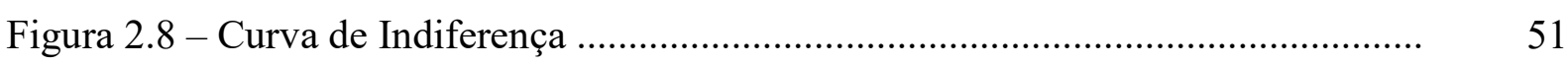

Figura 2.9 - Determinantes da Decisão em Condições de Risco .................................. 53

Figura 2.10 - Esquema de Inter-relação das Competências do Provedor e Consumidor 59

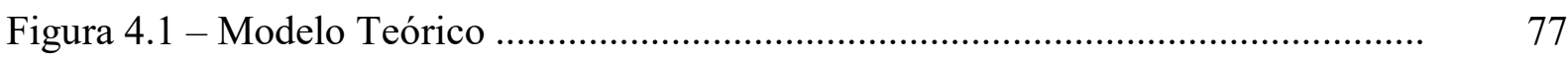

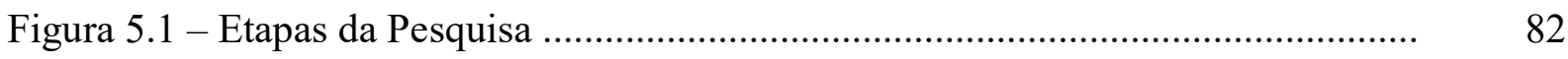

Figura 5.2 - Cálculo das Importâncias Relativas ......................................................... 96

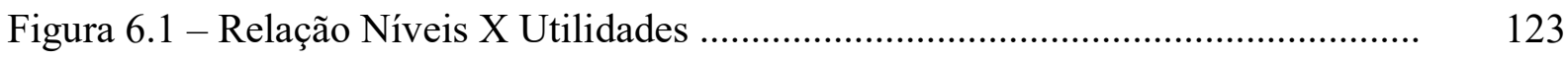

Figura 6.2 - Esquema para Tomada de Decisão de Investidores em Função da

Aversão ao Risco e do Estilo Cognitivo ......................................................................... 147

Figura 6.3 - Representação Gráfica Análise Discriminante ...................................... 155 


\section{LISTA DE QUADROS}

Quadro 2.1- Atributos Frequentemente Associados ao Conceito de Processamento

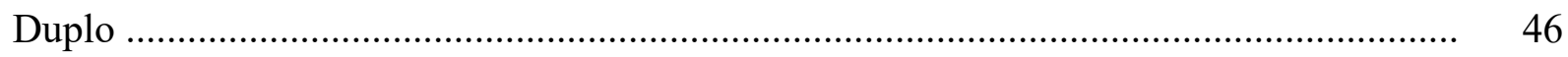

Quadro 4.1 - Sumário Hipóteses de Pesquisa ................................................................... 78

Quadro 5.1 - Roteiro das Entrevistas em Profundidade ………………………………... 84

Quadro 5.2 - Atributos e Níveis do Questionário ............................................................ 87

Quadro 5.3 - Exemplo Atributos e Níveis do Questionário .............................................. 88

Quadro 6.1 - Síntese das Hipóteses de Pesquisa ............................................................ 158 


\section{LISTA DE TABELAS}

Tabela 6.1a - Frequência - Dados Demográficos

Tabela 6.1b - Frequência - Conhecimento, Aversão ao Risco e Resposta Automática

Tabela 6.2a - Percentual de Respostas Automáticas (Intuitivas)..

Tabela $6.2 \mathrm{~b}$ - Percentual de Respostas Corretas

Tabela 6.3 - Cenário X Avaliação.

Tabela 6.4 - Importâncias Relativas para Cenários Distintos

Tabela 6.5 - Variação da Utilidade: Aversão ao Risco

Tabela 6.6 - Importância Relativa dos Atributos na Decisão: Aversão ao Risco.

Tabelas 6.7 - Importância Relativa dos Atributos na Decisão: Gênero

Tabela 6.8 - Gênero X Intuição

Tabela 6.9 - Aversão ao Risco X Conhecimento

Tabela 6.10 - Variação da Utilidade: Estilo Cognitivo

Tabela 6.11 - Importância Relativa dos Atributos na Decisão: Estilo Cognitivo

Tabela 6.12 - Estilo Cognitivo X Aversão ao Risco

Tabela 6.13 - Clusters: Importância Relativa dos Atributos na Decisão

Tabela 6.14 - Fator Preponderante na Decisão: Distribuição \% entre Clusters

Tabela 6.15 - Análise Discriminante: Significância das Variáveis Previsoras

Tabela 6.16 - Autovalor e Correlação Canônica

Tabela 6.17 - Coeficientes Padronizados da Função Discriminante Canônica

Tabela 6.18 - Matriz de Correlação Estrutural

Tabela 6.19 - Classificação dos Casos: Original X Previstos

Tabela 6.20 - Clusters X Aversão ao Risco 


\section{LISTA DE GRÁFICOS}

Gráfico 6.1 - Frequência Simples e Acumulada por Faixa Etária .................................. 113

Gráfico 6.2 - Comparação Perfil de Risco Brasil X EUA ................................................ 115

Gráfico 6.3 - Rentabilidade: Utilidades Parciais Médias dos Níveis .............................. 119

Gráfico 6.4 - Risco (pior rentabilidade): Utilidades Parciais Médias dos Níveis ............. 120

Gráfico 6.5 - Recomendação do Gerente: Utilidades Parciais Médias dos Níveis ........... 121

Gráfico 6.6 - Liquidez: Utilidades Parciais Médias dos Níveis ..................................... 121

Gráfico 6.7 - Taxa de Administração: Utilidades parciais médias dos Níveis .................. 122

Gráfico 6.8 - Importância Relativa dos Fatores na Decisão ........................................... 125

Gráfico 6.9- Fator mais Importante na Decisão (\% de respondentes) ............................ 126

Gráfico 6.10 - Efeitos Isolados das Variáveis Intuição e Aversão .................................... 143

Gráfico 6.11 - Efeitos do Estilo Cognitivo e da Aversão ao Risco na Recomendação do

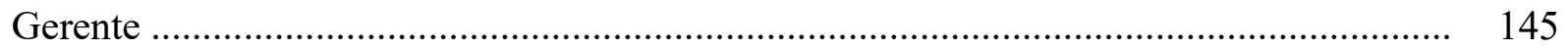

Gráfico 6.12 - Relação entre as Importâncias dos Atributos: Clusters X Média Geral .... 150

Gráfico 6.13 - Variação das Utilidades dos Atributos por Cluster.................................... 152 


\section{LISTA DE ABREVIATURAS E SIGLAS}

ANBIMA - Associação Brasileira das Instituições dos Mercados Financeiro e de Capitais

BACEN - Banco Central do Brasil

CVM - Comissão de Valores Mobiliários

FEBRABAN - Federação Brasileira de Bancos

IBGE - Instituto Brasileiro de Geografia e Estatística

ICI - Investment Company Institute 


\section{Introdução}

O paradigma da racionalidade plena do ser humano dominou a teoria econômica por longo período. O Homo economicus é um modelo urdido no século XIX pelos economistas neoclássicos que o conceberam como um indivíduo racional e com preferências e objetivos bem definidos.

Ainda em 1988, Thaler definia a economia como uma ciência única que de maneira distinta das demais ciências sociais não buscava entender como as pessoas se comportam, mas, ao contrário, idealizava um comportamento e analisava os fatos a partir deste modelo. Em um mercado sem barreiras para que os preços se ajustassem, com informações circulando livremente e preferências estáveis e claras, o consumidor racional conseguiria tomar as melhores decisões aos seus interesses. Nesta concepção, comportamentos que não pudessem ser explicados pelos princípios da racionalidade seriam considerados como anomalias (Thaler, 1988).

"Se você olhar os livros de economia, aprenderá que o Homo economicus pode pensar como Albert Eisnten, armazenar tanta memória quanto o Big Blue da IBM e ter a força de vontade de Mahatma Ghandi” (Thaler \& Sustein, 2009, p. 7).

O algoritmo de decisão do Homo economicus busca maximizar a satisfação de cada escolha. Para medir a satisfação alcançada os economistas neoclássicos adotaram o conceito de utilidade esperada, proposto, em 1738, por Daniel Bernoulli. Por este conceito, o valor de um bem não deve ser baseado em seu preço, mas sim na utilidade que ele gera, que decresce conforme aumenta a quantidade possuída do bem. A questão da utilidade marginal decrescente implica em outro conceito, qual seja: o ser humano é avesso ao risco, ou seja, ele tende a rejeitar um jogo justo, aquele em que os valores esperados ao final são iguais para ambos os participantes (Kritzman, 1988; Schoemaker, 1982).

Von Neumann e Morgenstern (1944) formalizaram a teoria da utilidade esperada (expected utility theory, EUT) representando-a por meio de um conjunto de axiomas lógicos que deveriam ser utilizados para orientar uma decisão eminentemente racional, aquela que 
maximiza a utilidade esperada. Estes axiomas permitiram quantificar a utilidade de forma que maiores valores correspondem a maior preferência (Schoemaker, 1982).

Decisões envolvem tradeoffs em relação aos diferentes benefícios desejados e incerteza quanto às consequências a serem incorridas. A decisão do Homo Economicus repousa sobre preferências estáveis, cálculos de probabilidades e seu nível de aversão ao risco. É um paradigma essencialmente normativo baseado na crença de que o consumidor e/ou investidor se comporta de acordo com regras que o conduzirão às melhores decisões, aquelas que levariam à maximização da utilidade esperada (Baron, 2008; Keeney \& Raiffa, 1993).

Em finanças, a chamada moderna teoria de portfolio (modern portfolio theory, MTP) incorporou os preceitos da EUT, em que a escolha por uma opção de investimento foi formulada como um problema de otimização entre média e variância dos retornos, onde a observação do passado é utilizada como insumo para prever o futuro e dirigir as escolhas. $\mathrm{O}$ conceito de risco passa a ser formalmente sinônimo de variância e a maximização da utilidade de uma aposta passa, então, a ser definida como resultado da diferença entre o retorno esperado e sua variância ajustada pelo coeficiente de aversão a risco de cada investidor. Um conceito derivado é o de equivalentes certos (centainty equivalent) que pode ser entendido como o valor do ativo sem risco que gera a mesma utilidade da aposta (Damodaran, 2009, Elton \& Gruber, 1997, Markowitz, 1952).

Explicar o comportamento humano apenas pelo paradigma racional se mostrou com o passar do tempo insuficiente e os desvios em relação ao prescrito pelas normas da teoria tradicional de finanças se tornaram mais evidentes. Muitas das decisões que precisam ser tomadas não são simples. Em especial, decisões de investimento envolvem conhecimentos sobre ativos, dinâmicas de mercado, séries histórias, cálculos estatísticos e outros tantos conhecimentos e informações que tornam o processo complexo.

Coube à psicologia as críticas mais incisivas aos princípios da teoria normativa. Psicólogos cognitivos apontaram limites para a racionalidade. Para eles o desafio era substituir a racionalidade econômica do homem por alguma racionalidade comportamental, ou seja, compatível com sua capacidade de processamento (Simon, 1955). 
A busca por um paradigma alternativo que se preocupasse em entender e descrever o comportamento humano, ao invés de idealizá-lo, contou com a colaboração da psicologia cognitiva para contestar alguns dos principais pilares da EUT. Entre estes, em especial, a capacidade de processamento de informações e a formação da preferência (Camerer \& Loewenstein, 2004).

A partir de um programa sobre habilidade das pessoas com cálculos estatísticos, Tversky e Kahneman (1974), publicaram artigo sobre julgamentos em condições de incerteza, em que defendiam que as pessoas se utilizam de heurísticas para simplificar e facilitar o processo de avaliar as diferentes consequências e probabilidades de uma decisão. Estas heurísticas, se por um lado reduzem o esforço de processamento, por outro, podem conduzir a erros sistemáticos (Kahneman, 2003, 2011; Tversky \& Kahneman, 1974).

Os axiomas da EUT prescrevem o ser humano como racional e com preferências ordenadas e estáveis. Uma série de artigos publicados desde a década de 70 apresentou evidências de violação desta suposta estabilidade, em especial causadas por questões de enquadramento, da forma como a situação é apresentada (framing effects), destacando-se os trabalhos pioneiros de Lichtenstein \& Slovic (1971), Tversky \& Kahneman (1981; 1986), Tversky, Slovic \& Kahneman (1990) e Tversky \& Thaler (1990).

Em artigo publicado em 1979, Kahneman e Tversky lançaram a prospect theory que, em resumo, lançou o conceito de aversão à perda, propôs que as pessoas avaliam ganhos e perdas ao invés de estados de riqueza, que a função valor é assimétrica (mais intensa nas perdas que nos ganhos) e incorporou o conceito de que o julgamento se processa a partir de um ponto de referência que pode ser influenciado pelo enquadramento da situação. A teoria do prospecto se constitui em um modelo alternativo à teoria da utilidade. Enquanto esta é axiomática e deduz o comportamento humano por meio de lógica e axiomas, a teoria do prospecto é descritiva (Barberis, 2013; Kahneman, 2011; Kahneman \& Tversky, 1979). Em 2002, Kahneman foi laureado com o prêmio Nobel de economia, por conta, principalmente, desta teoria (Royal Swedish Academy of Sciences, 2002).

A teoria do prospecto se tornou um marco no estudo sobre decisão em condições de risco e lançou luz a uma série de trabalhos acadêmicos de natureza descritiva. Esta tese comunga da ideia de que as teorias normativas e descritivas não se opõem, apenas, estas últimas 
incorporam à racionalidade elementos que permitem descrever com mais realismo o comportamento humano e acabam por elevar o poder de explicação das análises econômicas.

Um dos pontos lapidares da teoria do prospecto é a dependência do ponto de referência, a partir do qual são formadas as representações que serão avaliadas e conduzirão à formação de preferência e escolha. Essas representações são formadas por meio do sistema perceptual que parece ser mais sensível a mudanças de estado (Kanheman, 2003).

O risco adquire, assim, uma nova dimensão. Risco não pode mais ser encarado somente como uma análise de regras, lógica, cálculos de probabilidades e consequências. A decisão de investimento não pode mais ser vista como uma avaliação limitada ao espaço de risco e retorno. O risco, em si, não pode ser apenas o resultado da variância dos retornos passados. A percepção de risco é formada automática e intuitivamente, as emoções e o afeto atuam e os fatos se transformam em imagens que significam perigo ou segurança, em que risco é um sentimento (Kanheman, 2003, 2011; Slovic, Finucane, Peters \& MacGregor, 2004).

A emoção e o afeto foram definitivamente incorporados ao arcabouço teórico para se tentar entender o comportamento do consumidor e/ou investidor. As informações são processadas de forma dupla, a primeira automática, não deliberada, rápida, baseada na experiência e carregada de emoção. A segunda é controlada, deliberada, lenta e orientada às consequências. Estas formas foram usualmente denominadas de Sistema 1 e Sistema 2, respectivamente. O Sistema 1 é perceptual, gera impressões e faz julgamentos intuitivos; já o Sistema 2 é acionado quando existe tensão e necessidade de esforço para processar julgamentos (Evans \& Stanovich, 2013; Kahneman, 2003; Stanovich \& West, 2000). A formação destas percepções não é deliberada e pode ser influenciada pelo estado de humor no momento da escolha ou mesmo pela facilidade com que a informação é absorvida (Alter, Oppenheimer, Eppley \& Eyre, 2007; Bolte, Goschke \& Kuhl, 2003).

Para a maioria das pessoas, investir é algo complexo (Estelami, 2012). É preciso, pelo menos, definir quanto se é capaz de poupar, qual é o objetivo do investimento - apreciação ou preservação de capital - qual é o prazo e qual é a tolerância à perda. A decisão sobre investimento financeiro exige conhecimento específico e esforço. Além disto, a possibilidade de não ter seus objetivos alcançados ou mesmo de perder parte, ou todo, o capital a investir 
torna o processo ainda mais tenso. Nesse sentido ela está envolta em emoção e demanda alto esforço cognitivo.

De acordo com o Relatório ANBIMA de Distribuição de Produtos no Varejo (ANBIMA, 2015) existem no Brasil nove milhões de investidores em produtos financeiros neste segmento. Já a Pesquisa FEBRABAN de Tecnologia Bancária 2014 (FEBRABAN, 2014) indica a existência de cento e oito milhões de contas correntes e em torno de $60 \%$ da população bancarizada. A despeito dos números não serem diretamente comparáveis, a discrepância em suas magnitudes permite inferir que há razoável espaço para o crescimento da base de investidores financeiros no Brasil.

Adicionalmente, o longo período em que o Brasil conviveu com taxas de juros elevadas contribuiu para atrair parte substancial dos recursos disponíveis para aplicações com perfil de renda fixa. O relatório Consolidado Histórico de Fundos de Investimento (ANBIMA, 2015), indica que $71 \%$ dos recursos da indústria brasileira de fundos estão alocados em produtos de renda fixa. Nos últimos anos, contudo, o patamar das taxas de juros vem se reduzindo paulatinamente e espera-se que, no longo prazo, não seja mais possível manter o tripé alta rentabilidade-baixo risco-alta liquidez, o que deverá forçar uma diversificação da oferta de produtos.

Neste contexto, entender o comportamento dos investidores, quais fatores influenciam a formação da preferência e sua decisão pode se tornar um diferencial competitivo na busca por parcelas destes potenciais investidores financeiros. Esta pesquisa pretende contribuir para aprofundar este entendimento ao desvendar a hierarquia de preferência do investidor financeiro e identificar os impactos que o estilo de processamento cognitivo pode exercer sobre a decisão de investimento.

A literatura sobre o processo decisório do investidor em relação a produtos financeiros é escassa. Abordagens que enfoquem a forma como o risco é percebido e quais estratégias o investidor pode utilizar para sua mitigação são ainda mais raras. Em especial, esta pesquisa aborda a importância do estilo cognitivo na decisão de investimento em produtos financeiros.

O conhecimento produzido e estruturado, ao fim, pretende contribuir para que empresas e profissionais que trabalhem na gestão e na distribuição de produtos de investimento financeiro 
possam, por meio do entendimento mais aprofundado sobre a formação da preferência do investidor, formatar uma oferta mais adequada de produtos e estabelecer estratégias mais efetivas de atendimento que ajudem a aumentar a satisfação, a reforçar a confiança e a criar lealdade de forma a contribuir para geração de valor das companhias.

Este trabalho de pesquisa contou inicialmente com uma revisão de literatura, em seguida foi realizado estudo exploratório, por meio de entrevistas em profundidade com executivos ligados ao segmento de gestão de fundos de investimento e, por fim, foi levada a cabo uma pesquisa de campo em que questionários foram aplicados via internet e para a qual foi utilizada a técnica estatística conjoint based choice (CBC) para decomposição da estrutura de preferência do investidor em produtos financeiros.

A versatilidade oferecida pelos fundos de investimento, que permitem uma diversidade de relações entre retorno, risco e liquidez e a proximidade com profissionais da área foram fundamentais para a escolha deste instrumento como base para os estímulos utilizados no questionário. Vale a pena destacar, ainda, a relevância do setor que em novembro contava com mais de onze milhões de contas ativas e cerca de três trilhões de Reais (ANBIMA, 2015).

No próximo capítulo apresenta-se a revisão de literatura que suportou e dirigiu esta pesquisa, em seguida a contextualização e problema focam o objeto de estudo de interesse deste trabalho. A partir destas duas seções foi elaborado o modelo teórico que serve como uma representação lógica que ajuda a entender e estudar o problema de pesquisa. No capítulo método são descritos os procedimentos operacionais de coleta de dados e estatísticos adotados e, por fim, apresenta-se o capítulo de análise de resultados. Este último está dividido em duas partes, a primeira em que, de forma objetiva, são apresentados os resultados das entrevistas em profundidade e, a segunda, em que são analisadas as respostas dos questionários e se procura responder às hipóteses traçadas no modelo teórico.

$\mathrm{Na}$ fundamentação teórica apresentada em seguida discorre-se sobre a o setor de gestão de recursos de terceiros e fundos de investimento em especial; na sequência tem lugar uma sucinta apresentação dos conceitos de investimento e risco na teoria de finanças e, por último, são discutidos fatores que possam influenciar as decisões dos investidores financeiros. 


\section{Fundamentação Teórica}

Esta seção está dividida em subseções ou tópicos que pretendem inicialmente definir a atividade de Gestão de Recursos de Terceiros e entender como ela está estruturada no Brasil, então conceituar o que é investimento e risco em conformidade com os princípios da moderna teoria de finanças e, por fim, abordar aspectos da teoria de decisão e os principais fatores que afetam a tomada de decisão do investidor.

Esta pesquisa bibliográfica tem a finalidade principal subsidiar a construção do modelo teórico e, adicionalmente, a pesquisa qualitativa que será apresentada à frente. Os aprendizados colhidos tanto por esta fundamentação quanto pelos resultados do estudo exploratório constituem as bases para desenvolver da seção análise de resultados.

\subsection{A Atividade de Gestão de Recursos de Terceiros (Asset Management)}

As atividades ligadas a captar e gerir dinheiro de terceiros, tais como as desempenhadas por instituições financeiras e empresas de gestão de recursos de terceiros, em qualquer lugar do mundo são bastante reguladas, no Brasil não seria diferente. No caso da gestão de recursos de terceiros, o conflito latente entre os interesses do próprio gestor profissional, contratado para gerir os recursos, e os do investidor que confiou a ele os citados recursos impele as autoridades a adotar regras que garantam a observância do dever de fidúcia, que pode ser resumido como "cuidar dos recursos do investidor como se fossem seus".

O desafio da indústria financeira e de seus reguladores tem sido permitir uma competição justa entre os competidores e paralelamente proteger os consumidores e investidores pouco informados em suas decisões (Estelami, 2012).

Já há bastante tempo Toledo (1978) discutia esta questão do ponto de vista da disciplina do marketing. Dois aspectos conflitantes eram então contrapostos: de um lado deve se reconhecer as vantagens da regulação e controle para o público, por outro não há como negar que tal rigidez impõe custos e menor competitividade que inibem a geração de benefícios.

A gestão de recursos de terceiros se caracteriza como um serviço oferecido, por instituições financeiras ou não, ao público com objetivo gerir valores poupados em conformidade com um 
mandato, previamente conhecido, que compatibilize retorno, risco e liquidez ao horizonte de prazo e restrições orçamentárias do investidor.

Hoffman, Bateson, Ikeda e Campomar (2010), traçam marcos sobre o que são serviços. Os autores definem bens como objetos ou dispositivos e confrontam este conceito com o de serviços, que seriam ações, esforços ou desempenhos e acabam por descrever o produto como sendo tanto um bem quanto um serviço. Por fim, eles sustentam que a diferença principal entre ambos é a propriedade da intangibilidade. Desta forma, os bens puros são predominantemente tangíveis enquanto os serviços puros são predominantemente intangíveis, ou seja, estes últimos não podem ser possuídos fisicamente apenas podem ser experimentados. Abaixo as principais características apontadas como próprias de serviços.

- Intangibilidade: não podem ser trocados ou sentidos da mesma maneira que os bens físicos

- Inseparabilidade: interconexão entre prestador do serviço e cliente;

- Heterogeneidade: como dependem de pessoas e momentos, podem variar; e

- Perecibilidade: não pode ser armazenado ou estocado.

Parasuraman, Zeithhalm e Berry (1985), já argumentavam que as características de intangibilidade, heterogeneidade e inseparabilidade são inerentes à prestação de serviço e são fundamentais para se entender e poder medir sua qualidade. A maneira como é mensurada a qualidade para bens, notadamente industriais, é insuficiente para medir qualidade em serviços que considera: a comparação entre desempenho esperado e realizado e envolve a avaliação do processo, da interação entre prestador e consumidor do serviço. Neste caso, a avaliação recai não somente sobre o resultado, mas, também, sobre a percepção construída pelo consumidor durante a prestação do serviço.

De acordo com Estelami (2012), o marketing de serviços financeiros é único e altamente especializado. Segundo o autor, todos os serviços financeiros têm uma série de inputs e pelo menos um output. Três inputs estão presentes na maioria destes, quais sejam: liquidez, risco e valor aplicado ou pago. O output, em geral, é o valor resultante da aplicação ou pagamento (recompensa). Como exemplo, uma apólice de seguros tem um valor de prêmio (input) e um valor de sinistro (output). Para as Assets, a relação pode ser vista como: montante investido em um fundo e montante corrigido (valor inicial mais remuneração). A figura 2.1, abaixo, apresenta o esquema proposto por Estelami. 


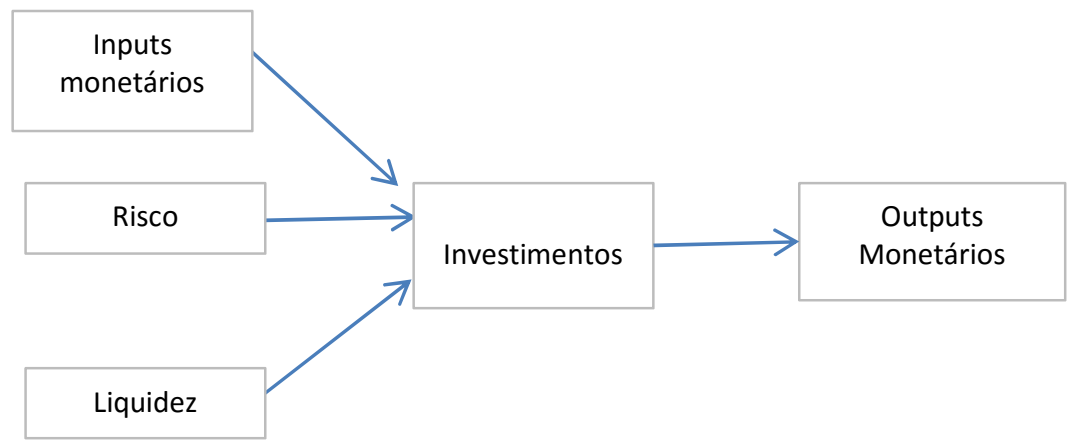

Figura 2.1 - Esquema Básico Input/Output

Referência: Estelami (2012)

No Brasil a atividade de gestão de recursos de terceiros é regulada pela Comissão de Valores Mobiliários (CVM) e a gestão é privativa de pessoa física ou jurídica autorizada por ela nos termos da instrução 558/2015. No caso das Assets ligadas a instituições financeiras, estas se estruturaram como verdadeiras unidades estratégicas de negócios, UEN's. Segundo Kotler e Keller (2012), as UEN's são unidades isoladas dos outros negócios que possuem um grupo específico de concorrentes, atendem clientes próprios e possuem um gestor independente.

Os serviços financeiros são distintos ainda por sua natureza complexa e pouco familiar e nada excitante. Segundo a Organisation for Economic Co-operation and Development (OECD) (2004), na Austrália, por exemplo, apenas 37\% dos investidores conseguem entender que o valor de suas aplicações pode flutuar. Toledo (1978), Las Casas (2007) e Estelami (2012) indicam que esta situação causa impactos em diferentes estratégias de negócios do setor. Alguns aspectos abordados são:

- Publicidade, ela tende a abordar tangencialmente os produtos e dirigir seu foco para a imagem do banco e sua robustez;

- Profissionais, estes possuem um perfil muito técnico e tendem a dedicar muita atenção à formulação de novos serviços e pouca as necessidades dos clientes;

- Produto, em geral são bem elaborados, mas existe pouca preocupação com a abordagem de venda que costuma ser muito técnica;

- Cliente, em geral se torna indeciso e um tanto desconfiado;

- Marketing, esta é uma atividade de staff e não uma das funções da organização.

A cadeia de valor no setor de gestão de recursos incorpora diferentes funções, que podem ser exercidas por um ou mais prestadores de serviços. Ela se inicia com o distribuidor, aquele que 
vende e recompra as cotas, passando pelo gestor, administrador, custodiante e controlador de ativos e passivos.

Abaixo um esquema, inspirado em Mobius (2007), a cadeia de serviços envolvida na atividade de gestão de recursos de terceiros.

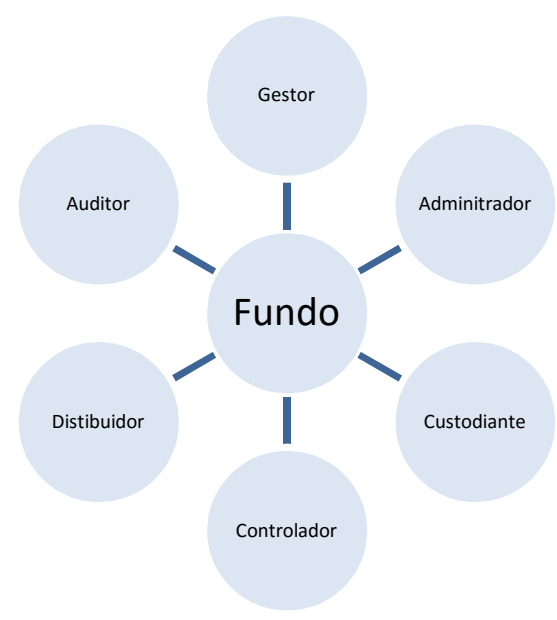

Figura 2.2 - Serviços Envolvidos na Gestão

Referência: Mobius (2007)

No Brasil, o veículo de investimento mais utilizado pelas empresas de gestão de recursos de terceiros são os fundos de investimento. Estes são constituídos como condomínios para investimento coletivo que se caracterizam basicamente por: recursos aplicados em pool e direitos e deveres proporcionais ao número de cotas detida pelo investidor (cotista).

Em um estudo já clássico sobre as origens dos fundos de investimento, Rouwenhorst (2004) indica que o primeiro fundo surgiu na Holanda em 1774, após crise financeira ocorrida entre 1772-73, e se chamava "Eendragt Maakt Magt". Um mercador chamado Abraham van Ketwich convidou pessoas e iniciou um processo de venda ou distribuição para pequenos investidores com a proposta de diversificação de suas economias. Tal como nos dias de hoje, o fundo tinha um contrato ou estatuto, registrado em cartório, em que constavam direitos, obrigações e uma política de investimento. Este fundo emitiu duas mil cotas por prazo de vinte e cinco anos, ou seja, dispositivo similar ao adotado pelos fundos fechados (close-end funds) atuais. 
Os motivos listados pelo autor para o surgimento deste fundo são, em geral, muito similares aos que hoje são lembrados como atributos que os tornam instrumentos ímpares na indústria de investimento.

Inicialmente, existia demanda por parte das pessoas que possuíam quantias menores e poucas opções interessantes.

Ao adquirir títulos emitidos por bancos e governos que estavam em posse de seus credores, o fundo criou liquidez (transformou papel em dinheiro) para estes além de ter ampliado potencial de diversificação em relação aos devedores. Vale notar que liquidez e diversificação reduzem o risco e melhoram a precificação dos ativos.

Ainda para estes detentores de títulos bancários ou governamentais, havia mais uma vantagem adicional, qual seja: a antecipação do fluxo de caixa. Neste caso, mediante um taxa de desconto incidente sobre o valor dos ativos adquiridos para o fundo que, desta maneira, forma a base para a geração de retorno das cotas.

Para os investidores surgiram como vantagens a opção de adquirir cotas com valores relativamente menores e assim permitir uma melhor diversificação de risco, tanto pelo fato das cotas representarem um miríade de ativos e devedores quanto por permitir a aplicação em mais instrumentos que aceitem aplicações "mais baratas".

O guia Understanding Mutual Funds editado pelo Investment Company Institute (ICI), organização que representa os interesses das Assets nos Estados Unidos, ainda indica pelo menos outras duas vantagens no investimento por meio de fundos: a redução de custo, advinda dos ganhos de escala auferidos pelo investimento em pool dos recursos dos investidores - cujos volumes mais elevados possibilitam a obtenção de descontos nas transações e melhores remunerações em suas aplicações - e a gestão profissional que conta com equipes qualificadas e um conjunto de conhecimentos e tecnologias próprias para incrementar a capacidade de detectar tendências, identificar boas oportunidades e realizar bons negócios. 
Entre os serviços listados acima, a gestão é com certeza aquele capaz de agregar maior valor ao cliente e o que melhor descreve a atividade. A distribuição está relacionada à capacidade de venda e os demais estão afeitos a eficiência operacional e redução de custos.

A gestão de recursos de terceiros, portanto, implica em captar recursos de investidores e aplicá-los em opções de investimento que preservem ou até ampliem o poder de compra deste dinheiro. Desta forma, os objetivos de um investimento podem ser genericamente definidos como de preservação ou apreciação de capital.

\subsection{Investimento}

\subsubsection{O Conceito de Investimento}

A expressão "randon walk" significa algo como futuro incerto e incapaz de ser previsto. Quando aplicada ao mercado de investimentos financeiros ela traduz a aleatoriedade dos retornos dos diferentes ativos, a falta de padrões de comportamento ou de informações no presente que possibilitem descobrir o caminho a ser seguido pelas cotações de ações, cotas dos fundos ou qualquer outra opção de investimento. Segundo Malkiel (2007, p. 24) por esta lógica extrema é como se um macaco com venda nos olhos arremessasse dardos em uma página de um jornal especializado em finanças e pudesse selecionar um portfolio que obtivesse um desempenho tão bom quanto outro selecionado por especialistas.

As dificuldades enfrentadas para que seja possível antever os preços dos ativos financeiros, estão na raiz da gestão profisssional e do aconselhamento financeiro, que são eminentemente apoiados por capacitação técnica e tecnologia que pretendem dotar estes profissionais de maior chance de acertar o futuro.

Ainda de acordo com Malkiel (2007), por investimento deve-se entender como a aplicação de recursos em ativos com intenção de remunerar o capital mediante uma intenção de retorno, dado um nível de risco, em determinado período de tempo. Apesar de todo profissionalismo e tecnologia envolvidos, investir, em alguma medida, pode ser comparado a um jogo, cujo futuro não pode ser previsto com exatidão, cuja incerteza não pode ser eliminada. Duas abordagens são oferecidas pelo autor para buscar descobrir os preços dos ativos: "firm- 
foundation theory" e "castle-in-the-air". A primeira identifica o valor dos ativos por meio de estimativas sobre o valor intrínseco no presente descontado por uma taxa de juros; já a segunda, incorpora a psicologia, observa o comportamento dos investidores, as ondas de otimismo/pessimismo e busca se antecipar e aproveitar as oportunidades de valorização/desvalorização de preços.

De acordo com Reilly e Brown (2012) o investimento deve ser entendido como o comprometimento de recursos financeiros por um período de tempo com objetivo de receber estas importâncias de volta remuneradas por uma taxa de retorno que compense: (i) o tempo que os recursos foram cedidos e estavam indisponíveis, (ii) a inflação acumulada no período, e (iii) a incerteza inerente ao futuro. Os investidores podem ser indivíduos, corporações, institucionais ou governo, no caso desta pesquisa interessa as decisões de investimento tomadas pelas pessoas físicas.

O investimento pode ser visto, portanto, a partir de três aspectos: retorno, risco e prazo. Os recursos devem ser devolvidos a uma taxa que, conforme avaliação do investidor, o remunere adequadamente pelo prazo e pela incerteza.

O processo de investimento pode ser visto como uma cadeia de ações coordenadas e que devem respeitar uma sequência cujo objetivo final é maximização da satisfação ou, em termos teóricos, da utilidade, do investidor.

Segundo Damodaran (Bernstein e Damodaran, 1998, p.1) "Um entendimento do processo de investimento é crítico para todos os investidores, e as funções do processo devem ser comunicadas pelos advisers".

A estrutura básica do processo de investimento pode ser assim descrita:

- Identificar os objetivos, preferências e restrições do cliente;

- A partir destas informações, estabelecer uma política de investimentos;

- Executar a política de investimentos traçada; e

- Medir a performance do gestor.

O processo de investimento sempre começa pelo entendimento das necessidades e preferências do investidor. Para um gestor de carteira, cada investidor é um cliente que possui necessidades únicas, restrições e, mais importante, preferências pessoais em relação ao risco. 
Sendo assim, a primeira providência é decidir sobre objetivo de investimento e política para compra de ativos para carteira de modo a buscar a rentabilidade compatível ao risco desejado. Tal situação impõe tradeoffs, tais como: acumular riqueza ou apostas arrojadas, retorno em termos absolutos ou em relação a algum parâmetro de mercado, resultados de curto ou longo prazo. Por risco entende-se incerteza, ou seja, o preço futuro é incerto, aleatório, e, por mais, que se utilizem distribuições de probabilidade passadas ou modelos quantitativos mais avançados, o máximo que se consegue é aumentar a chance de acerto, persiste a incerteza (Damodaran, 1998).

De acordo com Ellis (1998) investir significa renunciar aos prazeres no presente na esperança de alcançar algo melhor no futuro. Ao decidir cursar uma faculdade o indivíduo esta abrindo mão de lazer e diversão pela expectativa de atingir um nível de renda e bem estar social superior no futuro. $\mathrm{O}$ investimento em ativos reais difere do financeiro principalmente pelo aspecto da liquidez que está associada à capacidade de vender os ativos e transformar seu valor em dinheiro em pouco tempo. Sendo assim, o investidor pode ajustar suas posições vendendo ativos e substituindo-os por outros que julgue mais apropriados minimizando as expectativas de perda.

Os benefícios de uma aplicação financeira, portanto, estão usualmente associados a acumular recursos para aquisição de objetos e serviços de valor relativamente elevado, garantir reservas para fazer frente a períodos adversos e permitir a manutenção de um padrão de vida coerente após deixar a vida profissional. Sendo assim, a remuneração obtida pela aplicação destes recursos desviados do consumo é crucial para que tais objetivos sejam alcançados, o que torna o processo de decisão naturalmente tenso. Situação esta que é agravada pela possibilidade, em alguns casos, de perda dos recursos investidos com consequente destruição dos "sonhos" projetados.

\subsubsection{O Conceito de Risco na Teoria de Finanças}

Harry Markowitz (1952) é amplamente reconhecido como o precursor da moderna teoria de portfolio, modern portfolio theory (MPT) e seu artigo Portfolio Selection é considerado a base teórica desta abordagem. De acordo com o texto, o processo de seleção de um portfolio se divide um dois estágios; o primeiro inicia com a observação do passado e termina com as 
apostas sobre o desempenho futuro dos ativos disponíveis e o segundo se inicia com a priorização das apostas e se encerra com a escolha de um portfolio.

Segundo Elton e Gruber (1997), Markowitz formulou a questão como uma escolha entre a média de retorno e a respectiva variância do portfolio. O problema foi apresentado como uma otimização entre a obtenção do maior taxa retorno para um dado nível de variância ou a menor variância dos retornos para uma dada taxa de retorno do portfolio. A composição dos ativos subjacentes ao portfolio gera um conjunto de ordenadas variância-média das taxas retornos que se assentam em uma fronteira cujo investidor pode escolher seu portfolio preferido conforme nível individual de risco que suporte. Esta fronteira ganhou o nome de fronteira eficiente.

Risco é tipicamente definido ou considerado como sinônimo de incerteza. Ou seja, resultado de nossa incapacidade em prever, com certeza, o futuro. Para minimizar esta limitação, os economistas observam a distribuição dos retornos passados, calculam sua variabilidade e tentam estimar um intervalo possível para o futuro. O risco, portanto, é amplamente associado à variância ou desvio padrão.

Desta forma, as pessoas têm uma expectativa de retorno $\mathrm{E}(\mathrm{R})$ para a qual admitem um determinado nível de risco, ou variabilidade $\left(\sigma^{2}\right)$. Em que:

$$
\begin{gathered}
E(R)=\sum_{i=1}^{n}\left(P_{i}\right)\left(R_{i}\right) \\
\sigma^{2}=\sum_{i=1}^{n}\left(P_{i}\right)\left[R_{i}-E\left(R_{i}\right)\right]^{2}
\end{gathered}
$$

Onde:

$\mathrm{P}_{\mathrm{i}}=$ Probabilidade de retorno do ativo

$\mathrm{R}_{\mathrm{i}}=$ Possibilidade de retorno do ativo

Por conta do risco embutido nas opções de investimentos escolhidas, os investidores esperam receber um adicional sobre uma taxa livre de risco (aquela que se pode auferir sem incorrer em risco, geralmente associada aos títulos de dívida emitidos por Países). Este incremento da taxa de retorno é denominado de prêmio de risco. 
Segundo a MPT as pessoas não decidem apenas por um determinado nível de retorno ou risco, elas, de fato, buscam maximizar sua satisfação, conhecida como utilidade.

Para a teoria de finanças tradicional (MPT) os investidores são racionais - buscam maximizar a utilidade esperada a partir das estimativas de retorno e risco - e os mercados são eficientes, ou seja, as forças do mercado movem os preços dos ativos de tal forma que estes se ajustam rapidamente as condições do ambiente e reflitam toda informação disponível.

Considerando que uma decisão de investimento se define entre um prazo em que o investidor aceita abrir mão de seus recursos com objetivo uma expectativa de retorno e de risco, dado um nível de tolerância, adiante discute-se quais fatores podem influenciar de forma relevante esta decisão.

\subsection{Fatores Influenciadores da Decisão do Investidor}

A decisão é o resultado de uma escolha que está associada a uma ação que terá um curso. Decisões são tomadas para que se atinjam objetivos pré-definidos e estão baseadas em crenças sobre o futuro e nas consequências para quem as tomou. Em uma decisão deve existir mais de uma possibilidade de ação em comparação, o tomador da decisão tem expectativas sobre o futuro e as consequências associadas a cada ação potencial podem ser avaliadas comparativamente. A teoria de decisão é uma área de conhecimento interdisciplinar compartilhada entre filósofos, economistas, psicólogos e outras tantas disciplinas. Existe amplo consenso sobre a existência de dois modelos básicos representativos do processo de decisório, quais sejam, o modelo descritivo e o normativo (Baron, 2008; Hastie \& Dawes, 2010).

O modelo descritivo busca representar a forma como de fato as pessoas julgam as situações que se apresentam e tomam decisões. Estes modelos muitas vezes são descritos por meio de heurísticas, ou regras de bolso, que são rotineiramente utilizadas na resolução dos problemas. Já a abordagem normativa encara a decisão como um processo centrado no objetivo da decisão e no melhor curso de ação, o mais eficiente para alcança-lo. Neste sentido, a decisão envolve cálculos de probabilidades e avaliação comparativa destas. Esta é considerada uma 
decisão racional, que consome tempo e elevado esforço cognitivo para que se alcance o objetivo de maximizar a satisfação com o resultado (Baron, 2008; Einhorn \& Hogart, 1981; Peterson, 2009).

De acordo com Simon (1955) o número de alternativas, e suas consequências em termos de satisfação, associado às restrições e limitações psicológicas de processamento para classificálas e ordená-las, implicam em simplificações que desafiam os princípios da racionalidade ilimitada (bounded rationality).

Este item da fundamentação teórica aborda a incialmente aspectos relevantes relacionados à abordagem normativa, qual seja a teoria da utilidade esperada (expected utility theory, EUT) e a decisão que envolve trocas (tradeoffs) entre diferentes objetivos multiattribute utility theory (MAUT). Na sequência o item denominado "Além da Racionalidade" introduz a discussão sobre elementos adicionais à racionalidade e, portanto, à abordagem normativa, que estão presentes no processo decisório e, assim, prepara o terreno para apresentação da teoria do prospecto, esta de viés descritivo, uma alternativa à teoria da utilidade esperada.

Após este contraponto entre as abordagens normativa e descritiva, são tratados aqui os temas emoção, heurística do afeto e intuição, a influência da percepção de risco na decisão, a importância do gerente e, por fim, uma rápida visão sobre escolhas intertemporais (inerente à decisão de investimento).

\subsubsection{Utilidade Esperada}

As decisões sobre futuro são baseadas em valores esperados ou estimados que levem as pessoas a alcançar a maior satisfação. Contudo, na busca por uma escolha que maximize o valor esperado de uma aposta existe a incerteza e, para lidar com ela, o tomador de decisão necessita associar probabilidades a cada um dos possíveis resultados que se possa atingir.

Em investimentos, em geral, o objetivo principal é garantir ou maximizar o retorno dado um determinado risco ou minimizar a possibilidade da perda dado determinado retorno. Alcançar qualquer destes objetivos ou a combinação deles equivale a maximizar a satisfação ou a utilidade esperada de uma decisão de investimento. 
Daniel Bernoulli publicou em 1738 o trabalho intitulado "Exposition of a New Theory on the Measurement of Risk" (Bernoulli, 1954) em que discute a questão do risco em uma decisão e introduz o conceito de utilidade. Segundo o autor:

“[...] a determinação do valor de um item não deve ser baseada em seu preço, mas sim na utilidade que ele confere. O preço de um item depende dele próprio e é igual para todos; a utilidade, entretanto, é dependente de circunstâncias particulares que a pessoa estima. Sendo assim, não existe dúvida que um ganho de mil moedas é mais significante para um pobre do que para um homem rico embora ambos ganhem o mesmo montante." (Bernoulli, 1954, p. 24).

Ainda segundo Bernoulli, não existe razão plausível para que duas pessoas avaliem os riscos de uma aposta de forma idêntica. As expectativas de cada um em relação ao risco embutido nas diferentes alternativas dependem das circunstâncias financeiras próprias existentes no contexto e momento da avaliação. A utilidade de um item se altera conforme as circunstâncias. Não é possível mensurar o valor da utilidade de algo sem que se leve em conta o risco e o retorno esperado. Um exemplo de como a utilidade se altera conforme a circunstância é proposto, pelo o autor, com a ilustração de um prisioneiro que possui dois mil ducados e que precisa de outros tantos para recomprar sua liberdade. Neste caso, estes dois mil ducados tem maior utilidade para este prisioneiro do que para outro que tenha menos dinheiro.

Com relação à riqueza, Bernoulli introduziu o conceito de utilidade marginal decrescente, ou seja, quanto maior o estoque de riqueza menor a utilidade proporcionada por um incremento. De outra forma, uma unidade adicional de riqueza acarreta uma utilidade menor que o acréscimo da anterior. A partir da noção de utilidade marginal decrescente se depreende, portanto, que a perda de uma unidade de riqueza representa maior utilidade que o ganho da mesma unidade.

A partir deste conceito de utilidade marginal decrescente, Bernoulli propôs uma curva de utilidade côncava de modo que unidades adicionais de riqueza produzam ganhos inferiores de utilidade. Abaixo na figura 2.3 apresenta a representação da curva de utilidade marginal decrescente descrita por Bernoulli. 


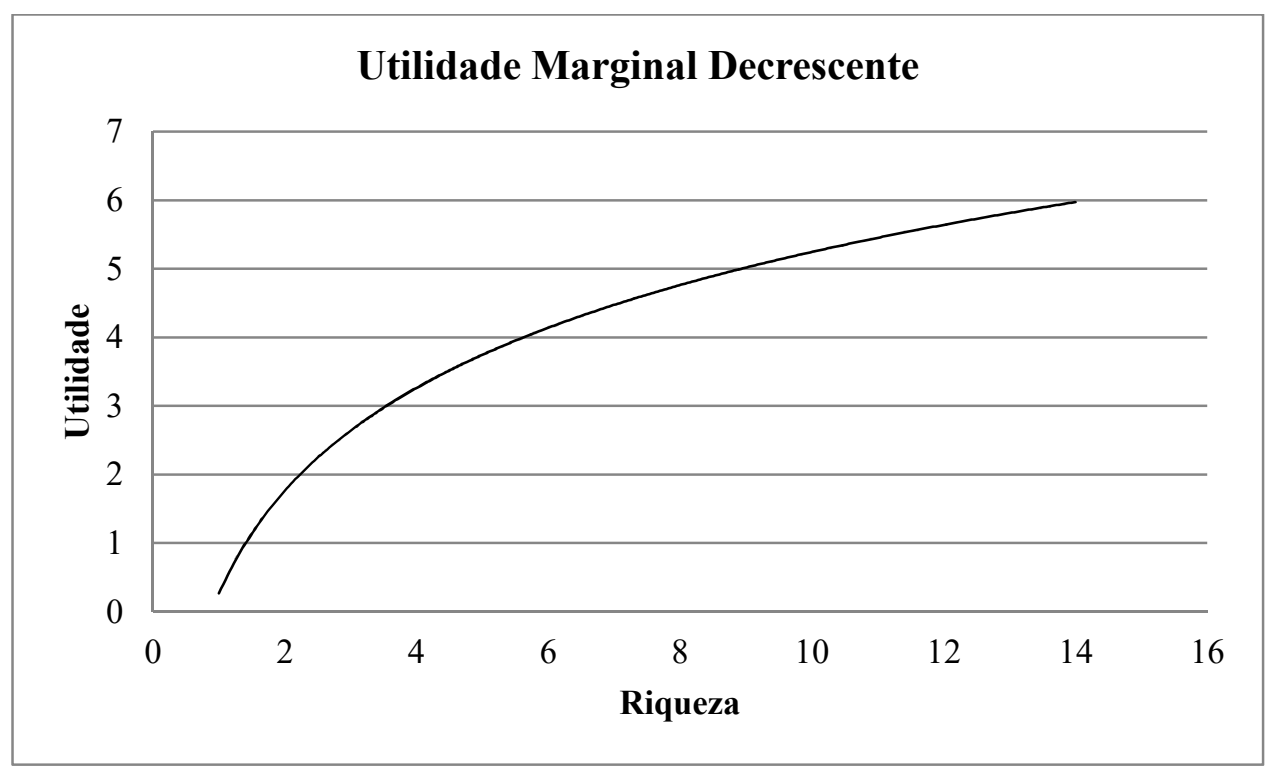

Figura 2.3 - Curva de Utilidade de Bernoulli

O conceito de utilidade marginal decrescente está iminentemente associado a outro, qual seja, o de aversão ao risco. Considerando que um indivíduo tenha diante de si um jogo com $50 \%$ de probabilidade de ganhar ou perder a mesma importância (por exemplo, \$1.000) e que a utilidade decorrente da perda é maior que a proporcionada pelo ganho, este jogador rejeitará esta aposta. As pessoas, em geral, são avessas ao risco, ou seja, quando confrontadas com um jogo justo, aquele em que o resultado esperado é igual para ambas às partes, elas o rejeitam. Dessa forma, os investidores em geral são classificados, conforme sua atitude em relação ao risco: (i) avessos, que rejeitam o jogo justo; (ii) neutros, que são indiferentes; e (iii) favoráveis que aceitam o jogo justo (Kritzman, 1998).

Dado estes diferentes perfis de preferência por risco, cada um em cada aposta, segundo as circunstâncias, espera uma taxa de retorno que, no mínimo, lhe remunere com uma taxa de retorno livre de risco (risk free). $\mathrm{O}$ valor de uma alternativa sem risco que proporciona a mesma utilidade esperada de uma aposta incerta é chamado de equivalente a certeza (certainty equivalent) (Bernstein \& Damodaran, 1998; Bodie, Marcus \& Kane, 2013).

Segundo Schoemaker (1982) o conceito de utilidade de Bernoulli era mais descritivo e menos normativo. Coube a John Von Neumann e Oskar Morgenstern (1944) formular a teoria da utilidade esperada como uma função de maximização de uma decisão em termos racionais. De acordo com a Royal Swedish Academy of Sciences (2002) a teoria econômica tradicional 
está essencialmente assentada no princípio da maximização da utilidade esperada fundado por Von Neumann e Morgenstern e aprofundada por Savage.

Para Von Neumann e Morgenstern a maximização da utilidade esperada é fruto de um processo racional de decisão baseados em axiomas que quantificam os resultados e permitem ordená-los de maneira que quanto maior a utilidade esperada maior a preferência. Neste sentido, a utilidade é cardinal, pode ser mensurada, de forma que o indivíduo racional poderá ordenar os resultados e escolher aquele que apresentar maior utilidade. Por dedução, a escolha recairá sobre o resultado que apresentar maior utilidade, ou seja, este será o preferido. Quanto maior a utilidade mais alta a preferência (Bernstein \& Damodaran, 1998; Damodaran, 2009; Schoemaker, 1982).

Pilli (2012), citando vários autores, apresenta estes axiomas que são postulados como relações de preferência-indiferença. Desta forma, assumindo um conjunto $\mathrm{X}$ composto das opções $x, y$ e $z$ os axiomas são assim definidos:

- Completude, ou integralidade: as pessoas podem comparar e ordenar todos os itens de um conjunto de maneira que $x$ pode ser preferido à $y, y$ pode ser preferido a $x$ ou pode haver indiferença entre $x$ e $y$;

- Transitividade: se $y$ é preferido a $x$ e $z$ é preferido a $y$, então $z$ é preferido a $x$; se houver indiferença entre $x$ e $y$ e $y$ e $z$, então $x$ e $z$ serão indiferentes entre si;

- Continuidade: se $y$ é preferido a $x$ e $z$ é preferido a $y$ e supondo que existe uma probabilidade $p$ (ente $0 \mathrm{e}$ 1) de ocorrência de cada opção, então existe um valor que torna as valor das opções indiferente;

- Independência e substituição: para qualquer $p$ entre 0 e 1 , se $p(y)+(1-p)(z)$ é preferido a $p(x)+(1$ $p)(z)$, então a relação de preferência entre $x$ e $y$ é independente de $z$.

Hausman (2012) advoga, ainda, que tais axiomas não expressam preferência, de fato, mas relações de superioridade. Ou seja, que $x$ é "tão bom quanto" ou "melhor" que $y$ e não necessariamente preferido. Dois outros axiomas, segundo o autor menos conhecidos, são apresentados, quais sejam:

- Determinação da escolha (choice determination) cujo conceito prevê que diante de um conjunto de alternativas julgadas disponíveis a escolha recairá sobre a que estiver posicionada na posição mais elevada do ranking, $\mathrm{e}$

- Independência de contexto, ou seja, a preferência de $x$ sobre $y$ permanecerá estável independente do contexto.

Para Schoemaker (1982) as escolhas, em relação a cenários incertos, devem ser determinadas pela intensidade da preferência e a atitude em relação ao risco, isto levando em consideração que, segundo o conceito da utilidade esperada, o indivíduo é avesso ao risco. Segundo o autor, 
os modelos de utilidade esperada são concebidos como um conjunto de escolhas em relação a alternativas em condições de risco.

\subsubsection{Análise Racional da Decisão do Consumidor ou Investidor.}

"Em um mundo incerto a pessoa responsável por tomar decisões deve balancear os julgamentos acerca das incertezas com suas preferências pelos resultados decorrentes". (Keeney \& Raiffa, p. 1, 1993).

De acordo com os autores o processo de análise de decisão pode ser sumarizado em cinco etapas:

- Pré-análise: o problema é identificado;

- Análise estrutural: uma árvore de decisão é traçada, as possíveis escolhas são listadas e os pontos de decisão identificados;

- Análise de incerteza: as probabilidades de ocorrência de cada ramificação da árvore são definidas;

- Utilidade ou análise de valor: as consequências de cada decisão são calculadas. Benefícios, custos (econômicos e psicológicos) e suas implicações são descritos e balanceados nesta etapa.

- Otimização: a partir das utilidades e das probabilidades, deve se identificar o melhor caminho para se alcançar a maximização da utilidade esperada.

Para Louviere (1988) a decisão em contexto complexo é um processo de avaliação e comparação no qual os consumidores decidem sobre quais aspectos entre produtos e serviços são mais importantes de forma que estes possam ser comparados, avaliados e escolhidos.

Segundo o autor, após comparar e avaliar produtos e serviços em relação aos atributos selecionados previamente, os consumidores, ou investidores, eliminam algumas alternativas e definem um conjunto de alternativas de interesse. A Comparação implica em julgamentos e atribuição de valores baseados em impressões formadas a partir de crenças, fatores psicológicos e emocionais. O que está em avaliação não são características físicas ou objetivas, mas sim a imagem concebida de algo por alguém. São estas impressões perceptuais que serão classificadas e posicionadas em uma ordem de preferência. A figura 2.4, abaixo, esquematiza o processo.

Tais impressões e, por conseguinte, julgamentos podem ser modificados mediante novas alternativas, novas informações, mudança de crenças ou até de estados emocionais. 


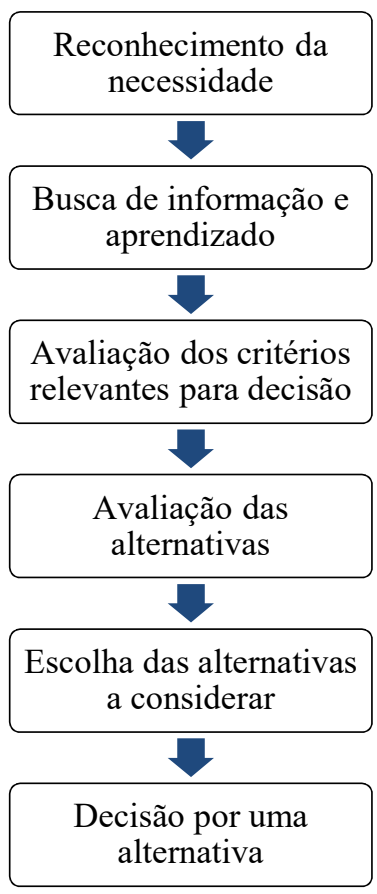

Figura 2.4 - Esquema de Análise de Decisão de Louviere (1988) Referência: Louviere (1988, p. 10)

Problemas cujo objetivo seja único, quantificável, ordenados em uma escala numérica (como valores monetários) podem ser considerados como problemas simples. Se o valor associado a uma consequência $C^{\prime}$ é $X\left(C^{\prime}\right)=x$ ' e o valor associado a $C$ ' 'é $X\left(C^{\prime}\right.$ ' $=x$ ', e $x$ ' e $x$ ' forem números correspondentes a valores reais, então C' será preferido a C" quando $\mathrm{x}$ ' $>\mathrm{x}$ ', (Keeney \& Raiffa, 1993). Decisões complexas, por outro lado, não podem ser descritas por objetivos únicos e consequências mensuráveis e diretamente comparáveis.

Segundo os autores em decisões complexas a pessoa tem diante de si duas ou mais opções, ou ações, similar a uma loteria, ela deve selecionar a preferida de acordo com as consequências de cada opção e as probabilidades que associa a cada uma delas. Os resultados estão definidos em um conjunto $x_{i} \equiv\left(x_{i 1}, x_{i 2}, \ldots, x_{i n}\right)$ e $l$ pode ser interpretado como a distribuição de probabilidades associada a cada opção. A figura 2.5 ilustra o esquema da árvore de decisão. 


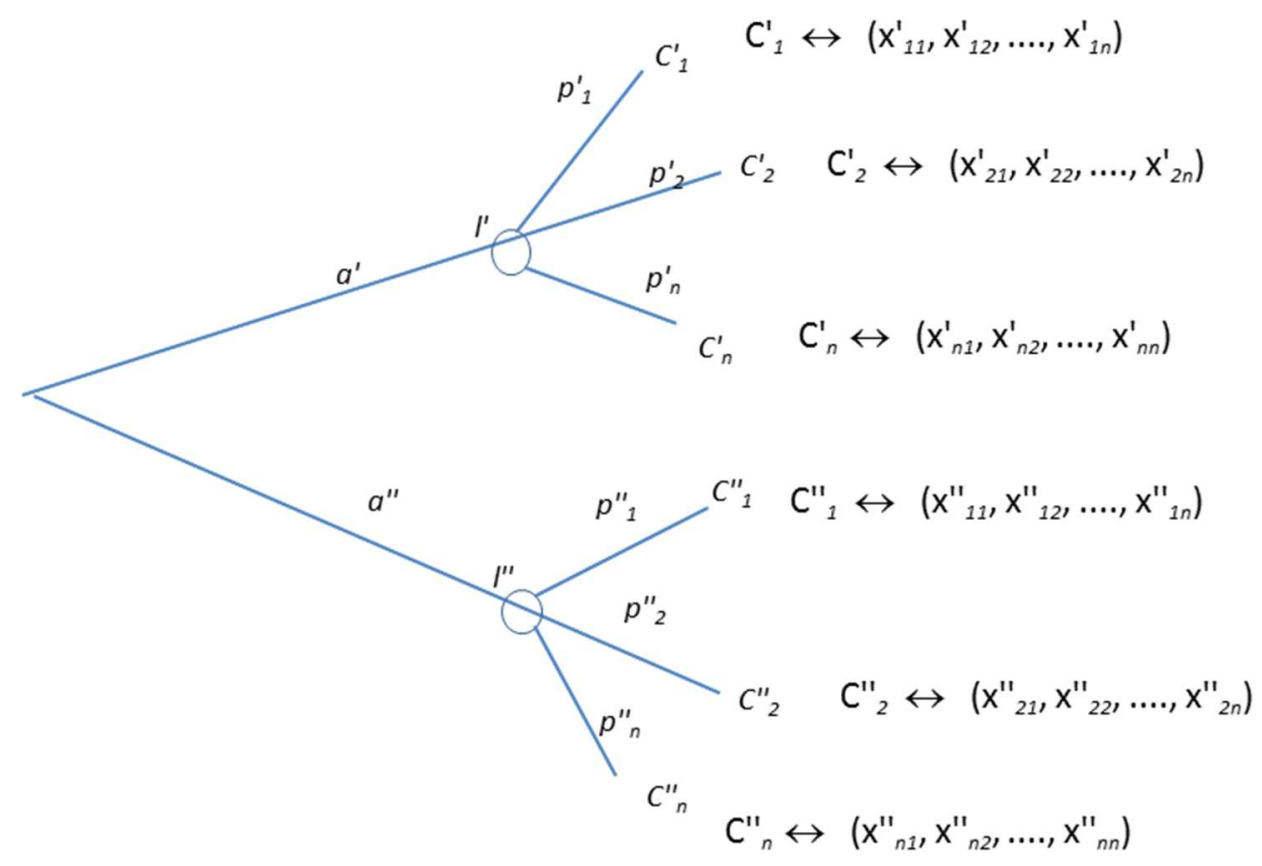

Figura 2.5 - Árvore de Decisão

A utilidade associada a cada um dos resultados e suas probabilidades, transmite ao tomador da decisão as informações necessárias ao julgamento sobre qual das loterias fornecerá a maior satisfação (utilidade). Sendo assim, a opção $a$ ' será preferida a $a$ '” se:

$$
\sum_{i=1}^{n}\left(p_{i}^{\prime} u_{i}^{\prime}\right)>\sum_{i=1}^{n}\left(p^{\prime \prime}{ }_{i} u^{\prime \prime}{ }_{i}\right)
$$

Onde:

$p=$ probabilidade

$u=$ utilidade

Louviere (1988, p.12-14) discute os aspectos teóricos da tomada de decisões complexas e esquematiza os componentes do processo. A seguir uma sumarização destes:

- Aspectos físicos, as variáveis observadas que podem ser comparadas e sobre as quais se formam impressões;

- Atributos, as características que os consumidores julgam relevantes e usam para avaliar os produtos e serviços;

- Posição, os consumidores formam impressões, crenças, sobre a posição relativa de cada produto levando em consideração os atributos em avaliação de acordo com níveis (valores) assumidos por estes;

- Estimativa de utilidades parciais, processo de atribuir utilidade por meio da comparação entre os atributos;

- Avaliações globais, julgamentos, impressões e avaliações que contemplam todos os atributos relevantes para decisão;

- Julgamento, comparações sobre o quão satisfatório, bom, adequado etc... está associado ao conceito de utilidade e sua maximização; 
- Marca, um produto ou serviços específico sob avaliação;

- Conjunto final para escolha, marcas pré-selecionadas pelo consumidor para uma avaliação e escolha final;

- Escolha, se refere ao processo cognitivo por meio do qual o consumidor, após avaliar todas as marcas e selecionar um conjunto final de opções, escolhe uma delas ou nenhuma (desistência).

As seguintes relações delineiam um sistema de decisões complexas.

$$
\begin{aligned}
& S_{j k}=f 1_{k}\left(X_{j k}\right),(k=1,2,3, \ldots, K ; j=1,2,3, \ldots, J) \\
& V\left(S_{j k}\right)=f 2_{k}\left(S_{j k}\right), \\
& U_{j}=f 3\left[V\left(S_{j k}\right)\right], \\
& p(j \mid A)=f 4\left(U_{j}\right),
\end{aligned}
$$

Onde:

$\mathrm{X}_{\mathrm{jk}}$ representa o conjunto $\mathrm{J} \times \mathrm{K}$ de aspectos físicos ( $\mathrm{J}$ representa o número total de marcas e $\mathrm{K}$ o número total de atributos determinantes para avaliação) que constitui a base para a formação das percepções sobre cada atributo;

$\mathrm{S}_{\mathrm{jk}}$ representa o conjunto dimensional das percepções dos consumidores sobre os níveis do atributo k para cada marca j;

$\mathrm{V}\left(\mathrm{S}_{\mathrm{jk}}\right)$ representa o conjunto dimensional que contem as medidas de utilidades estimadas de cada elemento Sjk, ou seja, a percepção do consumidor sobre a posição relativa da marca $\mathrm{j}$ em relação ao atributo $\mathrm{k}$;

$U_{j}$ avaliação global de valor ou estimativa de utilidade para cada marca $\mathrm{j}$;

$\mathrm{p}(\mathrm{j} \mid \mathrm{A})$ é a probabilidade de se escolher uma marca j em um conjunto pré-selecionado A;

Por meio de um processo de substituição chega-se a:

$$
\begin{aligned}
& \mathrm{p}(\mathrm{j} \mid \mathrm{A})=\mathrm{f} 4\left\{\mathrm{f} 3\left[\mathrm{f} 2_{\mathrm{k}}\left(\mathrm{f} 1_{\mathrm{k}}\left(\mathrm{X}_{\mathrm{k} j}\right)\right)\right]\right\}, \text { ou } \\
& \mathrm{p}(\mathrm{j} \mid \mathrm{A})=\mathrm{F}\left(\mathrm{X}_{\mathrm{jk}}\right)
\end{aligned}
$$

Sendo assim, F é uma função que compõe diferentes elementos que ajudam a explicar os elementos levados em consideração no processo de escolha, quais sejam: (a) aspectos físicos; (b) percepções sobre os atributos; (c) estimativa de sobre utilidades e ordenação; e (d) composição das variáveis anteriores.

De acordo com Raiffa e Keenney (1993), o tomador de decisão deve, além de avaliar as consequências de sua decisão, levar em conta suas preferências e atitudes em relação a risco em termos de uma função de utilidade. Em geral não se consegue maximizar benefícios ao mesmo tempo em que se reduzem os custos, não é de se esperar que seja possível maximizar 
rentabilidades enquanto se reduzem os riscos. Se há incerteza em relação aos resultados, o problema a ser encarado acrescenta ao tradeoff a questão da avaliação subjetiva do tomador de decisão.

\subsubsection{Além da Racionalidade}

Preferências e desejos não podem ser considerados sinônimos. A principal diferença entre estes conceitos é que a preferência implica comparação entre distintas alternativas. Todas podem ser desejadas, mas apenas uma será a preferida. Por serem comparativas, as preferências, requerem que a pessoa analise os objetos, pondere seus benefícios e custos e caminhe para uma decisão. Sendo assim, a formação da preferência demanda maior esforço cognitivo por conta da avaliação e julgamento. Além dos desejos, a preferência depende de crenças, emoções, intenções, razão, valores e, não menos importante, como ela afeta as escolhas e o bem-estar (Hausman, 2012).

Como já visto na seção anterior, a tradição da ciência econômica é essencialmente normativa, ou seja, ela pressupõe que o ser humano se comporta conforme os princípios prescritos pela racionalidade, de forma a maximizar a utilidade de suas decisões. Tais princípios são compartilhados pela moderna teoria de finanças (MPT) que idealiza o comportamento humano por meio do conceito do Homo economicus, ou seja, aquele que segundo Thaler e Sustein, pensa como Einstein, tem uma memória de um super computador e a força de vontade de Ghandi (Thaler \& Sustein, 2009).

Tversky e Kahneman (1986) argumentam que a representação axiomática do comportamento não pode descrevê-lo adequadamente. Os desvios em relação ao prescrito são muitos e frequentemente sistemáticos para serem atribuídos ao acaso ou considerados anomalias ao modelo. Os autores advogam que os princípios sobre os quais se assentam estes axiomas não podem mais ser considerados válidos. Entre estes, eles relacionam:

- Dada uma determinada ordem de preferência entre objetos, ela não se altera pela presença de uma nova opção,

- Dominância, a escolha recai sobre a que for considerada melhor independente da situação, e

- Invariância, a preferência entre as opções é independente da forma como a situação é apresentada.

Segundo os autores (1974), as probabilidades, em geral, estão baseadas em crenças relativas à chance relativa a eventos incertos. Estas crenças usualmente estão expressas por frases do tipo 
“eu acho ..." ou por forma de probabilidades subjetivas. Eles advogam que tais crenças estão baseadas em princípios heurísticos que reduzem tarefas complexas de avaliar probabilidades e predizer valores a operações mais simples de juízo. De modo geral estas heurísticas são bastante úteis, mas às vezes levam a erros graves e sistemáticos. Para eles, muitas das decisões estão baseadas em crenças que não encontram respaldo em probabilidades ou conhecimento formal ou científico. Tais decisões estão associadas às experiências de cada um, a proximidade da informação, a conceitos pré-concebidos e outras causas que levam as pessoas a buscar heurísticas, regras de bolso, para se apoiar no momento da decisão e reduzir seu "custo" pessoal incorrido para julgar e selecionar uma opção. Tais heurísticas criam uma sensação de confiança, reduzem o "custo" da decisão, mas podem levar a erros sistemáticos.

Os autores apresentaram uma forte crítica à teoria da utilidade ao lançar a teoria do prospecto. Em particular, eles defendem que as pessoas são avessas a perdas, a dor da perda é muito mais significativa que o prazer do ganho. De acordo com os autores, diante de uma perda certa os indivíduos preferem o risco são, portanto, risk lovers (Kahneman \& Tversky, 1979). Assunto que será abordado na próxima seção.

De acordo com Simon (1955) o número de alternativas, e suas consequências em termos de satisfação, associado às restrições e limitações psicológicas de processamento para classificálas e ordená-las, implicam em simplificações que desafiam os princípios da racionalidade ilimitada. Para ele, o desafio era substituir a racionalidade econômica do homem por alguma racionalidade comportamental, ou seja, compatível com sua capacidade de processamento.

Segundo a Royal Swedish Academy of Sciences (2002) a psicologia cognitiva considera que o processo decisório é influenciado por uma série de fatores que se inter-relacionam e o torna complexo. Estes componentes influenciadores contemplam a percepção individual, as crenças ou modelos mentais utilizados para interpretar a realidade, as emoções e as atitudes. Além destes, a memória sobre decisões anteriores e suas consequências também exerce influência no processo. A decisão, ainda, é particularmente dependente do contexto em que ela tem lugar.

Para Lichtenstein e Slovic (2006) em muitas situações nós realmente não sabemos o que preferimos. Nestes casos, de fato, as preferências são construídas conforme a situação se 
apresenta. Quando a preferência prévia é insuficiente para resolver um problema que demanda uma decisão, então é necessário construir uma preferência para o momento conforme as restrições do ambiente. Estes casos ocorrem quando pelo menos uma das três situações seguintes está presente:

- Quando algum elemento necessário para a tomada de decisão é desconhecido;

- As opções de escolha disponíveis embutem um conflito entre preferências previamente conhecidas que impõem um tradeoff; e

- É preciso traduzir nossas percepções sobre o que melhor ou pior em termos de números, tais como probabilidades.

Ainda segundo os autores, os métodos de escolha e as preferências não são determinados apenas por razão, emoção e memória, mas, também, por aspectos relacionados ao ambiente tais como a descrição da situação ou como ela é apresentada. A preferência é formada de diferentes modos, ela se constrói e reconstrói continuamente e, portanto, não é estável não podendo ser considerada algo real ou substantivo. Para eles, a principal questão da decisão é construção da preferência, portanto, a teoria da decisão pode ser entendida como uma teoria da construção da preferência. Desta forma, assim como a preferência é construída a decisão também é construída.

Bettman, Luce e Payne (2006) argumentam que a racionalidade limitada e a capacidade de processamento pelo ser humano são consistentes com o conceito de que a preferência é construída, é formada, e não simplesmente revelada. Em processos de decisão envoltos por situações complexas ou inéditas, as pessoas, em geral, não possuem preferências bem definidas, ao contrário, elas as constroem quando precisam, no momento em que devem tomar a decisão. Desta forma, a preferência é formada no momento e depende, entre outros, do ambiente e das informações disponíveis que serão processadas conforme o conhecimento prévio acumulado e seguindo abordagens próprias ou individuais. Sendo assim, podem ocorrer inconsistências entre preferências e escolhas, decorrentes das informações disponíveis, da forma como são apresentadas, da maneira como são processadas e do contexto no momento da tomada de decisão.

Segundo os autores, a escolha depende entre outras:

- Dos objetivos do tomador de decisão,

- Da complexidade da decisão,

- Das opções oferecidas, todas deverão ser comparadas entre si, e

- Da forma como a questão é construída ou de como o problema é apresentado (frame). 
Para Ola Svenson (2006) a tomada de decisão pode ser considerada como um tipo resolução de conflitos no qual os objetivos contraditórios são contrapostos, julgamentos são feitos e uma contínua negociação tem lugar para que se construa a solução. Esta negociação é dependente do contexto e dos fatores individuais que tornam o processo de difícil compreensão e ratificam sua individualidade. Este conflito impõe o "custo" cognitivo e as heurísticas funcionam como um mecanismo para reduzi-lo.

Lichtenstein e Slovic (2006) encontraram evidências de reversão de preferências entre pessoas submetidas a diferentes experimentos, ou seja, conforme a situação era apresentada elas alteravam sua preferência entre as alternativas $A$ e $B$. Segundo os autores, as escolhas são influenciadas pelas crenças, estas influenciam a percepção de risco que cada pessoa forma sobre cada aspecto ou consequência de sua decisão e faz com que estas sejam essencialmente particulares. Adicionalmente, as crenças também moldam a maneira como cada um processa a informação e, portanto, a importância relativa atribuída a cada fator envolvido na decisão.

Tice, Bratslavsky e Baumeister (2001), em experimentos realizados, concluíram que diante de um cenário de estresse ou insatisfação é mais difícil que as pessoas controlem seu ímpeto para consumir. Este fato indica que o consumo pode ser visto como uma compensação para alguma frustração e que diante de contextos distintos provoca sentimentos e emoções diferentes que resultam em decisões também distintas.

Tversky e Thaler (1990) ironizam a visão que a economia positiva tem do comportamento humano, como algo estável cujas preferências são bem definidas e as decisões tomadas de forma consistente e racional. Também em um contraponto a esta concepção Slovic et al. (2002) introduziram a questão do afeto como um fator importante para influenciar julgamentos e decisões. Por afeto, eles entendem como um estado de espírito (consciente ou não) que de forma rápida e automática cria um sentimento positivo ou negativo em relação a algo. Estes preceitos são consolidados no conceito de heurística do afeto. Em certa medida, a heurística do afeto lança luz a um elemento até então relegado a um plano secundário, qual seja, a emoção.

Segundo Royal Swedish Academy of Sciences (2002) a teoria do prospecto (Kahneman \& Tversky, 1979), além de uma crítica, se constitui um modelo alternativo a teoria da utilidade. 
Enquanto esta é axiomática e deduz o comportamento humano por meio de lógica e axiomas a teoria do prospecto é descritiva e busca entender o comportamento por meio da observação dos fatos. A seguir são apresentados alguns pilares da teoria do prospecto.

\subsubsection{Prospect Theory (Teoria do Prospecto)}

Segundo Thaler (1980) a teoria econômica tradicional está calcada no princípio da racionalidade do ser humano e é essencialmente normativa. Ela supõe que os indivíduos agirão conforme determinado pela teoria. Contudo, desvios em relação ao comportamento prescrito explicitam sua fragilidade em descrever, de fato, o comportamento do ser humano. Estes desvios são intitulados como ilusões mentais.

Em seu ensaio sobre a premiação de Daniel Kanheman ao Nobel de economia de 2002 a Royal Swedish Academy of Sciences (2002) atribui a Kanheman e Amos Tversky o mérito de combinar com sucesso psicologia cognitiva e ciência econômica ao publicarem suas descobertas sobre julgamento e decisões em condições de risco. O artigo "Prospect Theory: An Analisys of Decision Under Risk" publicado por Kahneman e Tversky em 1979 é considerado por muitos como obra seminal para a construção do arcabouço atual sobre preferência, escolha e decisão.

Segundo os autores a teoria do prospecto é uma alternativa à teoria da utilidade esperada e como tal apresenta críticas a seus pressupostos e efetividade. Valendo-se de jogos em que os resultados, ganhos ou perdas, e suas probabilidades eram conhecidos e apresentados a grupos de indivíduos, construiu-se uma nova teoria sobre como os indivíduos tomam decisões em situações de incerteza.

Vale lembrar que esta contribuição conjunta entre economia e psicologia deu origem a behaviohal economics ou economia comportamental.

A economia positiva, assim como a teoria tradicional de finanças, está assentada nos princípios da utilidade esperada, ou seja, nos pressupostos de que as preferências são estáveis, bem conhecidas e que o tomador de decisão é capaz de realizar cálculos de probabilidade com intuito de maximizar sua utilidade. Ou seja, os axiomas propostos por Von Neumann e 
Morgenstrern (1944) governariam o comportamento das pessoas diante das necessidades de julgamento e decisão.

Como já visto, os pressupostos da utilidade esperada foram desafiados por uma série de evidências sobre violações a seus princípios que abriram caminho para uma nova compreensão sobre o comportamento humano na decisão. Em resumo, este novo marco teórico propõe que as pessoas são mais sensíveis as alterações (incrementos) de riqueza que ao seu estoque e que elas mediante a perda iminente preferem a incerteza do jogo. Ou seja, elas são avessas ao risco frente à escolhas que envolvem ganhos certos, e propensas ao risco nas situações que envolvem perdas certas. A dor da perda equivale a duas vezes o prazer do ganho (Kahneman \& Tversky, 1979; Tversky \& Kahneman, 1992).

Para Thaler (1985, p. 200), a prospect theory rompe com o paradigma normativo, que se caracterizava como uma solução em busca de um problema, ao focar nos indivíduos e em como eles de fato se comportam para descrever suas ações.

O texto a seguir pretende apresentar os principais elementos da teoria do prospecto e está baseado em Kahneman e Tversky (1979, 1983), Tversky e Kahneman (1981, 1986, 1991, 1992), Thaler (1980), Wakker (2010) e Barberis (2012, 2013).

Segundo a teoria da utilidade esperada, para uma dada função utilidade, a opção $a$ será preferida opção $b$ quando:

$$
\sum_{i} p_{i} u\left(w_{i}\right)>\sum_{i} q_{i} u\left(w_{i}\right)
$$

Onde:

$p_{\mathrm{i}}=$ probabilidade do evento $a ;$

$w_{\mathrm{i}}=$ nível de riqueza;

$q_{\mathrm{i}}=$ probabilidade do evento $b$. 
De outra forma (Barberis, 2013), o resultado de uma aposta deve ser avaliado por:

$$
\sum_{i=m}^{n} p_{i} U\left(W+x_{i}\right)
$$

Onde:

$p_{\mathrm{i}}=$ probabilidade de ocorrência do evento;

$U=$ função utilidade, crescente e côncava conforme a riqueza;

$W=$ nível de riqueza;

$x_{\mathrm{i}}=$ resultado da aposta ou incremento da riqueza $\left(\mathrm{W}_{\mathrm{i}}-\mathrm{W}_{0}\right)$.

Sob os princípios da teoria do prospecto, estas equações podem ser reescritas como:

$$
\sum_{i} \pi\left(p_{i}\right) v\left(x_{i}\right)>\sum_{i} \pi\left(q_{i}\right) v\left(x_{i}\right)
$$

Onde:

$p_{\mathrm{i}}=$ probabilidade de ocorrência do evento $a$;

$q_{\mathrm{i}}=$ probabilidade de $b$;

$v=$ função valor;

$x_{\mathrm{i}}=$ resultado da aposta ou incremento da riqueza $\left(\mathrm{W}_{\mathrm{i}}-\mathrm{W}_{0}\right)$;

$\Pi=$ é uma função que transforma as probabilidades objetivas em pesos a serem utilizados na decisão.

De acordo com Barberis (2013) quatro são os pilares que descrevem a teoria do prospecto e, em decorrência, se afirmam como diferenças fundamentais em relação à teoria da utilidade esperada. São eles:

1. Dependência do ponto relativo de referência;

2. Aversão à perda;

3. Diminuição da sensibilidade; e

4. Ponderação das probabilidades.

Dependência de um ponto relativo de referência. De acordo com a teoria do prospecto, as pessoas formam sua avaliação sobre a utilidade a partir dos ganhos e perdas medidos em relação ao ponto de referência, ao invés do nível absoluto de riqueza. Kahneman e Tversky argumentam que de forma similar às percepções sensoriais, as pessoas reagem com maior 
intensidade às mudanças em claridade, barulho, temperatura entre outros do que à magnitude absoluta.

Como visto, para Bernoulli as pessoas avaliam suas apostas em função do resultado final em termos de riqueza. Kanheman e Tversky (1979, 1983), argumentam ser este pressuposto pouco realístico, de acordo com a teoria do prospecto as pessoas avaliam as opções em relação aos incrementos ou decrementos de riqueza, ou melhor, em relação aos ganhos ou perdas. Os resultados de um jogo envolvendo risco são incertos e os resultados negativos ou positivos (perdas ou ganhos) são comparados a um ponto neutro que assume um valor equivalente à zero.

O ponto de referência é construído sobre ganhos e perdas e não em referência ao resultado final da riqueza, sendo que o framing a partir do qual a situação é avaliada pode induzir o julgamento (Thaler, 1985).

Aversão à perda. Considerando valores de mesma magnitude, deduz-se que as pessoas são muito mais sensíveis às perdas, mesmo para valores pequenos, que aos ganhos. A função valor $(v)$ captura a aversão à perda e faz com que ela seja mais inclinada no campo das perdas que dos ganhos. A figura 2.6 apresenta a função valor, em que no eixo das abcissas estão ganhos e perdas e nas ordenadas o valor assumido por estes. Vale notar que para uma mesma unidade $x$, de ganho ou perda, o valor associado às perdas é maior. 


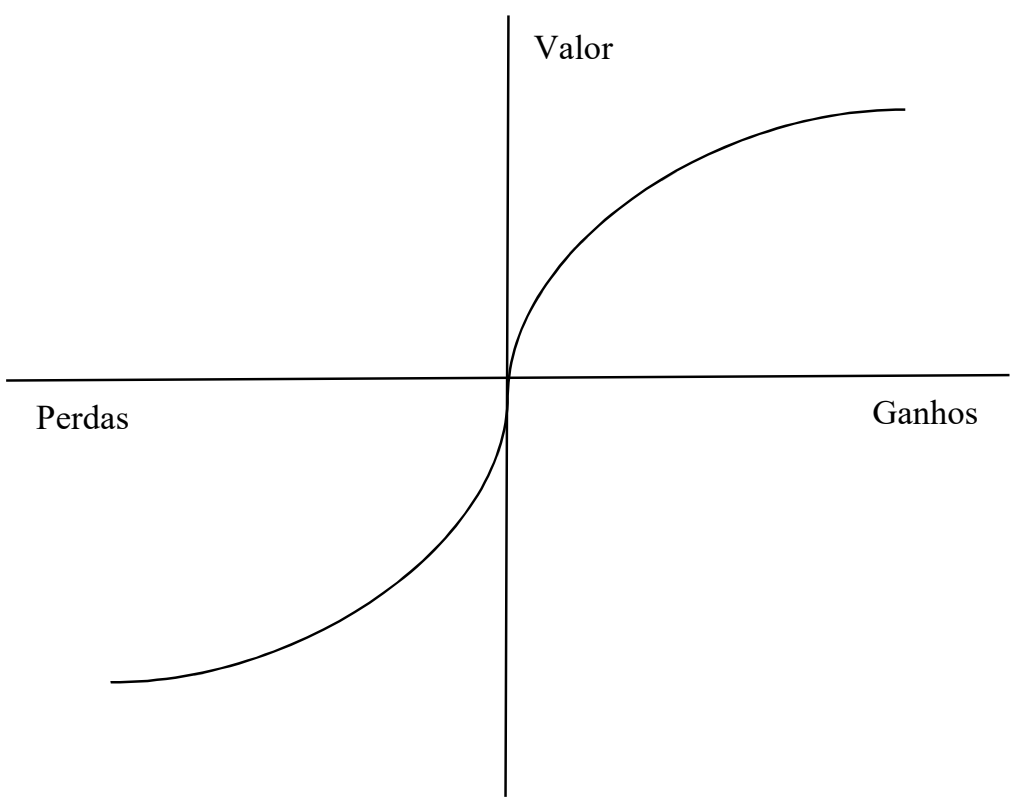

Figura 2.6 - Função Valor da Teoria do Prospecto

Considerando a aversão à perda e que as pessoas avaliam ganhos e perdas em relação a um ponto de referência, a função valor pode ser descrita como (Tversky \& Kahneman, 1986):

- Definida a partir de ganhos e perdas,

- Geralmente côncava no terreno dos ganhos e convexa no das perdas, e

- Mais inclinada nas perdas do que nos ganhos.

Os valores estimados para uma determinada alternativa são influenciados pelo ponto de referência. Ela é aceitável quando o valor das vantagens excede o das desvantagens. Estas são combinadas de forma a resultar em uma avaliação total do objeto que, se positiva, a tornará elegível para a escolha.

Diminuição da sensibilidade. A função valor é côncava na região dos ganhos e convexa no campo das perdas. Desta forma, variações em ganhos ou perdas menores, como de \$100 para $\$ 200$, tem impacto significativo na utilidade enquanto para variações entre valores maiores, por exemplo, de $\$ 1.000$ para $\$ 1.100$, causam impacto menor. A concavidade na região dos ganhos indica que as pessoas tendem a ser avessas aos riscos, ou seja, elas preferem o ganho certo a um resultado esperado de mesmo valor. No entanto, as pessoas tendem ao risco na região das perdas, elas preferem a correr o risco de perder determinado valor a uma perda certa de mesmo valor esperado. 
Ponderação de probabilidade. Os pesos atribuídos pelas pessoas as probabilidades objetivas de um evento $\left(p_{i}\right)$ são transformados, ou seja, assumem outros valores que não aqueles definidos estatisticamente. $\mathrm{O}$ valor de um resultado incerto é multiplicado por um peso. Esta função é indicada por $\pi_{\mathrm{i}}$.

A figura 2.7 apresenta o gráfico que cruza as probabilidades $(p)$ e a função $\pi_{\mathrm{i}}$ que transforma $\mathrm{o}$ valor $\mathrm{p}$ em $\pi(p)$. A linha pontilhada, inclinação de 45 graus, representa as coordenadas em que os pesos e probabilidades assumem os mesmos valores. $\mathrm{O}$ que se deduz é que as pessoas sobrevalorizam as probabilidades menores e subavaliam as probabilidades maiores. De acordo com a função, valores impossíveis são descartados $(\pi(0)=0)$ e diferenças em relação a probabilidades $(p)$ extremas são sobre avaliadas quando comparadas a diferenças entre probabilidades localizadas no meio da escala $\left(\pi\left(p_{1}\right)-\pi\left(p_{2}\right)\right.$ para $\left.0<p<1\right)$. Vale destacar, ainda, que esta função não se comporta de forma consistente em relação a probabilidades extremas.

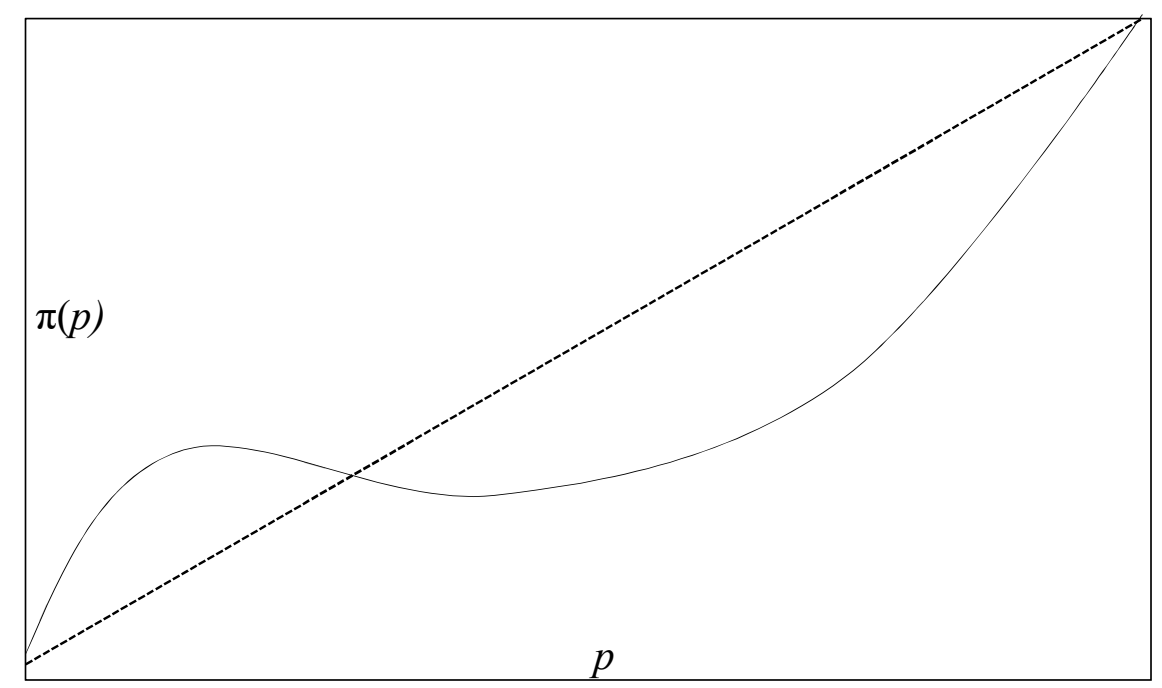

Figura 2.7 - Função Transformação de Probabilidades

Por fim, por conta das características de não linearidades tanto da função $\pi$ quanto da função $v$ mudanças no frame de decisão podem causar diferentes escolhas (Tversky \& Kanheman, 1981). 
Kahneman e Tversky argumentam que a decisão pode ser vista em dois estágios. No primeiro, chamado de edição, as informações disponíveis são recolhidas, o ponto de referência é construído e as informações são codificadas em termos de ganhos e perdas. No segundo, denominado de avaliação, são realizadas as comparações entre os valores das diferentes opções.

A seguir serão abordados dois aspectos relevantes abordados ou relacionados à teoria do prospecto relevantes para esta pesquisa, os conceitos de aversão à perda e de efeitos de enquadramento (framing effects).

\subsubsection{Aversão à Perda}

Em seu processo de escolha e tomada de decisão, as pessoas buscam um ponto de referência a partir do qual ancoram sua avaliação sobre as alternativas disponíveis e forma julgamentos sobre quão bom / ruim ou sobre ganhos / perdas de cada uma (Kahneman \& Tversky, 1979; Tversky \& Kahneman, 1974, 1992).

A assimetria entre ganhos e perdas é um ponto crucial da teoria do prospecto. Como já citado, ela explica porque a curva em forma de $\mathrm{S}$ da função valor é mais inclinada no terreno das perdas do que no dos ganhos. O sentimento negativo associado à perda é muito mais intenso do que o prazer proporcionado pelo ganho. No processo de tomada de decisão, contribuirão para a percepção do risco em relação às perdas alguns dos elementos já vistos até aqui, entre eles, os efeitos do enquadramento, o ponto de referência e a dependência do contexto. (Hausman, 2012)

Considerando que o valor da perda é maior que o proporcionado pelo ganho, a função valor nos moldes da teoria do prospecto pode ser expressa por:

$$
v(x)<-v(x)
$$

A esta assimetria, em que a perda de utilidade decorrente de se desfazer de algo é maior que o ganho de utilidade proveniente de se adquirir algo, foi dado o nome de aversão à perda. (Kanhneman, Knetsch \& Thaler, 1991). 
Segundo Abdellaoui, Bleichrodt e Paraschiv (2007), a função de ponderação de probabilidades presente na teoria do prospecto atribui pesos diferentes para os ganhos e para as perdas, característica que pode amplificar os efeitos da aversão ao risco.

A avaliação de perdas e ganhos é construída a partir de um ponto de referência presente no momento em que se comparam as opções, assim sendo, mudanças neste ponto de referência alteram a percepção de ganhos e perdas, podendo, inclusive, inverter o sentido de ambos e causar a reversão da preferência. (Kanheman et al., 1991; Tversky \& Kahneman, 1991).

Os trabalhos de Benartzi e Thaler $(1995,1999)$ identificaram um padrão de aversão à perda denominado, por eles, de "aversão míope", no qual os indivíduos que acompanham com maior frequência os rendimentos da bolsa tendem a não suportar as perdas, acabam por abandonar suas ações e não realizam os ganhos de longo prazo. Ganhos estes estimados em $7 \%$ para o mercado acionário contra $1 \%$ para os títulos do tesouro americano, entre os anos de 1926 e 1995.

Thaler (1980) estudou o comportamento de compra e venda de objetos e detectou um padrão no qual as pessoas exigem um valor muito maior para desfazer de algo, ou vender, do que estão dispostas a dispender para adquirir o mesmo objeto. A este padrão ele deu o nome de endowment effect (efeito dotação).

Um dos exemplos que ele oferece neste artigo é a o caso de um apreciador de vinhos que anos atrás comprou uma caixa de um bom vinho por $\$ 5$ a garrafa e que anos depois recebeu uma proposta para revender as garrafas remanescentes por $\$ 100$ a cada uma. Ele recusou, embora jamais tenha pago mais que $\$ 35$ por uma garrafa de vinho. Este efeito se estende também para uma relação de compra e venda, em que o valor pago para adquirir um bem é visto como uma perda enquanto ao valor recebido pela venda é visto como um ganho. Nesta transação, o ganho é subdimensionado em relação à perda.

Kanhneman, Knetsch e Thaler, (1990) realizaram experimentos com estudantes para testar o endowment effect. Foram fornecidas xícaras para metade dos alunos de uma classe e estes deveriam vendê-las para a outra metade em um processo que buscava encontrar evidências de surgimento de um mercado de compra e venda, conforme prescrito pela teoria tradicional. De 
fato, o que se observou é que poucas xícaras foram comercializadas. O preço mediano pedido na venda foi de $\$ 5,25$ enquanto o preço mediano oferecido na compra foi de $\$ 2,50$.

Os autores, assim como Thaler (1980), advogam que os desembolsos são vistos como perdas, e, portanto, causam uma percepção maior de valor (que causa dor) enquanto o valor da venda é considerado custo de oportunidade, similar a um ganho (prazer). Ou seja, as pessoas geralmente buscam um preço maior (willingness to accept, WTA) para vender algo que possuem do estão dispostas a pagar pelo mesmo item (willingness to pay, WTP).

Vale destacar, que o efeito da aversão à perda e o endowment effect não se manifestam em relações comerciais nas quais os bens foram adquiridos com intenção de revenda. De fato, a aversão à perda está primariamente presente em situações em que proprietários de bens precisam vender algo ou recebem ofertas por estes. (Kanheman et al., 1991; Novemsky e Kanheman, 2005)

Uma abordagem complementar para explicar as causas do endowment effect é oferecida por Weaver e Frederick (2012) que atribuem o efeito não somente a "dor da perda". Em algumas situações o endowment effect pode ser explicado melhor pela relutância em se desfazer de algo por um preço que parece desfavorável. As pessoas avaliam suas transações pelos preços de referência praticados no mercado, uma espécie de ponto de referência, e como em geral os preços praticados no mercado excedem as avaliações dos bens transacionados em negociações particulares acabam por criar uma sensação de desvantagem. Experimentos em que se reduziram os gaps entre as avaliações e os preços de referência reduziram ou até eliminaram o endowment effect. Nesta situação, ele é entendido como uma aversão a maus negócios ou resultados do que a aversão por perder a posse de bens. Os autores alertam que ambas as teorias explicam o fenômeno em termos de aversão à perda diferindo, contudo, em relação ao ponto de referência a partir do qual ganhos e perdas serão avaliados.

O endowment effect está relacionado a outro viés denominado por Samuelson e Zeckhauser (1988) de status quo, que é compreendido como a opção por manter algo, uma situação ou uma decisão anterior. Ou seja, a opção por não tomar uma decisão. Segundo os autores, as pessoas tem uma forte tendência por manter o status quo, por conta da aversão à perda, já que o sentimento de perda provocado pela decisão de se desfazer de algo será muito maior que o ganho que poderia advir da troca. 
Em experimentos com estudantes, eles foram apresentados a um cenário em que recebiam uma herança composta parte em dinheiro e parte em uma carteia de investimentos financeiros. Em relação aos investimentos, um grupo foi testado para uma carteira de ações de alto risco, outro de médio risco e outro com título do tesouro. Foi solicitado que aplicassem parte do dinheiro herdado em ativos financeiros, o resultado é que independentemente dos próprios perfis de risco e retorno, os respondentes mantiveram as opções de risco-retorno previamente contratadas.

Adicionalmente, percebeu-se que o status quo se eleva conforme aumentam as opções disponíveis para escolha. Quanto mais complexa a decisão a ser tomada maior a probabilidade de que se escolha por manter o status quo. Evitar uma mudança pode reduzir as chances de arrependimento.

O arrependimento foi tratado por Thaler (1980) que o relacionou aos custos psicológicos inerentes a uma tomada de decisão associados aos sentimentos de culpa e responsabilidade. Neste caso, a redução do número de alternativas tende a diminuir este custo.

Shefrin e Statman (1985) cunharam o termo disposition effect (efeito disposição) para definir um viés intimamente ligado ao arrependimento. Para os autores, as pessoas buscam por um lado evitar o sentimento de arrependimento e por outro encontrar motivos para que se orgulhem de si mesmas. Sendo assim, elas acabam por ter uma predisposição por vender seus ativos financeiros muito cedo diante de uma valorização ou por mantê-los por tempo demais quando acusam desvalorização.

O arrependimento é definido por eles como um sentimento negativo motivado por uma decisão tomada no passado que teve um resultado diferente do desejado. O orgulho é justamente o contrário, o sentimento de regozijo provocado por um resultado igual ou melhor que o esperado.

Portanto, vender ativos que acumulam prejuízo significa realizar as perdas que provoca o arrependimento. Enquanto a venda de ativos lucrativos cria a sensação de orgulho. Como a função valor amplifica a sensação provocada pelas perdas (aversão à perda) em relação aos 
ganhos, os indivíduos tem uma maior disposição a vender aos ativos com ganhos do que a realizar as perdas.

Em outro estudo sobre o efeito disposição, Terrance Odean (1988) acompanhou transações realizadas por 10.000 contas de uma corretora. As evidências indicaram que os investidores apresentam forte preferência por vender as ações com ganhos e relutam em realizar as perdas.

\subsubsection{Framing Effects (Efeito de Enquadramento)}

O efeito enquadramento pode ser entendido como impacto da forma como a pergunta é apresentada na resposta obtida ou na decisão tomada.

Segundo Royal Swedish Academy of Sciences (2002) durante a fase de edição, de acordo com a teoria do prospecto, a maneira como as pessoas combinam as informações e como constroem seu ponto de referência depende da forma como o problema é formulado. Deste modo, a percepção sobre ganhos e perdas também é influenciada pelo enquadramento.

Tversky e Kahneman $(1981,1986)$ e Kahneman e Tversky (1983) estudaram a o efeito de enquadramento (framing effect) e sua relação com a escolha. Segundo os autores, a forma como o problema é apresentado desafia os princípios da racionalidade ilimitada. As preferências são significativamente afetadas pelo frame, ou seja, os pressupostos de transitividade da preferência são violados consistentemente como resultado da forma como o problema é formulado. Nestes casos, verifica-se o fenômeno conhecido como reversão da preferência (preference reversal) em que aspectos ligados ao contexto em que a decisão tem lugar influenciam a formação da preferência e desafiam os princípios da independência de contexto e da invariância.

Segundo os autores, a análise de viés normativo pressupõe que a decisão é racional e segue uma lógica enquanto a análise descritiva se baseia em crenças, ações e preferências que as pessoas têm em seu dia-a-dia e não, em contraste, como elas deveriam ser.

Para Tversky e Kahneman (1981, p. 453) o frame of decision se refere à forma como o tomador de decisão percebe atos, resultados e contingências associadas a uma determinada 
escolha. A maneira como o problema é formulado e apresentado exerce influência dominante sobre a construção do frame a ser adotado na decisão.

Ao avaliar resultados de diferentes opções, as pessoas constroem um ponto de referência, uma espécie de resultado neutro ou ponto zero as escala, a partir do qual ganhos e perdas são estimados. A forma como esta situação é formulada e apresentada pode, portanto, alterar o ponto de referência e, considerando, a não linearidade tanto da função valor quanto da função peso das probabilidades, pode-se, por fim, impactar a preferência e a decisão, desafiando, assim, o pressuposto da invariância. (Kahneman \& Tversky, 1983).

“A avaliação dos resultados é suscetível à formulação dos efeitos por conta da não linearidade da função valor e da tendência das pessoas em avaliar as opções em relação a um ponto de referência sugerido ou implícito na formulação do problema" (Kahneman \& Tversky, 1983, p. 346).

Em pesquisa feita com estudantes, os autores investigaram o efeito do enquadramento na decisão. Dois problemas foram formulados em termos abordagem ou enquadramento um positivo e outro negativo e os respondentes foram instados a escolher entre as opções apresentadas.

Abaixo são apresentados o cenário e os dois problemas para decisão.

\section{Cenário}

Imagine que os EUA estão se preparando para enfrentar um surto de uma moléstia incomum cuja estimativa é que cause a morte de 600 pessoas.

\section{Problema 1}

Dois programas de combate são propostos e suas estimativas de efetividade são:

Se o programa A for adotado 200 pessoas serão salvas; e

Se o programa B for adotado existe $1 / 3$ de probabilidade de que 600 sejam salvas e $2 / 3$ de probabilidade de que ninguém seja salvo.

Problema 2

Dois programas de combate são propostos e suas estimativas de efetividade são:

Se o programa C for adotado 400 pessoas morrerão; e 
Se o programa $\mathrm{D}$ for adotado existe $1 / 3$ de probabilidade de ninguém morra, e 2/3 de probabilidade de 600 pessoas morram.

As opções A e C são idênticas, em ambas 200 pessoas serão salvas ou 400 serão vitimadas. A diferença é que enquanto a alternativa $\mathrm{A}$ é formulada de forma positiva a alternativa $\mathrm{C}$ é apresentada de forma negativa.

Se as pessoas não sofressem influência do frame, seria de se esperar que a mesma proporção de respondentes escolhessem as alternativas A e C. Contudo, o resultado alcançado foi bastante diferente. Enquanto $72 \%$ das pessoas escolheram a opção A, sem risco no problema 1 , contra apenas $28 \%$ que escolheram a opção $\mathrm{B}$; no problema 2 , a alternativa $\mathrm{C}$ foi a selecionada por somente $22 \%$ contra $78 \%$ que se decidiram pela alternativa D. O resultado comprova que, diante de um cenário positivo, a opção preferida e escolhida é aquela que garante salvar 200 ( ganho certo) vidas e que diante do frame negativo a decisão recaiu sobre evitar a perda iminente de 200 vidas pela possibilidade de salvar 200.

Estas atitudes inconsistentes em relação a risco são, porém, consistentes com a teoria do prospecto em relação à aversão à perda. De forma análoga, independentemente da equivalência das probabilidades fica claro que ao tomar sua decisão a pessoa atribui pesos distintos destas probabilidades.

Outro aspecto salientado por Kahneman e Tversky (1983), e também alinhado à teoria do prospecto, é que o número de 600 vidas funciona como um ponto de referência a partir do qual as escolhas devem ser feitas, e, portanto, a partir do qual os ganhos e perdas são avaliados.

De acordo com Tversky e Kahneman (1981) na maior parte das situações as pessoas não estão conscientes dos efeitos do enquadramento do problema em suas decisões. Para os autores, as decisões mudam conforme a situação é formulada e apresentada para o tomador de decisão que em geral não tem consegue perceber formas alternativas de avaliar a situação que se coloca.

Um efeito de frame não relacionado a apostas é descrito por Thaler (1980) ao citar o caso da indústria de cartão de crédito americana, cujos representantes defendiam que a diferença entre 
valores para pagamento com cartão ou a vista fosse apresentada como desconto ao invés de sobre taxa para pagamento com cartão. A sobretaxa seria avaliada como algo negativo enquanto o desconto seria avaliado como positivo.

Nofsinger e Varma (2007) realizaram estudo com estudantes para detectar a influencia dos estilos de processamento de informação na decisão. A partir do uso da escala conhecida como CRT (cognitive reflection test), proposta por Frederick (2005), foram definidos dois grupos, quais sejam: aqueles com CRT mais elevado, com processamento mais cognitivo, e outro com CRT mais baixo considerado mais intuitivo. O resultado apontou que as pessoas do primeiro grupo, mais cognitivo, decidem com maior independência em relação ao frame que as do segundo.

A teoria do prospecto é descritiva, incorpora contribuições da psicologia cognitiva e fundamentos do comportamento humano, como a emoção e o uso de heurísticas para amenizar o esforço cognitivo, para formar um modelo que represente com mais precisão a decisão em condições de incerteza. Ao longo das décadas de 80 e 90 uma série de estudos enfocando supostas anomalias em relação ao comportamento prescrito pela teoria da utilidade foi estudada, tais como endowment effect, status quo bias, loss aversion e preference reversals (Royal Swedish Academy of Sciences, 2002; Wakker, 2010).

A partir da teoria do prospecto a emoção e o esforço cognitivo foram definitivamente introduzidos nas discussões e sobre a decisão em situações de risco. A heurística do afeto incorpora a emoção e a pré-disposição afetiva como aspectos inerentes ao julgamento e relacionam reações emocionais e processamento cognitivo.

\subsubsection{Heurística do Afeto}

Slovic, Finucane, Peters e MacGregor (2002) apresentam novas perspectivas sobre a temática percepção de risco. A heurística do afeto descreve sua importância para orientar julgamentos e decisões. Para os autores, neste contexto, afeto é uma qualidade que expressa o sentido de "bondade" ou "maldade". Ela transmite um sentimento ou sensação (consciente ou não) de bem ou mal estar que influencia na forma como algo é percebido. A resposta afetiva ocorre rápida e automaticamente. 
Para os autores, existem duas formas fundamentais que os seres humanos utilizam para formar sua compreensão sobre risco: "sistema analítico", no qual cálculos numéricos, probabilidades e regras são processadas e os riscos são medidos, ele é lento altamente consciente; e o "sistema experiencial" que é intuitivo rápido, automático e pouco consciente. Os autores atribuem ao sistema "experiencial" as reações à natureza que permitiram aos seres humanos sobreviver e evoluir até o estágio atual, estes sistema é, portanto, o maior responsável pela maneira como respondemos ao risco. Ele confia em imagens e representações formadas pela experiência passada e faz surgir emoções e afeto que atuam sobre a formação da percepção.

Segundo estes, os primeiros estudos sobre a percepção de risco detectaram sinais de correlação positiva entre risco e retorno, contudo pesquisas associadas à heurística do afeto encontraram evidências de correlação negativa, ou seja, maiores recompensas não estão associadas a maiores riscos. A princípio parece existir uma escala bipolar em que a situação em análise é enquadrada em modelos tais como bom/ruim, bonito/feio ou seguro/perigoso.

Em pesquisas sobre a utilização de energia nuclear em que foram manipuladas informações sobre os benefícios e os riscos encontram evidências de que o sentimento, pré-disposição, das pessoas em relação ao uso da tecnologia é determinante no julgamento. Se o sentimento é favorável, os indivíduos tendem a considerar que os benefícios percebidos são elevados e os riscos percebidos são baixos, mas se o sentimento é desfavorável eles tendem a considerar que os benefícios são baixos para os riscos potenciais. Sob esta perspectiva, o afeto tende a dominar o julgamento sobre riscos e retornos.

Loewenstein, Weber, Hsee e Welch. (2001) advogam que as reações emocionais em situações de risco por vezes divergem das avaliações lógicas. Nestes casos, a resposta emocional será dominante e direcionará a ação. Existem emoções presentes no momento da decisão e emoções que são antecipadas. Estas últimas, tais como frustração e arrependimento, são levadas em conta no momento da decisão. A avaliação dos resultados incorpora às consequências os estados emocionais que o tomador de decisão espera experimentar no futuro. Assim, como a perda vale mais que ganho de mesma magnitude, as pessoas tentam evitar emoções negativas com mais ênfase que buscam as positivas. 
Slovic, Finucane, Peters e MacGregor (2004) advogam que o sistema experiencial se orienta por imagens, representações e associações que se interligam pela emoção e afeto e, portanto, este processamento intuitivo traduz risco como algo emocional, um sentimento de perigo ou segurança. Os sistemas experiencial e analítico operam em paralelo, de forma integrada e dependente. As evidências indicam que a emoção e o afeto são fundamentais para a efetividade da avaliação processada pelo sistema reflexivo. Para os autores três conceitos de risco coexistem, são eles: risco como sensação, que se refere ao processamento rápido e intuitivo, que reage ao perigo; risco como análise, lento, reflexivo, deliberado e que gerencia o perigo; e risco como política, em situações de conflito e tensão provocadas pela incompatibilidade entre os julgamentos da intuição e da racionalidade.

Segundo Slovic, (1999) enquanto o perigo possui uma dimensão real o risco é algo construído em meio à sociedade. Avaliações sobe o que é e sobre sua intensidade dependem de fatores sociais, individuais, culturais, ideologia, emoções e tantos outros fatores que cercam a humanidade. Pesquisas indicam que para o público em geral risco está associado à incerteza, ao passo que para os experts ele está ligado as probabilidades de danos, é mais quantitativo, sem contudo perder sua dimensão real.

Os resultados de pesquisas indicam que a emoção orienta o sentido sobre qual é o tamanho de cada risco, ela influencia diretamente e fundamentalmente a avaliação de risco. A emoção assim como os valores e as crenças permitem que o ser humano navegue pelo mundo tomando decisões de forma rápida, automática, e eficiente em meio às incertezas. A heurística do afeto funciona como uma pré-disposição para apostar, perceber benefícios e atenuar riscos em situações que gostamos e ignorar benefícios e realçar risco nas que não gostamos. A heurística do afeto reduz a tensão causada pelo tradeoff entre benefícios e riscos. O afeto positivo ou negativo cria representações positivas ou negativas que ajudam a prever atitudes e comportamentos (Slovic, 1999; Slovic et al., 2002; 2004).

De acordo com o autor, confiança é um algo que se constrói pacientemente, mas que se destrói rapidamente. As relações pessoais e sociais se baseiam na confiança e para que as pessoas possam tomar suas decisões em acordo com as orientações de autoridades, políticos e profissionais das mais diversas especialidades é necessário que se estabeleça um elo de confiança entre o tomador de decisão e o responsável pela recomendação. 
Por meio de jogos que simulavam empréstimos, entre credores e agentes de companhias de investimento, Schniter et al., (2013) identificaram que os supostos agentes que reembolsaram os investidores conforme os valores previamente combinados inspiraram confiança em seus parceiros e lograram fazer novos negócios com menores taxas de desconto.

\subsubsection{Pensamento Intuitivo}

Kahneman (2003) discute a questão da racionalidade limitada e o papel que as heurísticas assumem no processo de julgamento de decisão. Especificamente, o autor se aprofunda no estudo da cognição e como a facilidade de acesso às informações mais próximas determinam um tipo de pensamento intuitivo em contraste com outro mais deliberado e reflexivo. As decisões rotineiras são guiadas pela intuição que se utiliza de representações da realidade e heurísticas para operacionalizar as decisões mais rapidamente e sem esforço, o que leva a vieses sistemáticos. Os sistemas perceptivo e intuitivo trabalham de forma conjunta, de modo que a os fatos percebidos pelo primeiro são processados de forma automática gerando impressões da realidade a partir das quais são feitos os julgamentos intuitivos.

Para o autor, ambiguidade e incerteza tendem a ser eliminadas pela percepção que, em geral, tende a adaptar as informações e as enquadrar em representações já conhecidas impedindo que se vislumbrem alternativas concorrentes e, assim, evitando o desconforto da tomada de uma decisão complexa. Nos campos da percepção e intuição, as heurísticas funcionam para, por exemplo, aliviar o esforço em questões que necessitem de execução de cálculos financeiros. Desta forma, elas serão equacionadas por similaridade e associação de impressões, conceitos e outras representações que tornem a decisão mais rápida e confortável.

Kahneman e Frederick (2002) traçaram um panorama da evolução das pesquisas sobre os processos cognitivos destacando que as heurísticas e vieses ocupam lugar no campo da intuição, algo que ocorre entre a percepção e pensamento controlado pela razão, uma fronteira inseparável, obscura e permeável. Este pensamento controlado, quando acionado por alguma tensão, é que receberá e processará as impressões criadas pelo pensamento intuitivo e as corrigirá se necessário. As pessoas possuem um modelo duplo de processamento de informação em que em alguns momentos e/ou para alguns assuntos se utilizam mais de um processamento intuitivo, rápido, automático e sem esforço, e em outras ocasiões o processamento reflexivo, lento, controlado e esforçado. 
Estes dois tipos de processamento, o intuitivo e outro ligado à razão, o reflexivo, foram denominadas por Stanovich e West (2000) de forma genérica como Sistema 1 e Sistema 2, respectivamente.

Evans e Stanovich (2013) propõem uma nova denominação para as duas formas de processamento, são elas Tipo 1 e Tipo 2 para os pensamentos automático e reflexivo, respectivamente. Os autores propõem a mudança de nomenclatura para evitar interpretações de que equivocadas de que poderiam ser "dois cérebros" ou processamentos independentes, não interligados. Os autores defendem que o processamento do Tipo 2 se distingue pela habilidade cognitiva de decompor as partes, fazer simulações mentais e recorrer intensamente aos recursos da memória. Para eles o Tipo 1 se diferencia pelo pensamento, autônomo, automático e por não requerer recursos da memória, contudo, é possível se acrescentar outras características que não são tão consensuais entre os teóricos ou que causa certa variabilidade na definição do conceito. O quadro 2.1, abaixo, apresenta os principais atributos que distinguem os dois tipos de processamento.

\begin{tabular}{|l|l|}
\hline Tipo 1 (Intuitivo) & Tipo 2 (Reflexivo \\
\hline \multicolumn{3}{|l|}{$\begin{array}{c}\text { Não requer recursos da memória } \\
\text { Autônomo }\end{array}$} & Características Definidoras \\
\hline & Requer recursos da memória \\
Rápido & Decomposição; simulação mental \\
Alta capacidade & Associações Frequentes \\
Paralelo & Lento \\
Não consciente & Capacidade limitada \\
Respostas viesadas & Serial \\
Contextualizado & Consciente \\
Automático & Respostas normativas \\
Associativo & Abstrato \\
Decisão baseada na experiência & Controlado \\
Independente da habilidade cognitiva & Baseado em regras \\
& Decisão orientada pelas consequências \\
\hline Sistema 1 (mente antiga) & Correlacionado com a habilidade cognitiva \\
\hline Envolvimento no início & \\
Cognição similar a do animal & Sistema 2 (mente nova) \\
Conhecimento implícito & Envolvimento tardio \\
Emoções básicas & Cognição humana \\
\hline
\end{tabular}

Quadro 2.1 - Atributos Frequentemente Associados ao Conceito de Processamento Duplo ou Sistema Duplo de Processamento

Referência: de Evans e Stanovich (2013, p. 225) 
Nesta pesquisa os termos Sistema 1 e Tipo 1 assim como Sistema 2 e Tipo 2 serão utilizados indistintamente.

De acordo com Kahneman (2011) as situações com as quais as pessoas se deparam são automaticamente avaliadas pelo Sistema 1 que determinará a necessidade de esforço extra e do Sistema 2. Segundo o autor quando as pessoas estão relaxadas, em geral, elas estão bem, não percebem ameaças ou novidades que venham a exigir mais atenção e a necessidade de mobilizar esforço cognitivo extra que exija a participação do Sistema 2. Já quando estão tensas, em geral, estão diante de um problema, uma situação difícil que exige a atuação do Sistema 2. Quando relaxadas as pessoas experimentam a sensação de conforto cognitivo e quando tensas a sensação de tensão ou desconforto cognitivo.

Segundo Alter et al. (2007), se uma informação é considerada simples ela é processada facilmente ou fluentemente de forma intuitiva (Sistema 1) já se a informação é percebida como complexa, ela é processada com dificuldade ou sem fluência, a tarefa é considerada difícil e o Sistema 1 evocará o Sistema 2. A partir dos resultados de quatro experimentos em que foram manipulados os estados de fluência de informação a fim de gerar tensão cognitiva, os autores encontraram evidência de que situações consideradas difíceis criam, de fato, um estado de tensão cognitiva que faz com que seja requerido mais esforço cognitivo fazendo com que as pessoas se engajem em um processamento de informação mais analítico (Sistema 2).

Estudos conduzidos por Alter e Oppenheimer (2006) e Pensa (2006) encontraram evidências de que as cotações de empresas cujos nomes são fáceis, cognitivamente mais assimiláveis ou fluentes, são melhor avaliadas pelos investidores e, até, de que suas cotações apresentam desempenhos superiores aquelas com nomes pouco fluentes. Nestes casos, os autores atribuem os resultados a fatores tais como facilidade de memorização, simpatia e outros que gerem uma sensação de fluência ou conforto cognitivo, implicando na simplificação do julgamento e, assim, substituindo um processamento mais complexo.

Topolinski e Strack (2009) realizaram estudo com tríades de palavras algumas coerentes, em que era possível estabelecer algum tipo de associação entre as palavras, e outras incoerentes, em que não se conseguia estabelecer qualquer associação. Os autores identificaram que as tríades coerentes geram uma sensação de afeto positiva e que tríades que são processadas 
mais rapidamente geram a sensação de coerência e de conforto. Os julgamentos intuitivos que estão a cargo do Sistema 1 estão associados ao conforto cognitivo e ao afeto positivo.

Frederick (2005) desenvolveu uma escala para medir o reflexo cognitivo, ou seja, a habilidade ou disposição para se resistir a uma resposta que primeiro e rapidamente vem a mente, esta escala foi denominada de CRT (cognitive reflection test). Kahneman (2003) argumenta que o Sistema 1 é intuitivo e automático e recorre a informações que estejam mais rápida e facilmente acessíveis.

A escala CRT é composta de três perguntas simples (mais detalhes na seção planejamento da pesquisa) cujas respostas surgem imediatamente à mente. Frederick (2005) aplicou os testes a 3.428 estudantes de diferentes universidades americanas. Em relação à preferência por risco, os resultados indicam que pessoas com maior CRT, ou seja, mais cognitivas, são mais propensas ao jogo que as menos cognitivas (menor CRT) quando as apostas envolvem ganhos, especialmente quando os valores em questão são mais elevados.

A teoria do prospecto advoga que mediante a certeza da perda as pessoas preferem o jogo, ou seja, elas são avessas à perda e preferem a incerteza do jogo. Contudo, em situações de perda, os resultados da pesquisa de Frederick comprovaram ser esta assertiva verdadeira apenas para o grupo com baixo CRT, já que os indivíduos com alto CRT preferiram realizar a perda. Os resultados comprovam a importância da habilidade cognitiva na tomada de decisão.

\subsubsection{A Percepção de Risco}

"Muitas pessoas tomam parte de um jogo em uma determinada situação mas não em outra. As possibilidades de ganhar \$20 em um jogo não se modificam em cenários diferentes e, portanto, o valor esperado das apostas permanece o mesmo. Tanto o risco quanto a recompensa não se alteram mas a reação das pessoas muda diante do risco". (Nofsinger, 2011, p. 35).

A frase acima traduz a ideia de que embora as probabilidades e as recompensas não se alterem em um determinado jogo, a percepção de risco de cada indivíduo será particular e dependente de suas crenças, emoções, cognição, cultura e tantos outros aspectos em ação no momento da 
decisão. Cada pessoa tem uma personalidade e uma história que moldam sua forma de processar as informações. Adicionalmente, a forma como o problema é apresentado tem papel crucial na construção do ponto de referência a partir do qual os ganhos e perdas decorrentes da decisão serão projetados.

"Nós não gostamos de incerteza em nossa vida financeira, pois, o dinheiro que nos ajuda a evitar a pobreza é mais valioso que aquele que nos ajuda a ficar mais ricos" (Rabin, 2000, p. 1281).

Segundo Shefrin (2002) as pessoas não tem um comportamento uniforme em relação ao risco, elas podem ser mais ou menos tolerantes conforme a situação se apresenta, se as possibilidades de perda parecerem menores ou maiores.

Para Slovic (1987, p.280) a percepção é inerente aos seres humanos (ou vivos) e ocorre naturalmente quando as pessoas precisam fazer julgamentos que impliquem em avaliação de danos ou prejuízos a si ou para outros.

Segundo o autor:

A habilidade de perceber e evitar danos que possam comprometer as condições ambientais é necessária para garantir a sobrevivência de todos os seres vivos. A habilidade em codificar e aprender com a experiência passada é, também fundamental para a sobrevivência. Os seres humanos possuem uma capacidade adicional que os permitem alterar o ambiente assim como reagir a ele. Esta capacidade pode tanto criar quanto reduzir riscos.

Esta necessidade de se perceber e de se evitar riscos está, portanto, ligada ao instinto de sobrevivência sendo um traço relevante na formação do comportamento e atitude da cada ser humano.

Ainda segundo Slovic, as pessoas desenvolvem modelos mentais, atalhos ou heurísticas, que empregam para avaliar alternativas, cujos resultados são incertos. Estas heurísticas reduzem o esforço cognitivo e muitas vezes levam a vieses que causam erros persistentes de avaliação, notadamente em relação a tratar de probabilidades. 
Em finanças, risco é um conceito associado à possibilidade de perdas. Atribui-se Markowitz (1952) a elevação da variância ou do desvio padrão como métrica amplamente utilizada para medir o risco de uma alternativa.

Holton (2004), em artigo sobre uma definição para risco, advoga que independentemente do conceito que se utilize dois componentes devem estar presentes. O primeiro é a incerteza sobre o resultado que será alcançado e a segunda é que o objeto em avaliação seja, de fato, algo que tenha importância para a pessoa que terá de tomar a decisão.

Para o autor duas frases do artigo Portfolio Selection (1952) indicam tal associação.

“[...] o investidor considera o retorno esperado como desejado e a variância dos retornos como algo indesejado." (Markowitz, 1952, p. 77).

"Os conceitos de "rendimento" e "risco" aparecem frequentemente nos textos de finanças. Usualmente, o termo "rendimento" é utilizado como sinônimo de "rendimento esperado" ou "retorno esperado" e "risco" como sinônimo de "variância do retorno", aparentemente o resultado em termos de sentido é o basicamente o mesmo" (Markowitz, 1952, p. 89).

Como já abordado, ao ingressar em uma aposta, assim como em um investimento, as pessoas esperam ganhar um valor que lhe forneça determinado nível de satisfação ou utilidade. Supondo que a aposta tenha dois resultados possíveis, A e B, com probabilidade p e $(1-p)$, o valor esperado (VE) é o resultado de:

$$
V E=p A+(1-p) B
$$

Para uma pessoa neutra ao risco a utilidade de VE será igual ao próprio VE, ou seja, ao próprio equivalente certo (certainty equivalent, $\mathrm{CE}$ ).

$$
U(V E)=p U(A)+(1-p) U(B)
$$


Porém, indivíduos avessos ao risco exigirão valores esperados maiores para participar de uma aposta como forma de compensação pelo risco a incorrer, ou seja, exigirão o chamado prêmio de risco:

$$
V E>p(A)+(1-p)(B)
$$

Segundo Kritzman (1998) a utilidade esperada em um investimento é representada pela seguinte fórmula:

$$
E(U)=E(r)-\lambda \sigma^{2}
$$

$\mathrm{E}(\mathrm{U})$ - Utilidade esperada

$\mathrm{E}(\mathrm{r})=$ Retorno esperado do investimento

$\lambda=$ Coeficiente de aversão ao risco

$\sigma=$ Desvio padrão dos retornos

Desta forma, quanto maior o coeficiente de aversão ao risco, maiores deverão ser os retornos esperados para que se possa alcançar o mesmo nível de utilidade de uma pessoa menos avessa.

Cada indivíduo tem uma curva de indiferença na qual a utilidade é constante em qualquer ponto da curva. Quanto maior o coeficiente de aversão mais alta será a curva que descreve o comportamento do investidor em relação ao binômio risco-retorno. Abaixo figura 2.8.

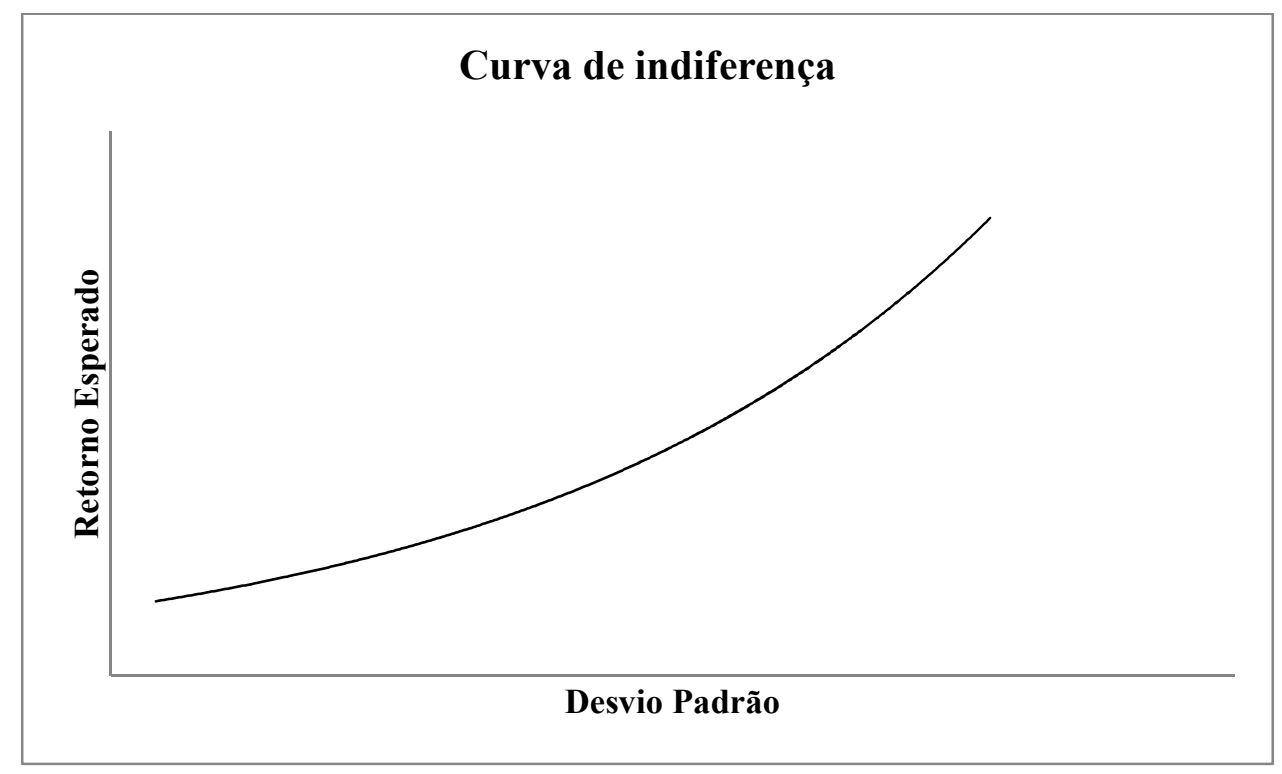

Figura 2.8 - Curva de Indiferença 
$\mathrm{Na}$ literatura, risco é considerado uma situação especial em condições de incerteza, na qual as probabilidades de ocorrência de um resultado são conhecidas. Alguns autores (Hela Maafi, 2011; Trautmann, Vieider \& Wakker, 2011) adotam o conceito de ambíguo, ou em condições de ambiguidade, para os cenários em que as probabilidades são desconhecidas.

Segundo Weber, Anderson e Birnbaun (1992, p. 493), “... risco parece fazer parte da categoria de conceitos abstratos (ex. beleza) em que não existe uma definição precisa, cada pessoa faz seu julgamento. A conhecida assertiva estabelecida pela suprema corte de justiça sobre pornografia ("Eu não sei se posso definir pornografia, mas eu a reconheço quando assisto uma cena") parece ser bem empregada para o conceito de risco."

Sitkin e Pablo (1992) definem risco como uma medida de incerteza associada a potenciais resultados negativos significativos decorrentes de uma decisão. Os autores argumentam que a variabilidade dos resultados potenciais é indesejada, ela amplifica a incerteza, e para compensá-la as pessoas devem esperar um resultado melhor (ou um retorno maior). Neste contexto, a falta de conhecimento sobre a distribuição dos possíveis resultados assim como de suas probabilidades intensifica o contexto de incerteza. A despeito deste conceito de risco, eles lembram que usualmente risco está associado a resultados negativos.

A partir da abordagem proposta por Sitkin e Pablo, Sitkin e Weingart (1995), analisaram os construtos percepção de risco e propensão a risco e os definiram da seguinte forma: (i) percepção de risco é uma avaliação individual sobre o quão arriscada é uma situação em termos de estimativas de probabilidade, capacidade de controle e confiança nas próprias estimativas; (ii) propensão ao risco é uma tendência individual para buscar ou evitar situações de risco, mutável no tempo e que se materializa conforme a situação é enfrentada.

Os autores defendem que a percepção de risco e a propensão ao risco interagem com a experiência passada e com a forma como a situação se apresenta (frame) e acabam por definir o comportamento de decisão em risco dos indivíduos. Neste sentido, encontraram uma relação negativa entre percepção de risco e propensão ao risco. 
Abaixo a figura 2.9 contendo o modelo desenvolvido por Sitkin e Weingart (1995).

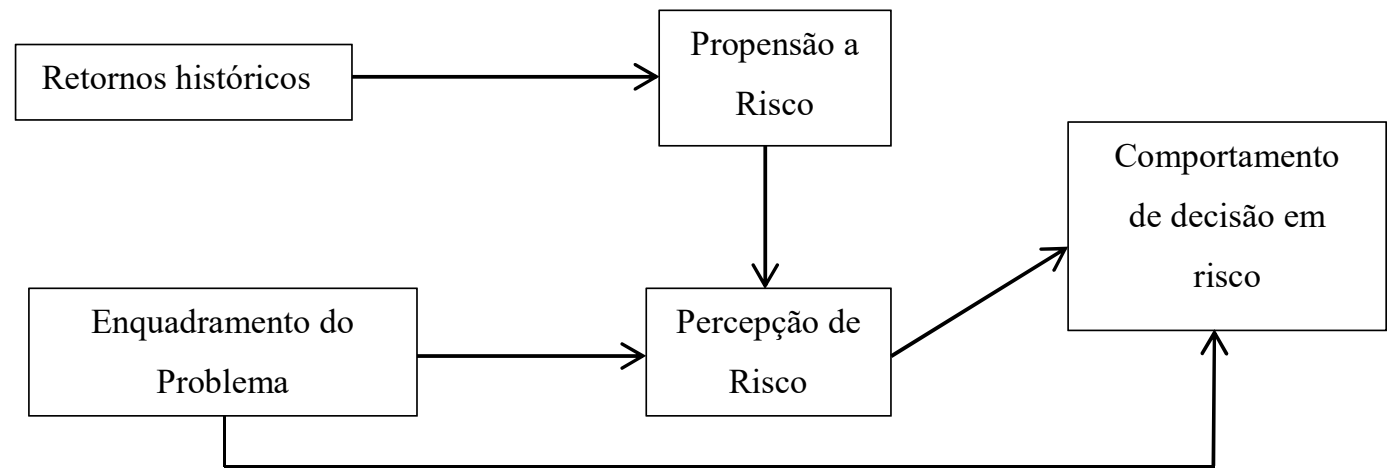

Figura 2.9 - Determinantes da Decisão em Condições de Risco

Referência: Sitikin e Pablo (1995, p.1586)

O termo propensão a risco tem sido tratado por diferentes acepções na literatura, entre elas, tolerância ao risco e atitude em relação ao risco. A despeito das diferentes formas, o conceito, que se deseja identificar é o trade off entre aversão a risco contra busca pelo risco.

Tendo como base o modelo de Sitkin e Weingart (1995), Byrne (2005) desenvolveu pesquisa junto a clientes do ramo de seguros em que simulou decisões sobre alternativas de investimento, ao invés de jogos. A autora, a partir da oferta de diferentes produtos com distintas relações de risco-retorno, identificou que as experiências prévias influenciam e estão correlacionadas com a atitude em relação ao risco e que esta se relaciona negativamente com a percepção de risco, quanto mais atraído pelo risco menor a percepção de risco que se formará a partir de uma situação. Por outro lado, o enquadramento do problema está positivamente correlacionado com a percepção de risco, um frame positivo incita uma percepção de risco positiva.

Thaler e Johnson (1991) também estudaram a influência das experiências anteriores na percepção do risco, defendem que durante a fase de edição os ganhos ou perdas em apostas anteriores podem influenciar de forma sistemática as escolhas atuais. Os autores denominaram de "house Money effect" o efeito causado pelos ganhos anteriores na redução da aversão a risco ou, de outra forma, na maior predisposição a aceitar o risco. Já as perdas passadas causam efeito contrário, ou seja, reduzem a atratividade do jogo e foi denominada de "break even". 
Já Weber e Zuchel (2005) confirmaram as conclusões de Thaler e Johnson em relação a jogos, mas chegaram a conclusão diferente em relação a decisões sobre portfolio. Nestes casos, parece haver maior predisposição ao risco diante de perdas anteriores. Os autores atribuem o fato a concepção de que uma decisão de investimento está relacionada a decisões prévias que fazem parte de uma ação contínua em que a fase anterior é vista como uma fase inicial, fenômeno denominado como "escalation commitment".

Segundo Staw (1976, 1981), em muitas situações, mesmo adversas, as pessoas tomam decisões como parte de uma sequencia e não de forma isolada. Nestas situações elas incorrem em mais custos e sacrifícios a despeito de resultados negativos já incorridos ou mesmo de perspectivas desanimadoras. Nestes casos, elas estão comprometidas como o curso de uma decisão e o abandono implica em desprezar os esforços empreendidos até o momento. Objetivos de longo prazo e custos já suportados até então reforçam o comprometimento (escalation commitment) e as decisões são vistas como parte de um curso de ações.

De acordo com Lunenburg (2010) o fenômeno escalation commitment é uma fonte considerável de erros em processos de tomada de decisão, a expressão "arremessar um dinheiro bom após um mau" sintetiza o sentido. A despeito de serem tecnicamente bem preparados, os executivos também estão sujeitos à racionalidade limitada e, portanto, a vieses na tomada de decisão. Neste contexto, a manutenção ou até ampliação de um plano de investimentos é uma forma de justificar a decisão original e não reconhecer os erros e as perdas.

Para Steinkühler, Mahlendorf e Brettel (2014) a necessidade de justificar a própria decisão representa a real motivação para dar continuidade a projetos de investimento com desempenho negativo ou abaixo do esperado. Isto cria uma percepção excessivamente otimista sobre as possibilidades futuras e uma supervalorização sobre a necessidade de recuperar os custos já incorridos.

Fazendo um contraponto a Schoemaker (1993), que advoga sobre a atitude em relação ao risco é um traço pessoal estável que não se altera conforme diferentes estímulos ou contextos, Weber e Milliman (1997) argumentam que diferentes métodos de medição podem resultar em classificações distintas e que as pessoas reagem de forma inconsistente conforme as situações 
são apresentadas. A percepção de risco depende do ponto de referência da pessoa que pode ser manipulado de diversas formas (tanto pela expectativa de resultado quanto pelas probabilidades), o que influencia fundamentalmente a decisão em condições de risco. A percepção de risco e a atitude são influenciadas pelo contexto, momento, histórico e atuam, em conjunto, para definir o comportamento em relação ao risco e a decisão.

Jordan e Kaas (2002) estudaram a comportamento de decisão em risco de investidores em fundos de investimento em relação a anúncios veiculados na imprensa. Tais decisões de investimento são caracterizadas pela incerteza sobre como se comportarão no futuro os retornos das alternativas em avaliação. Sendo assim, a percepção de risco e a expectativas de retorno assumem papel crucial na decisão. A partir de estudos sobre como os investidores pessoas físicas percebem o risco, os autores advogam que estes não enxergam risco como uma medida quantitativa, mas, de outra forma, como algo qualitativo, intuitivo, mais emocional que é orientado pela percepção individual do risco envolvido na situação e no momento. Dada as dificuldades inerentes aos cálculos financeiros, os autores, citando Kahneman e Riepe (1998) defendem que os investidores se valem de atalhos, "regras de bolso", as heurísticas, para processar as informações, simplificar a decisão mesmo que isto implique vieses e erros decorrentes de um algoritmo sub ótimo.

Segundo os autores, foram encontrados efeitos de ancoragem em relação aos indicadores de risco-retorno previamente apresentados a eles, ou seja, as pessoas tendem utilizar valores veiculados em publicidade ou mesmo informações sobre o desempenho pregresso dos fundos como uma espécie de âncora a partir da qual são estimados os retornos futuros e suas possibilidades de revés. Este efeito, contudo, não foi verificado em relação ao risco percebido. Também foi testada a heurística da representatividade, por meio da representação da marca. Neste caso, os investidores não fizeram distinção entre instituições conhecidas e não conhecidas em relação ao retorno estimado, mas em relação ao risco perceberam as menos conhecidas como mais arriscadas.

Sobre as heurísticas, verificou-se que elas atuam tanto sobre investidores mais informados quanto sobre os menos informados, contudo, estes últimos são mais suscetíveis aos vieses, resultado consistente com os encontrados. Ainda sobre este tema, nível de informação dos investidores, Ganzach (2000) identificou, por meio de experimentos, que aqueles mais familiarizados com mercado financeiro têm uma percepção acerca do risco que leva a escolha 
de produtos cuja relação risco-retorno é positiva, ou seja, enxergam os ativos mais arriscados como aqueles que oferecem maior prêmio. Esta relação não foi encontrada entre os menos familiarizados.

Ainda sobre as heurísticas, estudo de Klos et al. (2005) com estudantes de administração identificou que as pessoas não são capazes de associar risco à desvio padrão. Contudo, ao classificarem as alternativas em termos de risco percebeu-se alguma correlação entre julgamento sobre risco e probabilidade e tamanho das perdas.

\subsubsection{A Influência do Conhecimento e do Gênero na Percepção de Risco}

Para Slovic (1982) as pessoas, pelo menos as leigas, ao serem perguntadas sobre nível de risco raramente buscam informações e realizam cálculos estatísticos, de fato, elas recorrem a fatos recentes na memória, histórias e fatos marcantes para inferir ou buscar quantificar o risco embutido em alguma opção. Nestes casos, a heurística da disponibilidade costuma ser bastante empregada para reduzir o esforço mental e criar uma sensação de maior conforto. As pessoas respondem aos fatos conforme estes são percebidos.

Sobre a questão da expertise com investimentos financeiros, este estudo detectou que investidores experientes tem uma percepção mais precisa sobre risco e entendem melhor a relação entre risco e retorno. Tal nível de entendimento não foi encontrado entre os investidores menos experientes.

Ainda sobre a questão da influência do conhecimento técnico na tolerância ao risco, a frase de Hathaway e Khatiwada (2008, p.1) "O senso comum nos indica que consumidor mais informado é um consumidor melhor", resume bem a o que se espera da educação financeira. Segundo os autores, pressupõe-se que a educação financeira corresponda a maior conhecimento que leva ao melhor comportamento com as finanças que conduziria a melhores decisões e resultados. Contudo, a dúvida posta pelos mesmos é se a educação financeira de fato se traduz em maior conhecimento sobre finanças. Ou melhor, se os programas de educação financeira realmente funcionam. A despeito da ausência de sinais palpáveis sobre a relação educação financeira e comportamento os autores argumentam que treinamentos mais 
específicos, para audiências com necessidades relativamente homogêneas e sobre produtos similares em momentos mais próximos a decisões financeiras tendem a ser mais efetivos.

Dolvin e Templeton (2006) estudaram a efetividade de seminários dedicados à participantes de planos de pensão, em relação a melhor diversificação dos recursos entre as diferentes classes de ativos. Os indivíduos foram separados em dois grupos, os que assistiram às palestras e os que não tomaram parte destes eventos. Os resultados demonstraram que os indivíduos do primeiro grupo, ao conhecerem melhor os riscos envolvidos nos produtos que estavam disponíveis, escolheram aqueles mais adequados a sua tolerância ao risco promovendo desta forma uma maior diversificação e alcançando maiores taxas de retorno com menor nível de risco. Estas conclusões estão em linha com as Hathaway e Khatiwada (2008) sobre treinamentos mais específicos e, em relação à diversificação, parecem convergir com os estudos de Fellner e Maciejovsky (2007) que detectaram que à maior aversão a risco, mesmo que causada por desconhecimento, corresponde uma menor diversificação ou, de outra forma, uma diversificação ineficiente.

Em estudo publicado, Mandell e Klein (2009) relatam os resultados alcançados por meio da aplicação de um questionário a estudantes de graduação. Estes foram separados em dois grupos o primeiro composto por aqueles participaram de cursos de seis meses de finanças pessoais e os que não participaram. $\mathrm{O}$ questionário continha questões tanto sobre conhecimentos em finanças quanto sobre comportamento financeiro. Em relação ao nível de conhecimento os resultados apontaram para a inexistência de diferença entre os grupos o que parece estar relacionado ao fato de também não se ter verificado comportamentos distintos em relação a poupar ou consumir. Os autores defendem, contudo, que treinamentos mais específicos e próximos aos momentos em que as pessoas precisarão dos conhecimentos para tomar as decisões sobre consumir ou poupar podem ser mais efetivos.

Em relação à propensão ao risco, estudos têm apontado, de forma consistente, a existência de diferenças de comportamento entre gênero, masculino e feminino. Os resultados indicam de maneira consistente que as mulheres são mais avessas ao risco que os homens (Miller \& Schafer, 1999). Resultado também alcançado por Frederick (2005) em seu estudo sobre influência do traço cognitivo na preferência por risco. 
Charness e Gneezy (2012), por meio de um conjunto de experimentos, englobando diferentes países, submeteram indivíduos a jogos que simulavam um mesmo investimento financeiro e detectaram evidências que comprovam que as mulheres são mais avessas ao risco que os homens.

Dwyer, Gilkenson e List (2002), em estudo baseado em pesquisa sobre investidores em cerca de dois mil fundos de investimento no mercado norte americano chegaram ao mesmo resultado, porém concluíram que esta diferença de gênero é atenuada quanto maior o nível de conhecimento sobre mercados financeiros e produtos de investimento. Powell e Ansic (1997) estudaram o comportamento de risco entre profissionais de gestão de recursos financeiros e também detectaram diferenças entre gênero, neste caso, as mulheres costumam adotar estratégias de gestão menos arriscadas.

Segundo os preceitos da heurística do afeto a percepção de risco é inversamente influenciada pelo sentimento positivo ou negativo que se tem sobre um objeto (Alhakami \& Solvic, 1994, Slovic et al., 2002; Slovic \& Peters, 2006; Slovic \& Vastfjall, 2010). Por outro lado, investir é algo complexo para a maioria das pessoas (Estelami, 2012) e, em geral, gera tensão e desconforto cognitivo que pode exacerbar a sensação de vulnerabilidade (Alter et al., 2007; Topolinski \& Strack, 2009). Considerando estes suposições, é de se esperar que a opinião de um profissional reconhecido como competente na área de investimentos possa reduzir a percepção de risco e evitar o desconforto cognitivo e a tensão emocional decorrente deste julgamento.

\subsubsection{A importância do Gerente na Decisão de Investimento}

A inseparabilidade é uma das principais características distintivas dos serviços, a interação entre cliente e pessoal de atendimento ou prestador de serviço é inerente aos serviços, a coprodução é um aspecto intrínseco e o resultado final é consequência desta inter-relação. A experiência de um serviço depende fundamentalmente da relação provedor-cliente e da interação entre clientes que por fim podem provocar mudanças no próprio serviço oferecido (Lovelok \& Wirtz, 2011). 
O modelo concebido por Gallouj e Weinstein (1997) enfatiza a questão da experiência do serviço que implica na interação entre cliente-provedor e está calcado no conhecimento e nas competências da firma, incluindo aquelas possuídas também pelos indivíduos provedores dos serviços, e dos clientes. A tecnologia colabora de forma determinante para alcançar o resultado final. O modelo é, portanto, uma síntese da inter-relação das competências de provedor e consumidor dos serviços, figura 2.10 .

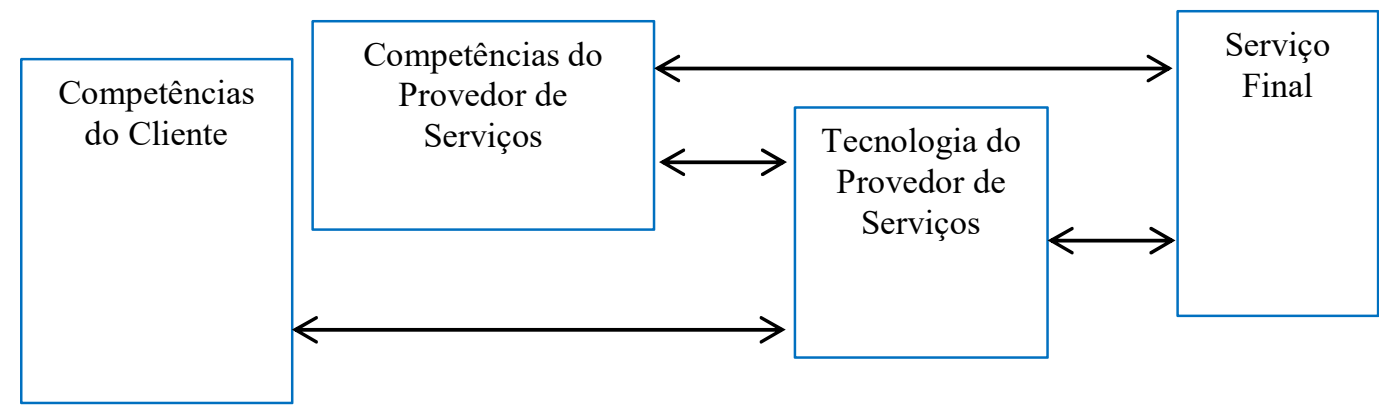

Figura 2.10 - Esquema de Inter-relação das Competências do Provedor e Consumidor Referência: Gallouj e Weinstein (1997, p. 546)

Os investidores em geral tem pouca familiaridade com conceitos de mercado financeiro e produtos de investimento. Para ajuda-los em seu processo de escolha bancos e distribuidores contam com gerentes e especialistas que buscam entender as necessidades e restrições dos clientes e, partir destas, recomendar as opções mais adequadas a cada momento. Este processo pode contemplar desde um aconselhamento ou consultoria mais aprofundada até uma mera recomendação, contudo, qualquer que seja o caso, tem lugar uma relação em que alguém supostamente tecnicamente qualificado orienta a decisão de alguém supostamente leigo. Esta é uma relação que Shainesh (2012) classifica como de alta importância e envolvimento do cliente que experimenta uma sensação de incerteza.

Há mais de três décadas, Berry (1995) argumentava que quando o consumidor, ou investidor, desenvolve uma relação de confiança com o prestador de serviço esta reduz a percepção de incerteza e a sensação de vulnerabilidade e torna a decisão mais confortável. $\mathrm{O}$ comportamento de tomada de risco de um consumidor ou investidor reflete sua percepção em relação ao nível de incerteza presente na situação em análise. A percepção de risco se acentua conforme a incerteza se eleva, os resultados potencialmente negativos devem ser evitados, e a 
sensação de perda acentua o sentimento de aversão (Baumann, Elliot \& Hamin, 2010; Dholakia, 2001).

O ambiente e os elementos presentes no momento da interação entre o provedor do serviço e o consumidor influenciam sua avaliação, percepções e intenções (Bitner, 1990). Shostack (1985, p. 243) define um "encontro de serviço" como "um período de tempo no qual o consumidor interage diretamente com o serviço". Booms e Bitner (1981) advogam que o mix de marketing para serviços devem incluir as características do local em que ele tem lugar, os processos, recursos de TI e procedimentos e, por fim, as pessoas tanto as que atendem quanto os demais consumidores.

Segundo Estelami (2012) a natureza complexa dos serviços financeiros torna a interações entre profissionais de atendimento e seus clientes um aspecto relevante da prestação do serviço. Esta relação exerce grande influência na formação da percepção do cliente sobre a empresa e a qualidade de seus serviços.

Moorman, Deshpandé e Zaltman (1993) contrapõem dois conceitos de confiança, o primeiro associado a uma vontade de crer, acreditar em um parceiro que lhe transmita a sensação de confiabilidade e o segundo associado à necessidade de um parceiro que reduza sua insegurança e vulnerabilidade, alguém em que possa confiar e trazer conforto.

Para Mayer confiança é “[...] a disposição de uma parte em estar vulnerável às ações da outra parte baseada na expectativa de que esta executará uma ação particular importante para a primeira, independentemente de sua capacidade de monitorar ou controlar a outra parte." (Mayer, 1995, p. 712). O autor desenvolveu um modelo multidimensional para explicar confiança como resultante de habilidade, benevolência e integridade. Por habilidade entendese competência, capacitação, expertise; já benevolência está associada a acreditar que o parceiro em que se confia está disposto a fazer o bem de forma altruísta e; por fim, integridade se relaciona à identidade de valores, tais como honestidade. Segundo o modelo a confiança atua junto à percepção de risco e quanto maior ela for, em comparação a percepção de risco, maior será a possibilidade de o consumidor se engajar em um processo de tomada de risco. 
Sirdeshmukh, Singh e Sabol (2002) estudaram a importância dos profissionais de atendimento (FLE, front line employee) e das políticas e práticas experimentadas diretamente pelos consumidores no encontro (MPP, management policies and practices) na formação da confiança entre consumidor e provedor de serviço. Os autores decompuseram a confiabilidade nas dimensões competência operacional, benevolência e orientação à resolução de problemas e desenvolveram um modelo que identificou a influência de cada dimensão na confiança. Os autores, de fato, identificaram que FLE e MPP são fatores críticos para formação da confiança, contudo encontram efeitos assimétricos em relação às dimensões.

No caso do FLE, foco desta seção, a benevolência apresenta efeito dominante negativo (uma unidade de desempenho negativo tem efeito maior que uma unidade de desempenho positivo) enquanto a orientação à resolução de problemas é dominante positiva (uma unidade de desempenho positivo tem efeito maior que uma unidade de desempenho negativo). Por fim, identificou-se que a percepção de valor (diferença entre benefícios menos ganhos na manutenção do relacionamento) tem efeito de mediar à relação entre confiança e lealdade.

Para Shainesh (2012) a interação entre FLE e os consumidores exerce papel crucial na formação da percepção favorável dos clientes sobre os serviços e a companhia. Em serviços intensivos em pessoas, a qualidade do serviço é largamente determinada pelas habilidades e atitudes dos profissionais que interagem com os clientes.

A confiança no prestador de serviço reduz a percepção de risco e tem impacto positivo na intenção de ampliar o relacionamento. Uma relação considerada satisfatória entre o profissional de atendimento e o cliente cria a percepção de qualidade e pode influenciar no relacionamento com a própria empresa

Em 2014 a ANBIMA contratou a Officina Sophia, empresa especializada em pesquisas sobre percepção de clientes, para elaborar pesquisa entre investidores e profissionais de atendimento certificados para venda de produtos de investimento com objetivo, entre outros, de verificar "percepções e comportamentos que possam ajudar no processo de modernização das certificações" (ANBIMA, 2014a). Descobrir o que os investidores esperam dos profissionais certificados para venda de produtos de investimento se colocava como principal objetivo. A pesquisa contou com um módulo exploratório (composto de 6 grupos de discussão com investidores e 14 entrevistas em profundidade com profissionais) e outro quantitativo 
(envolvendo 1.084 profissionais e 1.600 investidores). $\mathrm{O}$ alvo da pesquisa foram os canais de varejo e varejo alta renda, portanto, apenas investidores e profissionais deste segmento fizeram parte da amostra.

Dentre os resultados da pesquisa, vale destacar, os comportamentos que os investidores esperam ou desejam de seus gerentes. São eles:

conhecimento, do mercado, dos produtos e dos próprios clientes;

orientação, considerada como atividade fundamental;

proatividade, demonstrar real preocupação com o investidor (não estar interessado em bater metas); e pertinência, conhece as necessidade do investidor e procura, de fato, atende-las.

A pesquisa também buscou identificar gaps entre o atendimento esperado e o atendimento percebido pelos investidores. Dentre estes gaps, o menor se relaciona a capacitação técnica, está eminentemente ligada à expertise sobre o mercado financeiro e os produtos de investimento. Já o maior gap detectado se refere à pertinência, ou seja, os clientes sentem que seus gerentes não os conhecem e não oferecem os produtos mais adequados. Esta situação, embora não seja abordada pela pesquisa, pode avalizar a percepção dos investidores que seus gerentes estão mais preocupados em bater suas metas, tornando-se um inibidor para construção da confiança que habilite uma relação de longo prazo. Adicionalmente, foram identificados entre os principais motivadores para que o cliente concentrasse seus investimentos em determinada instituição, à confiança na marca e o relacionamento com gerente.

Em outra pesquisa, também de 2014, a ANBIMA, desta vez por meio da empresa ItsNoon, buscou entender os motivos pelos quais os gerentes são importantes para os clientes, principalmente no papel de investidores. Os resultados das pesquisas são convergentes. Em resumo, apurou-se que os investidores esperam dos gerentes, além do conhecimento técnico, que eles conheçam suas necessidades e características, ofereçam produtos adequados, ofereçam aconselhamento e orientação e se propiciem, de fato, com seu bem estar. Por outro lado, os investidores não toleram de seus gerentes o distanciamento, o fato de não estarem legitimamente preocupados e a sensação de que os negócios são bons para a instituição a despeito dos interesses dos clientes (ANBIMA, 2014b). 


\subsubsection{Intertemporal Choice (Escolha intertemporal)}

"Intertemporal choice é o que fazemos quando temos de avaliar o tradeoffs entre custos e benefícios entre diferentes momentos no tempo. Nós estamos todo o tempo fazendo escolhas intertemporais - quando nós escolhemos entre [...] aumentar nossa contribuição para previdência ou uma viagem para o Hawaii; entre o pecado ou a vida eterna." (Loewenstein, Read \& Baumeister, 2003, p. 2).

Segundo Frederick, Loewenstein e Ted O'Donoghue (2002) desde sua origem a ciência econômica está atenta a questão das escolhas intertemporais, como exemplo eles citam Adam Smith e seus escritos sobre a importância das escolhas intertemporais para a riqueza das nações.

(Frederick et al. 2002), discorrendo sobre o estudo de John Era, de 1834, aborda a questão do desejo de acumulação presente entre países e sociedades que difere entre elas e determina o nível de poupança e investimento. Dois fatores contribuiriam para inibir tal capacidade de investir, seriam eles: a incerteza sobre os eventos futuros e a natural excitação advinda do consumo imediato, ainda mais quando confrontado com o desconforto causado por adiar a realização do prazer.

Considerando a incerteza relacionada ao futuro e a aversão à perda, é natural que as pessoas, ao avaliar, por exemplo, o tradeoff entre consumir já ou poupar para o futuro exijam uma remuneração que compense a postergação do prazer. Quanto maior o autocontrole maior tende a ser a capacidade de renúncia. Contudo, como já visto, as decisões se dão no momento em que a situação se forma e, portanto, sofre interferência de vários fatores ambientais. Luce, Payne e Bettman (1999) analisaram os tradeoffs enfrentados no momento da decisão e identificaram a importância do estado emocional nas mesmas.

O trabalho de Samuelson (1937) é reconhecido como pioneiro na introdução do conceito de discounted-utility (DU), em que buscou sintetizar em um único fator todos os elementos que atuam para descontar o futuro, uma taxa de desconto que permita encontrar um valor equivalente. 
Segundo Frederick et al. (2002) o modelo DU foi bastante aceito pelos da escola normativa e influenciou muitos estudos. Contudo, não encontrou respaldo na realidade sendo, portanto, contestado pelos partidários da abordagem descritiva.

A despeito de suas limitações, o modelo é bastante útil para ilustrar o tradeoff. Soman, Ainslie, Li, Lynch, Moreau, Mitchell, Read, Sawyer, Trope, Wertenbroch e Zauberman (2005) apresentam a seguinte equação que sumariza a ideia. Considerando um valor $\$ x_{1}$ no presente $\left(t_{1}\right)$, qual a taxa de desconto que aplicada a um valor $\$ x_{2}$ em $t_{2}$ torna os valores $\$ x_{1} \mathrm{e}$ $\$ x_{2}$ equivalentes.

$$
\left(x_{1}, t_{1}\right) \approx\left(x_{2}, t_{2}\right)
$$

Desta forma, existe uma taxa $r$ que aplicada ao longo dos dois pontos no tempo que equipara as utilidades dos dois valores, qual seja:

$$
u\left(x_{1}\right)(1+r)^{d}=u\left(x_{2}\right)
$$

Onde: $d=t_{2}-t_{1}$.

Soman et al. (2005) e Frederick et al. (2002) demarcam a distinção entre time discount e time preference, a primeira relacionada a mudanças na utilidade em decorrência da passagem do tempo e a segunda a pura preferência por consumir hoje ao invés de adiar o consumo.

No que tange ao tema desta pesquisa, a questão da escolha intertemporal é inerente à decisão de investir. Investir significa renunciar ao prazer imediato pela recompensa incerta de um nível maior de satisfação no futuro. Este tradeoff, envolve um julgamento sob condições de incerteza, que evoca uma percepção de risco e a possibilidade de perda.

Esse modelo teórico, juntamente com a fundamentação teórica, busca trazer luz a estes elementos que junto com os aspectos relacionados à formação da preferência e elucidados na teoria do prospecto em muito colaboraram para a pesquisa qualitativa e construção do questionário e serão muito úteis na análise dos resultados da pesquisa empírica. 


\section{Contextualização e Problema da Pesquisa}

De acordo com Bersntein e Damodaran (1998), “ ... o processo de definir os objetivos de investimento consiste em balancear alguns tradeoffs, são eles: acumular riqueza ou se expor a riscos; retorno absoluto ou relativo; e, entre objetivos de curto ou longo prazo". Até muito recentemente, as taxas de juros brasileiras não impunham estas restrições aos investidores, já que, quando comparadas aos mercados de países desenvolvidos, elas garantiam altos retornos, com risco baixo e prazos muito curtos.

Se por um lado este tripé (alta rentabilidade, baixo risco e alta liquidez) ajudou a carrear recursos para os fundos com perfil de renda fixa, por outro, também, foi responsável pela baixa diferenciação da oferta, que a despeito do número de classificações não impediu a baixa diversificação de estratégias de investimento e a proliferação de fundos cujos comportamentos de risco-retorno são similares. Face a esta situação, os executivos entrevistados enxergam que havia pouco incentivo para se identificar quem são e o que desejam os possíveis investidores, mesmo entre a base de clientes da própria instituição.

Em adição a este quadro, a distribuição é eminentemente "bancarizada" e as empresas de gestão funcionam como unidades de negócio cujos produtos concorrem com os demais produtos (não necessariamente investimentos) oferecidos pelos bancos, muitos dos quais se constituem em funding para as próprias instituições.

O patamar atual das taxas de juros nominais, em torno de $14 \%$ ao ano, é sensivelmente menor que o registrado no início dos nos 2000, quando as taxas alcançavam o nível de $20 \%$ ao ano. Vale lembrar, ainda, que em junho de 2006 - quando se deu a primeira reunião do COPOM, colegiado do Banco Central do Brasil responsável por definir o nível da taxa de juros - este se situava em torno de uma média de $23 \%$ ao ano. Neste estágio, é de se esperar um rearranjo na oferta de produtos de investimento que a torne mais diversificada e aderente aos pressupostos da teoria de finanças (BACEN, 2015). A obtenção de ganhos elevados, ausência de risco de mercado e imediata disponibilidade dos recursos (conjugação que denominamos de tripé) avalizada pelo elevado patamar de taxa de juros não deve ser mais factível de implementação. Estratégias mais sofisticadas serão necessárias para garantir retornos mais elevados e estas implicarão em maiores riscos e em menor liquidez. 
Embora seja um movimento longo e sujeito a avanços e retrocessos, um novo paradigma composto por maior volatilidade e menor liquidez está em formação e deve dar início a um processo de mudança cultural entre os investidores. Criará oportunidades, assim como ameaças; acirrará a competição e criará incentivos para se investir no desenvolvimento de produtos diferenciados. Por outro lado, estimulará os distribuidores, notadamente bancos, a investir em educação financeira e em pesquisas para se compreender quem são os investidores e o que estes realmente desejam. Entender quais suas preferências, seu processo de decisão e como avaliam as alternativas se tornará um diferencial competitivo.

Adicionalmente, como apontado pela pesquisa da ANBIMA (2014) sobre o que os investidores esperam de seus gerentes, as instituições deverão investir na sua força de venda, em tecnologia da informação e em processos para criar uma estrutura capaz de reconhecer as necessidades de seus clientes, cultivar relacionamentos e conquistar sua confiança e lealdade.

Encarar o produto de investimento como um componente do serviço que busca entregar valor para o cliente e não como um fim. Nesta perspectiva, migrar de uma orientação a produto para uma orientação a marketing que, na definição de Kotler e Keller (2012), significa ser mais eficaz que seus concorrentes na criação, na entrega e na comunicação de um valor superior aos seus clientes.

Tantos anos de convivência com este tripé moldaram comportamentos e criaram traços culturais bem demarcados. Statman e Klimek (2010) publicaram artigo com os resultados de uma pesquisa - feita entre quatro mil pessoas de vinte e dois países - em que buscavam entender, entre outros, os efeitos da cultura local nas decisões de alocação de portfolio ou, de outra forma, seus impactos na aversão ao risco. Os pesquisadores mediram o quanto os entrevistados estavam dispostos a aceitar de perda em seu portfolio para poder participar de um jogo com 50/50 de chance de aumentar em outros 50\% este mesmo portfolio. A partir da consolidação das respostas sobre tolerância à perda decorrente de decisões de alocação de capital, o Brasil atingiu a vigésima primeira posição, registrando um índice de $10,6 \%$ do portfolio em risco contra uma mediana de $12,6 \%$. Ou seja, é o segundo país mais avesso à tomada de risco. Vale ressaltar que o estudo encontrou evidências sobre a existência de relação negativa entre nível de incerteza no ambiente político-econômico e tolerância ao risco. 
Em sintonia com o estudo acima, pode-se considerar que a elevada concentração em ativos de renda fixa no mercado brasileiro denota um comportamento substancialmente mais avesso a risco. Cotejando-se os resultados apurados pelo estudo de Fellner e Maciejovsky (2007) que apontam relação inversa entre aversão a risco e número de transações no mercado de capitais com a elevada concentração em ativos da dívida pública federal, pode-se inferir o tamanho do desafio a ser enfrentado pelos gestores de recursos para desenvolver os mercados de renda variável no Brasil.

Neste contexto, esta pesquisa pretende colaborar para elevar o nível de conhecimento sobre o processo de tomada de decisão do investidor brasileiro. Para tanto, foi levada a cabo pesquisa de campo em que estímulos foram apresentados a grupos amostrais de potenciais investidores e os resultados analisados por meio da técnica de análise conjunta (conjoint analysis), que busca decompor a utilidade e, desta forma, permite hierarquizar os fatores que determinam as preferências.

Até o momento, foram aqui relacionadas variáveis sociais, políticas e econômicas que afetam o conjunto da sociedade e ajudam a moldar a cultura da população de modo geral. Embora, para todos, tais condições sejam as mesmas, cada indivíduo reage de forma diferente ao ambiente. Cada pessoa é única. Adicionalmente, como visto, as preferências se formam no momento da decisão, o que pode levar as pessoas a fazerem escolhas distintas para problemas idênticos conforme o momento ou a maneira como estes se apresentam.

As pessoas possuem níveis diferenciados de aversão a risco, assim como partem de pontos de referência distintos para tomar sua decisão. As decisões de investimento podem ser tomadas a partir da análise detalhada das informações e de uma avaliação sobre riscos e recompensas das diferentes alternativas, Sistema 2, como advoga a teoria de finanças ou baseada na sensação de risco induzida pela emoção e afeto, algo mais intuitivo decorrente da percepção formada ainda no Sistema 1. Decisão esta que os defensores da teoria de finanças costumam denominar de irracional (Damodaran, 2009; Loeweinstei et al., 2001; Kritzman, 1998; Slovic, 1999; Slovic et al., 2002; Slovic et al., 2004).

Para conhecer o perfil de risco de seus clientes, se mais ou menos avessos, os distribuidores de produtos de investimento se utilizam de questionários (conhecidos como suitability). A iniciativa vem suscitando um processo de reflexão entre os investidores, contudo, parece 
insuficiente para garantir a adequação entre as expectativas do investidor e o portfólio, para ele, recomendado. Este método pode ser considerado apenas como um ponto de partida.

O chamado perfil de risco do cliente não existe a priori, este, assim como as preferências, é construído e reconstruído continuamente (Slovic \& Lichtenstein, 2006). Dependerá de aspectos ligados ao indivíduo e também do momento, de seu histórico e do ambiente da decisão. Entre outros, a disponibilidade das informações (e ao peso que se atribui a estas), a ancoragem, a forma como a situação é apresentada, ao ponto de referência de que parte (Kahneman \& Tversky, 1979; Tversky \& Kahneman, 1974, 1981).

Por outro lado, considerando os avanços alcançados nos últimos anos sobre os modos de processamento de informação (Alter et al. , 2007; Alter \& Oppenheimer, 2006; Evans \& Stanovich, 2013; Pensa, 2006; Schniter et al., 2013; Topolinski \& Strack, 2009) interessa também a esta pesquisa identificar se, assim como o perfil de risco, é possível segregar os investidores conforme seu estilo de processamento de informações. Particularmente, considerando seus objetivos, esta segregação talvez seja mais eficaz por conta da maior estabilidade do estilo cognitivo em comparação ao perfil de risco. Desta forma, uma identificação e segmentação dos clientes por esta característica pode trazer benefícios para as empresas na sua relação com a base de investidores que resultem aumento de valor para o negócio.

Charles D. Ellis (2014) defende que o objetivo dos gestores de patrimônio não é superar os retornos dos índices de mercado e sim assessorar seus clientes na definição dos objetivos (em consonância com suas restrições) e dos produtos mais adequados. O produto é apenas um dos componentes da prestação de serviço.

Considerando a escassa bibliografia sobre a estrutura de decisão dos investidores e sobre a influência do estilo cognitivo na decisão de investimento, esta pesquisa busca identificar a importância relativa de um conjunto de atributos determinantes de uma alternativa de investimento na decisão, possíveis evidências de aspectos emocionais na decisão e a influência do estilo cognitivo. 
Entre as contribuições da revisão de literatura, encontra-se a definição dos atributos que melhor caracterizariam uma alternativa de investimento. Estes atributos são:

- rentabilidade passada;

- possibilidade de perda (emana a percepção de risco) ;

- liquidez;

- taxa de administração; e

- recomendação do gerente (positiva ou negativa).

Desta forma, o problema de pesquisa pode ser resumido nas duas perguntas a seguir:

$\checkmark$ Considerando o conjunto de atributos acima, qual a hierarquia de preferência do investidor no momento da decisão? Existem diferenças significativas entre as importâncias relativas atribuídas a estes fatores para grupos formados por investidores com estilo cognitivo mais intuitivo, ou automático, com aqueles formados por menos intuitivos?

$\checkmark$ É possível identificar aspectos emocionais na decisão que desafiem a teoria da utilidade esperada? 


\section{Modelo Teórico}

Este capítulo pretende, por meio da formulação e testes de hipóteses, associar o conhecimento estruturado durante a fundamentação teórica ao problema de pesquisa e, assim, ajudar a responder as questões ali colocadas. Segundo Malhotra (2012) um modelo teórico representa a um processo real por meio de inter-relações entre as variáveis.

\subsection{Objetivos e Hipóteses}

As hipóteses são afirmações ou proposições não comprovadas, ou provisórias, formuladas com intenção de fornecer respostas ou explicações ao problema de pesquisa (Köche, 2002; Malhotra, 2012).

Para a grande maioria das pessoas a decisão de investimento é algo complexo, envolto em muitas dúvidas e receios (Estelami, 2012). Ela é uma decisão em condições de incerteza, em que as probabilidades associadas aos possíveis resultados da aplicação dos recursos são desconhecidas (Tversky \& Fox, 1995). Adicionalmente, as evidências sugerem que as pessoas são mais avessas a decisões em situações de incerteza em comparação a condições de risco (Trautmann et al., 2011).

As decisões em situações de risco vêm sendo estudadas há muito tempo, desde Bernoulli já em 1738 (1954), passando por Von Neumann e Morgenstern (1944) e sua representação axiomática para uma decisão racional até a teoria do prospecto (Kahneman \& Tversky, 1979) que incorporaram definitivamente a emoção e as heurísticas ao processo decisório, lançando luz às teorias de viés descritivo e que imprimiram mais realismo às análises. Desde então o estudo de fatores tais como emoção, percepção de risco como expressão de sentimento, influência do afeto e estilo de processamento cognitivo vêm sendo aprofundado (Loewenstein et al., 2001; Slovic et al., 2002; Thaler, 2000).

As decisões de investimento são aquelas cujo objetivo está associado a preservar ou apreciar determinada quantia, considerando uma perspectiva de risco por tempo definido (Malkiel, 2007). Contudo, o que o tomador de decisão tem de informação sobre risco é apenas uma percepção formada no momento da decisão em função dos fatores ambientais, da forma como 
a situação se apresenta, ambos avaliados por intermédio de sua tolerância ao risco. Neste sentido, risco parece ser uma representação emocional e algo intuitiva (Byrne, 2005; Jordan \& Kaas, 2002; Kahneman \& Riepe, 1998; Sitkin \& Pablo, 1992; Sitkin \& Weingart, 1995; Weber \& Milliman, 1997; Weber \& Zuchel, 2005).

Desta forma, algumas das hipóteses deste modelo teórico pretendem ajudar a elucidar a influência que a propensão ao risco exerce nas decisões de investimento.

Sobre fatores emocionais e afetivos relacionados à decisão de investimento, as hipóteses a seguir estudam o comportamento de investidores conforme seu estilo de processamento de informações. Segundo Slovic (1999) o modo de processamento experiencial (Sistema 1) está associado à emoção e afeto, reage rapidamente e busca se proteger. Especificamente, algumas outras hipóteses tratam de tentar explicar o comportamento decisório daqueles cujo processo é mais intuitivo e automático.

As pessoas com Sistema 1 mais ativo buscam decidir com menos esforço, querem evitar a tensão e desconforto do processo decisório e desejam evitar a pressão emocional advindas de decisões complexas, tais como a de investir.

Para os considerados não intuitivos, o pensamento reflexivo, mais lógico, se faz mais presente. Estes decidem a partir da análise das informações, fazem simulações, usam a lógica e a razão como forma de avaliar benefícios e custos. Para os intuitivos, o risco se assimila, em maior medida, a sensação de perigo, a um sentimento, enquanto os menos intuitivos o enxergam como algo mais probabilístico que pode e deve ser avaliado (Alter, et al., 2007; Alter \& Oppenheimer, 2006; Evans \& Stanovich, 2013; Kahneman, 2003; Pensa, 2006; Schniter et al., 2013; Slovic et al., 2004; Topolinski \& Strack, 2009).

Para a realização da pesquisa empírica, foram construídos estímulos, ou seja, alternativas de investimento - baseadas em fatores relevantes para o processo de decisão - e seus respectivos níveis. Os fatores selecionados foram: rentabilidade no ano anterior, pior rentabilidade em um mês (possibilidade de perda que emula risco), liquidez, taxa de administração e recomendação do gerente (positiva ou negativa). 
A formação da preferência e a decisão estão assentadas no ambiente, nos fatos vivenciados (na história) e em características individuais. A pesquisa bibliográfica indicou um conjunto de dimensões que podem atuar na percepção de risco e, assim, afetar sua resposta aos estímulos.

Para algumas destas dimensões existe razoável arcabouço teórico que indica sua influência no comportamento das pessoas. Entre estas, a aversão a risco e modo de processamento de informações (intuitivo e reflexivo) foram selecionados como os mais relevantes para os objetivos deste trabalho. Adicionalmente gênero e nível de conhecimento, no caso de investimentos, foram também escolhidos para complementar as análises (Alter et al., 2007; Anderson \& Birnbaun, 1992; Charness \& Gneezy, 2012; Dolvin \& Templeton, 2006; Frederick \& Kahneman, 2002; Hausman, 2012; Holton, 2004; Kahneman, 2011; Lichtenstein \& Slovic, 2006; Rabin, 2000; Slovic, 1987; Weber et al., 2008).

Considerando que o gerente pode, ao inspirar confiança, amenizar a sensação de insegurança, vulnerabilidade e, por fim, a percepção de risco do investidor, existe razoável bibliografia sobre o efeito da aversão ao risco na decisão de compra e, por extensão, em como pode este profissional atenuar esta percepção. (Moorman et al., 1993; Berry, 1995; Sirdeshmukh et al., 2002); Shainesh, 2012; Schniter et al, 2013).

No campo das finanças, contudo, existe pouca literatura sobre a influência dos gerentes na mitigação da percepção de risco dos investidores. A maioria das pesquisas foca nas características do produto e em como o cliente ou investidor reage aos movimentos de rentabilidade positiva e negativa, em geral associando aversão a risco com movimentos de aportes ou resgates mais intensos conforme o nível de aversão.

Por outro lado, é escassa a literatura sobre a influência do modo de processamento cognitivo na decisão de investimento. Como este se relaciona com o produto e mais especificamente como o gerente ou especialista de investimento pode influenciar nesta decisão.

Para que se possa compreender o modelo teórico proposto, é importante esclarecer aqui suas suposições básicas, são elas: 
$\checkmark$ Produtos de investimento são complexos, e induzem a sensação de vulnerabilidade nos clientes;

$\checkmark$ Os clientes esperam que gerentes ou especialistas de investimento reduzam sua sensação de vulnerabilidade e mitiguem a percepção de risco da decisão;

$\checkmark$ Risco é percebido inerentemente como uma sensação;

$\checkmark$ A aversão ao risco e a intuição são fortemente influenciadas pela emoção;

Para investigar as questões acima, foram propostas algumas hipóteses que ajudaram a testar as relações entre os fatores elencados neste estudo e a decisão de investimento.

\subsection{Hipóteses de Pesquisa}

Considerando os atributos de um objeto em avaliação, o tomador de decisão precisa enfrentar tradeoffs e decidir conforme suas preferências em relação a cada um destes atributos (multiattribute utility theory, MAUT). Segundo os pressupostos da teoria da utilidade esperada os investidores deveriam tomar suas decisões de forma racional conforme as expectativas sobre as probabilidades de retorno e risco, de forma individual segundo seus níveis de tolerância a risco (Damodaran, 2009; Kritzman, 1998; Sanches, 2013). Por esta assertiva, a opinião de outras pessoas não deveria influenciar no julgamento do investidor.

Já a teoria do prospecto advoga que as pessoas tem uma forma própria de avaliar as probabilidades, as transformam conforme regras próprias por meio de heurísticas e avaliam a situação em relação a mudanças de estado (Barberis, 2012, 2013; Kahneman \& Tversky, 1979; Kutchukian, 2010; Pindyck \& Rubinfeld, 2010; Tversky \& Kahneman, 1992; Wakker, 2010). Segundo esta teoria, os ganhos e perdas de utilidade são menos pronunciados nos extremos e a dor da perda é maior que o prazer do ganho. Desta forma, o primeiro grupo de hipóteses é:

$H_{1 a}$ : Existe relação monotônica entre os níveis de cada atributo de decisão;

$H_{l b}$ : Existe diferença entre as importâncias relativas dos atributos de decisão;

$H_{l c}$ : Rentabilidade e risco registram, respectivamente, as maiores importâncias relativas na decisão;

$H_{1 d}$ : A recomendação do gerente deve assumir peso significativamente menor que rentabilidade ou possibilidade de perda. 
Um contexto de decisão mais adverso pode alterar o ponto de referência da decisão ao exacerbar a percepção de risco e causar alteração ou até reversão da ordem de preferência das pessoas (Barberis, 2012, 2013; Byrne, 2005; Kahneman \& Tversky, 1979, 1983; Sitkin \& Weingart, 1995; Tversky \& Kahneman, 1981, 1992). Desta forma, buscou-se manipular o frame of decision para investigar seus efeitos na decisão do investidor. Para tanto, um grupo de respondentes foi apresentado a um cenário considerado "benigno" e outro a um cenário "adverso", com objetivo de manipular a percepção de risco.

$H_{2 a}:$ Em um cenário positivo a importância relativa da rentabilidade é maior que a do risco;

$H_{2 b}$ : Em um cenário negativo a importância relativa do risco é maior que da rentabilidade;

$H_{2 c}$ : Em um cenário negativo se registra uma inversão de preferência e a importância relativa do risco passa a ser maior que a da rentabilidade;

$H_{2 d}$ : Em um cenário adverso se registra uma inversão de preferência e a importância relativa da possibilidade da recomendação do gerente passa a ser maior que a da rentabilidade;

As hipóteses formuladas a seguir visam testar a reação dos investidores conforme seu nível declarado de aversão ao risco. Investidores mais avessos ao risco tendem a perceber maior risco para tomada de decisão e, dado determinado nível de risco exigem maiores rentabilidades, ou, de outra forma, dada certa taxa de retorno buscam opções menos arriscadas, implicando, assim, em equivalentes certos mais elevados (Barberis, 2012, 2013; Byrne, 2005; Damodaran, 2009; Ganzach, 2000; Kahneman, 2011; Kahneman \& Tversky, 1979; Pindyck e Rubinfeld, 2010; Shainesh, 2012, Sirdeshmukh, et al., 2002; Sitkin \& Weingart, 1995; Slovic et al., 2002, 2004; Slovic \& Peters, 2006; Wakker, 2010).

$H_{3 a}$ : O ganho de utilidade decorrente do aumento da rentabilidade é maior para os considerados avessos;

$H_{3 b}$ : A perda de utilidade decorrente do aumento do risco é maior para os considerados avessos;

$H_{3 c}$ : A importância relativa do atributo rentabilidade é maior para o grupo que se considera mais avesso ao risco;

$H_{3 d}$ : A importância relativa do atributo risco é maior para o grupo que se considera mais avesso ao risco; 
$H_{3 e}: \mathrm{O}$ ganho de utilidade decorrente da recomendação do gerente é maior para os considerados avessos;

$H_{3 f}$. A importância relativa do atributo recomendação do gerente é maior para o grupo que se considera mais avesso ao risco.

Existe razoável convergência na literatura sobre serem as mulheres mais avessas que os homens em relação ao risco (Charness \& Gneezy, 2012; Dwyer, Gilkenson \& List, 2002; Powell \& Ansic, 1997). Estes estudos indicam que elas têm uma atitude menos propensa ao risco e que, portanto, enxergam maior risco na decisão.

$H_{4 a}$ : A proporção de mulheres que se consideram mais avessas ao risco é maior que a proporção de homens;

$H_{4 b}$ : A importância relativa do atributo rentabilidade é menor para as mulheres do que para os homens;

$H_{4 c}$ : A importância relativa do atributo possibilidade de perda é maior para as mulheres;

$H_{4 d}$ : A importância relativa do atributo recomendação do gerente é maior para as mulheres;

Espera-se que o nível de conhecimento reduza a incerteza e atenue a percepção de risco. Quanto maior o conhecimento sobre algo, melhor deveriam ser as condições de julgamento e maior o conforto para a tomada de decisão. Independente do nível e conhecimento, contudo, todos se utilizam, em menor ou maior grau, de heurísticas para decisão, e estão suscetíveis aos fatores emocionais, ao momento e ao ambiente de cada decisão (Dolvin \& Templeton, 2006; Fellner \& Maciejovsky, 2007; Ganzach, 2000; Hathaway \& Khatiwada, 2008; Mandell \& Klein, 2009).

$H_{5 a}$ : A proporção de pessoas menos letradas em investimentos e avessas ao risco é maior que as mais letradas;

$H_{5 b}$ : A importância relativa do atributo risco é maior para as pessoas que se declaram menos letradas em investimentos;

$H_{5 c}$ : A importância relativa do atributo recomendação do gerente é maior para as pessoas que se declaram menos letradas em investimentos. 
As pessoas consideradas mais intuitivas são aquelas cujo modo de processamento cognitivo é caracterizado, entre outras, por ser rápido, automático, associativo, de baixo esforço e mais emocional. Estas percebem o risco mais como uma sensação de perda ou perigo enquanto os menos intuitivos são mais propensos e enxergar o risco como um exercício mais lógico, algo a ser controlado (Alter et al., 2007; Alter \& Oppenheimer, 2006; Evans \& Stanovich, 2013; Frederick, 2005; Ganzach, 2000; Kahneman, 2003, 2011; Kahneman \& Frederick, 2002; 2006; Oppenheimer \& Kelso, 2015; Pensa, 2006; Slovic, 1999; Slovic, et al., 2002, 2004, Slovic \& Peters, 2006; Tversky \& kahneman, 1974). A identificação e classificação dos respondentes entre mais intuitivos e menos intuitivos foi baseada no teste conhecido como cognition refletion test (CRT) desenvolvido por Frederick (2005) que utiliza o conceito de resposta intuitiva.

$H_{6 a}$ : Não existe diferença significativa entre o incremento da rentabilidade para os grupos mais intuitivo e menos intuitivo;

$H_{6 b}$ : Não existe diferença significativa entre o incremento do risco para os grupos mais intuitivo e menos intuitivo;

$H_{6 c}$ : Não existe diferença entre a importância relativa da rentabilidade para os grupos mais intuitivo e menos intuitivo;

$H_{6 d}$ : Não existe diferença significativa entre a importância relativa do risco para os grupos mais intuitivo e menos intuitivo;

$H_{6 e}$ : Não existe diferença significativa entre o incremento da recomendação do gerente para os grupos mais intuitivo e menos intuitivo;

$H_{6 f}$. Não existe diferença significativa entre a importância relativa da recomendação do gerente para o grupo mais intuitivo;

$H_{7}$ : Em relação à importância relativa da recomendação do gerente, ela é maior para os mais intuitivos mesmo quando se ignora a aversão ao risco.

Vale ressaltar, que de forma distinta à aversão ao risco, existe escassa literatura sobre a relação entre o modo de processamento cognitivo e as decisões de investimento. O quadro a seguir sumariza as hipóteses e suas teorias direcionadoras.

Tendo por base os autores citados nesta seção, em especial Sitikin e Weingart (1995), Alter et al. (2007) e Alter e Oppenheimer (2006), o seguinte modelo teórico é proposto. 


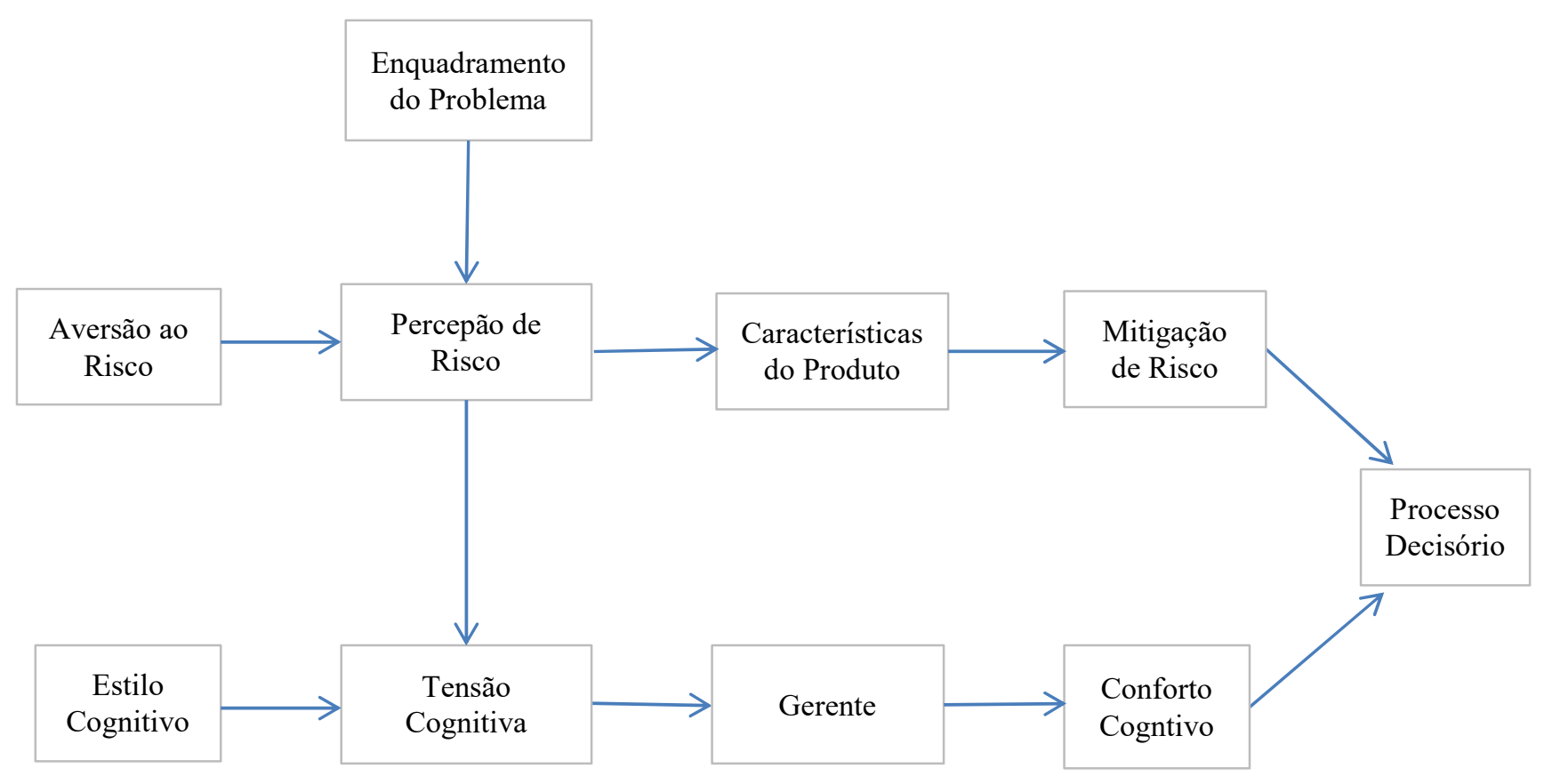

Figura 4.1 - Modelo Teórico

De forma esquemática, o que este modelo teórico propõe é que os investidores estão suscetíveis a dois traços comportamentais distintos, quais sejam: aversão ao risco e estilo cognitivo.

A aversão ao risco se relaciona de forma direta com a percepção de risco (quanto maior uma maior a outra). Desta forma, os investidores devem buscar nas características do produto uma forma de mitigar a sensação de risco percebido, esperam uma relação de risco e retorno que compense esta percepção.

Já o estilo cognitivo se relaciona com a tensão cognitiva associada a uma decisão. Neste caso, quanto mais intuitivo for o investidor, maior sua predisposição em buscar conforto cognitivo para sua decisão. Neste caso, a opinião do gerente ou especialista serviria como uma espécie de avalista para a decisão e aliviaria a pressão do processo decisório, acarretando, assim, conforto cognitivo.

Por fim, a forma com a situação ou problema se apresenta altera o ponto de referência a partir do qual o investidor avalia as diferentes alternativas em relação à possibilidade de ganhos e perdas e pode influir na percepção de risco que, se mais acentuada, tende a elevar a tensão cognitiva associada à decisão. Os aspectos gênero e nível e de conhecimento foram estudados de forma complementar e, portanto, não foram considerados nesta visão esquemática. 
A seguir, o quadro 4.1 apresenta de forma sumarizada as hipóteses.

\begin{tabular}{|c|c|c|}
\hline Grupos & Hipóteses & Teoria e Justificativa \\
\hline \multirow{4}{*}{$\begin{array}{l}\text { Hierarquia de } \\
\text { preferência dos } \\
\text { atributos }\end{array}$} & $\begin{array}{l}H 1_{a} \text { : Existe relação monotônica entre os } \\
\text { níveis de cada atributo de decisão. }\end{array}$ & $\begin{array}{l}\text { Segundo axiomas da EUT mais (ou } \\
\text { menos) é sempre melhor. } \\
\text { Kahneman \& Tversky, 1979; Pindyck e } \\
\text { Rubinfeld, } 2010 .\end{array}$ \\
\hline & $\begin{array}{l}H_{l b} \text { : Existe diferença entre as importâncias } \\
\text { relativas dos atributos de decisão. }\end{array}$ & Pindyck e Rubinfeld, 2010. \\
\hline & $\begin{array}{l}H_{l c}: \text { Rentabilidade e risco registram, } \\
\text { respectivamente, as maiores importâncias } \\
\text { relativas na decisão. }\end{array}$ & \multirow{2}{*}{$\begin{array}{l}\text { Pelos princípios da decisão normativa } \\
\text { risco e retorno deveriam dominar a } \\
\text { decisão. A recomendação do gerente não } \\
\text { deveria exercer influência na decisão. } \\
\text { Damodaran, 2009; Kritzman, } 1998 . \\
\text { (Teoria normativa). } \\
\text { Barberis, 2012, 2013; Kahneman e } \\
\text { Tversky, 1979; Tversky e Kahneman, } \\
\text { 1992; Wakker, } 2010 \text { (teoria descritiva). }\end{array}$} \\
\hline & $\begin{array}{l}H_{l d}: \text { A recomendação do gerente deve } \\
\text { assumir peso significativamente menor que } \\
\text { rentabilidade ou possibilidade de perda. }\end{array}$ & \\
\hline \multirow{4}{*}{$\begin{array}{l}\text { Enquadramento da } \\
\text { situação }\end{array}$} & $\begin{array}{l}H_{2 a}: \text { Em um cenário positivo a importância } \\
\text { relativa da rentabilidade é maior que a do } \\
\text { risco. }\end{array}$ & \multirow{4}{*}{$\begin{array}{l}\text { Um contexto de decisão mais adverso } \\
\text { pode alterar o ponto de referência da } \\
\text { decisão ao exacerbar a percepção de risco } \\
\text { e causar alteração ou até reversão da } \\
\text { ordem de preferência das pessoas. } \\
\text { Byrne, 2005; Barberis, 2012, 2013; } \\
\text { Kahneman e Tversky, 1979, 1983; Sitkin e } \\
\text { Weingart, 1995; Tversky e Kahneman, } \\
\text { 1981, 1992. }\end{array}$} \\
\hline & $\begin{array}{l}H_{2 b} \text { : Em um cenário negativo a } \\
\text { importância relativa do risco é maior que } \\
\text { da rentabilidade. }\end{array}$ & \\
\hline & $\begin{array}{l}H_{2 c} \text { : Em um cenário negativo se registra } \\
\text { uma inversão de preferência e a } \\
\text { importância relativa do risco passa a ser } \\
\text { maior que a da rentabilidade. }\end{array}$ & \\
\hline & $\begin{array}{l}H_{2 d} \text { : Em um cenário adverso se registra } \\
\text { uma inversão de preferência e a } \\
\text { importância relativa da possibilidade da } \\
\text { recomendação do gerente passa a ser maior } \\
\text { que a da rentabilidade. }\end{array}$ & \\
\hline \multirow{5}{*}{ Aversão ao risco } & $\begin{array}{l}H_{3 a}: \text { O ganho de utilidade decorrente do } \\
\text { aumento da rentabilidade é maior para os } \\
\text { considerados avessos. }\end{array}$ & \multirow{4}{*}{$\begin{array}{l}\text { Investidores mais avessos ao risco tendem } \\
\text { a perceber maior risco para tomada de } \\
\text { decisão e acabam por exigir maiores } \\
\text { rentabilidades, implicando em } \\
\text { equivalentes certos mais elevados. Por } \\
\text { outro lado podem também preferir reduzir } \\
\text { expectativas de perda para preservar o } \\
\text { capital. } \\
\text { Damodaran, 2009; Pindyck e Rubinfeld, } \\
\text { 2010; Sitkin e Weingart, } 1995 \text {. }\end{array}$} \\
\hline & $\begin{array}{l}H_{3 b}: \text { A perda de utilidade decorrente do } \\
\text { aumento do risco é maior para os } \\
\text { considerados avessos. }\end{array}$ & \\
\hline & $\begin{array}{l}H_{3 c}: \text { A importância relativa do atributo } \\
\text { rentabilidade é maior para o grupo que se } \\
\text { considera mais avesso ao risco. }\end{array}$ & \\
\hline & $\begin{array}{l}H_{3 d}: \text { A importância relativa do atributo } \\
\text { risco é maior para o grupo que se } \\
\text { considera mais avesso ao risco. }\end{array}$ & \\
\hline & $\begin{array}{l}H_{3 e}: \text { O ganho de utilidade decorrente do da } \\
\text { recomendação do gerente é maior para os } \\
\text { considerados avessos. }\end{array}$ & $\begin{array}{l}\text { A recomendação do gerente não faz parte } \\
\text { do conjunto de atributos que determinam a } \\
\text { relação de risco e retorno, contudo, alivi a }\end{array}$ \\
\hline
\end{tabular}




\begin{tabular}{|c|c|c|}
\hline & $\begin{array}{l}H_{3 f} \text { A importância relativa do atributo } \\
\text { recomendação do gerente é maior para o } \\
\text { grupo que se considera mais avesso ao } \\
\text { risco. }\end{array}$ & $\begin{array}{l}\text { tensão emocional da decisão e traz } \\
\text { conforto cognitivo. A opinião de alguém } \\
\text { que seja considerado competente e, em } \\
\text { última instância se confie, pode trazer este } \\
\text { alívio. } \\
\text { Barberis, 2012, 2013; Byrne, 2005; } \\
\text { Finucane et al., 2000; Ganzach, 2000; } \\
\text { Kahneman, 2011; Kahneman e Tversky, } \\
\text { 1979; Shainesh, 2012; Sirdeshmukh, et } \\
\text { al., 2002; Slovic et al., 2002, 2004; Slovic } \\
\text { e Peters, 2006; Tversky e Kahneman, } \\
\text { 1992; Wakker, 2010. }\end{array}$ \\
\hline \multirow{4}{*}{ Gênero } & $\begin{array}{l}H_{4 a}: \text { A proporção de mulheres que se } \\
\text { consideram mais avessas ao risco é maior } \\
\text { que a proporção de homens. }\end{array}$ & \multirow{4}{*}{$\begin{array}{l}\text { Estudos indicam que as mulheres têm uma } \\
\text { atitude menos propensa ao risco e que, } \\
\text { portanto, enxergam maior risco na } \\
\text { decisão. } \\
\text { (Charness \& Gneezy, 2012; Dwyer, } \\
\text { Gilkenson e List, 2002; Powell e Ansic, } \\
1997 .\end{array}$} \\
\hline & $\begin{array}{l}H_{4 b}: \text { A importância relativa do atributo } \\
\text { rentabilidade é menor para as mulheres do } \\
\text { que para os homens. }\end{array}$ & \\
\hline & $\begin{array}{l}H_{4 c}: \text { A importância relativa do atributo } \\
\text { possibilidade de perda é maior para as } \\
\text { mulheres. }\end{array}$ & \\
\hline & $\begin{array}{l}H_{4 d}: \text { A importância relativa do atributo } \\
\text { recomendação do gerente é maior para as } \\
\text { mulheres. }\end{array}$ & \\
\hline \multirow{3}{*}{$\begin{array}{c}\text { Nível de } \\
\text { conhecimento }\end{array}$} & $\begin{array}{l}H_{5 a}: \text { A proporção de pessoas menos } \\
\text { letradas em investimentos e avessas ao } \\
\text { risco é maior que as mais letradas. }\end{array}$ & \multirow{3}{*}{$\begin{array}{l}\text { O nível de conhecimento reduz a incerteza } \\
\text { e atenua a percepção de risco. Quanto } \\
\text { maior o nível de conhecimento sobre um } \\
\text { objeto melhor devem as condições de } \\
\text { julgamento e maior o conforto para a } \\
\text { decisão. } \\
\text { Dolvin e Templeton, 2006; Fellner e } \\
\text { Maciejovsky, 2007; Ganzach, 2000; } \\
\text { Hathaway e Khatiwada, 2008; Mandell e } \\
\text { Klein, } 2009 \text {. }\end{array}$} \\
\hline & $\begin{array}{l}H_{5 b} \text { : A importância relativa do atributo } \\
\text { risco é maior para as pessoas que se } \\
\text { declaram menos letradas em } \\
\text { investimentos. }\end{array}$ & \\
\hline & $\begin{array}{l}H_{5 c}: \text { A importância relativa do atributo } \\
\text { recomendação do gerente é maior para as } \\
\text { pessoas que se declaram menos letradas } \\
\text { em investimentos. }\end{array}$ & \\
\hline \multirow{5}{*}{ Estilo cognitivo } & $\begin{array}{l}H_{6 a}: \text { Não existe diferença significativa } \\
\text { entre o incremento da rentabilidade para os } \\
\text { grupos mais intuitivo e menos intuitivo. }\end{array}$ & \multirow{4}{*}{$\begin{array}{l}\text { A literatura sugere que as pessoas } \\
\text { consideradas mais intuitivas percebem o } \\
\text { risco como uma sensação de perda ou } \\
\text { perigo enquanto os menos intuitivos são } \\
\text { mais propensos e enxergar o risco como } \\
\text { um exercício mais lógico, algo a ser } \\
\text { controlado. Contudo, não existem } \\
\text { evidências de que elas sejam mais ou } \\
\text { menos avessas ao risco. } \\
\text { Slovic, 1999; Slovic, et al., 2002, 2004; } \\
\text { Slovic e Peters, } 2006 \text {. }\end{array}$} \\
\hline & $\begin{array}{l}H_{6 b}: \text { Não existe diferença significativa } \\
\text { entre o incremento do risco para os grupos } \\
\text { mais intuitivo e menos intuitivo. }\end{array}$ & \\
\hline & $\begin{array}{l}H_{6 c}: \text { Não existe diferença entre a } \\
\text { importância relativa da rentabilidade para } \\
\text { os grupos mais intuitivo e menos intuitivo. }\end{array}$ & \\
\hline & $\begin{array}{l}H_{6 d}: \text { Não existe diferença significativa } \\
\text { entre a importância relativa do risco para } \\
\text { os grupos mais intuitivo e menos intuitivo. }\end{array}$ & \\
\hline & $\begin{array}{l}H_{6 e:} \text { Não existe diferença significativa } \\
\text { entre o incremento da recomendação do } \\
\text { gerente para os grupos mais intuitivo e } \\
\text { menos intuitivo. }\end{array}$ & $\begin{array}{l}\text { Pessoas mais intuitivas desejam evitar a } \\
\text { tensão e desconforto de decisões } \\
\text { complexas o apoio de profissionais pode } \\
\text { mitigar esta sensação. }\end{array}$ \\
\hline
\end{tabular}




\begin{tabular}{|l|l|l|}
\hline & $\begin{array}{l}H_{6 f} \text { Não existe diferença significativa } \\
\text { entre a importância relativa da } \\
\text { recomendação do gerente para o grupo } \\
\text { mais intuitivo. }\end{array}$ & $\begin{array}{l}\text { Alter et al., 2007; Alter e Oppenheimer, } \\
\text { 2006; Ganzach, 2000; Oppenheimer e } \\
\text { Kelso, 2015, Tverskky e Kahneman, } 1974 .\end{array}$ \\
\cline { 1 - 2 } $\begin{array}{l}\text { Aversão ao risco X } \\
\text { estilo cognitivo }\end{array}$ & $\begin{array}{l}H_{7} \text { : Em relação à importância relativa da } \\
\text { recomendação do gerente, ela é maior para } \\
\text { os mais intuitivos mesmo quando se ignora } \\
\text { a aversão ao risco. }\end{array}$ \\
\hline
\end{tabular}

Quadro 4.1 - Sumário Hipóteses de Pesquisa 


\section{Método}

Este capítulo apresenta os procedimentos metodológicos utilizados nesta pesquisa para obtenção e análise dos dados e das informações com objetivo de discutir e responder as questões aqui propostas.

A partir do problema de pesquisa foi realizada uma revisão de literatura que inicialmente se preocupou em explicar o sentido da atividade de gestão de recursos de terceiros e fundos de investimento (o principal veículo de investimento). Na sequência foram introduzidos os conceitos de investimento e risco conforme a visão da teoria tradicional de finanças. Por fim, foram abordados diferentes aspectos teóricos sobre a decisão do investidor, tais como, formação da preferência, percepção de risco e a influência dos fatores emocionais.

A revisão de literatura teve por objetivo sistematizar o conhecimento teórico necessário para definir o problema de pesquisa, suportar as hipóteses sobre suas causas e relações e subsidiar a análise dos dados e informações, neste caso, obtidos por meio da pesquisa de campo (Malhotra, 2012).

Para assuntos de pesquisa para os quais há pouco conhecimento estruturado, um estudo exploratório ajuda a compreender o problema e a analisar as informações disponíveis. Neste contexto, as entrevistas com especialistas do setor correspondem ao método mais utilizado para se obter insights que podem tornar a definição do problema mais precisa e sua análise mais profunda (Malhotra, 2012).

A despeito de existir ampla bibliografia com viés normativo sobre aversão a risco e a relação entre risco-retorno na teoria de finanças e sobre vieses de decisão e aspectos de cunho descritivo relacionados à emoção na literatura, pouco se encontra sobre a decisão em investimentos e, particularmente, sobre a hierarquia de preferência do investidor.

Desta forma, a partir do conhecimento obtido na revisão de literatura, resolveu-se inicialmente identificar qual a opinião dos responsáveis pelo desenvolvimento e/ou comercialização dos produtos sobre os direcionadores para o desenvolvimento da oferta de fundos e sobre os fatores influenciadores da decisão do investidor por este ou aquele fundo de investimento. 
Considerando estas informações foi, então, realizada uma pesquisa de campo, junto aos investidores pessoas físicas, para mensurar a importância relativa destes fatores em sua decisão.

Desta forma, esta pesquisa foi constituída de duas etapas, a saber: um estudo exploratório de cunho qualitativo realizado por meio de entrevistas em profundidade com executivos e uma etapa quantitativa empreendida junto aos potenciais investidores. Abaixo a figura 5.1 apresenta de forma esquemática as etapas desta pesquisa.

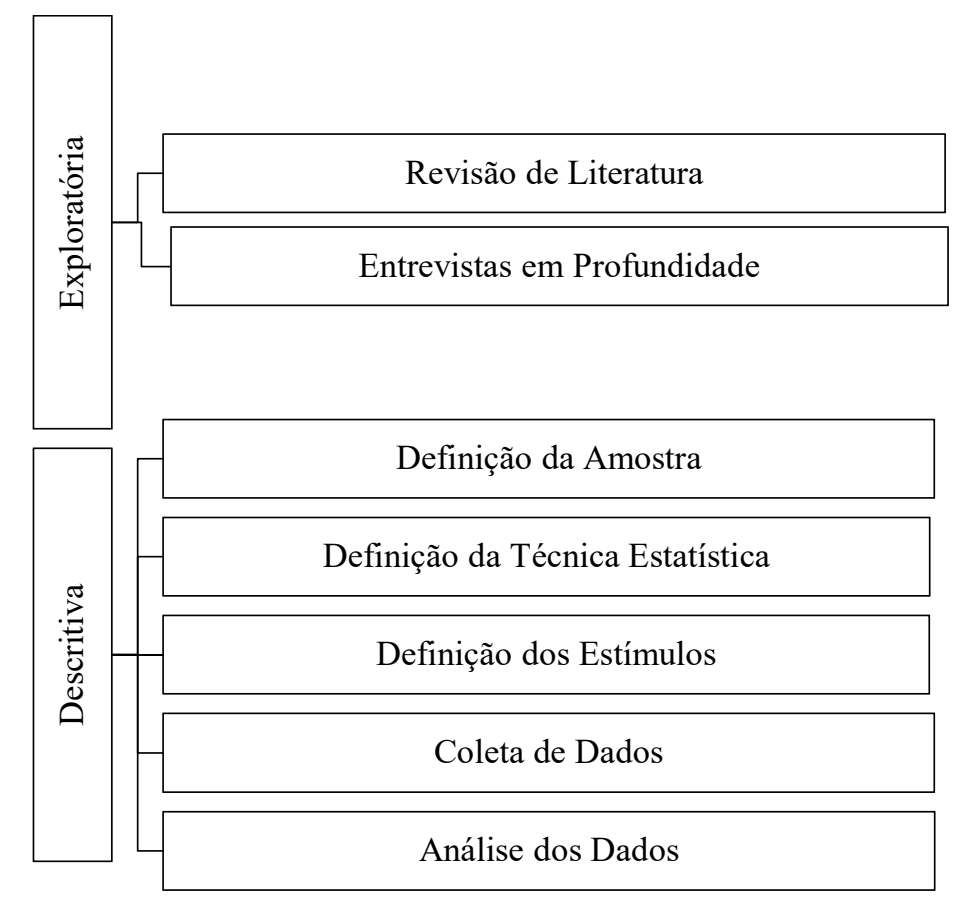

Figura 5.1 - Etapas da Pesquisa

\subsection{Pesquisa Exploratória}

Com o objetivo de ajudar a definir o problema com maior precisão, foram realizadas nove entrevistas em profundidade no segundo semestre de 2014. Considerando o interesse especial desta pesquisa, na decisão dos investidores pessoas físicas responsáveis por suas próprias decisões de investimento, foram selecionadas as seis maiores empresas de gestão de recursos de terceiros que atuam no segmento de varejo (incluindo o segmento voltado a clientes considerados de alta renda). Estas seis instituições respondiam em novembro de 2015 por 
$85 \%$ dos recursos de propriedade de pessoas físicas atendidas pelo segmento varejo (ANBIMA, 2015).

Além do critério de relevância, optou-se pelo número de seis empresas pela disponibilidade que com estes executivos se dispuseram a serem entrevistados.

Seis destas entrevistas foram feitas com executivos seniores responsáveis, nas empresas de gestão, pelas áreas de desenvolvimento da oferta de fundos. Outras três foram realizadas junto a executivos seniores dos próprios bancos responsáveis pela comercialização de produtos de investimento para clientes atendidos pelo canal de varejo. Dentre os entrevistados, três eram gerentes seniores, um superintendente e cinco diretores. Vale ressaltar que os fundos de investimentos são desenvolvidos, majoritariamente, nas áreas de produtos das Assets a partir de demandas próprias ou originadas nos canais de distribuição.

As entrevistas em profundidade são uma das técnicas mais utilizadas em pesquisas exploratórias, entre suas vantagens destaca-se contar com a opinião de especialistas sobre a natureza do problema pesquisado (Hair, Babin, Money \& Samouel, 2005; Malhotra, 2012).

Para estas entrevistas foi elaborado um roteiro com perguntas agrupadas em quatro blocos: (i) objetivo e estrutura das Assets, (ii) esforços de marketing e propaganda, (iii) desenvolvimento de produtos e venda, e (iv) fatores que influenciam a decisão do investidor. Como é próprio desta técnica, o roteiro serviu como guia para conversas em que se descortinaram outros aspectos que contribuíram para aprofundar a compreensão do problema desta pesquisa. As entrevistas foram gravadas e transcritas. As respostas foram comparadas, sumarizadas pelos blocos acima e analisadas por meio da técnica de análise de conteúdo (Bardin, 1977).

Como próprio das pesquisas qualitativas, os resultados alcançados nestas entrevistas não podem ser generalizados. A maior contribuição desta etapa foi obter insights que ajudassem a formular proposições adicionais às hipóteses de pesquisa que contribuíssem no processo de construção do questionário e na posterior análise dos dados obtidos pela pesquisa de campo e de melhor descrição da realidade em estudo. 


\subsubsection{Roteiro de Entrevistas}

O roteiro de entrevista busca dar uma sequência lógica ao processo de entrevista e, assim, garantir que não sejam esquecidos tópicos de interesse sem, contudo, engessar o entrevistado

a ponto que se inibam o surgimento dos insights inerentes à posição destes especialistas (Malhotra, 2012).

Portanto, ele retrata essencialmente pontos a serem explorados pelo pesquisador durante o processo de entrevista. Apresenta-se, em seguida, quadro contendo o roteiro de referência adotado nas entrevistas em profundidade.

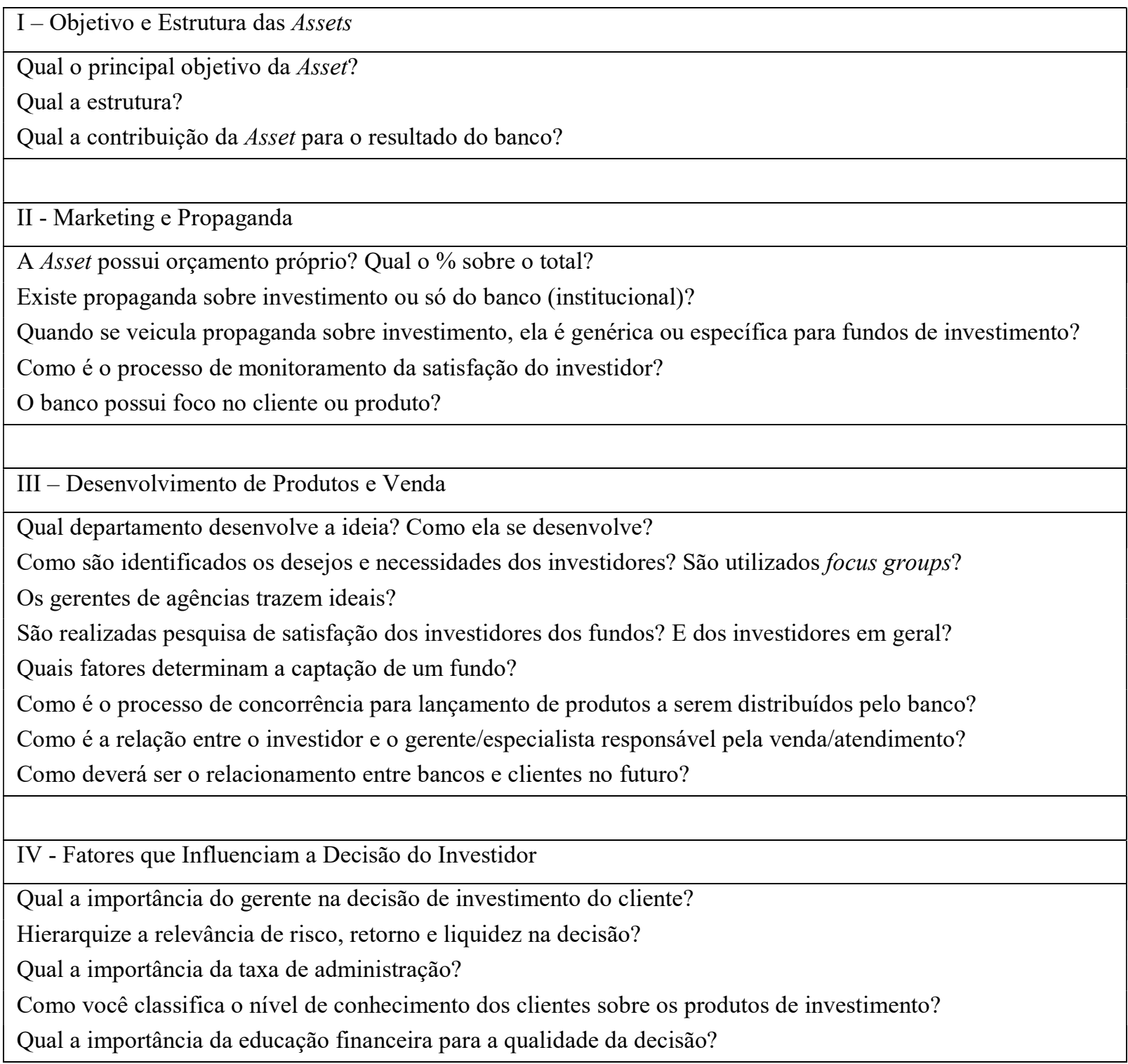

Quadro 5.1 - Roteiro das Entrevistas em Profundidade 


\subsection{Pesquisa de Campo}

Para esta segunda etapa foi elaborado questionário específico contendo basicamente cinco seções, quais sejam: (i) características socioeconômicas, (ii) percepção de tolerância a risco do investidor, (iii) percepção de nível de conhecimento sobre investimentos financeiros, (iv) identificação do estilo cognitivo preponderante (escala CRT), e (v) estímulos que simulavam uma decisão de investimentos entre produtos concorrentes, tradeoffs que ajudassem a avaliar a importância relativa dos fatores rentabilidade, possibilidade de perda (risco), liquidez, taxa de administração e recomendação (positiva ou negativa) do gerente na decisão alternativa de investimento.

Desta forma, os resultados obtidos a partir das respostas aos questionários indicaram qual a situação socioeconômica dos investidores e suas características individuais sobre aversão a risco, conhecimento de investimentos e estilo cognitivo. Mais importante, as respostas aos estímulos permitiram que fossem calculadas as importâncias relativas dos fatores ou atributos pesquisados na decisão de investimento que, por fim, desvendaram a própria hierarquia de preferência do investidor (HPI). Os respondentes foram classificados em grupos de afinidade conforme as características pesquisadas e análises comparativas entre os resultados de cada grupo foram realizadas.

Considerando a proposição de que a percepção de risco mais acentuada afetará a decisão privilegiando a aversão ao risco e, portanto, a preservação do capital, manipulou-se por meio do frame of decision a percepção do risco para que se tentasse medir sua influência no processo de formação da preferência e escolha.

A técnica estatística escolhida para decomposição das utilidades dos fatores intervenientes no processo de decisão foi a conjoint analysis. Trata-se de uma técnica multivariada cujo objetivo é entender como os respondentes formam preferências relativas entre os atributos de um produto ou serviço, quais são mais relevantes, por meio da avaliação das utilidades dos diferentes níveis associados a cada atributo. As combinações destes atributos e seus níveis possíveis valores que o atributo pode assumir - consistem nos estímulos que são apresentados aos respondentes que os avaliam em função de sua preferência (Malhotra, 2012; Orme, 2010). A seguir são detalhados os procedimentos adotados na pesquisa de campo. 


\subsubsection{Survey}

A decisão sobre a coleta de dados recaiu sobre o método survey com uso de cenários econômicos para embasar a decisão dos respondentes. A pesquisa foi desenvolvida junto a indivíduos que possuíam investimentos financeiros na data ou que tinham feito investimento nos últimos doze meses. Foi aplicado questionário com estímulos que foram manipulados para refletir um ambiente de decisão real. Estes estímulos simulavam uma decisão de investimento real em que os respondentes foram apresentados a diferentes opções de investimento que impunham tradeoffs e pretendiam emular a tensão presente no momento da decisão.

Para geração dos estímulos foi utilizada a análise conjunta baseada em escolha (CBC), técnica em que os estímulos se assemelham a uma decisão real em que os tradeoffs inerentes a uma decisão estão presentes. As respostas ao questionário foram avaliadas e a utilidade (ou satisfação) foi decomposta em utilidades parciais de cada um dos atributos definidores da opção de investimento (Orme, 2010).

Segundo Pilli, citando vários autores, a análise conjunta baseada em escolha (CBC) é um modelo que busca reconstruir a partir de julgamentos globais sobre um conjunto complexo de opções as redes individuais de utilidades por meio de modelos estatísticos. Ademais, "[...] a técnica baseada em escolha entre diferentes opções é uma representação das decisões discretas realizadas pelo consumidor em seu cotidiano e permite o estudo da variação na decisão do consumidor como resposta às variações de tamanho e composição dos estímulos." (Pilli, 2012, p. 86).

Adicionalmente, como já dito na seção anterior, o modelo $\mathrm{CBC}$ está amplamente testado e difundido sendo responsável por $78 \%$ dos experimentos realizados na plataforma da Sawtooth Software. Adicionalmente, o modelo CBC é reconhecido por sua habilidade em lidar com interações, ou seja, além de tratar os efeitos principais ele consegue medir a força das interações (Orme, 2010). 


\subsubsection{Delineamento dos Estímulos}

O delineamento dos estímulos é considerado uma das etapas mais importantes do planejamento experimental. Os atributos e níveis devem ter relevância na decisão, devem ser comunicáveis e acionáveis. Por comunicável entende-se inteligível, facilmente comunicados e entendidos. Já o conceito de acionáveis se relaciona com ser palpável e conseguir enxergá-los na prática (Orme, 2010).

Como já citado, os atributos foram selecionados da revisão de literatura e também junto aos executivos, como resultado da pesquisa exploratória. Vale ressaltar, que estes são amplamente conhecidos e utilizados cotidianamente no processo de venda ou mesmo na cobertura jornalística.

A fonte para a proposição dos níveis foram os relatórios de acompanhamento da indústria de fundos de investimento e a base de dados da ANBIMA. Para os fatores rentabilidade e taxa de administração foram utilizadas como ponto de partida as médias, por tipo de fundo, calculadas pela ANBIMA; já a liquidez foi baseada nas informações dos fundos registrados na base da Associação. Para incrementar a capacidade preditora do modelo, ampliou-se a distância entre os níveis sem, contudo, comprometer sua credibilidade. Assim, além dos fatores serem relevantes na decisão, os níveis selecionados comunicam sentido de realidade e aproximam a escolha de um processo cotidiano.

O quadro 5.2, a seguir, apresenta a relação de atributos e níveis utilizados no questionário. A rentabilidade anual está expressa em percentual ao ano (a.a.), assim como a taxa de administração, já a pior rentabilidade em um mês está expressa em percentual ao mês (a.m.).

\begin{tabular}{|l|c|c|c|c|c|}
\hline $\begin{array}{l}\text { Rentabilidade nominal no ano } \\
\text { anterior (\% a.a.) }\end{array}$ & $2 \%$ a.a & $6 \%$ a.a. & $10 \%$ a.a. & $14 \%$ a.a. & $18 \%$ a.a. \\
\hline $\begin{array}{l}\text { Pior rentabilidade em um mês } \\
\text { no último ano anterior (\% a.m.) }\end{array}$ & $-4 \%$ a.m. & $-3 \%$ a.m. & $-2 \%$ a.m. & $-1 \%$ a.m. & $0,0 \%$ a.m. \\
\hline Liquidez & $\begin{array}{c}\text { No dia } \\
\text { seguinte }\end{array}$ & Em 30 dias & Em 90 dias & - & - \\
\hline Taxa de Administração (\% a.a.) & $1,00 \%$ a.a. & $1,50 \%$ a.a. & $2,00 \%$ a.a. & $2,50 \%$ a.a. & $3,00 \%$ a.a. \\
\hline Recomendado pelo gerente & Recomendado & Indiferente & $\begin{array}{c}\text { Não } \\
\text { recomendado }\end{array}$ & - & - \\
\hline
\end{tabular}

Quadro 5.2 - Atributos e Níveis considerados no Questionário 
Para a formulação dos estímulos, foi utilizada a técnica conhecida como conjoint based choice (CBC), que simula um processo de escolha real. Ao invés de ordenar ou classificar as alternativas apresentadas, os respondentes são apresentados a um conjunto de alternativas que simula um processo de decisão usual, rotineiro. A CBC combina atributos e níveis de forma que resulte na geração aleatória de um conjunto manuseável, ou seja, um número de estímulos passível de ser compreendido e que não sobrecarregue o respondente com opções completas para escolha (Orme, 2010).

\subsubsection{Questionário}

O questionário foi implementado pela empresa Ilumeo na plataforma Qualtrics sendo composto de dezoito cenários, contendo cinco conjuntos, cada um com alternativas distintas de investimento, descritas por meio dos fatores e seus respectivos níveis.

Os conjuntos de alternativas foram compostos por meio de programação feita no software Qualtrics que combinou de forma randomizada os níveis de cada um dos atributos. O quadro a seguir apresenta um exemplo de estímulo gerado pela programação.

\begin{tabular}{|c|c|c|c|c|c|c|}
\hline & Opção 1 & Opção 2 & Opção 3 & Opção 4 & Opção 5 & Opção 6 \\
\hline $\begin{array}{l}\text { Rentabilidade } \\
\text { nominal no } \\
\text { ano anterior }\end{array}$ & $10 \%$ a.a. & $6 \%$ a.a. & $10 \%$ a.a. & $2 \%$ a.a. & $18 \%$ a.a. & \multirow{5}{*}{$\begin{array}{l}\text { Não considero } \\
\text { as opções } \\
\text { suficientemente } \\
\text { atrativas, } \\
\text { prefiro não } \\
\text { realizar o } \\
\text { investimento }\end{array}$} \\
\hline $\begin{array}{l}\text { Pior } \\
\text { rentabilidade } \\
\text { em um mês no } \\
\text { último ano } \\
\text { anterior }\end{array}$ & $0,0 \%$ a.m. & $0,0 \%$ a.m. & $-1 \%$ a.m. & $-4 \%$ a.m. & $-2 \%$ a.m. & \\
\hline Liquidez & $\begin{array}{l}\text { No dia } \\
\text { seguinte }\end{array}$ & $\begin{array}{l}\text { No dia } \\
\text { seguinte }\end{array}$ & $\begin{array}{l}\text { No dia } \\
\text { seguinte }\end{array}$ & $\begin{array}{c}\text { Em } 90 \\
\text { dias }\end{array}$ & Em 30 dias & \\
\hline $\begin{array}{l}\text { Taxa de } \\
\text { Administração } \\
(\% \text { ao ano })\end{array}$ & $3,00 \%$ a.a. & $1,50 \%$ a.a. & $1,00 \%$ a.a. & $3,00 \%$ a.a. & $2,50 \%$ a.a. & \\
\hline $\begin{array}{l}\text { Recomendado } \\
\text { pelo gerente }\end{array}$ & Recomendado & $\begin{array}{c}\text { Não } \\
\text { recomendado }\end{array}$ & Recomendado & Indiferente & $\begin{array}{c}\text { Não } \\
\text { recomendado }\end{array}$ & \\
\hline
\end{tabular}

Quadro 5.3 - Exemplo Atributos e Níveis do Questionário 
Para cada conjunto os respondentes tiveram de escolher a opção que consideravam a melhor ou, alternativamente, puderam escolher a opção nenhuma das alternativas oferecidas. Sendo assim, os respondentes foram submetidos a um processo de escolha similar aquele com que se deparam quando precisam decidir por um produto de investimento. Para cada conjunto, os respondentes deveriam escolher uma alternativa ou mesmo a opção de se abster da escolha e, na sequencia, eram apresentados ao próximo conjunto.

O questionário contou, ainda, com três cenários de holdouts, além dos quinze gerados de forma aleatória para cada respondente, de forma a evitar o efeito ordem de apresentação (Hair et al., 2009).

Para capturar os efeitos da percepção de risco, dois grupos de 150 respondentes foram submetidos a contextos de decisão distintos (enquadramento) e um terceiro, também de 150 indivíduos, respondeu ao questionário sem apresentação prévia a qualquer cenário. Os respondentes foram selecionados dentre o painel de consumidores da empresa de pesquisa de campo Ilumeo e deveriam ter mais de 21 anos, ter feito investimentos financeiros nos últimos 12 meses e ser responsável por suas decisões de investimento, mesmo que conte com um profissional para auxiliá-lo.

Para um grupo foi apresentado um contexto econômico considerado positivo em que os principais indicadores econômico-financeiros são positivos e avalizam a formação de expectativas animadoras que amenizam a percepção do risco envolvida na decisão

Já o outro grupo foi apresentado a um cenário considerado adverso, no qual se espera que os respondentes tenham sua percepção de risco acentuada e se tornem mais avessos às possibilidades de perda.

Para a formação dos cenários utilizou-se as estimativas capturadas pelo Banco Central do Brasil (BCB) em seu relatório Focus (2015), publicação semanal veiculada pelo BCB que compila as previsões de economistas do mercado financeiro sobre uma série de indicadores macroeconômicos. No caso, a edição que subsidiou este estudo é de 02 de janeiro de 2015 e as estimativas utilizadas são as medianas do agregado do mercado nesta data para o ano de 2015. Deste relatório foram selecionados os seguintes indicadores: 
$\checkmark \quad$ Inflação (medida pelo IPCA) $=6,56 \%$ a.a.

$\checkmark$ Taxa de câmbio para o final do ano $=$ R $\$ 2,80 /$ US\$

$\checkmark \quad$ Taxa Selic média para o ano $=12,47 \%$

$\checkmark$ PIB (crescimento) $=1,04 \%$

Para induzir as expectativas e reforçar a disparidade entre os cenários que permita incutir mudanças de percepção entre os grupos que acentuem o efeito de aversão ao risco, os indicadores foram calibrados com o intuito de realçar os aspectos bons ou ruins conforme o cenário.

A seguir os textos que informaram aos respondentes os cenários no qual as escolhas foram feitas.

\section{Cenário 1 (positivo)}

Após um ano de muita responsabilidade e trabalho intenso, sua empresa lhe pagou um bônus substancial como forma de reconhecimento por ter atingido as metas combinadas no ano anterior. Você não precisa desta importância para fazer frente a despesas e, neste momento, não pretende adquirir bens ou propriedades.

Sendo assim, você precisa tomar uma decisão sobre qual aplicação financeira investir este dinheiro. Considerando o cenário a seguir, qual das opções abaixo você escolheria?

$\mathrm{O}$ ano anterior foi muito bom para o Brasil e os principais analistas econômicos esperam que o ano corrente seja ainda melhor. Em relação às expectativas do mercado para este ano, estes analistas estimam que a inflação será reduzida para $4 \%$, abaixo do centro da meta, o Real (R\$) se fortalecerá e a taxa de câmbio terminará o ano abaixo de R $\$ 2$ reais por dólar (US\$), a taxa de juros cederá abaixo de $9 \%$ ao ano e o PIB crescerá cerca de 4,5\%, melhor resultado dos últimos anos. Este é um cenário bastante positivo que deve atrair mais investimentos e deve alavancar os níveis de renda e emprego.

\section{Cenário 2 (adverso)}

Após um ano de muita responsabilidade e trabalho intenso, sua empresa the pagou um bônus substancial como forma de reconhecimento por ter atingido as metas combinadas no ano anterior. Você não precisa desta importância para fazer frente a despesas e, neste momento, não pretende adquirir bens ou propriedades.

Sendo assim, você precisa tomar uma decisão sobre qual aplicação financeira investir este dinheiro. Considerando o cenário a seguir, qual das opções abaixo você escolheria?

$\mathrm{O}$ ano anterior foi muito ruim para o Brasil e os principais analistas econômicos esperam que o ano corrente seja ainda pior. Em relação às expectativas do mercado para este ano, estes analistas estimam que a inflação se elevará ao patamar de $10 \%$, mais que o dobro do centro da meta, a taxa de câmbio se 
deteriorará e terminará o ano acima de R\$ 3 reais por dólar (US\$), a taxa de juros subirá até 16\% ao ano e o PIB sofrerá uma retração de - 2,5\%, pior resultado dos últimos anos. Este é um cenário bastante adverso e deve inibir os investimentos com reflexos negativos nos níveis de renda e emprego.

Vale ressaltar que a frase que introduz tanto o cenário positivo quanto o negativo deixa claro que os recursos a serem investidos são o resultado do trabalho e, portanto, a recompensa por um ano de dedicação e esforço. Desta forma, pretende-se aproximar o ponto de referência a ser adotado para a decisão dos grupos. Segundo a teoria do prospecto (Kahneman \& Tversky, 1979) os ganhos e perdas são avaliados em relação a um ponto de referência que é construído durante a fase de edição das informações recolhidas. Adicionalmente, conforme Thaler e Johnson (1991) e Weber e Zuchel (2005), a forma como as pessoas lidam com o dinheiro é sensivelmente afetada pela maneira como obtiveram estes recursos. Neste caso, ao definir que tais recursos foram oriundos de esforço e sacrifício, pretendeu-se uniformizar o comportamento dos respondentes e a percepção do risco envolvida na aplicação dos recursos.

O questionário utilizado contou com uma seção específica para identificação do perfil socioeconômico dos respondentes. Estas informações permitem agrupar os respondentes por perfis e verificar as relações existentes entre estes e as utilidades. O questionário possui, ainda, uma seção com perguntas que buscam capturar a percepção do respondente em relação ao seu nível de conhecimento sobre investimentos e uma última seção que pretende identificar como o próprio classifica seu comportamento diante do binômio risco-retorno. As respostas destas últimas seções - nível de conhecimento sobre investimentos e atitude em relação ao risco-retorno - foram utilizadas para segregar, dentro de cada grupo experimental, os indivíduos em subgrupos afins.

Estudos sobre preferência, decisão e aversão a risco e a perda, em geral, consideram todos os respondentes como se estes apresentassem a mesma habilidade cognitiva (Kahneman \& Tversky, 1979; 1983; Thaler e Johnson, 1990. Contudo, trabalhos mais recentes têm desvelado diferenças no comportamento de pessoas mais e menos cognitivas. (Kahneman e Frederick, 2002; Shane Frederick, 2005; Alter et al., 2007))

Para cobrir esta lacuna, Shane Frederick (2005) introduziu uma nova escala chamada de cognitive reflection test (CRT). O teste é composto de três perguntas e pretende medir o tipo de habilidade ou processo cognitivo do respondente. Os resultados possíveis são $0,1,2$ e 3 , 
ou seja, desde nenhum acerto até todas certas. A ideia subjacente do teste é medir a capacidade cognitiva do respondente em resistir à resposta automática ou intuitiva.

"Não é nova a ideia de que os processos cognitivos podem ser particionados em duas grandes famílias - tradicionalmente chamadas de intuição e razão - que agora estão sendo agregadas sob o conceito teórico de dual-process." (Kahneman \& Frederick, 2002, p. 51).

Como já salientado, o processamento intuitivo é rápido, automático e livre de esforço enquanto o processamento racional é lento, reflexivo, controlado e exige esforço. Stanovich e West (2000) denominaram de Sistema 1 o processo intuitivo e de Sistema 2 o processo racional.

Considerando os Sistemas 1 e 2, a escala CRT pretende medir a capacidade do respondente de resistir à primeira resposta que vem a mente. Ou seja, pessoas com sistema 2 mais aguçado devem descartar a resposta automática do Sistema 1 e dedicar um esforço maior à reflexão. A seguir as perguntas da escala CRT:

(1) Um bastão e uma bola custam $\mathrm{R} \$ 1,10$. O bastão custa $\mathrm{R} \$ 1,00$ a mais que a bola. Quanto custa a bola? centavos

(2) Cinco máquinas levam 5 minutos para produzir 5 peças. Quanto tempo levará para 100 máquinas produzirem 100 peças? minutos

(3) Em um lago, há uma parte coberta por lírios. Todo dia esta parte dobra de tamanho. Se levar 48 dias para que os lírios cubram todo o lago, quanto tempo levaria para os lírios cubrissem metade do lago? dias

A proposição é de que os três problemas gerem respostas intuitivas, Sistema 1. Entre todas as possíveis respostas incorretas, as respostas intuitivas postuladas $(10,100$ e 24$)$ dominam.

Em seu artigo de 2005, Frederick estudou a relação entre preferência por risco e CRT por meio da comparação entre as respostas dos grupos com baixo e alto coeficiente. De acordo com os resultados, mediante apostas que envolviam ganho certo o grupo com alto CRT apresentou maior propensão ao jogo. Contudo, frente a situações que contrapunham perdas às apostas, o grupo considerado mais cognitivo preferiu assumir as perdas às apostas (ao jogo). Estes resultados divergem do prescrito pela teoria do prospecto que advoga que os indivíduos, 
frente a situações de perda irremediável, se tornam mais propensos ao risco, preferem o risco. Vale ressaltar que o grupo definido como de baixo CRT apresentou comportamento ajustado à teoria do prospecto.

A aplicação do teste CRT pretende, assim, identificar e segregar os respondentes em grupos conforme seu tipo de habilidade cognitiva (Sistema 1 e Sistema2) e permitir que se mensure e compare as diferenças de preferência em relação ao risco embutido nos estímulos.

O questionário foi desenvolvido e aplicado entre os meses de março e junho de 2015 com respondentes residentes em todos os estados do Brasil e as respostas foram processadas pelo suíte da Sawtooth Software que computou as utilidades dos níveis (part-worths) e a importância relativa dos fatores pesquisados (Orme, 2010).

\subsection{Métodos empregados na análise dos dados}

\subsubsection{Análise Conjunta}

Conjoint analysis, ou análise conjunta, significa decomposição das utilidades parciais ou valores atribuídos às partes considerando um conjunto de alternativas em avaliação, com o propósito de escolher aquela mais adequada (Louviere, 1988).

Segundo Green, Krieger e Wind (2001) os tomadores de decisão tem de lidar com situações em que produtos ou serviços precisam ser avaliados em relação a dois ou mais atributos. A decisão se apresenta como um tradeoff tal qual $\mathrm{X}$ é melhor do que $\mathrm{Y}$ em relação ao atributo $\mathrm{A}$ enquanto $\mathrm{Y}$ é melhor do que $\mathrm{X}$ em relação ao atributo B. Este conflito torna a decisão mais difícil, complexa, e exige um esforço cognitivo mais profundo.

Em decorrência da percepção e da propensão ao risco, ao analisar as diferentes alternativas disponíveis de produtos de investimento, os investidores comparam diferentes atributos e classificam as alternativas em busca daquela que melhor atenda suas necessidades e restrições.

Segundo os executivos entrevistados na fase exploratória do estudo, a rentabilidade e a recomendação do gerente se constituem nos atributos mais relevantes no julgamento do 
investidor. Ambos os atributos contam com amplo suporte teórico, enquanto a rentabilidade busca compensar o risco embutido no produto, a recomendação do gerente pretende atenuar a percepção de risco.

Outros atributos surgidos da pesquisa bibliográfica são o risco (aqui representado pela maior perda em um mês) e a liquidez (prazo para receber os recursos resgatados). Em relação ao primeiro os investidores buscam diminuí-lo ou alcançar rentabilidades superiores que o compensem; já o segundo deve ser aumentado para que se reduza o prazo em que o investidor fica exposto às oscilações de mercado. Quanto à taxa de administração, esta é vista como um preço que deve ser minimizado.

Ainda de acordo com Green, Krieger e Wind (2001), a análise conjunta é uma técnica utilizada para medir tradeoffs e analisar respostas em pesquisas acerca de preferências e intenções sobre comprar bens (ou contratar serviços); é um método para simular como os consumidores podem reagir a mudanças em produtos em comercialização ou à introdução de novos produtos. Em ambos os casos, sejam produtos ou serviços novos ou modificados, eles farão parte de conjuntos de opções concorrentes que competirão entre si na avaliação dos consumidores.

A utilidade é um julgamento subjetivo de preferência, um conceito fundamental para medir o valor que se atribui a algum objeto. Ela engloba características objetivas e subjetivas e está baseada no valor determinado a cada um dos níveis dos atributos (Hair et al, 2009).

A conjoint analysis tem uma grande vantagem sobre as outras técnicas multivariadas, pois permite simular um contexto decisório realista, ao apresentar combinações de atributos ao invés de exibi-los de forma isolada. O método pressupõe que a utilidade de uma marca pode ser decomposta nas utilidades dos níveis dos atributos que determinam a preferência por uma marca em detrimento de outra (Siqueira, 1997).

As utilidades ou part-worths tem propriedades de escala intervalar, ou seja, não tem uma origem determinada (um ponto zero fixo) e é definida pela distância entre os pontos; é idêntica para quaisquer dois pontos adjacentes em qualquer lugar da escala. Por conta disto, convencionou-se codificar a escala de tal forma que a soma das utilidades dos níveis de um 
atributo some zero, ou seja, a escala assume o zero como medida central dentro de cada atributo (zero-centered part-worth utilities). Desta forma, algumas assumem valores positivos enquanto outras assumem valores negativos o que não significa que estes níveis geram decréscimos de utilidade. Estas situações, em verdade, representam apenas uma escala de preferência em que os valores negativos são classificados abaixo dos positivos (Orme, 2010). Considerando que as distâncias entre os pontos são idênticas, é possível comparar incrementos e decrementos de utilidade entre os atributos.

Assim, a utilidade total de uma opção de investimento corresponde ao resultado da soma das utilidades parciais e pode ser representada pela seguinte fórmula (Malhotra, 2012, p. 534):

$$
\mathrm{U}(\mathrm{X})=\sum_{i=1}^{m} \sum_{j=1}^{k_{i}} \alpha_{i j x_{i j}}
$$

Onde:

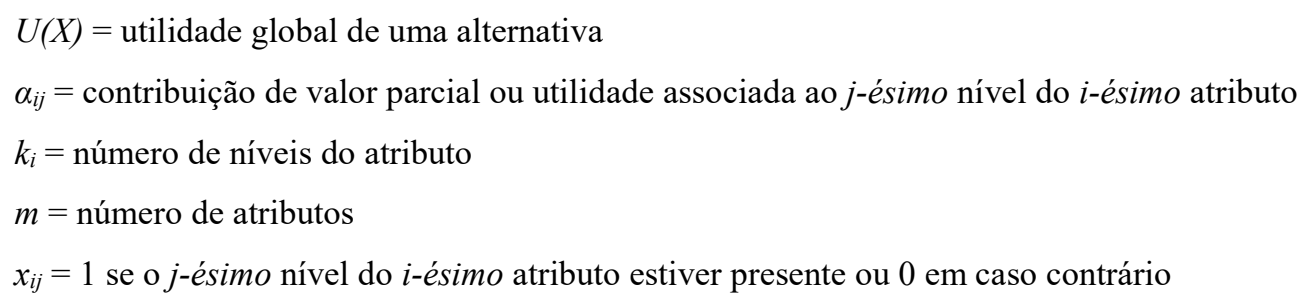

De acordo com Malhotra (2012), a análise conjunta está baseada em avaliações subjetivas dos entrevistados, cujos estímulos são combinações de níveis de atributos ambos determinados pelo pesquisador. Ela procura estabelecer funções de valor parcial que descrevem a utilidade associada aos níveis de cada atributo.

“Os modelos de decomposição têm o objetivo de estimar a importância de cada atributo (utilidades dos níveis dos atributos) a partir da avaliação de seu efeito conjunto (estímulos). Em outras palavras, partindo-se da avaliação de combinações de níveis, quer-se conhecer a contribuição de cada, em separado, na formação da preferência do entrevistado" (Siqueira, 1997, p.25).

Segundo Hair et al. (2009, p. 360) "a análise conjunta é uma técnica multivariada que busca entender como os respondentes desenvolvem preferências por produtos ou serviços. Ela parte da premissa de que o indivíduo forma sua percepção de valor sobre um objeto por meio da combinação dos valores transmitidos por cada atributo que o compõe. Sendo que, o valor é a 
base para a formação da utilidade que resulta dos valores percebidos em cada nível dos atributos que compõem o objeto".

Ainda segundo Hair et al., a utilidade é um julgamento subjetivo de preferência e a base conceitual para se medir valor. Por ser algo subjetivo a utilidade engloba todas as características tangíveis e intangíveis de um objeto.

Um objeto pode ser descrito pelo conjunto de atributos, físicos ou não, que o definem. Cada atributo é composto por diferentes características, chamadas de níveis, que são avaliadas e para as quais o observador atribui um valor. Este valor pode ser expresso como a utilidade parcial do objeto. Os objetos para os quais o consumidor atribui maior valor podem ser considerados preferidos em relação aos demais e tem maior chance de serem escolhidos.

A partir da amplitude dos intervalos das utilidades é calculada a contribuição de cada atributo na variação total das utilidades, que representa a importância relativa ou o peso de cada atributo na decisão do consumidor (Orme, 2010). A figura 5.2 ilustra o método para calcular as importâncias relativas.

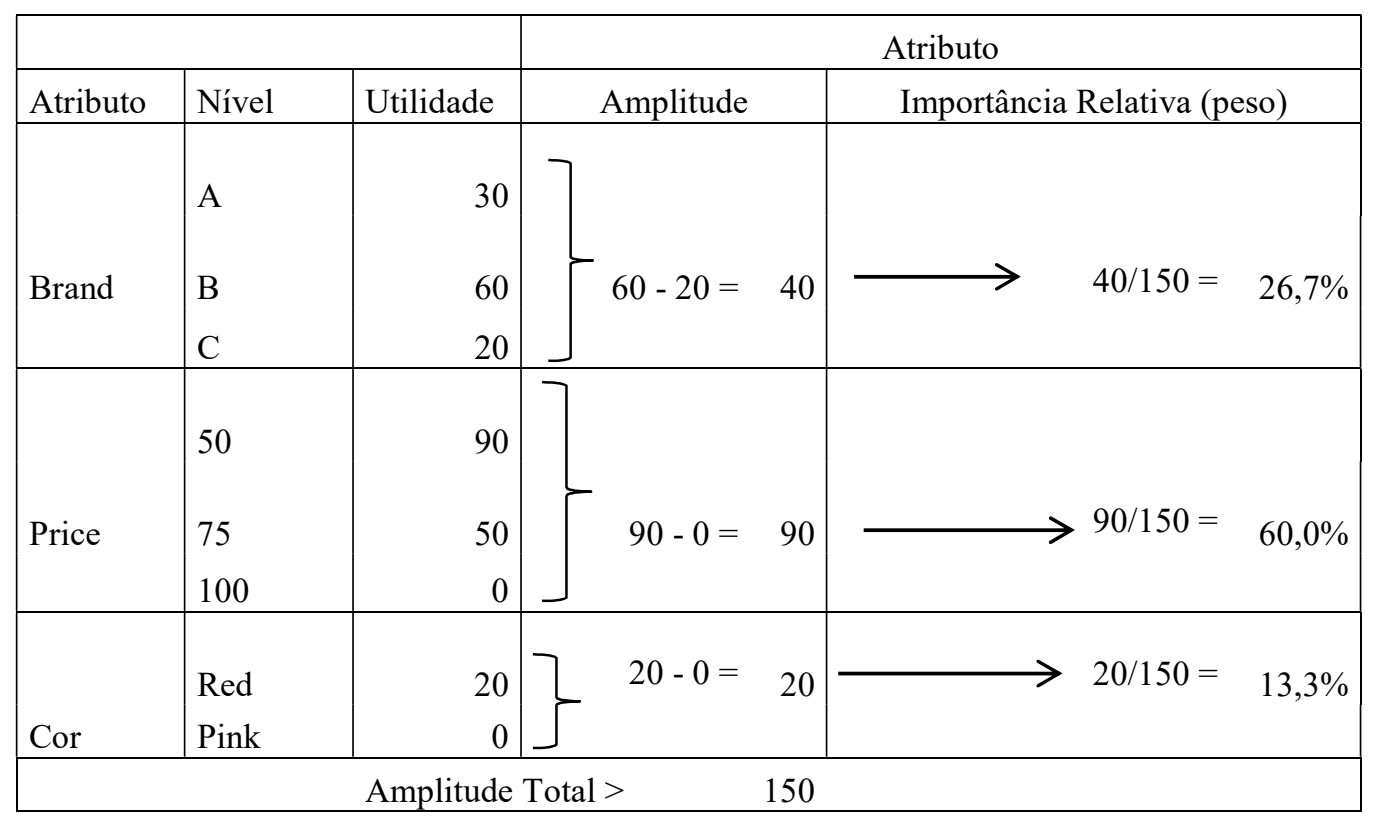

Figura 5.2 - Cálculo das Importâncias Relativas

Referência: Orme (2010, p. 80). 
Desta forma, é fundamental para o sucesso de uma pesquisa sobre a preferência dos indivíduos que o pesquisador identifique todos os atributos relevantes e os níveis que os definem, para que, de fato, consiga capturar as utilidades e a hierarquia de preferência do consumidor.

As combinações de atributos, também conhecidos como fatores, e níveis são denominadas de tratamentos ou estímulos. São estes conjuntos que são apresentados aos respondentes para que estes formulem seus julgamentos em termos de preferência, ou maior utilidade e maior chance de escolha. São estes estímulos que permitem entender a estrutura de preferência do indivíduo.

Ainda de acordo com Hair et al.(2009, p. 361), a estrutura de preferência explica também “como os níveis distintos dentro de um fator influenciam a formação de uma preferência geral (utilidade) [...] a análise conjunta também é conhecida como análise de troca, pois ao fazer um julgamento sobre um produto hipotético, os respondentes devem considerar as características "boas" e "ruins" do produto ao formar a preferência."

Green, Krirger e Wind (2001) em artigo de enfoque historicista sobre a evolução da conjoint analysis, defendem que o modelo baseado em escolhas (choice-based conjoint - CBC) representou uma inovação relevante em relação aos métodos tradicionais. Enquanto estes últimos se baseavam na classificação ou pontuação de vários produtos apresentados individualmente, no modelo baseado em escolha o respondente é apresentado a diferentes opções, que simulam produtos ou serviços, ou seja, com todos os atributos relevantes e seus níveis, simultaneamente e deve escolher a cada momento a sua preferida.

Orme (2010) advoga que o modelo CBC simula de forma muito próxima à realidade do contexto de uma tomada de decisão em que o consumidor tem produtos ou serviços concorrentes a serem comparados e que, em situações corriqueiras, deve escolher apenas um.

O modelo CBC se popularizou e hoje, segundo Orme (2010) é utilizado em 78\% das pesquisas realizadas com a plataforma da Sawtooth, empresa especializada em softwares para conjoint analysis. 


\subsubsection{Análise de Agrupamentos}

Segundo Hair et al. ( 2009) cluster analysis ou análise de agrupamentos é uma técnica multivariada que tem por objetivo identificar objetos semelhantes com base em suas características. Ou seja, dado um grupo de variáveis definidoras de cada objeto a análise de agrupamentos procura agregá-los em função da similaridade das variáveis. A finalidade da técnica é minimizar a distância entre os elementos dentro de um grupo (homogeneidade interna) ao mesmo tempo em que amplia a distância entre os grupos (heterogeneidade externa).

No caso desta pesquisa, as variáveis em estudo, aquelas julgadas relevantes para a tomada de decisão do investidor são a rentabilidade nos últimos meses, a pior rentabilidade em um mês (proxy de risco), liquidez, taxa de administração e recomendação do gerente. Para esta pesquisa, portanto, os respondentes foram classificados em função de sua reação à variação dos níveis destas variáveis e assim segregados em grupos por similaridade.

Os objetos de cada cluster devem ser semelhantes entre si, mas diferentes dos objetos de outros clusters, assim como devem pertencer a apenas um único cluster. Os grupos são definidos pelos dados ao invés de serem determinados a priori (Hair et al., 2009; Malhotra, 2012).

Dentre os objetivos relevantes da análise de agrupamentos, no que tange a esta pesquisa, destacam-se compreender o comportamento do consumidor e segmentar o mercado sem, contudo, generalizar os resultados. A partir da reação dos respondentes, ou investidores, às variações dos níveis atributos são calculadas as importâncias relativas de cada atributo (oriundas da análise conjunta) que se constituem nas variáveis que serão utilizadas para formação dos segmentos. Estes devem, na estatística média, apresentar reações distintas em relação aos estímulos apresentados e, portanto, devem ser suscetíveis a diferentes abordagens comerciais que resultarão em maior ou menor efetividade.

Desta forma, foi criada uma "taxonomia" em que os investidores serão classificados segundo seu comportamento em relação aos fatores que melhor definem sua decisão de investimento. 
De acordo com Fávero e Belfiore (2015), após definidos os objetivos da pesquisa deve ser selecionado um método para aglomeração das observações que são classificados em duas famílias: hierárquicos e não hierárquicos. Em paralelo, uma medida para de similaridade também deve ser escolhida.

Segundo Hair et al (2009) medidas de similaridade são um conceito básico na análise de dados medindo a semelhança entre objetos passíveis de serem agrupados. Segundo os autores, três critérios são considerados mais relevantes para esta medição, quais sejam: medidas correlacionais, de distância e por associação, dependendo do tipo de escala empregada. No presente estudo, face ao caráter intervalar da escala (peso de cada atributo na formação da preferência do investidor), empregou-se como medida de similaridade a distância euclidiana entre os respondentes.

Ainda segundo Hair et al. (2009) os métodos hierárquicos pressupõem que os objetos serão comparados de forma que, juntados, não mais se separam até a formação final dos clusters, sejam por meio de algoritmos aglomerativos ou divisivos. O primeiro método inicia com um cluster para cada objeto e promove o agrupamento destes em clusters progressivamente maiores. O método divisivo, ao contrário, inicia com um único cluster e os objetos são progressivamente distribuídos em outros menores.

De acordo com Malhotra (2012) os métodos aglomerativos consistem em técnicas de encadeamento entre os clusters, que medem a distância entre eles (linkage methods, considerando a variância dentro dos clusters e a distância entre os centróides). Já nos métodos não hierárquicos, conhecidos como k-means, a escolha dos centros dos clusters é arbitrária e os objetos vão sendo agrupados em torno destes até que se minimizem distâncias ou variâncias.

Para Malhotra (2012) os métodos não hierárquicos apresentam duas grandes desvantagens, primeiro são sensíveis à ordem em que os objetos estão dispostos e, segundo, a escolha do centro é arbitrária influenciando a formação dos grupos.

Para esta pesquisa foi escolhido o método hierárquico de Ward, que minimiza a variância dentro do cluster. Este método pressupõe que os clusters que apresentarem a menor soma de 
quadrados (das distâncias euclidianas) em cada estágio da sequência aglomerativa devem ser combinados. O software utilizado foi o SPSS, versão 20.

\subsubsection{Análise Discriminante}

Este método corresponde à “a combinação linear de duas (ou mais) variáveis independentes que melhor discriminarão entre os objetos (pessoas, empresas, etc.) nos grupos definidos $a$ priori" (Hair et al., 2009).

De acordo com Malhotra (2012, p. 450), a análise discriminante pode atender aos seguintes objetivos:

- Verificar se existem diferenças significativas entre grupos, em termos de variáveis previsoras;

- Determinar as variáveis previsoras que mais contribuem para a diferença entre os grupos;

- Enquadrar, ou classificar, novos casos em um dos grupos com base nos valores das variáveis previsoras.

Neste estudo, o objetivo da análise discriminante é encontrar os pesos das variáveis independentes (atributos de decisão de investimento) identificando aquelas que melhor discriminam a variável dependente (clusters de investidores), por meio da maximização das diferenças (distâncias) entre os grupos. A análise discriminante requer que as variáveis dependentes sejam categóricas e que as independentes, previsoras, sejam métricas ou dummies. Para tanto, deve-se estimar uma função discriminante, uma equação linear que combina os pesos e valores das variáveis independentes que melhor discriminem os grupos (Malhotra, 2012), no caso, os clusters identificados por meio da análise de conglomerados calcada na importância relativa de cada atributo oriunda da análise conjunta.

Sendo assim, um score discriminante é definido por:

$D=b_{0}+b_{1} x_{1}+b_{2} x_{2}+b_{3} x_{3}+\cdots+b_{n} x_{n}$

Onde:

$D=$ score discriminante,

$b_{i}=$ coeficiente ou peso discriminante,

$x_{i}=$ variável previsora ou independente. 
Os coeficientes são estimados de modo que os grupos sejam o mais distinto possível, isso em função da maximização da razão entre a soma dos quadrados entre os grupos e a soma dos quadrados dentro dos grupos (análise de variância).

A média dos scores discriminantes dos objetos dos grupos representa a média do grupo e é denominada de centroide. A comparação entre as distribuições dos scores de cada grupo permite avaliar a qualidade da discriminação efetuada; se houver razoável sobreposição das distribuições de scores das distribuições de cada grupo, a discriminação não pode ser aceita. Se a sobreposição das distribuições é pequena - o que significa maior distância entre os centroides dos grupos - a função discriminante foi boa preditora (separa bem os grupos).

Para avaliar o poder de diferenciação da função discriminante os objetos são separados em amostras de estimação e validação (holdout) de forma aleatória, respeitando-se assim a proporção observada entre os grupos. A função discriminante é calculada a partir da amostra de estimação e aplicada para a amostra houldout, permitindo assim a comparação do percentual de acerto na classificação entre as duas amostras. 


\section{Resultados}

Esta pesquisa foi desenvolvida em duas etapas a primeira de cunho exploratório contou com nove entrevistas em profundidade concedidas por executivos seniores ligados a Assets e áreas de distribuição de investimentos de bancos considerados de varejo. Nesta etapa buscou-se aprofundar o entendimento sobre o desenvolvimento da oferta de fundos de investimento e os fatores influenciadores da decisão do investidor. Como resultado desta etapa, surgiram insights que contribuíram sobremaneira para a análise dos insumos advindos da pesquisa de campo.

Já a segunda etapa contou com um survey para obtenção de respostas e, além de informações sobre os respondentes que permitissem categorizá-los, contou com robusto conjunto de estímulos para simular opções concorrentes que emulassem os tradeoffs usuais em decisões de investimento.

\subsection{Primeira etapa: estudo exploratório}

A seguir são apresentados os resultados das entrevistas em profundidade realizadas junto aos executivos com objetivo de aprofundar o conhecimento sobre o problema de pesquisa. As perguntas foram agrupadas em quatro blocos, a saber:

- Objetivos e estrutura das empresas de gestão de recursos de terceiros (Assets),

- Esforços de marketing e propaganda,

- Desenvolvimento de produtos e venda, e

- Fatores que influenciam a decisão do investidor.

A análise das respostas e os insights surgidos neste processo são apresentados no último tópico, denominado de insights.

\subsubsection{Objetivos e estrutura das $A$ ssets}

O principal objetivo apontado pelos executivos é a lucratividade. Alcançar uma determinada fatia de market share no ranking ANBIMA de gestão é apontado como segundo objetivo e ainda surge como alternativa atingir uma posição neste mesmo ranking. 
Para atingir estes objetivos, as Assets assumem, em média, a seguinte configuração em termos de headcounts: gestão (33\%), produto (5\%), distribuição (13\%), operacional, compliance e outros (49\%). Contudo, as estruturas organizacionais não são comparáveis, principalmente por conta de terceirização (por exemplo, atividade de backoffice interna ou externa) e escopo da área de distribuição que por vezes utiliza em maior ou menor escala a plataforma do banco. É importante ressaltar, que no caso de Asset, a distribuição está relacionada com a interface com os canais do banco.

Sobre a participação da Asset no negócio do banco, os números apurados variam entre 4\% e $20 \%$, evidenciando uma média de $9 \%$. Os executivos atribuem esta variabilidade ao fato de existirem diferentes modelos de organização e de compartilhamento de estrutura do banco, notadamente das áreas de backoffice. Estas disparidades implicam tanto no volume de despesas operacionais quanto, por vezes, na própria forma de computar os valores, o que dificulta a comparação.

\subsubsection{Bloco II - Esforços de Marketing e Propaganda}

Em geral as Assets possuem um orçamento próprio para atividades de marketing e propaganda. Contudo, em termos percentuais o valor é mínimo, não alcançando $1 \%$ do total da instituição, e, em geral, dedicado a eventos ou ações de comunicação. Já quando utilizado para propaganda, esta é de cunho institucional, não apoiando a venda de produtos em mídia impressa para divulgar a Asset e, em geral, associada a promover a premiação em algum ranking. No geral, o esforço de propaganda sobre a Asset é pequeno e bastante restrito a mídia impressa.

Os executivos concordaram que não se pratica propaganda sobre investimentos. Estes foram unânimes em apontar a propaganda como de cunho meramente institucional, ou seja, centrada no banco, seus produtos como um todo, conveniência, confiabilidade etc. Ocasionalmente algumas peças publicitárias também tratam de investimentos, mas no geral elas são consideradas omissas em relação ao tema. Em resumo, os executivos ressaltam que o objetivo principal do marketing em suas instituições é reforçar a marca, investir na "força da marca". De certa forma, investimentos são vistos como apenas mais um entre os diversos serviços oferecidos pelo banco. 
Sendo assim, nas ocasiões em que os produtos de investimento são veiculados na imprensa, estes, em geral, são apresentados por meio de propaganda genérica que tratam todos os investimentos de forma indistinta, algo do tipo "aplique em produtos de investimento de ...", em que não se distinguem características ou mesmo quais são as alternativas. Um executivo foi categórico e considerou que, haja vista o enfoque adotado, a propaganda deveria ser considerada exclusivamente institucional. Mais uma vez a mídia impressa especializada apareceu como o canal para divulgar fundos de investimento, mesmo assim ocasionalmente.

Se por um lado não existe um esforço específico para divulgar os produtos de investimento, por outro também não existe um processo de monitoramento da satisfação dos clientes com os produtos em que investiram. Neste caso, segundo estes executivos, fica a cargo dos representantes dos canais de distribuição inferir, tentar por meios indiretos entender e tentar medir a satisfação. Uma das premissas comumente adotadas é que se os canais estão satisfeitos com o produto é porque o produto é bom. Desta forma, pesquisas de satisfação, em geral, não são realizadas. Segundo estes, as pesquisas, assim como a propaganda, adquirem cunho institucional e pretendem capturar a satisfação com o banco como um todo, quando abordam algum produto de investimento o fazem de forma genérica.

Sobre a orientação dos esforços de marketing, os executivos foram unânimes em afirmar que sua instituição pratica foco em produto. Contudo, todos indicaram que no momento suas instituições estão em processo de migração para um olhar por cliente.

\subsubsection{Bloco III - Desenvolvimento de Produtos e Venda}

A ideia para o desenvolvimento de um novo produto pode surgir em qualquer departamento da própria Asset ou da área de investimentos ou distribuição do banco e ela sempre é desenvolvida na área de produtos. As discussões são feitas sempre em comitês ou fóruns específicos para "novos produtos". Em alguns casos existe na Asset outro comitê formado por executivos seniores que aprova a ideia antes que ela seja encaminhada para o comitê de produtos do banco, que discute quais produtos serão de fato lançados.

A decisão sobre o lançamento de novos produtos é tomada no âmbito deste comitê do próprio banco em que os executivos responsáveis por cada produto apresentam e defendem suas 
propostas para os demais, aí incluídos executivos do banco das áreas de distribuição, compliance, financeiro, risco etc. Os produtos discutidos pertencem a uma ampla gama de objetivos, desde investimento até linhas de crédito passando por planos de previdência e cartão de crédito. Em geral, para a tomada de decisão são considerados o cenário político, econômico e social, a estratégia do banco e suas necessidades de funding.

Para o desenvolvimento dos produtos de investimento, assim como no caso das pesquisas de satisfação, em geral desejos e necessidades dos investidores são capturados de forma indireta pela área de produtos que se alimenta a partir dos insights trazidos pelos executivos de distribuição da Asset ou pelos executivos responsáveis pela comercialização dos investimentos no banco (chamados de canais).

Outra forma de conhecer as demandas é promover o contato com gerentes de agências com objetivo de recolher informações que se traduzem em inputs para o desenvolvimento de novos produtos. Outra forma é o resultado do monitoramento dos concorrentes, com a premissa de que se um produto está captando bem "é por que os competidores identificaram a demanda antecipadamente". Por fim, e talvez mais importante, apurou-se que os executivos possuem forte formação técnica em finanças e, em especial em investimentos, que direcionam suas opiniões sobre quais produtos as Assets devem desenvolver e oferecer para quais públicos.

Os executivos consideram que os gerentes das agências tem um papel relevante no relacionamento com os clientes, contudo, consideram que estes ainda não foram capacitados a ponto de entender as demandas dos clientes e transformá-las em propostas para novos produtos. De acordo com os depoimentos, eles trazem algumas informações muito frágeis, tais como "os clientes estão comentando de um produto do concorrente" ou "os clientes estão reclamando da rentabilidade do fundo". Esta situação, contudo, é percebida como "normal", pois dada a atual estrutura do setor bancário, o gerente tem de vender uma série extensa de produtos. Ele deve estar preocupado com a venda dos produtos e menos em buscar entender o que o cliente deseja. Eles não possuem a especialização necessária para interpretar o que os clientes verbalizam e traduzir em políticas de investimento e produtos viáveis. Vale destacar aqui o resultado da pesquisa ANBIMA, a cargo da Officina Sophia, que detectou que os gerentes, em um dia típico, consomem apenas $20 \%$ do seu tempo com investimentos contra $38 \%$ dedicados a resolução de atendimentos de demandas sobre conta corrente ou problemas de rotina e outros $30 \%$ direcionados a assuntos relativos à tomada de crédito. 
Especificamente sobre fundos, assim como em produtos de investimento, no estágio atual não são feitas pesquisas sobre a satisfação dos investidores com fundos de investimento. Apesar disto, é interessante ressaltar que os executivos percebem que em meio às pesquisas de satisfação com o banco, de forma geral, tem se tornado mais comum perguntas sobre a satisfação dos clientes com produtos de investimento, porém de forma geral.

A despeito da ausência de pesquisas para entender os investidores, os executivos foram incisivos quando perguntados sobre o principal fator a impulsionar a venda de fundos. Eles apontaram diretamente a força de venda como sendo a principal responsável por incrementar a captação de um fundo. Segundo estes, os gerentes possuem metas de venda e os investidores tem objetivos ao investir seus recursos, portanto, respeitadas as preferências e restrições dos clientes, a indicação dos gerentes tende a ser acolhida.

É consenso que o sistema de metas cria distorções e a percepção de que os gerentes "empurram" os produtos mais interessantes para o banco do que para o cliente ou, até, em detrimento do cliente. Infelizmente, considerando o nível de conhecimento dos clientes, não resta a ele outro caminho a não ser o de seguir as recomendações. O sistema de metas dos gerentes ainda está majoritariamente associado à venda de produtos, e não ao valor do relacionamento. Contudo, existe a percepção de que os bancos estão em um momento de transição, eles já perceberam a importância em criar uma visão do cliente e já iniciaram o planejamento e investimentos para entender quem é e o que quer o cliente, buscando, assim, se aproximar e "enxergar" o cliente como um todo.

Desta forma, os executivos, em mais uma percepção consensual, consideram que os bancos deverão mudar da visão produto para a visão cliente. Os bancos precisarão conhecer seus clientes e suas necessidades e precisarão atendê-las para conseguir atingir a satisfação destes. Enxergar o relacionamento global do cliente com a instituição é fundamental. O gerente assumirá o papel de um consultor que conhece seu cliente e faz as melhores recomendações.

O relacionamento será baseado na confiança e na visão de longo prazo como forma de aumentar o valor do cliente. Processos deverão ser implementados para garantir estes 
objetivos e os incentivos deverão ser direcionados a relação banco-cliente ao invés de a transação (produto).

A TIC - Tecnologia de Informação e Comunicação, especialmente a plataforma web e as ferramentas de CRM, será uma importante habilitadora desta mudança ao permitir visualizar o cliente como um todo e acompanhar sua vida financeira. Desta forma, será possível conhecêlo, recomendar o mais adequado para o cliente na hora certa e atingir sua satisfação.

\subsubsection{Bloco IV - Fatores que Influenciam a Decisão do Investidor}

O gerente é visto como uma peça fundamental na decisão do investidor. Considerando um conjunto de opções que perfaçam seus objetivos em relação a risco-retorno-liquidez, os investidores priorizam a rentabilidade passada, contudo a indicação do gerente é determinante na decisão de investimento.

Sobre a importância relativa dos fatores risco e liquidez, estes executivos, consideram que em primeiro lugar os investidores olham o retorno passado e em segundo a liquidez. O risco foi apontado como uma variável difícil de ser entendida pelos investidores.

Já a taxa de administração, como ela tem estado mais aparente tanto por conta do menor patamar da taxa de juros quanto pela cobertura mais frequente da imprensa, seu peso na decisão parece estar aumentando, contudo, os executivos ressaltam que este ainda é muito baixo.

Entre os empecilhos para a ampliação da base de investidores, não considerando o aumento da renda, os entrevistados consideram que o nível de conhecimento muito baixo exerce influência relevante. Para estes os produtos são complexos por sua natureza, os bancos não sabem se comunicar, a linguagem é difícil e os gerentes se comportam de forma um tanto arrogante. Neste tocante, mais conhecimento poderia melhorar a capacidade de entender os produtos e de tomar decisões que resultariam na contratação de produtos mais adequados às suas necessidades. 
Contudo, eles são enfáticos ao declarar que os clientes querem respostas. Eles querem entender, mas não querem detalhes. Um exemplo citado é o do médico, o paciente não quer detalhes, ele acredita no diagnóstico e no tratamento, ele quer uma solução.

Dada a convicção de que o cliente com maior conhecimento toma melhores decisões, os executivos consideram que a educação financeira é fundamental para uma tomada consciente de decisão. Em um cenário de crescimento de renda e maior disseminação da educação financeira, a relação entre gerente e investidor potencial será outra e exigirá muito mais do gerente. Ela é essencial para formar uma classe verdadeiramente de investidores. Contudo, a educação financeira, por si só, não implica em melhor decisão é preciso que o indivíduo mude sua atitude, o seu comportamento.

\subsubsection{Insights}

As conclusões indicam que as Assets são, de fato, unidades de negócio que tem como principal negócio a gestão de recursos de terceiros, cujo objetivo primário é a lucratividade e em segundo plano alcançar um determinado market share. O setor, contudo, não conta com estratégia de posicionamento, apesar de desempenhar seu papel a contento, o negócio não tem visibilidade para os clientes que, sequer, tem a oportunidade de perceber a atividade. A propaganda é eminentemente institucional e calcada na "força da marca" e raramente aborda fundos de investimento, ou qualquer das outras opções de investimento oferecidas.

Em relação ao desenvolvimento de produtos, as Assets o fazem por meio da percepção que seus executivos e distribuidores têm sobre as necessidades, preferências e restrições dos investidores potenciais. Como não contam com instrumentos para aferir a satisfação dos investidores, se utilizam de métodos indiretos como monitorar a captação dos fundos (na premissa de que se positiva é porque os clientes estariam satisfeitos) ou por insumos trazidos pelos gerentes das agências. De fato, parece persistir no setor uma ótica de marketing orientada a produto, que Toledo (1978) já apontava. A crença de que os responsáveis pela geração do serviço devem conhecer o que o cliente deseja mais do que o próprio cliente está no centro deste conceito e pode ser responsável pela visão técnica a partir da qual os executivos devem conceber produtos considerados satisfatórios para o cliente. Neste sentido, 
os executivos compartilham de uma visão bastante normativa e pensam os produtos baseados em relações de risco e retorno e aversão ao risco (Baron, 2008; Peterson, 2009).

Para a concepção destes produtos, os executivos consideram que os clientes estão em busca primeiro de retorno e então de liquidez e que o risco seria uma variável pouco percebida pela própria dificuldade em se entender o conceito. Contudo, a interveniência do gerente é considerada fundamental para a escolha entre fundos de investimento ou quaisquer outros instrumentos de investimento financeiro. A decisão de investimento, em geral, recai sobre a alternativa indicada pelos gerentes. Estas impressões sugerem que talvez o risco seja, de fato, percebido como uma sensação ou sentimento, algo difícil de descrever, mas que se consegue sentir (Loewenstein et. al., 2001, Slovic et al., 2002; Slovic \& Peters, 2006). Por outro lado, esta decisão não seria baseada nos princípios axiomáticos da teoria da utilidade esperada já que não seria resultado de uma avalição racional das informações, considerando probabilidades e nível de aversão a risco (Kahneman \& Tversky, 1979; Tversky \& Kahneman, 1986, 1992; Schniter et al., 2013).

Contudo, eles admitem que, atualmente, a relação entre investidor e gerente se caracteriza mais por um traço de dependência (não resta outro caminho), em que o investidor, sem conhecimento, precisa do gerente, do que por uma relação de confiança, situação que já era apontada por Moorman et al. (1993). Esta realidade é reforçada pelos sistemas de bonificação de vendas que ainda estão baseados em metas por produtos, o que explica em parte a percepção de que muitos gerentes estão mais interessados em alcançar metas do que em atender os anseios dos clientes.

Por outro lado, o momento é considerado de transição para uma nova fase em que o aconselhamento do investidor e a valorização do relacionamento de longo prazo com o cliente deverão ser os principais direcionadores da estratégia comercial dos bancos. Para tanto, os executivos enxergam que a tecnologia da informação e comunicação assumirá papel relevante na viabilização desta transformação. Os resultados das pesquisas encomendadas pela ANBIMA (2014) às empresas ItsNoon e Officina Sophia, sugerem ser este um caminho promissor já que os investidores declararam precisar e querer confiar em seus gerentes para obter aconselhamento para suas decisões e enxergam neles a competência técnica para tal. 
Nesse contexto, entender como o investidor decide em relação à oferta de produtos, identificar atributos que possam ajudar a classificá-los e medir a importância do gerente na decisão pode colaborar neste esforço de estabelecer uma abordagem mais efetiva junto aos clientes. Uma estratégia que, segundo os executivos, passará por adotar uma orientação ao cliente, que aprofundará o relacionamento e exigirá novos processos e mudanças culturais. Uma decisão em linha com o conceito de customer lifetime value (CLV) que Rust, Zeithaml e Lemon (2000) já apontavam há mais de duas décadas.

O conceito de CLV está centrado no cliente e no valor que o relacionamento pode gerar para o negócio no longo prazo. Por este conceito, clientes satisfeitos devem interagir mais, à medida que aumenta a interação maior a capacidade da companhia de aprender sobre o cliente, suas necessidades e desejos, e, portanto, mais capacitada ela está para aprofundar a lealdade do cliente e defender seus clientes do assédio dos concorrentes (Kamakura, Wedel, Rosa \& Mazzon (2003). Para tanto as firmas devem adotar novas métricas de desempenho orientadas a medir os resultados do relacionamento ao invés das transações de vendas de produtos (Verhoef \& Lemon, 2013). Parte dos desafios reside em conseguir classificar clientes em rentáveis e identificá-los prontamente, outra parte reside em conseguir transformar a satisfação com a transação em lealdade, esta sim capaz de exercer impactos positivos no CLV (Qi, Zhou \& Chen, 2012).

A partir das opiniões colhidas junto aos executivos neste estudo exploratório, nas pesquisas encomendadas pela ANBIMA em 2014 e baseado nos artigos, entre outros, de Moorman, et al., 1993, de Shainesh, 2012, de Schniter et al., 2013 e de Sirdeshmukh, et al., 2002, foi elaborada a suposição de que o gerente pode estabelecer um elo emocional suficientemente forte, capaz de mitigar a percepção de risco e o desconforto e tensão cognitiva da decisão.

Relembrando as perguntas de pesquisa centrais deste trabalho:

Considerando o conjunto de atributos acima, qual a hierarquia de preferência do investidor no momento da decisão? Existem diferenças significativas entre as importâncias relativas atribuídas a estes fatores para grupos formados por investidores com estilo cognitivo mais intuitivo, ou automático, com aqueles formados por menos intuitivos? 
$\checkmark$ É possível identificar aspectos emocionais na decisão que desafiem a teoria da utilidade esperada?

Foram elaboradas algumas proposições que devem ajudar a elucidar as questões acima.

$P_{1}$ : As pessoas precisam e querem confiar em seus gerentes para tomar suas decisões, assim, a recomendação do gerente é o atributo mais importante na decisão de investimento;

$P_{2}$ : O fato de a recomendação do gerente ser o fator mais importante da decisão indica que os investidores querem evitar a tensão e desconforto cognitivo sugerindo que aspectos emocionais são relevantes para tomada de decisão;

$P_{3}$ : Pessoas mais intuitivas são mais propensas à recomendação do gerente.

A seguir, são apresentados os resultados do estudo quantitativo.

\subsection{Segunda Etapa: Estudo Quantitativo}

\subsubsection{Caracterização da amostra}

A pesquisa contou com quatrocentos e sessenta e nove respondentes sendo que nove foram desconsiderados durante o processamento das informações. Desta forma, restaram 460 casos para serem analisados. A tabela 6.1a, apresenta a dados demográficos da amostra. 
Tabela 6.1a

Frequência

Dados Demográficos

\begin{tabular}{|c|c|c|c|c|}
\hline & & Frequência & $\%$ & $\%$ Acumulado \\
\hline \multirow{2}{*}{ Sexo } & Feminino & 271 & $58,9 \%$ & $58,9 \%$ \\
\hline & Masculino & 189 & $41,1 \%$ & $100,0 \%$ \\
\hline \multirow{3}{*}{ Estado Civil } & Solteiro & 163 & $35,4 \%$ & $35,4 \%$ \\
\hline & Casado/"Mora Junto" & 267 & $58,1 \%$ & $93,5 \%$ \\
\hline & Divorciado/Viúvo & 30 & $6,5 \%$ & $100,0 \%$ \\
\hline \multirow{5}{*}{$\begin{array}{l}\text { Região } \\
\text { Geográfica }\end{array}$} & Centro Oeste & 50 & $10.9 \%$ & $10.9 \%$ \\
\hline & Nordeste & 182 & $39,6 \%$ & $50,5 \%$ \\
\hline & Norte & 14 & $3,0 \%$ & $53,5 \%$ \\
\hline & Sudeste & 67 & $14,5 \%$ & $68,0 \%$ \\
\hline & Sul & 147 & $32,0 \%$ & $100,0 \%$ \\
\hline & & & & \\
\hline \multirow{3}{*}{$\begin{array}{l}\text { Escolaridade } \\
\text { Máxima }\end{array}$} & Até o Médio & 123 & $26,7 \%$ & $26,7 \%$ \\
\hline & Superior & 224 & $48,7 \%$ & $75,4 \%$ \\
\hline & Pós /Mestrado/Doutorado & 113 & $24,6 \%$ & $100,0 \%$ \\
\hline \multirow{6}{*}{ Faixa de Renda } & Até 3.000 & 202 & $43,9 \%$ & $43,9 \%$ \\
\hline & De 3.000 a 5.000 & 101 & $22,0 \%$ & $65,9 \%$ \\
\hline & De 5.001 a 11.000 & 110 & $23,9 \%$ & $89,8 \%$ \\
\hline & De 11.001 a 20.000 & 22 & $4,8 \%$ & $94,6 \%$ \\
\hline & Acima de 20.000 & 15 & $3,2 \%$ & $97,8 \%$ \\
\hline & Não respondeu & 10 & $2,2 \%$ & $100,0 \%$ \\
\hline
\end{tabular}

Em relação a esta amostra, vale comentar, sobre o predomínio de pessoas com nível superior ou acima e, também, a concentração nas faixas de renda de até $\mathrm{R} \$ 5.000,00$. No que se refere ao perfil de renda, contudo, este se apresenta bastante alinhado ao verificado entre a população brasileira. Por outro lado, chama atenção à alta taxa de respondentes das regiões nordeste e sul em contraposição a reduzida participação da região sudeste. Este último fato, talvez possa ser creditado a maior dinâmica econômica que, possivelmente, contribui para reduzir disponibilidade e interesse em responder pesquisas acadêmicas.

Em termos etários, a amostra é composta de respondentes entre 23 e 61 anos, com idade média de 33 anos. O gráfico 6.1, abaixo, apresenta a distribuição de frequência dos 
respondentes por faixas etárias. Uma amostra concentrada nos mais jovens com $44 \%$ dos respondentes com idades até 30 anos e $70 \%$ até 35 anos.

Em decorrência deste perfil concentrado da amostra, provavelmente em função da coleta dos dados ter sido realizada por meio de questionário na internet, foram descartados testes e análises por categorias de faixa etária.

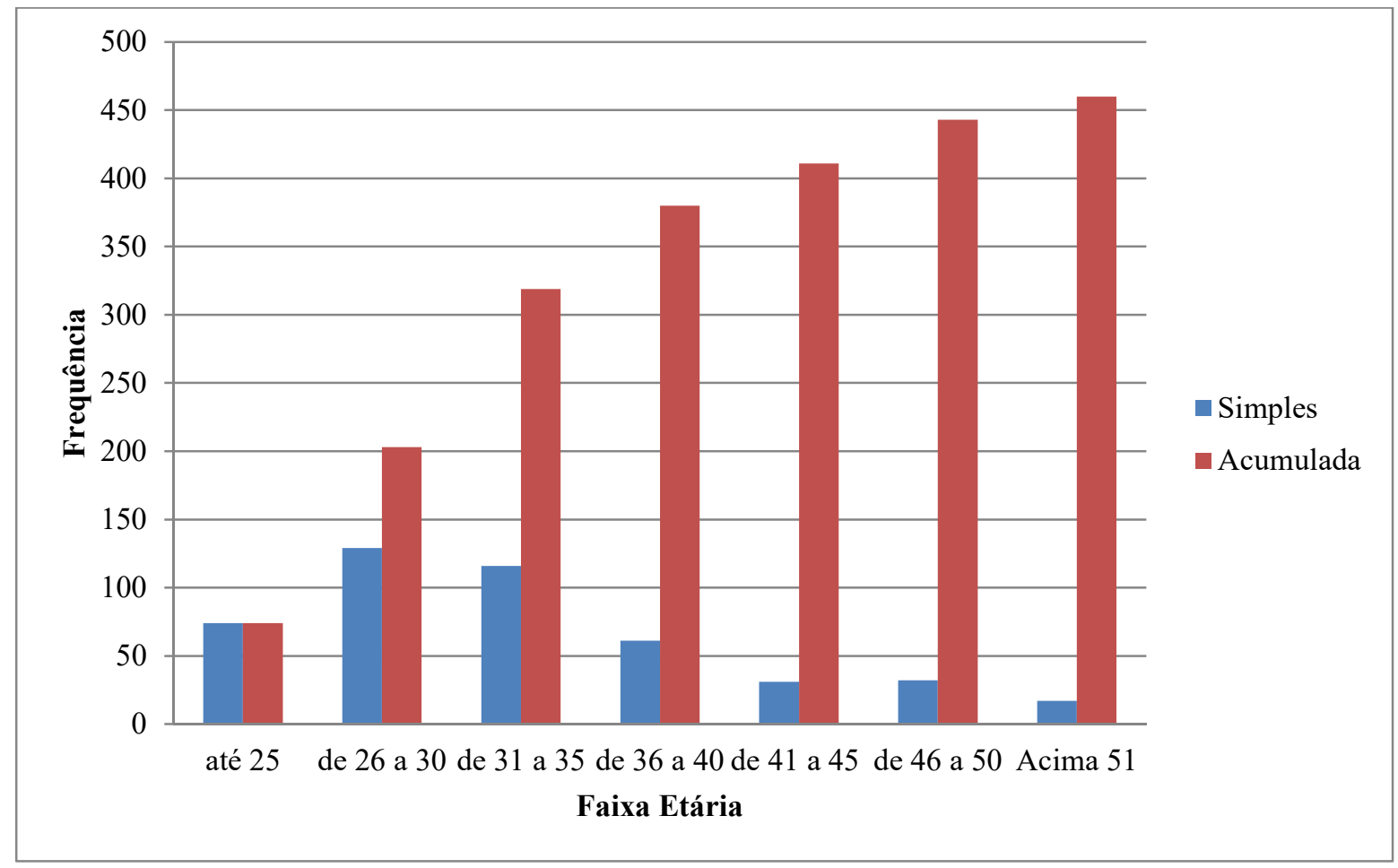

Gráfico 6.1 - Frequência Simples e Acumulada por Faixa Etária

A revisão de literatura e o estudo exploratório apontaram para três características individuais que podem influenciar na decisão, são elas: nível de conhecimento sobre produtos financeiros, propensão ou aversão ao risco e estilo cognitivo (inferido a partir da escala CRT). Desta forma, os respondentes foram destinados a estas categorias de forma a permitir a comparação entre as mesmas.

A tabela 6.1 b apresenta a distribuição de frequência dos respondentes entre características de conhecimento, nível de aversão a risco e estilo cognitivo. 
Tabela 6.1b

Frequência

Conhecimento, Aversão a Risco e Resposta Automática

\begin{tabular}{|c|c|c|c|c|}
\hline \multirow{5}{*}{$\begin{array}{c}\text { Nível de } \\
\text { Conhecimento }\end{array}$} & & Frequência & $\%$ & $\%$ acumulado \\
\hline & Alto & 72 & 15,7 & 15,7 \\
\hline & Baixo & 85 & 18,5 & 34,1 \\
\hline & Médio & 303 & 65,9 & 100,0 \\
\hline & Total & 460 & 100,0 & \\
\hline \multirow{4}{*}{$\begin{array}{c}\text { Nível de Aversão } \\
\text { ao Risco }\end{array}$} & Alta & 107 & 23,3 & 23,3 \\
\hline & Baixa & 18 & 3,9 & 27,2 \\
\hline & Média & 335 & 72,8 & 100,0 \\
\hline & Total & 460 & 100,0 & \\
\hline \multirow{3}{*}{$\begin{array}{l}\text { Resposta } \\
\text { Automática } \\
\text { (Intuitivos) }\end{array}$} & Não & 353 & 76,7 & 76,7 \\
\hline & Sim & 107 & 23,3 & 100,0 \\
\hline & Total & 460 & 100,0 & \\
\hline
\end{tabular}

Para classificação dos respondentes em relação ao nível de aversão a risco foram utilizadas duas questões. A primeira em que o respondente se classificava em uma escala de sete pontos em relação à aversão ao risco e uma segunda, empregada em 2013 pelo Investment Company Institute (ICI), em pesquisa junto a investidores em fundos de investimento nos EUA em que os respondentes se classificaram em uma escala de cinco pontos, desde o mais avesso, nenhum risco, até risco elevado para ganhos substanciais.

A comparação dos resultados entre os investidores do Brasil e EUA indica que em relação aos extremos, enquanto o Brasil conta $29 \%$ de pessoas que não querem risco algum ou preferem rentabilidade abaixo da média como recompensa por risco também abaixo da média, esta proporção nos EUA é de $22 \%$. Já na parte mais propensa ao risco, a proporção se inverte com os americanos dispostos a aceitar risco substancial ou acima da média em contrapartida a retornos também superiores ocupando uma fatia maior, $30 \%$ contra $23 \%$ dos brasileiros.

As escalas se mostraram convergentes e foram fundidas em uma única. Em ambas os respondentes se classificaram conforme a percepção que tinham de si próprios. O gráfico 6.2 apresenta a comparação entres os resultados desta pesquisa e a aplicada nos EUA. 


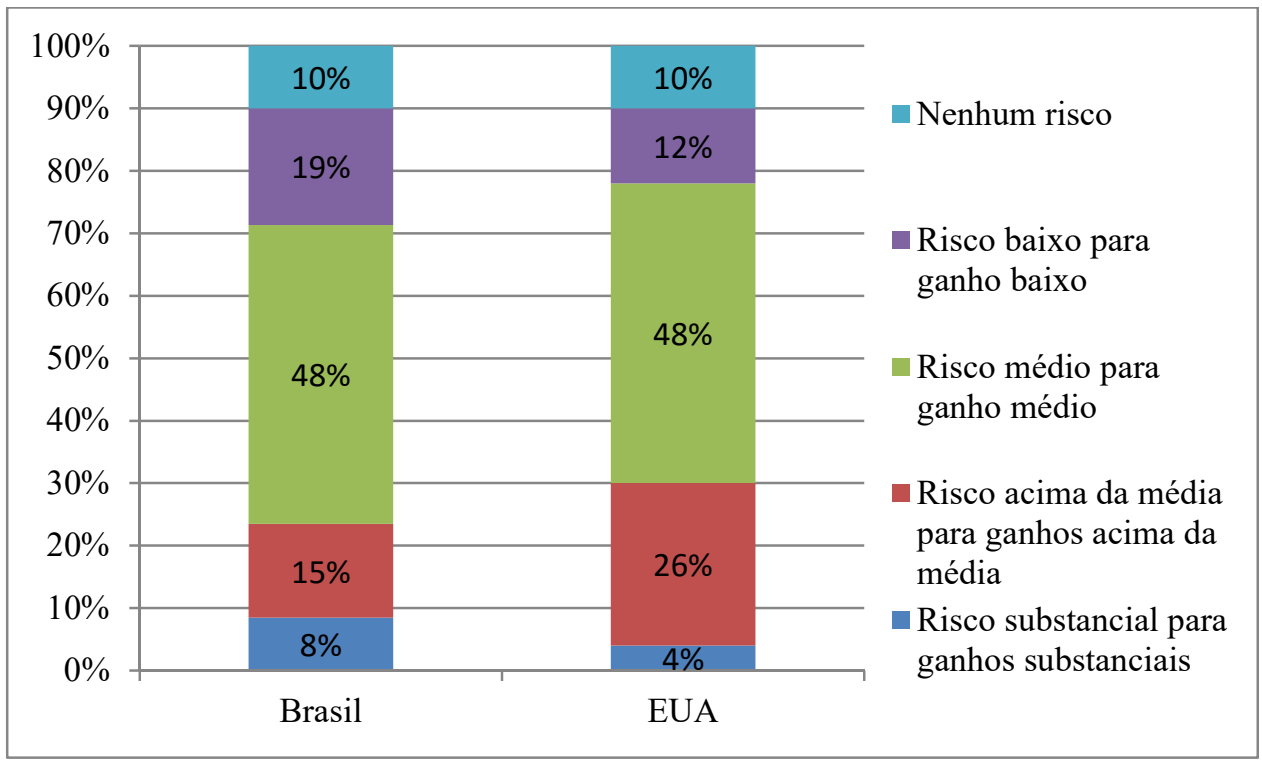

Gráfico 6.2 - Comparação Perfil de Risco Brasil X EUA

Este resultado parece estar em sintonia com os de Statman e Klimek (2010) que apontaram o Brasil como o segundo país com maior nível de aversão ao risco entre vinte e dois países. Para efeito de comparação, os norte-americanos ocupavam a $11^{\mathrm{a}}$ posição neste ranking enquanto os brasileiros detinham a $21^{a}$ posição.

Assim como o nível de aversão a risco, para categorização em relação ao nível de conhecimento sobre produtos de investimento financeiro, o questionário contava com duas perguntas, uma em que o respondente era solicitado a se classificar conforme seu nível de conhecimento sobre investimentos financeiros (cinco pontos, de muito baixo até muito alto) e outra sobre sua capacidade em dar conselhos sobre a matéria (sete pontos, de 1 até 7). As pontuações também foram convergentes e as duas escalas foram fundidas em uma única.

A classificação dos respondentes conforme seu nível de resposta automática, aquela fornecida pelo Sistema 1, aqui chamados de intuitivos, ou mais intuitivos, foi baseada na escala CRT (cognitive reflection test), desenvolvida por Shane Frederick (2005). Aqueles que, para as três perguntas, responderam conforme o esperado (resposta automática ou intuitiva) e atingiram os três pontos, foram classificados como intuitivos.

Frederick categorizou os grupos em relação ao número de respostas corretas, aquelas para as quais se demandou um esforço cognitivo não somente para resistir à resposta automática, mas, também, para se encontrar a resposta exata. Segundo o autor, entre as diferentes respostas 
possíveis, as intuitivas, ou automáticas, dominaram e, adicionalmente, mesmo entre aqueles que responderam corretamente, a resposta automática foi a primeira a surgir à mente.

Considerando os extremos, os resultados da pesquisa de Frederick apontaram 33\% de respondentes que não acertaram qualquer das três perguntas e $17 \%$ que forneceram respostas corretas para as três perguntas, ou seja, após refletir sobre cada pergunta e desenvolver cálculos logrou acertar a resposta.

A aplicação deste teste para esta pesquisa chegou a resultados distintos, apenas $1,5 \%$ dos respondentes lograram acertar as três respostas enquanto $73 \%$ erraram as três. Entre as causas que podem explicar esta disparidade, encontra-se a formação da amostra que neste estudo é composta por pessoas de diferentes formações enquanto a pesquisa de Frederick contou com alunos de algumas das mais renomadas universidades americanas.

Contudo, o interesse deste estudo repousa sobre os indivíduos com o Sistema 1 mais aguçado, aqueles que respondem com menor esforço cognitivo e, neste estudo, não resistiram à resposta automática. Valendo-se da mesma escala, os respondentes aqui foram categorizados de forma oposta, ou seja, aqueles que forneceram a resposta automática (e incorreta) para as três perguntas foram classificados como predominantemente intuitivos (ou mais intuitivos) enquanto os demais foram classificados como predominantemente não intuitivos (ou menos intuitivos). Desta forma, entre outros objetivos, considerando o perfil da amostra, esta pesquisa busca identificar a importância deste traço de comportamento, Sistema 1 mais presente, na decisão de investimento deste grupo. As tabelas 6.2a e 6.2b apresentam as distribuições das respostas entre automáticas, ou intuitivas, e corretas, respectivamente. 
Tabela 6.2a

$\%$ de Respostas

Intuitivas

\begin{tabular}{c|c|c}
\hline \multirow{2}{*}{ Pontos } & \multicolumn{2}{|c}{ Resposta Intuitiva } \\
\cline { 2 - 3 } & $\mathrm{N}$ & $\%$ \\
\hline 0 & 60 & $13,0 \%$ \\
1 & 118 & $25,7 \%$ \\
2 & 175 & $38,0 \%$ \\
3 & 107 & $23,3 \%$ \\
& 460 & \\
\hline
\end{tabular}

Tabela 6.2b

$\%$ de Respostas

Corretas

\begin{tabular}{c|c|c}
\hline \multirow{2}{*}{ Pontos } & \multicolumn{2}{|c}{ Resposta Correta } \\
\cline { 2 - 3 } & $\mathrm{N}$ & $\%$ \\
\hline 0 & 335 & $72,8 \%$ \\
1 & 90 & $19,6 \%$ \\
2 & 28 & $6,1 \%$ \\
3 & 7 & $1,5 \%$ \\
& 460 & \\
\hline
\end{tabular}

\subsubsection{Utilidades parciais}

Após responder as seções destinadas a conhecer os dados demográficos e psicossociais, os respondentes foram apresentados aos cenários econômicos, positivo ou negativo, como tentativa de induzir uma percepção de maior ou menor risco no momento da decisão. Basicamente, a amostra foi repartida aleatoriamente em três partes sendo uma delas apresentada ao cenário negativo, outra ao cenário positivo e outra foi dispensada de cenário se constituindo como uma espécie de grupo de base. Após esta etapa, finalmente, elas foram apresentadas aos dezoito diferentes conjuntos de opções que simulavam um processo de escolha por uma alternativa de investimento. Cada conjunto continha 5 subconjuntos para avaliação, cada um contendo 5 alternativas concorrentes mais a alternativa de não escolher qualquer delas, conforme descrito na seção 5.2.2.

Vale lembrar que cada opção apresentada aos respondentes se constituiu em um estímulo definido por seus atributos e níveis. Conforme cada opção é selecionada, os níveis são classificados em ordem de preferência e os valores de utilidade, em função deste processo de avaliação comparativa e escolha, são calculados. A partir das utilidades parciais dos níveis, que estão em uma escala comum dentro de cada atributo, é possível derivar a importância relativa de cada atributo, cuja soma é 100\% (Hair et al., 2009; Orme, 2010). No caso desta pesquisa, a preferência por cada atributo é resultado da composição das utilidades de rentabilidade, pior rentabilidade (que emula o risco), liquidez, taxa de administração e recomendação do gerente. 
O modelo teórico descrito, baseado na revisão de literatura pressupõe a existência de uma relação monotônica entre os níveis de cada atributo pesquisado. Para a rentabilidade nominal positiva no ano anterior espera-se uma relação direta, quanto maior a rentabilidade maior a utilidade. Esta mesma relação é teorizada para a recomendação do gerente. Já a liquidez e a taxa de administração, supostamente apresentam relação inversa, quanto maior o prazo para resgate e a taxa de administração menor a utilidade. No caso da pior rentabilidade, que induz a percepção de risco, espera-se que quanto pior a rentabilidade (mais negativa) menor a utilidade.

Para cada respondente foram calculadas as utilidades parciais de cada nível que resultaram nas importâncias relativas, pesos, de cada fator na decisão. A partir destes resultados individuais, foram calculadas médias para a amostra e para os grupos de interesse como forma de aumentar o poder preditivo para o comportamento em nível agregado das pessoas, objetivo principal desta pesquisa.

Vale lembrar que os valores das utilidades parciais possuem apenas propriedades de escala intervalar, ou seja, distâncias numericamente iguais representam valores iguais em relação ao objeto que está sendo medido. Há um intervalo igual entre os valores da escala, sendo seu ponto de origem arbitrário (Malhotra, 2012; Stevens, 1946).

O primeiro interesse desta pesquisa reside em verificar a existência da relação monotônica descrita anteriormente.

O gráfico 6.3 comprova a existência da relação monotônica para o atributo rentabilidade, implicando na não rejeição de $H_{l a}$. As utilidades são crescentes conforme se elevam as taxas de retorno com destaque para o incremento de vinte e seis pontos verificado entre os níveis de $6 \%$ a.a. e $10 \%$ a.a, de vinte pontos negativos para seis pontos positivos, uma inclinação sensivelmente mais pronunciada da curva. Embora não haja elementos para afirmar, tal fato pode ser atribuído ao efeito de ancoragem que pode ter sido provocado pelo longo e persistente período em que o brasileiro convive com taxas de juros nominais de dois dígitos (Gigerenzer \& Gaissmaier, 2011; Tversky \& Kahneman, 1974). 


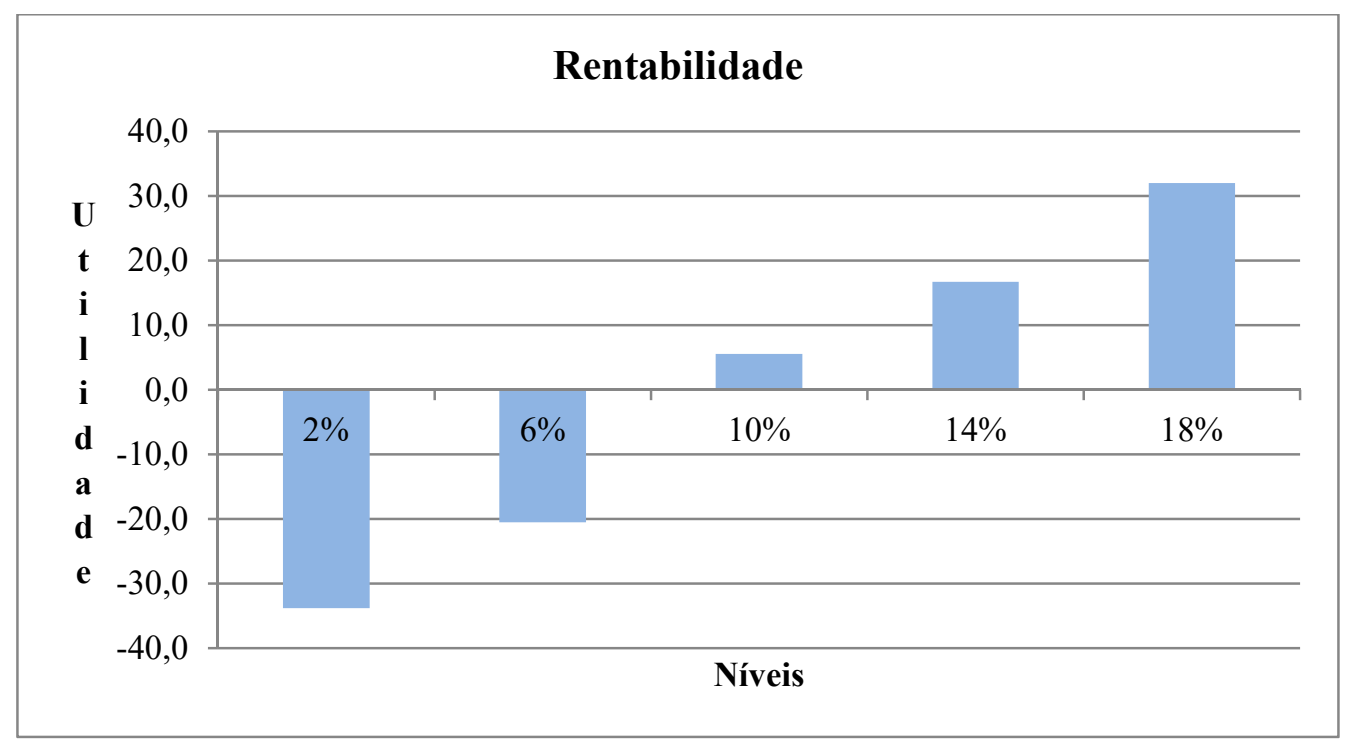

Gráfico 6.3 - Rentabilidade - Utilidades Parciais Médias dos Níveis

O gráfico 6.4 demonstra a relação monotônica esperada para as rentabilidades negativas, estímulo que evoca a sensação de risco, também confirmando a não rejeição de $H_{l a}$. Conforme as rentabilidades se deprimem, a utilidade decai com destaque para a inclinação verificada na curva entre $0 \%$ a.m. e $-1 \%$ a.m. Neste intervalo a utilidade regrediu em vinte e sete pontos. Esta redução parece encontrar correspondência com a teoria do prospecto (Barberis, 2013; Kahneman \& Tversky, 1979; Tversky \& Kahneman, 1992) que advoga que as pessoas são mais sensíveis à perda que ao ganho.

Ainda segundo a teoria do prospecto, a sensibilidade às alterações de estado se reduz nos pontos mais próximos aos extremos. O gráfico indica que ao entrar no campo das rentabilidades negativas os respondentes, em média, parecem experimentar, de fato, uma sensação de perda mais acentuada que se reflete no decréscimo mais intenso da utilidade. Contudo, nos níveis mais extremos, entre de $-3 \%$ e $-4 \%$, o decréscimo de utilidade é de apenas seis pontos negativos. Ou seja, após entrar no terreno das perdas, a sensibilidade aos novos reveses se torna menos vigorosa. Tal relação, contudo, não foi verificada em relação ao atributo rentabilidade que registrou ganhos de utilidade em torno de 14 pontos entre os níveis de $2 \%-6 \%$ e $14 \%-18 \%$. 


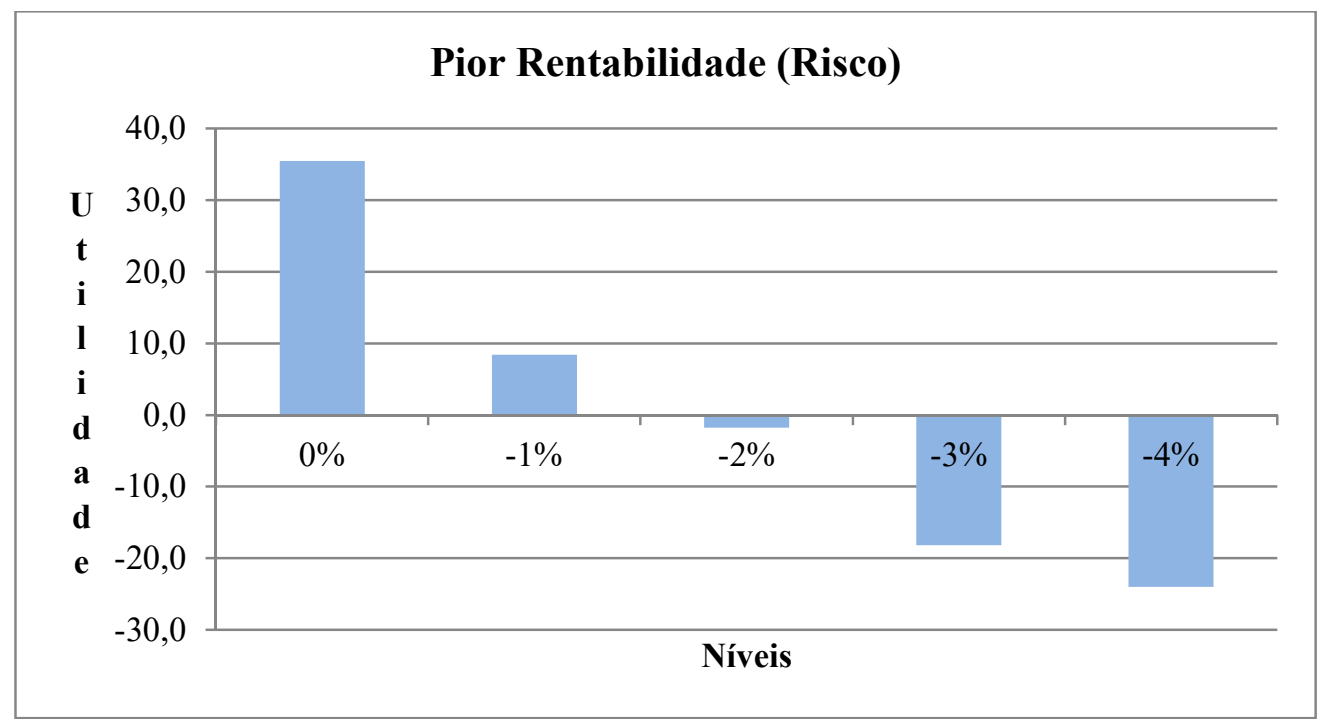

Gráfico 6.4 - Risco (pior rentabilidade) - Utilidades Parciais Médias dos Níveis

Em relação ao atributo recomendado pelo gerente, a relação também é monotônica com crescimento da utilidade em função direta da recomendação do gerente, confirmando igualmente $H_{l a}$. Em linha com os resultados da pesquisa exploratória, em que os executivos apontaram o gerente como fundamental na decisão do investidor, o gráfico aponta para elevado crescimento de utilidade decorrente da recomendação, indicando a força do gerente na escolha do cliente. Em consonância com Berry (1995), Sirdeshmukh et al. (2002) e Shainesh (2012), o gerente parece transmitir segurança, reduzir a percepção de risco e trazer conforto para a decisão. A recomendação do gerente apresenta, ainda, a maior amplitude entre as utilidades produzidas entre o primeiro e último nível, de oitenta e cinco pontos, quando comparadas a todos os demais atributos. Vale notar que tais resultados estão alinhados às pesquisas levadas a cabo pela ANBIMA (2014). O gráfico 6.5 apresenta os resultados. 


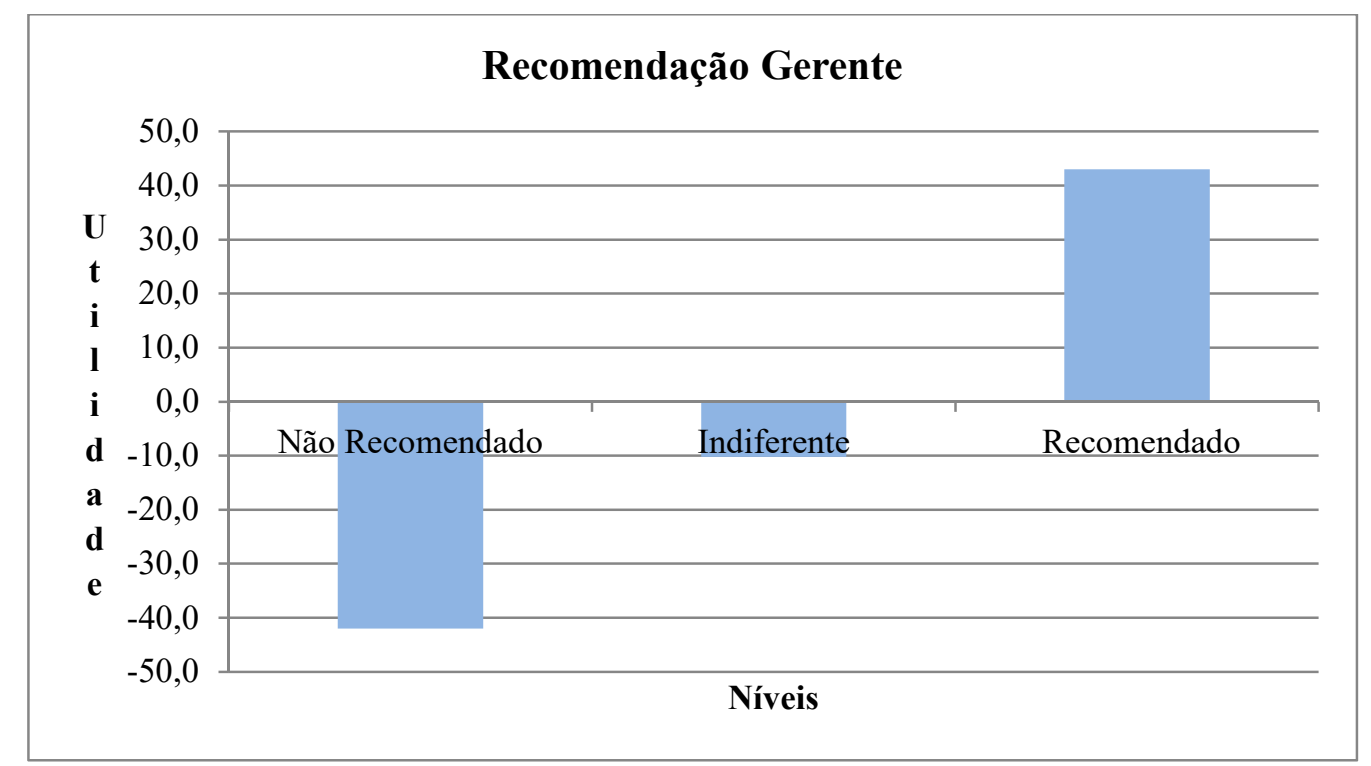

Gráfico 6.5 - Recomendação do Gerente - Utilidades Parciais Médias dos Níveis

A liquidez também apresenta relação monotônica, negativamente relacionada, com as utilidades progredindo de forma decrescente em função do aumento do prazo requerido para poder receber os recursos regatados, corroborando $H_{1 a}$. O gráfico 6.6 apresenta os valores.

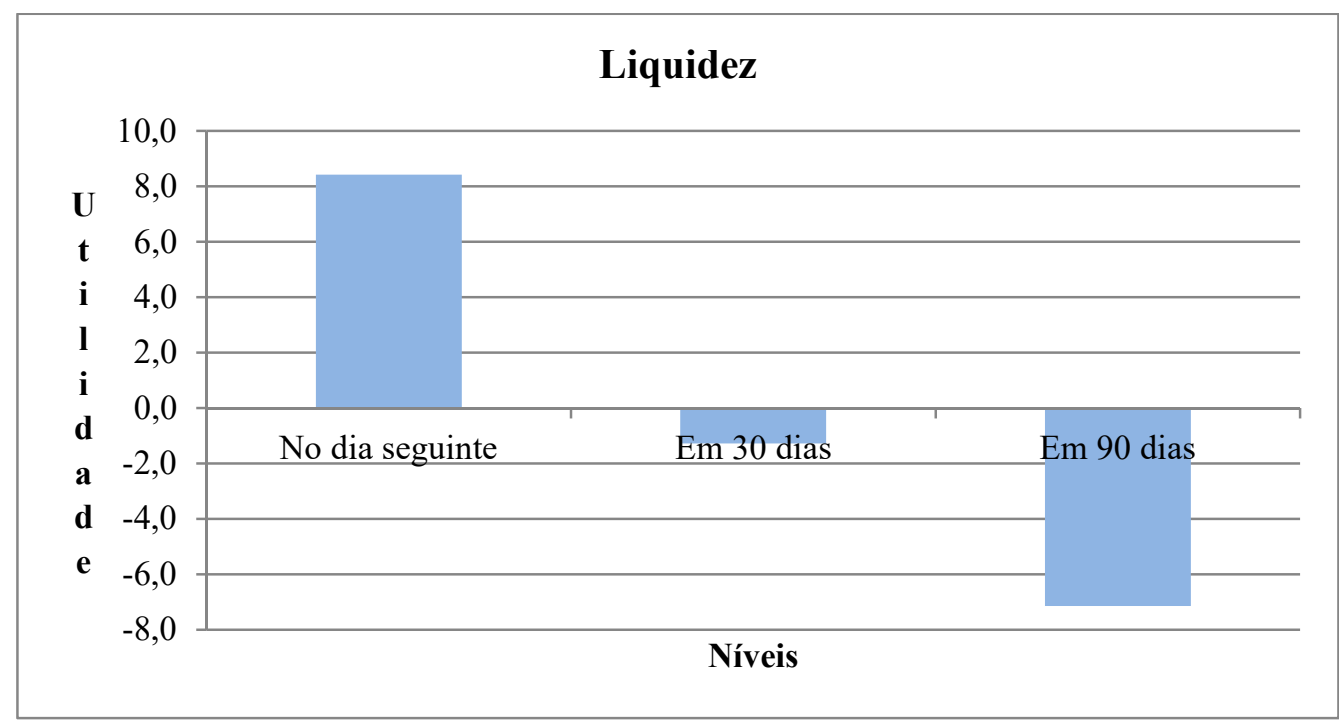

Gráfico 6.6 - Liquidez - Utilidades Parciais Médias dos Níveis

Em relação ao atributo taxa de administração, esta representa o preço que o investidor paga pela gestão dos seus recursos e, como tal, quanto maior seu valor menor utilidade produzida. Esta relação pode ser considerada monotônica e negativamente relacionada, apesar da 
inversão observada entre os níveis $2,0 \%$ a.a. e 2,5\% a.a. A despeito deste movimento, a tendência é de franco declínio das utilidades o que acarreta em não rejeição de $H_{l a}$.Vale lembrar os relatos obtidos durante as entrevistas com os executivos, embora os investidores estejam mais atentos à taxa de administração esta ainda não é um fator relevante entre suas preocupações. O gráfico 6.7 ilustra os resultados.

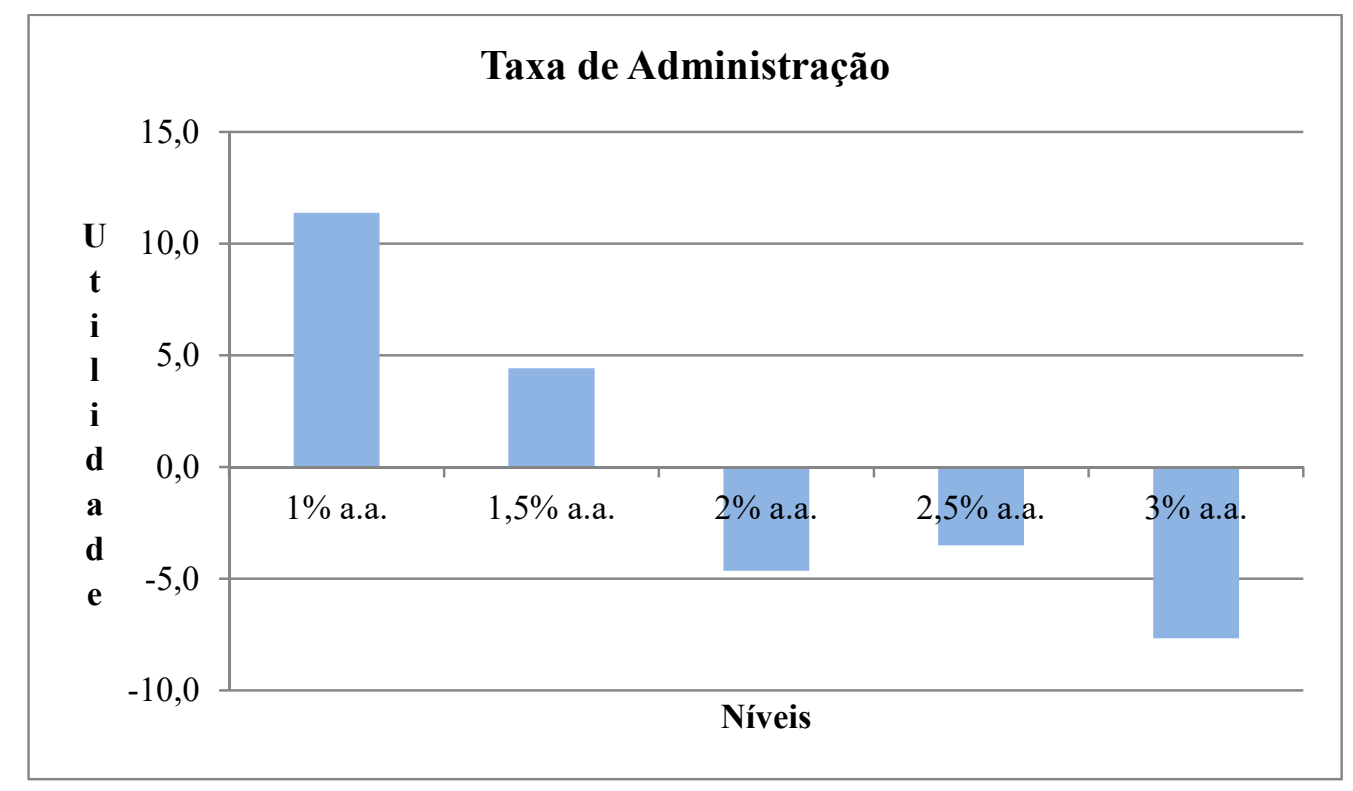

Gráfico 6.7 - Taxa de Administração - Utilidades parciais médias dos níveis

A figura abaixo sumariza os resultados das utilidades de cada nível para cada atributo. Rentabilidade e recomendação do gerente são positivamente relacionadas, quanto maior o nível na escala mais a alta a utilidade alcançada, sendo a inclinação da linha correspondente à recomendação sensivelmente mais pronunciada. Já taxa de administração, liquidez e risco são negativamente relacionadas aos níveis, com esta última indicando maior sensibilidade à variação dos níveis.

Vale notar que em consonância tanto com os pressupostos da teoria tradicional de finanças quanto com as teorias de viés descritivo, as curvas de rentabilidade e risco, aqui representado pela possibilidade de perda, são inversamente relacionadas, o que demostra que para maiores níveis de percepção de risco são esperadas taxas de retorno mais elevadas (Sitkin \& Weingart, 1995). Na figura 6.1, é possível verificar de forma visual a relação entre as utilidades produzidas pelos níveis dos cinco atributos. 


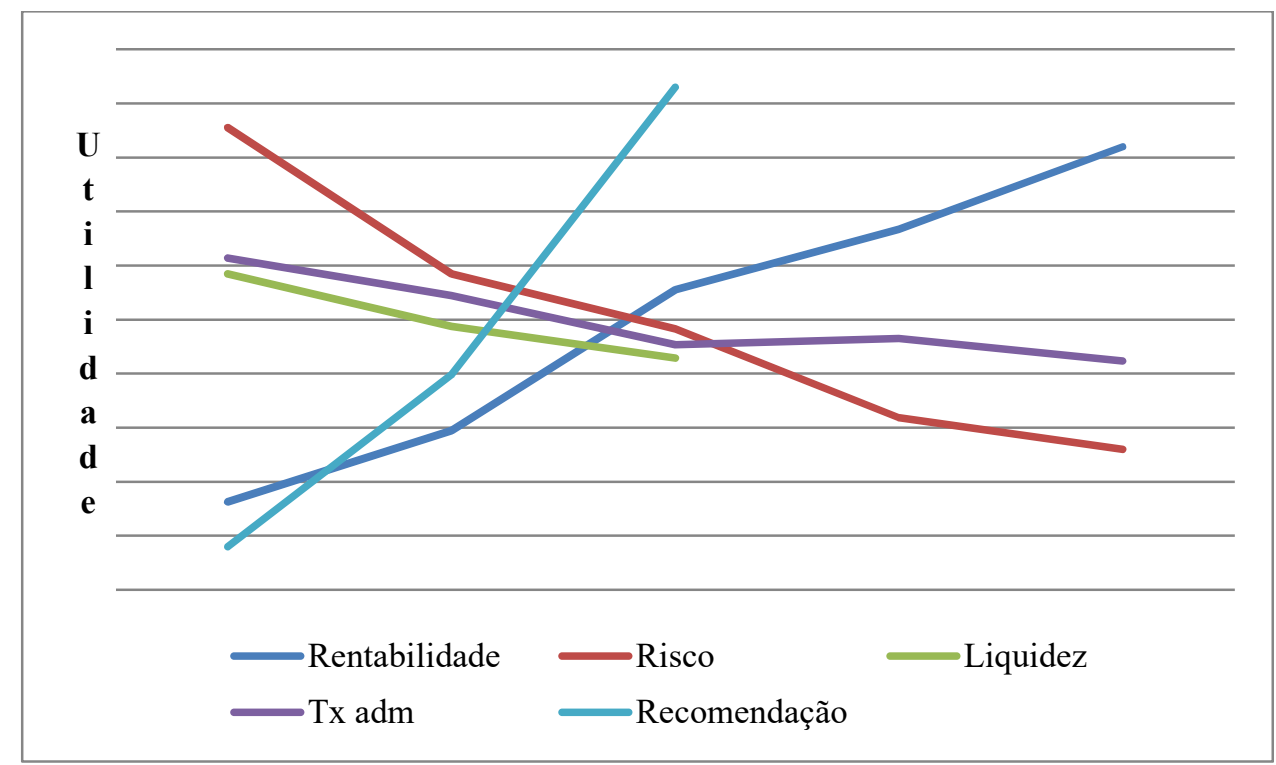

Figura 6.1 - Relação Níveis X Utilidades

\subsubsection{A importância relativa dos fatores na decisão}

O principal resultado da análise conjunta talvez seja o cálculo dos pesos relativos de cada atributo na escolha, ou seja, a importância relativa que cada um dos fatores assumiu no momento da decisão.

Sendo assim, para cada respondente calculou-se a participação relativa de cada atributo: rentabilidade do ano anterior, risco (pior rentabilidade em um mês), liquidez, taxa de administração e recomendação do gerente. A partir destes resultados individuais, foram calculadas as médias e os desvios padrões de cada atributo. Vale lembrar que a soma dos pesos relativos é igual a $100 \%$.

Inicialmente deseja-se saber se os atributos aqui pesquisados, de fato, são relevantes para a decisão do investidor e qual a importância de cada um.

Segundo Shleifer (2000) a teoria tradicional pressupõe que os mercados de trocas são eficientes (efficient market hypothesis, EMH), nele os preços dos ativos financeiros sempre refletem totalmente a informação disponível. A eficiência do mercado estaria assentada em três premissas: (i) os investidores são racionais, (ii) para o caso de haver não racionais, os negócios realizados em mercado são aleatórios e se compensariam de modo a não afetar os 
preços, (iii) existem arbitradores no mercado que percebem os desequilíbrios dos preços relativos, agem para se aproveitar destes e acabam por eliminá-los. Os preços reagem rapidamente à informação nova assim como ficam inertes em sua ausência.

Por esta perspectiva normativa (Bodie et al., 2013; Damodaran, 2009; Kritzman, 1998) os investidores tem as informações e a habilidade necessárias para calcular probabilidades e tomar decisões conscientes e baseadas em sua aversão ao risco, um traço pessoal estável que não se altera conforme diferentes estímulos ou contextos para a teoria tradicional (Schoemaker, 1993). Neste sentido, os investidores avaliam os atributos do produto e priorizam a relação de retorno e risco na tomada de decisão.

Contudo, os resultados alcançados indicam que a recomendação do gerente é responsável por $30 \%$ da decisão, sugerindo que os investidores são menos racionais que o prescrito pela teoria normativa, e preferem contar com a opinião de um especialista e, assim, evitar o desconforto proveniente de uma decisão complexa, como no caso de um investimento financeiro. (Alter et al., 2007; Kanhneman, 2011; Topolinski \& Strack, 2009; Slovic et al., 2004). Este resultado sugere, então, a não rejeição de $P_{1}$ e $P_{2}$.

Em relação à importância relativa dos demais atributos, rentabilidade e risco, atingiram pesos de $23 \%$ e $21 \%$, respectivamente. Já taxa de administração respondeu por $15 \%$ da preferência enquanto a liquidez atingiu $11 \%$. Os resultados implicam em não rejeição de $H_{l b}$. Abaixo o gráfico de pizza apresenta os valores calculados das importâncias relativas. 


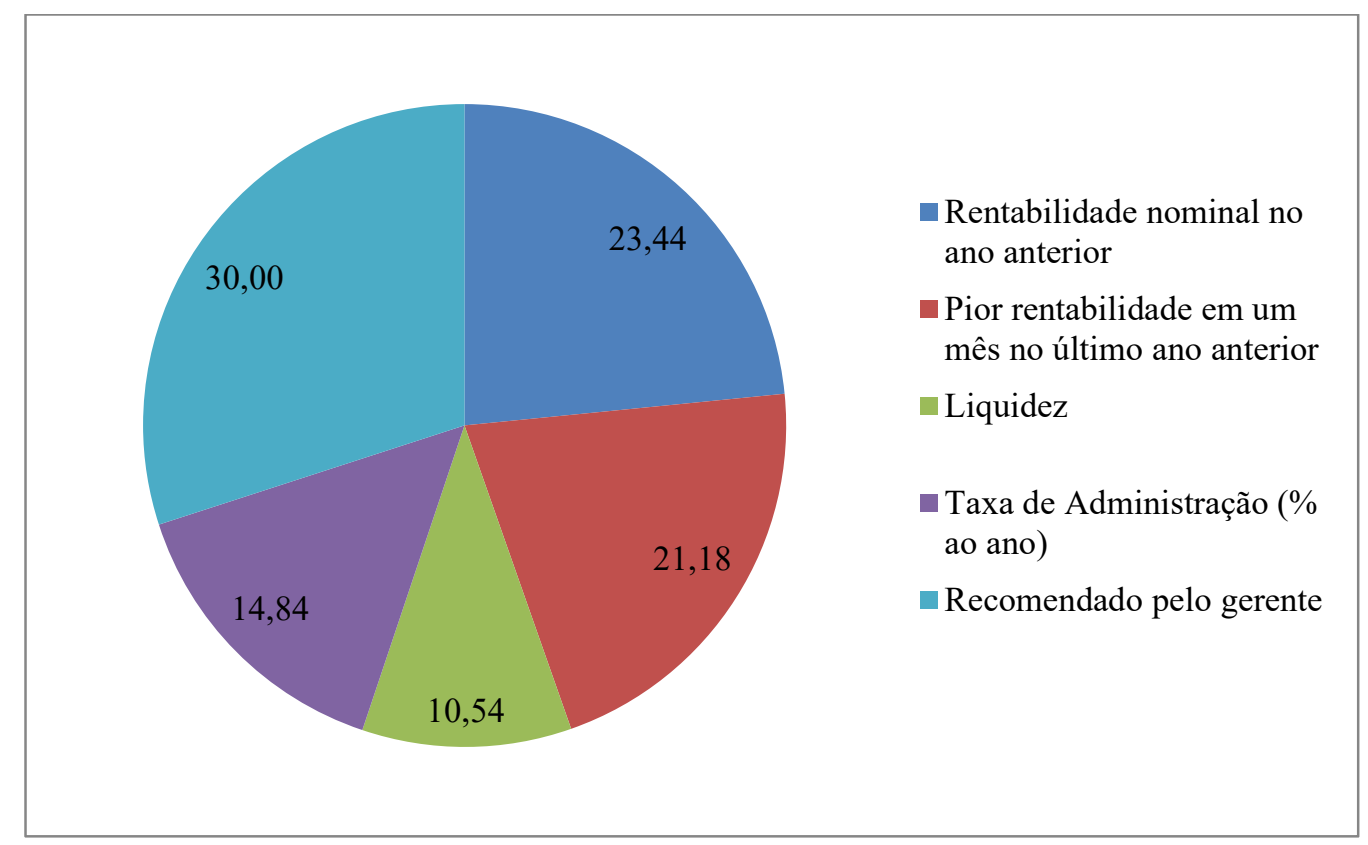

Gráfico 6.8 - Importância Relativa dos Fatores na Decisão

Diferente do que seria esperado pela EUT o binômio risco-retorno não assumiu a primazia entre os atributos julgados, fazendo rejeitar $H_{l C}$. Por outro lado, a importância relativa de $30 \%$ alcançada pela recomendação do gerente implica na rejeição de $H_{l d}$ e parece evidenciar que o paradigma da racionalidade não é suficiente para explicar a decisão do investidor.

A pesquisa da ANBIMA (2014a) apurou que os investidores esperam mais orientação e aconselhamento de seus gerentes mas que, apesar disto, estão satisfeitos com o nível de atendimento que vem recebendo. Estes resultados estão em linha com os da pesquisa também realizada pela ANBIMA (2014b) que apontam que os investidores esperam uma postura mais próxima ao aconselhamento e mais distante de uma postura eminentemente associada à resolução de problemas.

Este resultado desafia os preceitos da EUT segundo os quais as preferências deveriam ser formadas de forma racional em função das informações disponíveis e do julgamento autônomo de cada pessoa. Este resultado está mais ajustado às teorias consideradas descritivas - que experimentaram grande impulso a partir do advento da teoria do prospecto (Barberis, 2013; Kahneman \& Tversky, 1979; Tversky \& Kahneman, 1992) - cujos princípios advogam que fatores emocionais exercem influência significativa no processo de construção da preferência e decisão. 
A análise dos números de ocorrências corrobora os resultados em relação à preferência pela recomendação do gerente. Para 50,9\% este é o fator mais importante no momento de se decidir por uma opção de investimento. Em sintonia com as médias apuradas, a rentabilidade aparece como segundo fator mais relevante para 27,6\%. O gráfico 6.9, abaixo, apresenta os resultados para todos os atributos.

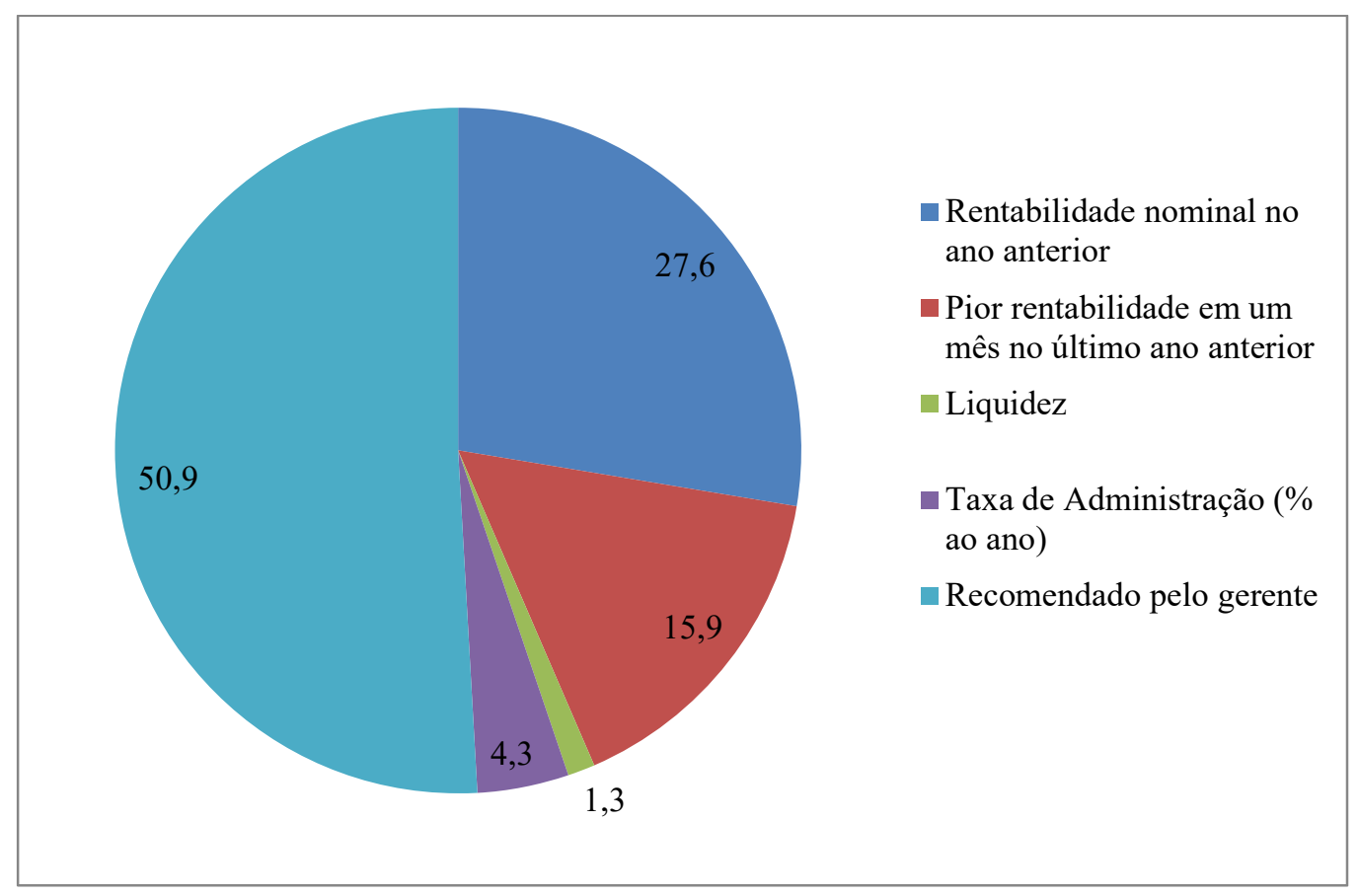

\section{Gráfico 6.9 - Fator mais Importante na Decisão (\% de respondentes)}

Segundo Oppenheimer e Kelso (2015) o indivíduo racional que calcula, avalia e decide está cedendo lugar para outro que toma suas decisões conforme processos cognitivos complexos que envolvem, entre outros, memória, atenção e percepção. Este processo se assemelha a juntar blocos e construir uma decisão. Os resultados apurados pela análise conjunta sugerem ser esta assertiva verdadeira quando se trata de decisões de investimento financeiro.

As decisões de investimento são complexas, envolvem o manuseio de uma série de informações e estão inerentemente associadas a uma percepção de risco, entendido como a possibilidade de sofrer perdas financeiras em relação ao capital investido, em relação às expectativas traçadas no momento ou em relação à evolução das cotações das opções concorrentes. Esta avaliação de risco não está baseada no entendimento do investidor sobre volatilidade ou cálculos financeiros, de outra forma ela é algo menos quantitativa, mais 
perceptual e intuitiva (Byrne, 2005; Estelami, 2012; Jordan \& Kaas, 2002; Loewenstein et al., 2001).

O julgamento sobre qual das alternativas deve ser a escolhida para investir seus recursos está envolto em muitas informações, mas os investidores, em geral, não sabem como usá-las e, portanto, acabam se valendo de heurísticas para simplificar o processo decisório mesmo que esta seja uma avaliação que leve a erros sistemáticos ou vieses (Jordan \& Kaas, 2002).

Ganzach (2000) encontrou evidências de que diante de alternativas de investimento desconhecidas do investidor, ele forma sua percepção de risco e retorno em função de uma atitude ou uma preferência geral expressa por uma relação afetiva de gostar (bom) ou não gostar (ruim) de cada alternativa. Desta forma, quando considera bom julga o risco como baixo e o retorno como alto.

O resultado obtido por Ganzach está em sintonia com os princípios da heurística do afeto, que advoga que as impressões afetivas são utilizadas para formar preferências e julgamentos de forma simples, sem esforço evitando assim avaliações complexas e tensão cognitiva decorrente (Slovic et al., 2002; Slovic \& Peters, 2006). Em estudo feito sobre a formação de preferência foram detectadas evidências de as pessoas, após serem apresentadas aos benefícios de determinada tecnologia, passaram a considerá-la positiva e, até, mudaram sua percepção sobre os riscos associados a ela (Finucane et al., 2000; Slovic et al., 2005). Neste caso, o afeto positivo cria a percepção de que benefícios altos correspondem a riscos baixos e riscos baixos a benefícios altos, enquanto o afeto negativo associa benefícios baixos a riscos altos e riscos altos a benefícios baixos. A heurística do afeto, assim como as demais, reduz a tensão emocional das decisões complexas ao tornar o processo decisório mais intuitivo (Finucane et al., 2000; Ganzach, 2000; Kahneman, 2011; Slovic, 1999; Slovic et al., 2002, 2004; Slovic \& Peters, 2006).

A discussão acima parece ajudar a entender a preferência pela recomendação do gerente. Investir é uma decisão em condições de incerteza, envolve o risco de perdas e é considerada complexa pela quantidade e natureza das informações que precisam ser avaliadas. Nesta situação, o que o resultado indica é que os investidores buscam em um profissional alguém que possa mitigar sua percepção de risco e/ou evitar a tensão emocional e o desconforto cognitivo desta decisão. Neste sentido, perceber no gerente alguém em que se possa confiar é 
essencial para se atingir este objetivo. Enxergar benevolência, competência e capacidade de resolver problema é crucial para que se crie a confiança. (Shainesh, 2012; Sirdeshmukh et al., 2002).

Vale lembrar a assertiva de Moorman et al. (1993) de que a confiança pode estar associada tanto a uma vontade de crer, acreditar em um parceiro que lhe transmita a sensação de confiabilidade ou simplesmente à necessidade de alguém que possa reduzir sua sensação de insegurança e vulnerabilidade, alguém em que possa se confiar e trazer conforto.

São analisados em seguida os resultados de liquidez e taxa de administração.

Sobre a liquidez, é de estranhar que em um país com histórico de inflação elevada, mudanças regulatórias frequentes e pouca persistência dos cenários econômicos, a liquidez responda, por apenas, $11 \%$ da decisão, percentual, inclusive, menor que o atribuído à taxa de administração, de $15 \%$. Talvez ajude a explicar o fato de os pesos serem relativos, posto que o acréscimo na participação de um fator se dá em detrimento de outro.

No caso da taxa de taxa de administração, durante apresentação dos conjuntos para escolha ela teve um nível de exposição acima do comum que talvez tenha ajudado a deprimir ainda mais a participação relativa da liquidez.

Nas seções seguintes serão abordados aspectos cobertos na revisão de literatura que influenciam na tomada de decisão do investidor, são eles:

- frame of decision,

- aversão a risco, incluindo questões sobre gênero e conhecimento, e

- estilos cognitivos.

\subsubsection{Avaliação de Cenários}

Entre os objetivos desta pesquisa encontra-se de testar o efeito de enquadramento (framing effects) na decisão dos investidores (Kahneman \& Tversky, 1983; Tversky \& Kahneman (1981, 1986). Para tanto, os respondentes foram apresentados a cenários econômicos distintos, um de viés negativo, outro de viés positivo e um terceiro grupo ao qual não foi apresentado qualquer cenário, funcionando como um grupo de controle. 
Para testar a eficácia da manipulação do cenário sobre a percepção dos respondentes, após a leitura do cenário e antes de responder ao questionário da análise conjunta, os respondentes tiveram de avaliar o cenário apresentado, classificando-o desde muito negativo até muito positivo (uma escala de cinco pontos).

Dos respondentes que avaliaram o cenário construído para exacerbar a percepção de risco, apenas $62 \%$ o consideraram negativo ao passo que o cenário que pretendia induzir a percepção de baixo risco foi assim entendido por somente $50 \%$ dos respondentes. A tabela 6.3 sumariza os resultados.

Tabela 6.3

Cenário X Avaliação

\begin{tabular}{l|r|r|r|r}
\hline Cenário $\backslash$ Avaliação & \multicolumn{1}{|c|}{ Neutro } & \multicolumn{1}{|c|}{ Negativa } & \multicolumn{1}{c}{ Positiva } & \multicolumn{1}{c}{ Total } \\
\hline Neutro & & & & 148 \\
\hline Negativo & $23,8 \%$ & $61,6 \%$ & $14,6 \%$ & 164 \\
\hline Positivo & $29,1 \%$ & $20,9 \%$ & $50,0 \%$ & 148 \\
\hline
\end{tabular}

O cenário negativo pretende exacerbar a percepção de risco e, assim, provocar uma das seguintes reações: aumentar a importância relativa do atributo rentabilidade, para compensar esta sensação de insegurança; ou elevar o peso atribuído ao risco, como forma de se evitar a possibilidade de perda, uma estratégia para buscar preservar o capital a ser investido.

O enquadramento para decisão altera a forma como se percebe os riscos envolvidos em uma decisão de investimento. Nesta situação, o ponto de referência a partir do qual a expectativa de ganhos ou de perdas das opções de investimento é avaliada é modificado. Quanto maior a percepção de risco maior será a expectativa de retorno cobrada (Byrne, 2005; Sitkin \& Weingart, 1995).

A despeito de o efeito de manipulação de cenários e de indução da percepção de risco ter sido efetivo apenas para pouco mais da metade da amostra submetida aos cenários, estes foram testados para o subgrupo para o qual os cenários lograram incutir sensação de maior ou menor risco. Ou seja, foram testados os efeitos de enquadramento apenas para aqueles respondentes que não foram excluídos no manipulation check. 
Para tanto, procedeu-se um teste ANOVA para as diferenças entre as médias de cada grupo, quais sejam, aqueles que avaliaram os cenários como negativo ou positivo em acordo com a intenção do mesmo (manipulation check).

Os resultados apontaram que para os atributos rentabilidade, risco, taxa de administração e recomendação do gerente não foram encontradas diferenças significativa entre as médias das importâncias relativas entre os grupos $(p<.05)$, levando a rejeição tanto de $H_{2 a}$ quanto de $H_{2 b}$. Adicionalmente, o fato de não terem sido verificadas diferenças significativas entre as médias implica que não terem ocorrido inversões de preferência e, portanto, $H_{2 c}$ e $H_{2 d}$ foram também rejeitadas.

Ou seja, aqueles que tomaram suas decisões a partir de um cenário futuro mais adverso e incerto não experimentaram alterações de utilidade significativas que resultassem em mudanças nas importâncias relativas atribuídas de cada um destes fatores em sua decisão. A tabela 6.4 sumariza estes resultados.

Tabela 6.4

Importâncias Relativas para Cenários Distintos

\begin{tabular}{l|rrr|r}
\hline & \multicolumn{3}{|c|}{ Cenário } & \\
\hline \multicolumn{1}{c|}{ Atributos $\backslash$ Pesos } & \multicolumn{1}{|c|}{ Neutro } & Negativo & Positivo & \multicolumn{1}{c}{ Sig. } \\
\hline Rentabilidade & 23,12 & 23,99 & 24,69 & $\mathrm{p}=.55$ \\
Risco & 20,72 & 22,35 & 20,71 & $\mathrm{p}=.29$ \\
Liquidez & 10,38 & 8,69 & 10,95 & $\mathrm{p}=.02$ \\
Taxa de Adm. & 14,80 & 13,56 & 13,78 & $\mathrm{p}=.27$ \\
Recomendação & 30,98 & 31,42 & 29,88 & $\mathrm{p}=.73$ \\
\hline
\end{tabular}

Estes resultados podem ser explicados por características inerentes desta pesquisa e da decisão de investimento.

Esta pesquisa busca simular uma decisão real de investimento. Os respondentes foram submetidos a um amplo conjunto de alternativas de investimento e tiveram de tomar uma série de decisões em sequência tal como um processo real de seleção entre as várias alternativas de investimento disponíveis em nosso dia-a-dia. Para o sucesso destes estímulos 
era fundamental manter o vínculo com a realidade e, para tanto, não foi possível manipular os níveis de forma arbitrária. Este procedimento criaria um cenário irreal que, se por um lado poderia exacerbar a percepção de risco dos respondentes, por outro poderia comprometer a efetividade dos estímulos e por consequência da própria pesquisa. Decisões de investimentos não são decisões sobre jogos, manter o realismo dos estímulos é essencial para que se possa criar tradeoffs críveis.

Outra possível explicação para esta ausência de diferenciação entre os cenários encontra relação com fenômeno denominado de escalation commitment (Lunenburg, 2010; Staw, 1976, 1981; Steinkühler, Mahlendorf, \& Brettel, 2014) em que as decisões de investimento são vistas como uma sequência contínua, orientada por objetivos de longo prazo em que os reveses incorridos podem ser compensados por novos investimentos que busquem compensar as perdas.

Considerando que os cenários não lograram induzir diferenças de comportamento entre os grupos pesquisados, as análises e testes a seguir foram realizados sobre a totalidade da amostra, ou seja, sobre todas as quatrocentas e sessenta observações.

\subsubsection{Aversão ao Risco}

De acordo com Damodaran (2009) as pessoas avessas ao risco rejeitam uma aposta em que o valor esperado é igual ao equivalente certo, sem risco. Neste sentido, quanto mais avessa maior deve ser o resultado esperado da aposta ou o prêmio de risco, diferença entre o valor esperado da aposta e o equivalente certo. O risco é considerado uma situação especial de incerteza em que as probabilidades de cada resultado são conhecidas.

Contudo, em decisões de investimento as probabilidades de que os preços dos ativos no futuro atinjam determinado valor são desconhecidas. Por meio de métodos estatísticos os profissionais do mercado financeiro se valem de séries históricas e tentam estimar estas chances, mas, de fato, os resultados não passam de conjecturas. Em particular, esta pesquisa trata de investidores não profissionais que tomam suas próprias decisões e dificilmente tem acesso a estas estimativas. Portanto, seu julgamento se dá em condições de incerteza ou ambiguidade, o que tende a exacerbar a percepção de risco (Trautmann et al., 2011). 
Para completar, segundo Sitkin e Weingart (1995) a tolerância ao risco é inversamente relacionada com a percepção de risco, ou seja, quanto maior a tolerância menor a percepção de risco provocada por determinada situação.

A aversão ao risco fez parte do questionário de pesquisa, na amostra coletada apenas dezoito pessoas se declararam com baixa aversão ao risco, o que impediu a execução de testes estatísticos e determinou a junção deste grupo ao que se considera de média aversão. Desta forma, os grupos se definiram com 107 respondentes que se declararam de alta aversão (23\%) e 353 de média ou baixa aversão (77\%).

No caso desta pesquisa, as rentabilidades negativas emulam a possibilidade de perda e devem amplificar a percepção de risco. Considerando que esta percepção é mais intensa para os mais avessos, o resultado esperado é que estes exijam taxas de remuneração mais elevadas como forma de compensação pelo risco percebido (Sitkin e Weingart, 1995). Assim como os equivalentes certos, considerando o investimento como uma aposta, as perdas passadas funcionam como menores chances de ganho exigindo valores maiores que possam superar os equivalentes certos. De forma análoga, é possível, também, que diante de taxas de retorno pré-determinadas os investidores prefiram alternativas que embutam menor nível de risco.

As análises a seguir estão baseadas em dois grandes grupos de hipóteses, a saber: o primeiro que pressupõe que as pessoas mais avessas buscam atingir, mesmo que intuitivamente, uma relação risco e retorno que compense sua maior percepção de risco, e, o segundo, para o qual o risco se traduz em sentimento, algo eminentemente emocional e afetivo. As hipóteses grupo são baseadas no frame de Stikin e Pablo (1995) e em Damodaran (2009), enquanto as do segundo grupo nos pilares da heurística do afeto (Finucane et al., 2000; Loewenstein et al., 2001; Slovic et al., 2002, 2004; Slovic \& Peters, 2006).

A comparação das médias entre os grupos de maior e menor aversão apontou que o grupo mais avesso registrou diferença não significativa em relação à variação dos níveis tanto da rentabilidade quanto do risco $(p<.05)$, denotando a rejeição de $H_{3 a}$ e $H_{3 b}$. Já a recomendação do gerente registrou nível de significância de $\mathrm{p}=.014$ sendo considerada significativa e, portanto, indicando a não rejeição de $H_{3 e}$. 
Considerando que os níveis de possibilidade de perda e rentabilidade são iguais para todos os respondentes, mais e menos avessos, e que os primeiros esperam auferir taxas de retorno mais elevadas para dado risco, o resultado esperado deste teste, seria que estes percebessem menor ganho de utilidade. Contudo, o resultado é o oposto disto com acréscimo de 80 pontos de utilidade para mais avessos contra 62 para menos avessos. O que deveria sugerir a não rejeição de $H_{3 a}$.

Sendo assim, por conta do pressuposto dos equivalentes certos (Damodran, 2009), os mais avessos deveriam exigir prêmios de risco mais elevados para mesmo nível de risco, portanto, diante de uma mesma taxa de retorno os mais avessos deveriam extrair menor utilidade o que faria com que rejeitassem um jogo justo. De outra forma, não existiria motivo para se pagar taxas de juros maiores para pessoas mais propensas ao risco.

Já para a recomendação do gerente, o ganho de utilidade alcançado é significativamente maior para o grupo considerado mais avesso, acusando 102 pontos de ganho contra 80 dos menos avessos, sugerindo a não rejeição de $H_{3 e}(p<.05)$. A tabela 6.5 apresenta os resultados por nível de aversão ao risco.

Tabela 6.5

Variação da Utilidade

Aversão ao Risco

\begin{tabular}{c|l|r|r|r|c}
\hline Variação de Utilidade & \multicolumn{1}{|c|}{ Aversão } & Média & \multicolumn{1}{c}{ Desvio } & \multicolumn{1}{c}{ F } & Sig \\
\hline \multirow{2}{*}{ Rentabilidade } & Alta & 80,2 & 72,6 & & \\
& Média/Baixa & 61,4 & 94,1 & 3,626 & $\mathrm{p}=.058$ \\
\hline \multirow{2}{*}{ Risco } & Alta & $-72,1$ & 73,7 & & \\
& Média/Baixa & $-55,7$ & 77,2 & 3,798 & $\mathrm{p}=.052$ \\
\hline \multirow{2}{*}{ Liquidez } & Alta & $-12,2$ & 42,1 & & \\
& Média/Baixa & $-16,6$ & 48,5 & 0,727 & $\mathrm{p}=.394$ \\
\hline \multirow{2}{*}{ Taxa de Administração } & Alta & $-19,4$ & 45,4 & & \\
& Média/Baixa & $-18,9$ & 48,2 & 0,008 & $\mathrm{p}=.928$ \\
\hline \multirow{2}{*}{ Gerente } & Alta & 102,0 & 76,9 & & \\
& Média/Baixa & 79,9 & 82,9 & 6,061 & $\mathrm{p}=.014$ \\
\hline
\end{tabular}

Corroborando os resultados acima não foi encontrada diferença significativa entre os pesos médios dos atributos rentabilidade e risco para mais e menos avessos, indicando a rejeição das hipóteses $H_{3 c}$ e $H_{3 d}(\mathrm{p}<.05)$. Por outro lado, a hipótese $H_{3 f}$ não foi rejeitada $(\mathrm{p}<.05)$ sugerindo 
que a recomendação do gerente tem peso maior para os mais avessos, conforme evidenciado na tabela 6.6.

Tabela 6.6

Importância Relativa dos Atributos na Decisão Aversão ao Risco

\begin{tabular}{c|l|r|r|c|c}
\hline \multicolumn{7}{c}{ Aversão ao Risco } \\
\hline \multirow{2}{*}{ Pesos } & \multicolumn{1}{|c|}{ Aversão } & Média & Desvio & \multicolumn{1}{c|}{$\mathrm{F}$} & Sig \\
\hline \multirow{2}{*}{ Rentabilidade } & Alta & 22,8 & 8,8 & & \\
& Média/Baixa & 23,6 & 10,3 & 0,581 & $\mathrm{p}=.446$ \\
\hline \multirow{2}{*}{ Risco } & Alta & 21,6 & 9,3 & & \\
& Média/Baixa & 21,0 & 8,1 & 0,413 & $\mathrm{p}=.521$ \\
\hline \multirow{2}{*}{ Liquidez } & Alta & 9,5 & 5,4 & & \\
& Média/Baixa & 10,9 & 6,4 & 3,976 & $\mathrm{p}=.047$ \\
\hline \multirow{2}{*}{ Taxa de Administração } & Alta & 13,9 & 5,8 & & \\
& Média/Baixa & 15,1 & 6,8 & 2,617 & $\mathrm{p}=.106$ \\
\hline \multirow{2}{*}{ Gerente } & Alta & 32,1 & 12,5 & & \\
& Média/Baixa & 29,4 & 12,6 & 3,985 & $\mathrm{p}=.046$ \\
\hline
\end{tabular}

Estes resultados sugerem que os mais avessos percebem o risco como uma dimensão mais emocional que não se pode compensar pela relação de risco e retorno. Neste sentido, poder contar com um profissional parece ser o mais relevante para mitigar a percepção de risco e evitar o desconforto da decisão (Loewenstein et al., 2001; Sirdeshmukh et al., 2002; Slovic et al., 2002, 2004; Slovic \& Peters, 2006).

Os estudos sobre aversão ao risco por vezes enfocam a questão das diferenças de gênero e a influência do nível de conhecimento na percepção de risco. Estes dois aspectos são tratados nas duas próximas seções.

\subsubsection{A Questão do Gênero}

Existe razoável convergência na literatura sobre serem as mulheres mais avessas que os homens em relação ao risco (Charness \& Gneezy, 2012; Dwyer, Gilkenson \& List, 2002; Powell \& Ansic, 1997). Estes estudos indicam que elas têm uma atitude menos propensa ao risco e que, portanto, enxergam maior risco na decisão.

Incialmente rodou-se um teste Qui-quadrado, $\chi^{2}$, para se verificar se havia correspondência entre a visão que as mulheres têm sobre seu nível de aversão ao risco e as evidências 
encontradas na literatura. $\mathrm{O}$ resultado deste teste identificou que entre as mulheres $28 \%$ se consideram altamente avessas enquanto entre os homens este percentual alcança apenas 16\% $(p<.01)$ indicando, assim, que as mulheres realmente se percebem mais avessa ao risco que os homens. Assim, a hipótese $H_{4 a}$ foi considerada como não rejeitada.

Se de fato as mulheres forem mais avessas ao risco do que os homens, seria esperado que atribuíssem maior peso ao fator risco. Por outro lado, como visto acima, a recomendação do gerente parece ser um fator fundamental para a tomada de decisão dos mais avessos. Sendo assim, foram efetuados testes de diferença de médias, ANOVA, para verificar se existem diferenças estatisticamente significativas entre estes grupos.

Em relação à rentabilidade, de fato mulheres parecem estar menos interessadas nos retornos do que os homens. Para elas o peso da rentabilidade na decisão é de $22,3 \%$ contra $25,1 \%$ atribuídos pelos homens $(p<.01)$. Em relação ao risco, os resultados não sugerem ser a decisão das mulheres mais influenciada por este fator que a dos homens, ao contrário, enquanto para elas a importância relativa atinge 20,3\% para eles o risco alcança 22,5\%. Desta forma, $H_{4 b}$ não foi rejeitada enquanto $H_{4 c}$ foi rejeitada.

Sobre a importância do gerente na decisão, o teste ANOVA comprovou que as mulheres atribuem, em média, ao gerente $32,7 \%$ de sua decisão contra $26,1 \%$ atribuídos pelos homens ( $p<.001)$, implicando em não rejeição de $H_{4 d}$. A tabela 6.7 apresenta os resultados.

Tabelas 6.7

Importância Relativa dos Atributos na Decisão Gênero

\begin{tabular}{c|l|r|r|r|r}
\hline Pesos & Aversão & Média & Desvio & \multicolumn{1}{c|}{$\mathrm{F}$} & Sig \\
\hline \multirow{2}{*}{ Rentabilidade } & Feminino & 22,3 & 9,0 & & \\
& Masculino & 25,1 & 11,0 & 8,677 & $\mathrm{p}=.003$ \\
\hline \multirow{2}{*}{ Risco } & Feminino & 20,3 & 7,5 & & \\
& Masculino & 22,5 & 9,3 & 7,655 & $\mathrm{p}=.006$ \\
\hline \multirow{2}{*}{ Liquidez } & Feminino & 9,9 & 6,0 & & \\
& Masculino & 11,5 & 6,3 & 7,640 & $\mathrm{p}=.006$ \\
\hline \multirow{2}{*}{ Taxa de Administração } & Feminino & 14,8 & 7,0 & & \\
& Masculino & 14,9 & 6,0 & 0,050 & $\mathrm{p}=.823$ \\
\hline \multirow{2}{*}{ Gerente } & Feminino & 32,7 & 12,6 & & \\
& Masculino & 26,1 & 11,6 & 33,332 & $\mathrm{p}<.000$ \\
\hline
\end{tabular}


Embora não seja o foco desta seção, vale mencionar a comparação feita por Frederick (2005) entre gênero e estilo de processamento de informação intuitivo. Neste artigo foram comparados os percentuais de erros decorrentes do impulso pela resposta intuitiva e detectouse que a proporção de mulheres nesta situação era significativamente superior à de homens. Neste sentido, um teste qui-quadrado foi aplicado sobre a mostra e chegou-se a resultado semelhante, entre as mulheres $27 \%$ compõem o grupo intuitivo contra proporção de $18,5 \%$ encontrada entre os homens $(p<.05)$.

Tabela 6.8

Gênero X Intuição

\begin{tabular}{c|r|r|r|r}
\hline \multirow{2}{*}{ Gênero } & \multicolumn{2}{|c|}{ Intuitivos } & $\begin{array}{c}\text { Qui } \\
\text { Quadrado }\end{array}$ & Sig \\
\cline { 2 - 5 } & \multicolumn{1}{|c|}{ Menos } & \multicolumn{1}{c}{ Mais } & & \\
\hline Feminino & $73,4 \%$ & $26,6 \%$ & & \\
Masculino & $81,5 \%$ & $18,5 \%$ & 4,042 & $\mathrm{p}=.044$ \\
\hline
\end{tabular}

\subsubsection{Conhecimento}

O nível de conhecimento reduz a incerteza e atenua a percepção de risco. Quanto maior o nível de conhecimento sobre um objeto melhor devem ser as condições de julgamento e maior o conforto para a decisão. Independente do nível de conhecimento, contudo, todos se utilizam, em menor ou maior grau, de heurísticas para decisão, e estão suscetíveis aos fatores emocionais, ao momento e ao ambiente de cada decisão (Dolvin \& Templeton, 2006; Fellner \& Maciejovsky, 2007; Ganzach, 2000; Hathaway \& Khatiwada, 2008; Mandell \& Klein, 2009).

Considerando que o nível de proficiência em produtos financeiros é declaratório (uma informação sobre como a pessoa se percebe) e não tendo como verificar qual de fato é o seu grau de conhecimento, o interesse aqui repousa, apenas, em verificar como a percepção sobre seu nível de conhecimento pode afetar a percepção sobre o grau de aversão ao risco. 
Tabela 6.9

Aversão ao Risco X Conhecimento

\begin{tabular}{c|r|r|r|c}
\hline \multirow{2}{*}{$\begin{array}{c}\text { Conhecimento } \\
\text { Aversão }\end{array}$} & \multicolumn{2}{|c|}{ Aversão } & $\begin{array}{c}\text { Qui- } \\
\text { Quadrado }\end{array}$ & Sig \\
\cline { 2 - 5 } & Alta & $\begin{array}{l}\text { Baixa/ } \\
\text { Média }\end{array}$ & & \\
\hline Alto & $33,3 \%$ & $66,7 \%$ & & \\
Baixo & $38,8 \%$ & $61,2 \%$ & & \\
Médio & $16,5 \%$ & $83,5 \%$ & 23,380 & $\mathrm{p}<.000$ \\
\hline
\end{tabular}

O teste do $\chi^{2}$ indica que existe diferença significativa na maneira como os grupos formados a partir da própria percepção sobre nível de conhecimento se percebem em relação ao risco. Contudo, a despeito da diferença ser significativa, não parece haver correspondência entre nível de conhecimento auto declarado e aversão ao risco, pois o menor grau de aversão foi encontrado entre aqueles que se consideram dotados de conhecimentos médios, apenas 16,5\% se percebem altamente avessos. Enquanto isso, 33,3\% daqueles que se julgam bons conhecedores sobre produtos financeiros de investimento se percebem altamente avessos ao risco contra 38,8\% dos que se julgam menos aptos com investimentos. Estes resultados levam à conclusão de que pessoas que se consideram dotadas de maior conhecimento sobre produtos de investimento não parecem, de fato, se perceberem como menos avessa ao risco, sugerindo a rejeição de $H_{5 a}$.

Em relação ao teste de médias dos pesos dos atributos risco e recomendação do gerente, ambas as hipóteses, $H_{5 b}$ e $H_{5 c}$, foram rejeitadas ( $\left.\mathrm{p}<.05\right)$. Neste caso, os resultados sugerem que pessoas que se veem como portadoras de maior conhecimento sobre investimentos financeiros conferem a mesma importância para o risco e para a recomendação do gerente que as menos letradas.

\subsubsection{Resposta Intuitiva}

Como já dito, esta pesquisa tem interesse especial na relação entre o modo de processamento de informações predominantemente definido pelo Sistema 1, ou processamento Tipo 1, processo cognitivo mais emocional, automático e intuitivo que responde mais rapidamente com as informações que se encontram mais próximas ou disponíveis - e a decisão de investimento. Para tanto, os respondentes foram agrupados entre aqueles com modo de 
processamento mais intuitivo e aqueles cujo processamento é menos intuitivo e, portanto, mais próximo do Tipo 2, em que as informações são analisadas com maior esforço e de forma mais lógica e racional.

Considerando que o Sistema 1 é rápido, não orientado ao esforço e frequentemente dominado pela emoção (Evans \& Stanovich, 2013; Kahneman, 2003) as pessoas mais intuitivas devem estar mais propensas a reagir emocionalmente aos problemas do dia-a-dia. Devem buscar respostas em outros fatores que não os cálculos das probabilidades de risco e retorno. Devem tentar solucionar o problema de forma mais intuitiva e confortável e, assim, evitar acionar o Sistema 2. Para Evans e Stanovich (2013) os Tipos 1 e 2 não são modos distintos de processamento de informação, são apenas instâncias de processamento que se dão em um continuum. Para os autores o Tipo 1 é caracterizado pela autonomia, ele é ativo, não requer atenção controlada, é rápido e inicia seu processo assim que se depara com o estímulo e não requer muito da memória.

Os julgamentos processados pelo Sistema 1 são automáticos, associativos, rápidos, inconscientes, sem esforço e heurístico enquanto o Sistema 2 processa de forma baseado em regras formais, lento, consciente, esforçado, analítico e racional. O Sistema 1 é mais perceptual, visual é mais intuitivo e dominado pela emoção (Böhm \& Brun, 2008; Kruglanski \& Gigerenzer, 2011).

Estudos mostram que tríades de palavras mais coerentes e imagens mais nítidas afetam a forma como a informação é processada. Elas trazem conforto e são processadas intuitivamente. Por outro lado, a forma de processamento também pode ser afetada pelo humor, que quando está bom tende a julgar a situação mais positivamente. (Alter et al., 2007; Bolte et al., 2003; Topolinski \& Strack, 2009).

Desta forma, pessoas mais intuitivas fazem julgamentos mais emocionais, preferem evitar cálculos e preferem não enfrentar situações incoerentes. Julgam os problemas de forma mais afetiva e se valem mais de heurísticas. Para elas risco é uma sensação (Slovic et al. 2002; 2004). 
Conforme já verificado na seção que trata dos pesos atribuídos aos fatores no momento da decisão de investimento, estas características parecem afastar os julgamentos do campo racional, dos cálculos de risco e retorno, e parecem aproximar as pessoas da opinião do gerente que estaria cumprindo a função de tornar a informação mais fluente e fácil de ser processada.

Para classificar as pessoas entre mais e menos intuitivas foi utilizado o teste CRT de Frederick (2005). Contudo, de forma distinta da utilizada pelo autor, que estudou o efeito do pensamento mais analítico ou reflexivo nas decisões em situações de risco, neste caso a escala CRT foi utilizada para categorizar os mais intuitivos (Sistema 1 ou processamento Tipo 1) e, assim, permitir a observação das diferenças de comportamento em relação aos menos intuitivos. Desta forma, foram considerados mais intuitivos aqueles que não resistiram à resposta automática nas três perguntas formuladas do teste. Este grupo conta com cento e sete pessoas, ou $23 \%$ da amostra.

Os resultados da ANOVA realizada para comparar os ganhos e perdas de utilidade resultantes das variações dos níveis dos fatores rentabilidade, risco e recomendação do gerente indicam ser este o único para o qual existe diferença significativa entre as médias.

Sendo assim, as hipóteses $H_{6 e}$ foi rejeitada $(p<.01)$ indicando haver diferença significativa na recomendação do gerente que se elevou em 108 pontos para os mais intuitivos contra 78 pontos para os demais. Já as hipóteses $H_{6 a}$ e $H_{6 b}$ não foram rejeitadas ( $\left.p>.05\right)$ indicando não haver diferenças para o incremento de utilidade da rentabilidade e para o decremento acusado pelo risco. 
Tabela 6.10

Variação da Utilidade

Estilo Cognitivo

\begin{tabular}{c|l|r|r|r|c}
\hline Variação de Utilidade & Intuitivos & Média & Desvio & $\mathrm{F}$ & Sig \\
\hline \multirow{2}{*}{ Rentabilidade } & Menos & 67,0 & 93,1 & & \\
& Mais & 61,6 & 78,4 & 0,299 & $\mathrm{p}=.585$ \\
\hline \multirow{2}{*}{ Risco } & Menos & $-56,2$ & 78,8 & & \\
& Mais & $-70,5$ & 68,3 & 2,894 & $\mathrm{p}=.090$ \\
\hline \multirow{2}{*}{ Liquidez } & Menos & $-14,9$ & 48,0 & & \\
& Mais & $-17,7$ & 44,2 & 0,296 & $\mathrm{p}=.587$ \\
\hline Taxa de & Menos & $-16,6$ & 46,7 & & \\
Administração & Mais & $-27,3$ & 49,5 & 4,207 & $\mathrm{p}=.41$ \\
\hline \multirow{2}{*}{ Gerente } & Menos & 78,1 & 81,6 & & \\
& Mais & 107,8 & 79,3 & 11,015 & $\mathrm{p}=.001$ \\
\hline
\end{tabular}

A partir destes resultados, foi testada a existência de diferenças entre as importâncias relativas destes fatores na decisão para os grupos formados por menos e mais intuitivos.

Neste caso, a hipótese $H_{6 f}$ foi rejeitada $(p<.01)$, indicando que a importância atribuída pelos mais intuitivos à recomendação do gerente é significativamente maior para estes do que para o grupo menos intuitivo, $33,6 \%$ e $28,9 \%$ respectivamente.

Em linha com os resultados até aqui apurados, quando se observa o peso do fator rentabilidade na decisão, os mais intuitivos atribuem a ela uma importância menor que os mais intuitivos, $20,7 \%$ contra 24,3\%, respectivamente. Estes valores indicam que, em comparação aos menos intuitivos, os mais intuitivos consideram a rentabilidade menos importante. A despeito de haver diferença significativa $(p<.01)$, o que implica na rejeição de $H_{6 c}$, o resultado sugere que os mais intuitivos conferem menos peso à rentabilidade. Os resultados sugerem, ainda, que o grupo menos intuitivo tende a buscar na rentabilidade uma forma de compensação pelos riscos incorridos na aplicação de seus recursos, comportamento não verificado entre os mais intuitivos.

Já para o fator risco, não foi identificada diferença significativa entre as médias $(p>.05)$, levando a não rejeição de $H_{6 d}$. A tabela 6.11 apresenta os resultados. 
Tabela 6.11

Importância Relativa dos Atributos na Decisão

Estilo Cognitivo

\begin{tabular}{c|l|r|r|c|c}
\hline Pesos & Intuitivos & \multicolumn{1}{c|}{ Média } & Desvio & \multicolumn{1}{c|}{$\mathrm{F}$} & Sig \\
\hline \multirow{2}{*}{ Rentabilidade } & Menos & 24,3 & 10,2 & & \\
& Mais & 20,7 & 8,4 & 10,825 & $\mathrm{p}=.001$ \\
\hline \multirow{2}{*}{ Risco } & Menos & 21,3 & 8,4 & & \\
& Mais & 20,6 & 8,4 & 0,595 & $\mathrm{p}=.441$ \\
\hline \multirow{2}{*}{ Liquidez } & Menos & 10,7 & 6,3 & & \\
& Mais & 10,2 & 5,6 & 0,487 & $\mathrm{p}=.486$ \\
\hline Taxa de & Menos & 14,8 & 6,6 & & \\
Administração & Mais & 14,9 & 6,6 & 0,033 & $\mathrm{p}=.857$ \\
\hline \multirow{2}{*}{ Gerente } & Menos & 28,9 & 12,6 & & \\
& Mais & 33,6 & 12,0 & 11,292 & $\mathrm{p}=.001$ \\
\hline
\end{tabular}

Os resultados desta seção indicam que os mais intuitivos, tem sua satisfação mais dependente da recomendação do gerente e parecem encontrar neste o conforto cognitivo e emocional para tomar sua decisão de investimento. Ao invés de buscar compensação na possibilidade de ganhos futuros ou mesmo evitar apostas mais arriscadas, de forma a minimizar perdas, estes preferem confiar na recomendação do gerente para evitar não apenas a tensão e desconforto cognitivo da decisão como a dor da perda. Desta forma, a proposição $P_{3}$ não foi rejeitada.

Considerando que os mais intuitivos possuem o Sistema 1 mais aguçado e que este é perceptual, automático e emocional, estes resultados parecem corroborar a não rejeição da proposição $P_{2}$, que advoga serem os fatores emocionais relevantes para a decisão de investimento.

A comparação entre os resultados apurados para os atributos rentabilidade e recomendação do gerente, contudo, indicam ser esta última o fator mais importante para a tomada de decisão tanto dos mais quanto dos menos intuitivos, respondendo, cada um, por 33,6\% e 28,9\%, respectivamente. Cotejando tais resultados, depreende-se que os mais intuitivos buscam encontrar no gerente alguém que possa criar a sensação de maior conforto para uma decisão naturalmente complexa e que causa tensão. Sendo assim, é possível identificar, mais uma vez, que fatores emocionais são relevantes para o processo decisório do investidor, ratificando a proposição $P_{2}$. 
O fato de os investidores menos intuitivos, em média, atribuírem peso maior aos resultados de rentabilidade, parece reforçar, a ideia de que a possibilidade de minimização das perdas ou de elevação dos ganhos pode funcionar como um atenuante da sensação de risco, uma forma de compensação pelo risco incorrido ao se investir em algo incerto. Os menos intuitivos parecem mais propensos a cálculos e a buscar equivalentes certos mais adequados à sua atitude frente ao risco (Damodaran, 2009).

Em suma, mediante uma decisão complexa e que envolve a avaliação de muitas informações, os mais intuitivos parecem atribuir peso maior aquelas mais simples, ou para aquelas para as quais tenham um sentimento afetivo positivo. $\mathrm{O}$ afeto e o uso das heurísticas reduzem o esforço cognitivo. Os próprios estados de humor afetam o julgamento positiva ou negativamente conforme esteja bom ou ruim, respectivamente. Para estas pessoas a percepção de risco é um sentimento envolto em emoção. Por exemplo, Jordan e Kaas (2002) identificaram evidências de que anúncios de fundos de investimento com conteúdo emotivo, tais como imagens e tonalidades, consideradas positivas, provocaram uma redução na percepção de risco (Alter et al., 2007; Bolt et al., 2003; Loewenstein et al., 2001; Shah \& Oppenheimer, 2007; Slovic, 1999; Slovic et al., 2002, 2004).

\subsubsection{Avessos e Intuitivos}

Os resultados apurados até aqui para as importâncias relativas do atributo recomendação do gerente na decisão do investidor seguem no mesmo sentido e podem levantar a suspeita de que haja alta sobreposição entre estes grupos ou que de haja interação entre os efeitos de aversão e intuição.

Para tanto, inicialmente rodou-se um teste Qui-quadrado, $\chi^{2}$, para medir se existe independência entre os grupos e então uma ANOVA de dois fatores, intuição e aversão.

Tanto o grupo considerado de alta aversão quanto o de intuitivos contam, cada um, com cento e sete respondentes, destes apenas vinte e seis são comuns, ou seja, apenas $24 \%$ de sobreposição. Para identificar se esta relação entre os grupos denotados por intuição e aversão ao risco, um teste qui-qudrado foi executado para verificar se existe diferença significativa 
entre estes grupos. $\mathrm{O}$ valor $\chi^{2}$, de 0,084 equivale a $\mathrm{p}=.772$, implicando na conclusão de que não há relação entre os respondentes que se declaram avessos ao risco e os mais intuitivos.

Apesar da baixa sobreposição existente entre os grupos intuitivos e de alta aversão ao risco, perdura a dúvida sobre se há alguma possível dependência entre os efeitos das categorias intuição e aversão. Para esclarecer esta relação, é necessário isolar os efeitos das categorias aversão ao risco e da forma de processamento da informação.

A ANOVA de dois fatores é utilizada para medir a diferença nos valores médios da variável dependente métrica associados aos efeitos das variáveis independentes categóricas e permite identificar os efeitos de interação entre as categorias (Malhotra, 2012).

O gráfico 6.10 apresenta as médias da importância da recomendação do gerente para as variáveis denominadas intuição e aversão ao risco de forma isolada. Ratificando os resultados anteriores, mais intuitivos e mais avessos são claramente mais propensos à recomendação do gerente.

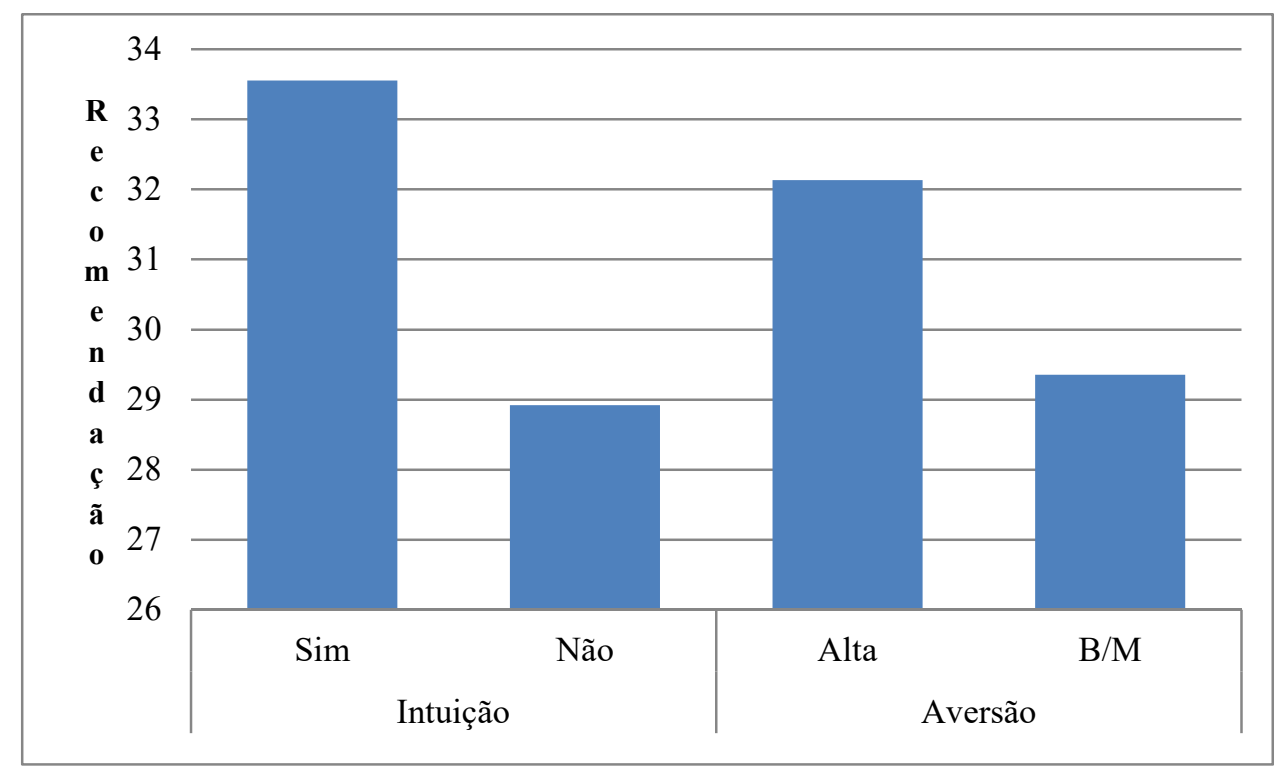

Gráfico 6.10 - Efeitos Isolados das Variáveis Intuição e Aversão

Os resultados da ANOVA indicaram que o efeito da interação não é significativo ao nível de $p<.05(F=0,673, \mathrm{p}=.412)$. Como o efeito de interação não é significativo, considera-se que os dois fatores podem exercer efeitos de forma independente. 
Sendo assim, intuição e aversão, ambos os fatores, exercem efeitos significativos e de forma independente sobre a importância relativa da recomendação do gerente. Desse modo, os efeitos de intuição e aversão são significativos na decisão do investidor, com $p<.01$ e $p<.05$, respectivamente, levando a não rejeição da hipótese $H_{7}$. O eta parcial quadrado indica a intensidade da variação da recomendação do gerente em função das variáveis, neste caso o processo cognitivo (intuição) exerce mais que o dobro de influência na decisão do investidor que a aversão ao risco. A tabela 6.12 sumariza os resultados.

Tabela 6.12

Estilo Cognitivo X Aversão ao Risco

\begin{tabular}{l|r|r|r|r|r|r}
\hline & \multicolumn{1}{c|}{$\begin{array}{c}\text { Soma dos } \\
\text { Quadrados }\end{array}$} & gl & \multicolumn{1}{c|}{$\begin{array}{c}\text { Média dos } \\
\text { Quadrados }\end{array}$} & \multicolumn{1}{c|}{ F } & \multicolumn{1}{c}{ Sig. } & \multicolumn{1}{c}{$\begin{array}{c}\text { Eta Parcial } \\
\text { Quadrado }\end{array}$} \\
\hline Montes de Variação & $416501,826^{\mathrm{a}}$ & 4 & 104125,457 & 670,058 & $\mathrm{p}<.000$ & 0,855 \\
Intuição & 1673,121 & 1 & 1673,121 & 10,767 & $\mathrm{p}=.001$ & 0,023 \\
Aversão & 692,549 & 1 & 692,549 & 4,457 & $\mathrm{p}=.035$ & 0,010 \\
Interação & 104,617 & 1 & 104,617 & 0,673 & $\mathrm{p}=.412$ & 0,001 \\
Erro & 70861,356 & 456 & 155,398 & & & \\
\hline Total & 487363,182 & 460 & & & & \\
\hline
\end{tabular}

a. $\mathrm{R}^{2}=0,855\left(\mathrm{R}^{2}\right.$ ajustado $\left.=0,853\right)$

O gráfico 6.11, abaixo, exibe retas paralelas sugerindo não haver interação entre as variáveis intuição e aversão ao risco. A leve inclinação encontrada para avessos quando mais intuitivos indica que estes podem ser ainda mais suscetíveis à recomendação do gerente. Contudo, esta magnitude do deslocamento do peso médio da recomendação do gerente é estatisticamente não significativa podendo, neste caso, ser decorrente do acaso. 


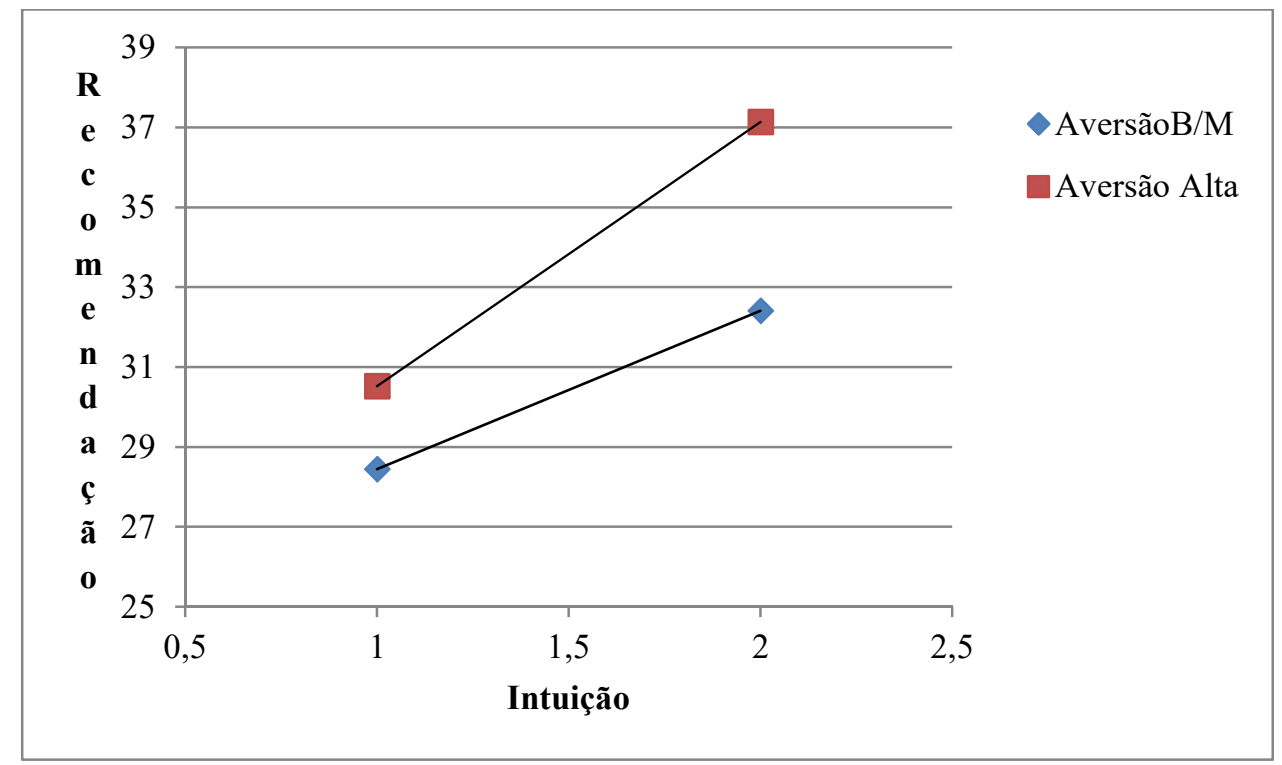

\section{Gráfico 6.11 - Efeitos do Estilo Cognitivo e da Aversão ao Risco na Recomendação do Gerente}

Existe ampla bibliografia sobre os efeitos da aversão ao risco no incremento das taxas de retorno esperadas e alguma sobre o papel de gerentes e especialistas na mitigação da percepção de risco pelos indivíduos. Investimento é um assunto complexo cujas consequências negativas podem comprometer o conforto e bem estar futuro dos tomadores de decisão.

Em geral a literatura aborda a importância do gerente ou especialista na redução do nível de percepção do risco do cliente no momento da decisão. O que esta pesquisa parece demonstrar é que além da aversão ao risco, um segundo traço parece estar presente nesta relação, qual seja, a forma de processamento de informações ou o estilo cognitivo.

Os resultados apresentados indicam que gerentes e especialistas além de mitigar os efeitos da aversão na percepção de risco também podem exercer um papel de reduzir a tensão desta decisão, tornar a informação mais fluída e conferir conforto cognitivo aos investidores. Em paralelo à aversão, estes clientes querem alguém que traga conforto para sua decisão e reduza o sofrimento causado pela responsabilidade sobre as consequências desta decisão. Estas pessoas parecem de fato ter uma reação mais emotiva e perceber o risco em uma dimensão mais perceptual. Neste sentido, contar com profissionais que os assessorem é uma boa estratégia para reduzir o desconforto da decisão (Topolinski \& Strack, 2009; Bolte et al., 2003; Kahneman, 2011; Shainesh, 2012; Slovic, 1999; Slovic et al., 2002, 2004). 
Adicionalmente, os resultados dessa pesquisa apontam que as pessoas mais intuitivas, que tem o Sistema 1 mais presente, atribuem maior importância ao gerente e esperam poder contar com ele para suas decisões e, portanto, estão mais propensas a estabelecer uma relação com estes gerentes.

Para efeito de estabelecer uma estratégia de aproximação com os clientes que incremente os indicadores de sucesso das áreas de investimento, o que os resultados sugerem é que os mais intuitivos são mais suscetíveis a abordagens que privilegiem o relacionamento com os gerentes e, por conseguinte com os bancos, o que pode funcionar como um elo para fortalecer uma relação de longo prazo (Sirdeshmukh et al., 2002; Shainesh, 2012).

Já os menos intuitivos, a despeito de também conferirem maior importância à recomendação do gerente, parecem mais propensos a tomar suas decisões de investimento contemplando em maior grau retornos históricos, possibilidades de perda e demais características do produto que julguem necessárias em seu processo decisório. Estes parecem confiar mais em suas próprias estimativas acerca do desempenho dos produtos de investimento e preferir arcar com as consequências de suas decisões quando comparados aos mais intuitivos.

Os resultados apurados por esta pesquisa sugerem que as proposições $P_{1}, P_{2}$ e $P_{3}$ não são rejeitadas, indicando ser o gerente o fator que exerce maior influência sobre a decisão de investimento em um ativo financeiro. Ao que parece, isto se deve à necessidade que o investidor tem de poder contar com apoio de um profissional para mitigar sua percepção de risco e transmitir a sensação de conforto emocional para a decisão.

A partir destes resultados, parece existir razoável convergência para que se proponha o esquema a seguir.

Os princípios da teoria do afeto, Finucane et al. (2000) e Slovic et al. (2002), complementam o modelo teórico proposto, e resultam na figura abaixo que representa de forma esquemática a forma como os traços de aversão ao risco e estilo cognitivo parecem influenciar o processo decisório. Em uma decisão de investimento financeiro, parece haver duas rotas de decisão, uma que busca amenizar a percepção de risco e outra que, possivelmente, busca evitar a 
tensão cognitiva. Elas podem até conduzir ao mesmo destino, porém, seguem por caminhos distintos. Para os mais avessos, o gerente parece mitigar a sensação de risco associada ao produto, na busca por uma relação compensadora entre risco e retorno. Já para os mais intuitivos, o gerente parece aliviar a tensão proveniente da decisão e transmitir uma sensação de conforto cognitivo.

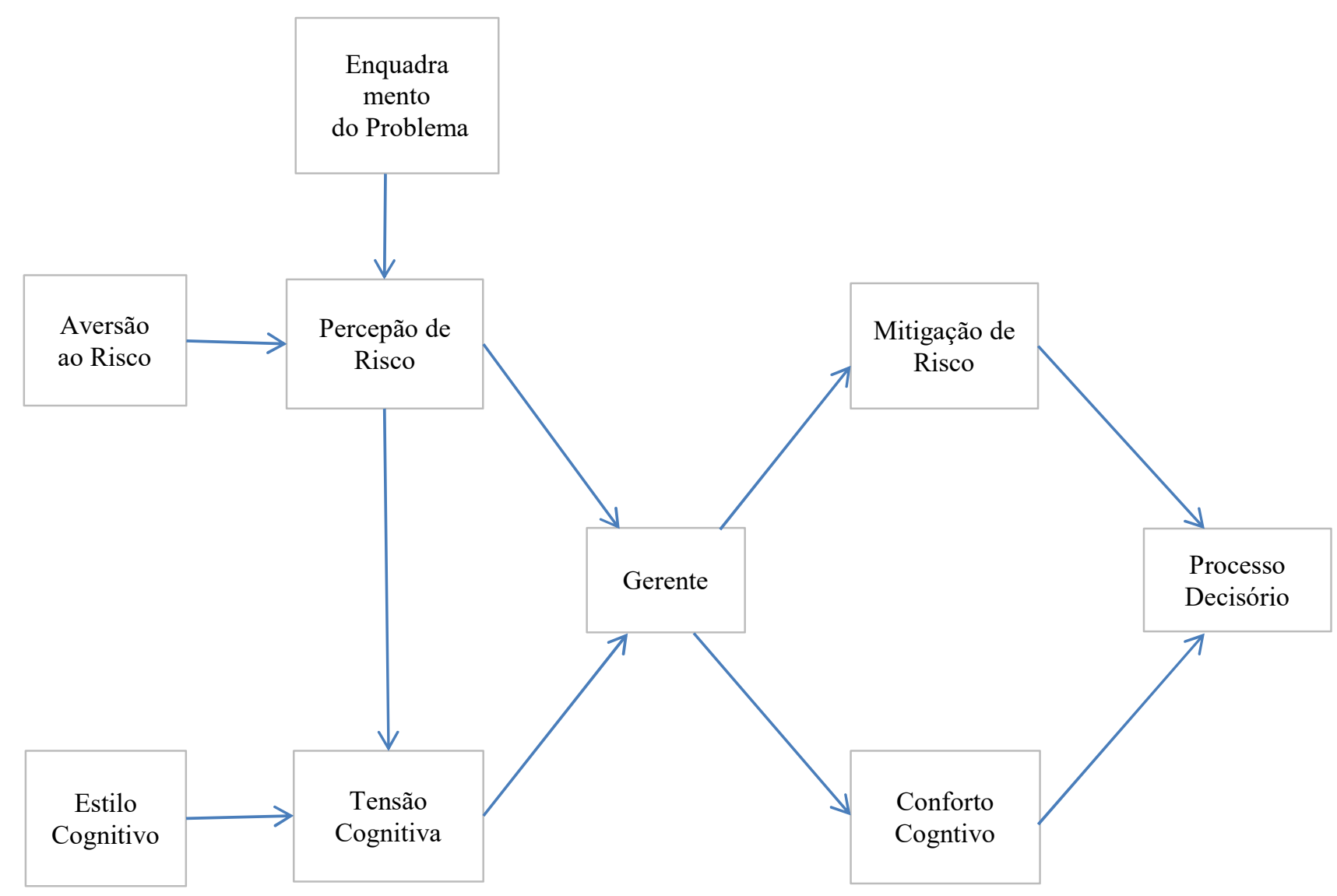

Figura 6.2 - Esquema para Tomada de Decisão de Investidores em Função da Aversão ao Risco e do Estilo Cognitivo

Com base nestes resultados colhidos até o momento, a seguir é feita uma discussão adicional sobre uma possível segmentação de clientes em dois grupos, quais sejam: um formado em torno da recomendação do gerente e outro em torno das características dos produtos. 


\subsubsection{Análise de segmentos}

A fim de aprofundar a compreensão sobre o processo decisório destes investidores gerando conhecimento que permitisse propor estratégias de relacionamento que incrementem a satisfação dos clientes e que rentabilizem melhor este investimento, a amostra foi segregada então em grupos, clusters, de forma a produzir segmentos mais homogêneos que revelassem não apenas comportamentos mais próximos entre si como também aqueles mais distantes de maneira que fosse possível demarcar nitidamente as diferenças entre os grupos. Para tanto, optou-se pela técnica estatística de análise de agrupamentos (cluster analysis).

Os resultados até aqui apurados indicam que fatores emocionais exercem forte influência sobre a decisão do investidor e parecem dominar o processo. Os pressupostos da teoria normativa, em que o tomador da decisão avalia as informações racionalmente conforme a relação de risco e retorno são desafiados pelo resultado desta pesquisa quando se identifica que o gerente exerce forte influência sobre a decisão, nada axiomática, do investidor.

Para a construção destes dois agrupamentos foi selecionado o método hierárquico de Ward baseado na distância euclidiana quadrática e configurado o parâmetro para segregação dos respondentes em dois grupos. Para isso foram utilizados os percentuais de importância relativa de cada respondente, calculados por meio da análise conjunta, como variáveis para medir semelhanças e disparidades entre os respondentes e identificar os grupos.

O resultado apurado pelo método de Ward para o parâmetro de dois clusters identificou um agrupamento contendo 267 respondentes (58\%) e com centroide definido pela recomendação do gerente, que responde por $38 \%$ da decisão, sendo seguido pelo atributo rentabilidade, este com peso de $20 \%$. O outro agrupamento agrega 193 respondentes (42\%) e apresenta centroide baseado na rentabilidade, $28 \%$, acompanhado pelo atributo risco que responde por $25 \%$ da decisão. Ou seja, para o primeiro grupo o gerente é considerado o fator preponderante com quase o dobro da importância atribuída ao segundo fator, rentabilidade. Já no segundo grupo, rentabilidade e risco apresentam percentuais próximos, $28 \%$ contra $25 \%$, respectivamente. O primeiro grupo foi denominado de Gerente e o segundo de Produto. 
Vale destacar que, para todos os atributos que definem o produto (retorno, risco, liquidez e taxa de administração), o grupo Gerente apresentou pontuações inferiores às registradas pelo grupo Produto. Em ambos os casos os dois principias fatores (gerente-rentabilidade e retornorisco) respondem por mais de $50 \%$ da decisão. O fato de rentabilidade e risco terem assumido a liderança entre os fatores definidores deste segundo grupo, Produto, sugere que este binômio está bastante presente na decisão deste grupo, conforme evidenciado na tabela 6.13.

Tabela 6.13

Clusters

Importância Relativa dos Atributos na Decisão

\begin{tabular}{l|r|r|r|r}
\hline & \multicolumn{2}{|c|}{ Grupos } & \multicolumn{2}{c}{ ANOVA } \\
\hline & Gerente & Produto & \multicolumn{1}{c|}{ F } & \multicolumn{1}{c|}{ Sig. } \\
\hline Rentabilidade & 20,30 & 27,78 & 73,193 & $\mathrm{p}<.000$ \\
Risco & 18,12 & 25,41 & 103,601 & $\mathrm{p}<.000$ \\
Liquidez & 9,62 & 11,82 & 14,600 & $\mathrm{p}<.000$ \\
Taxa de Administração & 13,86 & 16,19 & 14,469 & $\mathrm{p}<.000$ \\
Recomendado pelo gerente & 38,10 & 18,80 & 604,805 & $\mathrm{p}<.000$ \\
\hline Total & 100,00 & 100,00 & 193 \\
\hline Participantes & 267 & &
\end{tabular}

Em relação aos fatores julgados mais importantes em cada um dos dois grupos, em média os participantes do grupo Gerente atribuem 8 pontos percentuais acima da média geral para o fator recomendação enquanto os do grupo Produto atribuem 11 pontos a menos. Já em relação aos fatores rentabilidade e risco, o grupo Gerente atribuiu cerca de 3 pontos percentuais a menos para cada um deles, enquanto o grupo Produto acresceu pouco mais que 4 pontos percentuais. Taxa de administração e liquidez também apresentaram pesos superiores para o grupo Produto, contudo, as diferenças em relação à média geral são menores, em torno de 1 ponto percentual. O gráfico 6.12 apresenta a as diferenças de cada grupo em relação à média geral. 


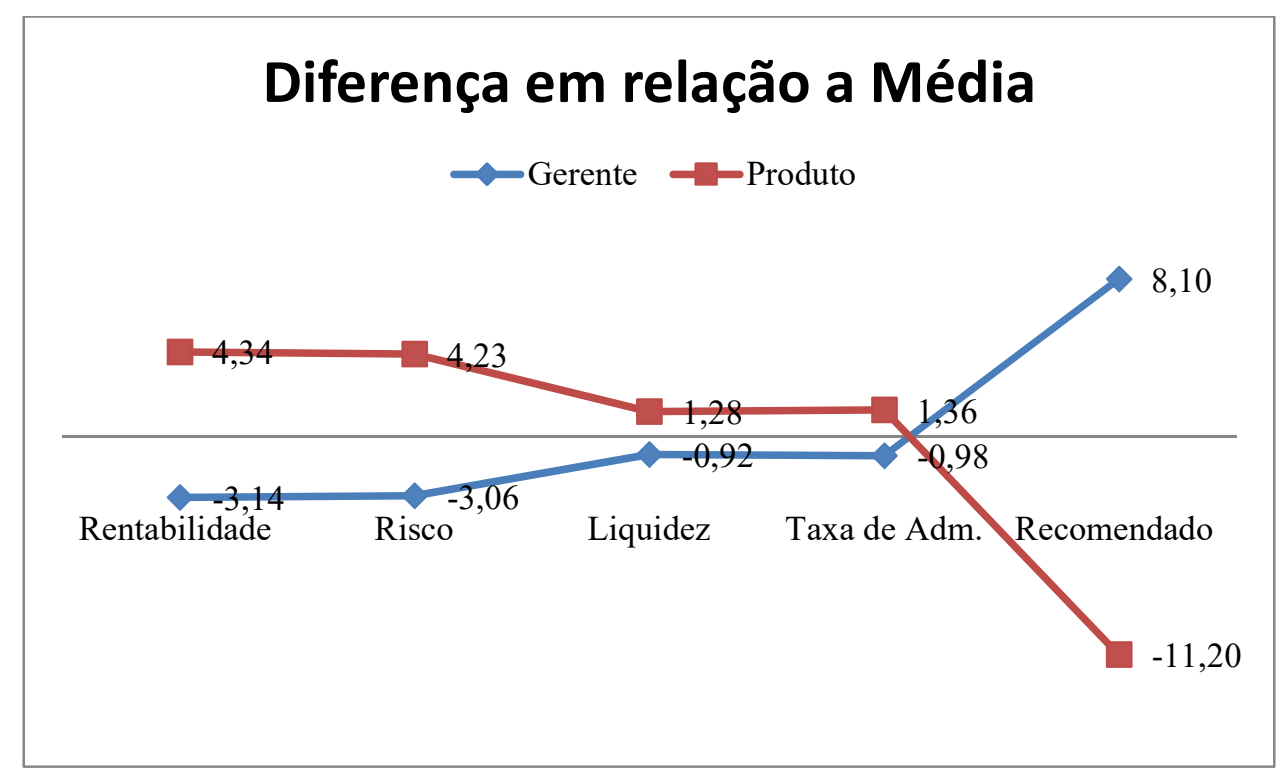

\section{Gráfico 6.12 - Relação entre as Importâncias dos Atributos Clusters X Média Geral}

A análise de agrupamentos categorizou os respondentes a partir das importâncias relativas dos atributos para a tomada de decisão. A observação de como os respondentes priorizaram os fatores ajuda a entender as preferências de cada grupo. Para esta análise foram calculadas, para cada grupo, as proporções de respondentes que tinham como primeira opção (opção preferida).

Os resultados indicaram alta relação entre o cluster Gerente e a preferência pelo fator recomendação do gerente, com $85 \%$ dos respondentes apontando ser este o principal responsável pela decisão. Já no cluster Produto, 50\% manifestaram preferência pelo fator rentabilidade e $35 \%$ pelo fator risco. É de se notar que no cluster Produto a recomendação do gerente é a preferida por apenas $4 \%$ dos respondentes. Por outro lado, rentabilidade e risco respondem, em conjunto, por $85 \%$ da decisão dos membros do grupo Produto. Foram realizados testes qui-quadrado para os três cruzamentos e todos foram considerados significativos $(p<.000)$. 
Tabela 6.14

Fator Preponderante na Decisão

Distribuição \% entre Clusters

\begin{tabular}{l|cc|cc|cc}
\hline \multirow{2}{*}{ Cluster } & \multicolumn{6}{|c|}{ Fator Preponderante para Decisão } \\
\cline { 2 - 8 } & \multicolumn{2}{|c|}{ Rentabilidade } & \multicolumn{2}{c}{ Risco } & \multicolumn{2}{c}{ Gerente } \\
\hline \multirow{2}{*}{ Gerente } & Não & Sim & Não & Sim & Não & Sim \\
Produto & $88,8 \%$ & $11,2 \%$ & $97,8 \%$ & $2,2 \%$ & $15,4 \%$ & $84,6 \%$ \\
& $49,7 \%$ & $50,3 \%$ & $65,3 \%$ & $34,7 \%$ & $95,9 \%$ & $4,1 \%$ \\
\hline & & & & & & \\
Pearson Chi Square & 85,354 & $\mathrm{p}<.000$ & 88,45 & $\mathrm{p}<.000$ & 290,459 & $\mathrm{p}<.000$ \\
\hline
\end{tabular}

Para os testes a seguir, foram utilizadas as utilidades e as importâncias relativas calculadas pela análise conjunta. A natureza desta técnica estatística pressupõe que os fatores mais importantes para a decisão são aqueles cujas utilidades dos níveis apresentam maior amplitude, ou seja, o efeito do nível sobre a satisfação da pessoa é tão impactante que pode levá-la a escolher ou desistir de algo.

Neste tocante, para os dois clusters foram calculados o incremento (decremento) de utilidade entre os valores de mínimo e máximo de cada fator pesquisado.

As médias dos valores acima foram calculadas para o grupo Gerente e Produto e comparadas por meio de ANOVA com intuito de se verificar se há diferença significativa entre estas medidas em relação aos clusters. Foram encontradas diferenças significativas entre as médias dos fatores recomendação do gerente $(p<.001)$ e risco $(\mathrm{p}<.05)$, indicando que as pessoas mais sensíveis à opinião do gerente respondem com maior intensidade a variações deste fator enquanto os mais ligados ao produto reagem com mais vigor ao incremento do risco. Para os demais fatores não foram identificadas diferenças estatisticamente significativas. 


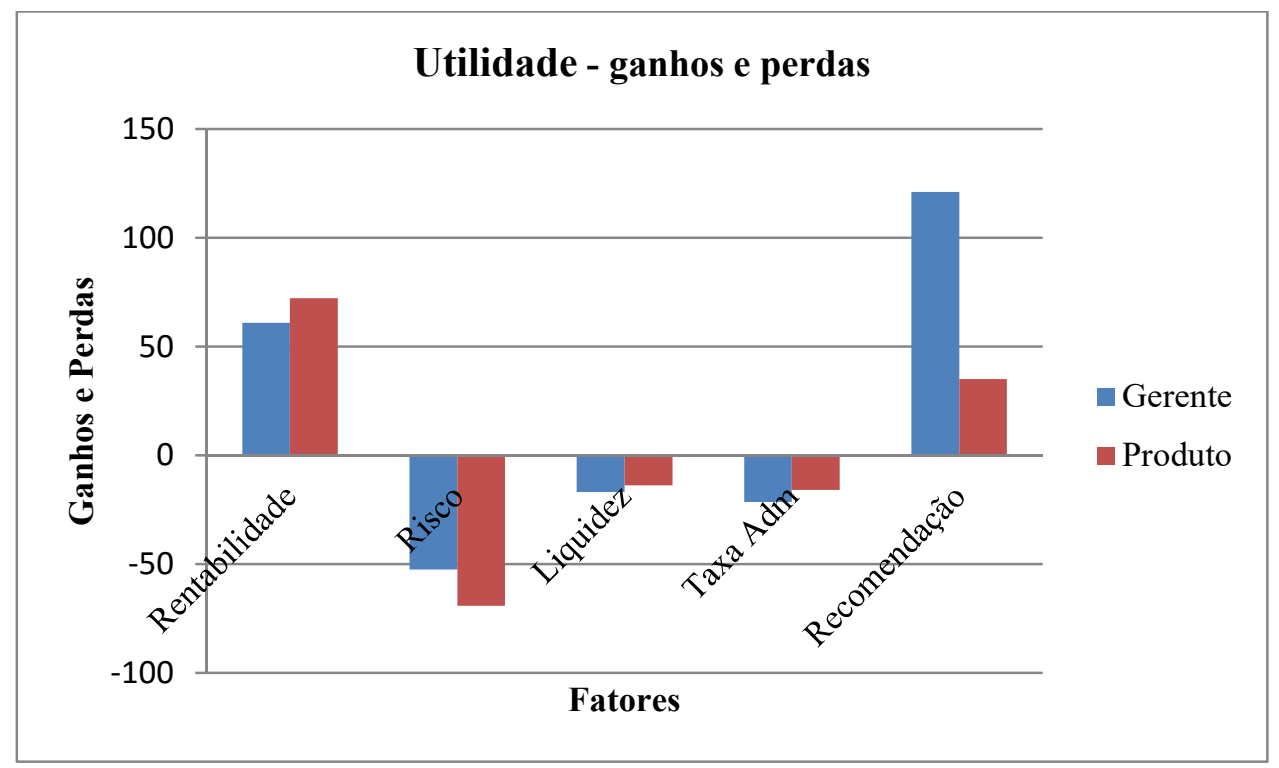

Gráfico 6.13 - Variação das Utilidades dos Atributos por Cluster

Os dois clusters foram definidos em função dos cinco atributos, e os resultados sugerem que os grupos Gerente e Produto são bem definidos e com características bem delimitadas que os caracterizam como grupos coesos. Contudo, vale aprofundar o conhecimento sobre quais fatores melhor descrevem os grupos, qual a importância destes fatores na diferenciação dos grupos.

A análise discriminante é a técnica estatística adequada para identificar quais variáveis independentes, métricas, melhor discriminam os objetos entre dois ou mais grupos, variável dependente categórica, definida a priori (Hair et al., 2009).

No caso desta pesquisa, a análise discriminante buscou identificar a contribuição das variáveis, rentabilidade, risco, liquidez, taxa de administração e recomendação do gerente na diferenciação dos dois grupos, Gerente e Produto.

Os participantes dos grupos Gerente e Produto foram aleatoriamente separados em duas amostras distintas, a primeira contendo $80 \%$ dos casos e a segunda os $20 \%$ restantes, respeitando-se, para cada grupo, estas proporções. À primeira amostra foi dado o nome de amostra de estimação e servirá para estimar a função discriminante. A segunda foi denominada de holdout, amostra de validação, que será utilizada para validar a função discriminante. 
Para estimar os coeficientes da função determinante foi utilizado o método direto em que todas as variáveis independentes, previsoras, são incluídas simultaneamente. A tabela 6.15 indica que, quando observadas isoladamente, as variáveis independentes são todas significativas para distinguir a participação nos grupos Gerente e Produto.

Tabela 6.15

Análise Discriminante Significância das Variáveis Previsoras

\begin{tabular}{l|r|r|l}
\hline \multicolumn{1}{c|}{ Atributos } & $\begin{array}{r}\text { Wilks' } \\
\text { Lambda }\end{array}$ & \multicolumn{1}{c|}{$\mathrm{F}$} & \multicolumn{1}{c}{ Sig. } \\
\hline Rentabilidade & 0,854 & 62,584 & $\mathrm{p}<.000$ \\
Risco & 0,806 & 88,154 & $\mathrm{p}<.000$ \\
Liquidez & 0,962 & 14,481 & $\mathrm{p}<.000$ \\
Taxa de administração & 0,972 & 10,513 & $\mathrm{p}=.001$ \\
Recomendado pelo gerente & 0,430 & 486,103 & $\mathrm{p}<.000$ \\
\hline
\end{tabular}

Como existem apenas dois grupos, apenas uma função discriminante foi calculada, evidenciando as estatísticas da tabela 6.16 ser essa função estatisticamente significativa $(\mathrm{p}<.0000)$.

Tabela 6.16

Autovalor e Correlação Canônica

\begin{tabular}{|c|c|c|c|c|c|c|}
\hline Função & Autovalor & $\begin{array}{c}\% \text { da } \\
\text { Variância }\end{array}$ & $\begin{array}{c}\text { Correlação } \\
\text { Canônica }\end{array}$ & $\begin{array}{c}\text { Wilks } \\
\text { lambda } \\
\text { Lambda }\end{array}$ & $\begin{array}{c}\text { Qui } \\
\text { Quadrado } \\
\end{array}$ & Sig. \\
\hline 1 & 1,510 & 100,00 & 0,776 & 0,398 & 335,45 & $\mathrm{p}<.000$ \\
\hline
\end{tabular}

Os coeficientes padronizados da função discriminante são multiplicados pelos valores padronizados das variáveis independentes para definir o score discriminante. Esta função é utilizada para cada observação da amostra e comparado ao score de corte para prever a pertinência a cada grupo.

Tabela 6.17

Coeficientes Padronizados da Função Discriminante Canônica

\begin{tabular}{l|c|c}
\hline \multicolumn{1}{c|}{ Atributos } & Função 1 & Coeficiente \\
\hline Rentabilidade & $5.699,7265$ & $B_{1}$ \\
Risco & $4.454,3463$ & $B_{2}$ \\
Liquidez & $3.726,4318$ & $B_{3}$ \\
Taxa de administração & $3.969,5662$ & $B_{4}$ \\
Recomendado pelo gerente & $5.167,8901$ & $B_{5}$ \\
\hline
\end{tabular}


Desta forma, a função discriminante se define como:

$$
Z=B_{1} *\left(\frac{x_{1}-m_{1}}{s_{1}}\right)+B_{2} *\left(\frac{x_{2}-m_{2}}{s_{2}}\right)+B_{3} *\left(\frac{x_{3}-m_{3}}{s_{3}}\right)+B_{4} *\left(\frac{x_{4}-m_{4}}{s_{4}}\right)+B_{5} *\left(\frac{x_{5}-m_{5}}{s_{5}}\right)
$$

Onde:

$\mathrm{Z}=$ score discriminante,

$B i=$ coeficiente padronizado $\mathrm{i}$,

$x_{i}=$ valor da observação da variável independente i,

$m_{i}=$ média da variável independente $\mathrm{i}, \mathrm{e}$

$S_{i}=$ desvio padrão da variável i.

As correlações estruturais, também chamadas de cargas discriminantes, indicam as importâncias relativas das variáveis previsoras na discriminação das pessoas entre os dois grupos. Os valores da tabela 6.18 revelam que a recomendação do gerente é o atributo que mais contribui para o modelo. Risco se apresenta como a segunda variável mais importante seguida de perto pela rentabilidade.

Tabela 6.18

Matriz de Correlação Estrutural

\begin{tabular}{l|r}
\hline \multicolumn{1}{c|}{ Atributos } & \multicolumn{1}{c}{ Função 1 } \\
\hline Recomendado pelo gerente & $-0,9366$ \\
Risco & 0,3988 \\
Rentabilidade & 0,3361 \\
Liquidez & 0,1616 \\
Taxa de Administração & 0,1377 \\
\hline
\end{tabular}

Os centroides representam os valores médios dos scores discriminantes calculados para cada grupo. O centroide do grupo Gerente é -1,031 e o do grupo Produto 1,456. Desta forma, cada grupo possui um score padronizado médio e a média ponderada pelo número de participantes é denominada de cut off, o ponto que separa um segmento de outro. A figura 6.3, abaixo, apresenta uma representação esquemática da relação entre os grupos, centroides e cut off. Os números 1 e 2 identificam os grupos Gerente e Produto, respectivamente. 


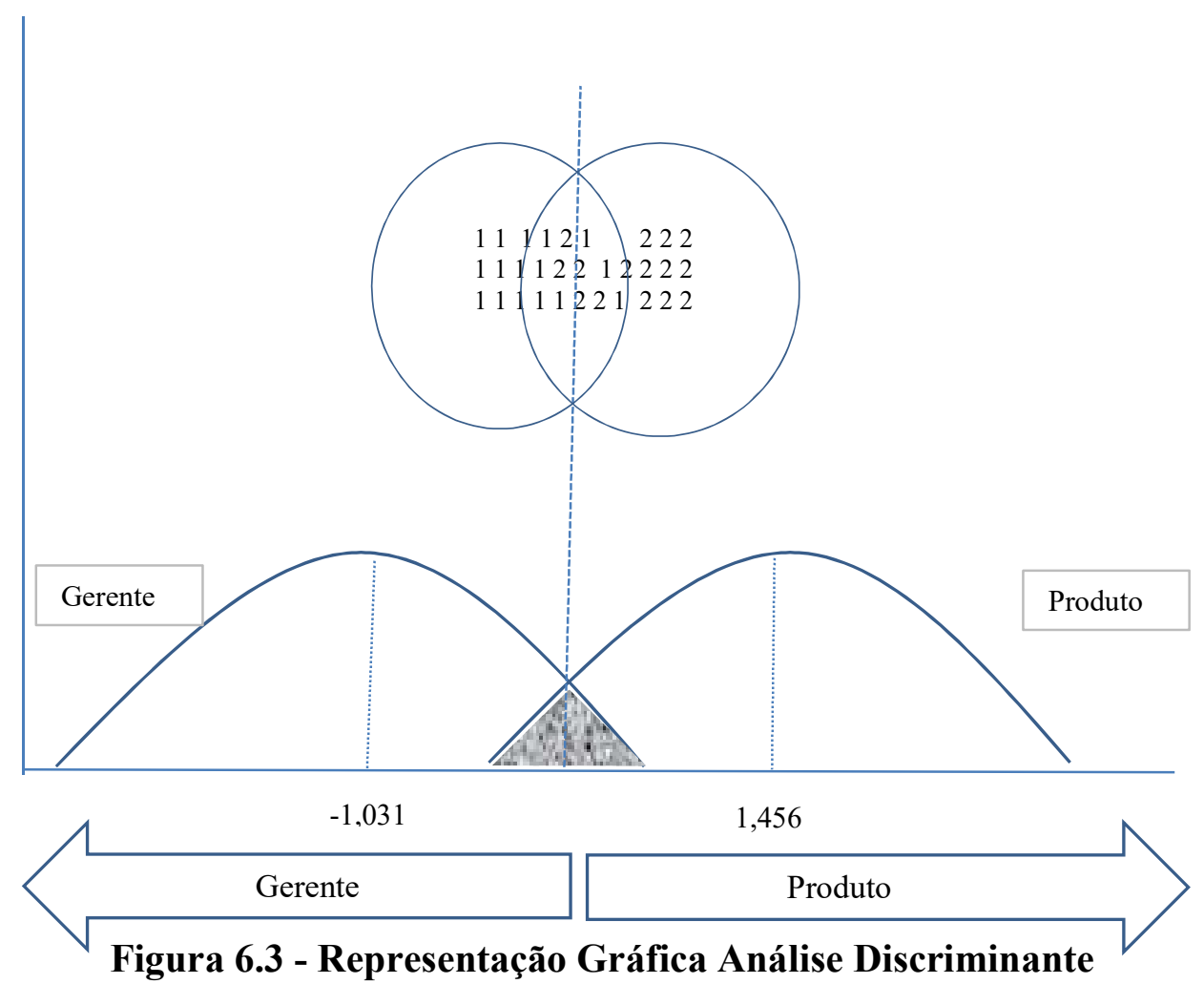

A capacidade preditiva da análise discriminante é comprovada pelos resultados da classificação dos participantes entre os grupos. Em relação à amostra de estimação, 93,8\% dos casos previstos são coincidentes com os grupos originais. A aplicação da função discriminante (deduzida a partir da amostra de estimação) sobre os dados da amostra holdout logrou classificar 91,2\% destes casos em conformidade com os grupos Gerente e Produto.

Tabela 6.19

Classificação dos Casos - Original X Previstos

\begin{tabular}{|c|c|c|c|c|c|}
\hline & & & & upos Previs & tos \\
\hline & & & Gerente & Produto & Total \\
\hline \multirow{4}{*}{ Casos Selecionados } & \multirow{2}{*}{ Quantidade } & Gerente & 196 & 20 & 216 \\
\hline & & Produto & 3 & 150 & 153 \\
\hline & \multirow{2}{*}{$\%$} & Gerente & 90,7 & 9,3 & 100 \\
\hline & & Produto & 2,0 & 98,0 & 100 \\
\hline \multirow{4}{*}{ Casos Não Selecionados } & \multirow{2}{*}{ Quantidade } & Gerente & 45 & 6 & 51 \\
\hline & & Produto & 2 & 38 & 40 \\
\hline & \multirow{2}{*}{$\%$} & Gerente & 88,2 & 11,8 & 100 \\
\hline & & Produto & 5,0 & 95,0 & 100 \\
\hline
\end{tabular}

a. 93,8\% dos casos selecionados foram classificados corretamente nos grupos

b. $91,2 \%$ dos casos não selecionados foram classificados corretamente nos grupos 
Os resultados da análise discriminante sugerem que a recomendação do gerente, o risco e a rentabilidade, nesta ordem, são as variáveis previsoras que mais contribuem para a discriminação dos grupos.

Após aprofundar no estudo sobre que variáveis melhor definem a distinção entre os grupos, na sequência é enfocada a relação entre aversão a risco e estilo cognitivo e estes grupos.

Quando se enfoca a questão da aversão ao risco, percebe-se que 68,2\% dos respondentes que se consideram mais avessos estão classificados no cluster Gerente contra $31,8 \%$ no cluster Produto. Um teste Qui-quadrado, $\chi^{2}$, foi executado e o resultado indicou haver forte identificação entre aversão ao risco declarada e o cluster gerente. A tabela 6.20 sumariza os resultados.

Tabela 6.20

\begin{tabular}{c|r|r|r|c}
\multicolumn{5}{c}{ Clusters X Aversão ao Risco } \\
\hline \multirow{2}{*}{ Aversão } & \multicolumn{2}{|c|}{ Grupos } & $\begin{array}{c}\text { Qui- } \\
\text { Quadrado }\end{array}$ & \multicolumn{1}{c}{ Sig } \\
\cline { 2 - 5 } & Gerente & \multicolumn{1}{c}{ Produto } & & \\
\hline \multirow{2}{*}{ Alta } & $68,2 \%$ & $31,8 \%$ & & \\
Baixa Média & $55,0 \%$ & $45,0 \%$ & 5,934 & $\mathrm{p}=.015$ \\
\hline
\end{tabular}

Em relação ao traço de processamento intuitivo, um teste qui-quadrado, $\chi^{2}$, foi aplicado para verificar a relevância da participação dos intuitivos no cluster gerente. A proposição é que os intuitivos demandam mais o gerente que os respondentes do grupo Produto.

Os resultados apontaram que $69 \%$ dos entrevistados categorizados como mais intuitivos estão presentes no cluster Gerente. O valor $\chi^{2}$ de 7,074 indica que foram encontradas evidências de que os mais intuitivos são predominantes no cluster gerente $(p<.01)$. A tabela 6.21 sumariza os resultados. 
Tabela 6.21

\begin{tabular}{c|r|r|r|c}
\multicolumn{4}{c}{ Clusters X Estilo Cognitivo } \\
\hline \multirow{2}{*}{ Intuitivos } & \multicolumn{2}{|c|}{ Grupos } & $\begin{array}{c}\text { Qui- } \\
\text { Quadrado }\end{array}$ & Sig \\
\cline { 2 - 5 } & Gerente & Produto & & \\
\hline Mais & $69,2 \%$ & $30,8 \%$ & & \\
Menos & $54,7 \%$ & $45,3 \%$ & 7,074 & $\mathrm{p}=.008$ \\
\hline
\end{tabular}

Investir é uma ação de alto envolvimento (Shainesh, 2012) em que as pessoas experimentam uma relação de insegurança e buscam em um profissional, supostamente qualificado, alguma orientação que reduza a sensação de insegurança. A percepção de risco se acentua conforme a incerteza se eleva, os resultados potencialmente negativos devem ser evitados e a sensação de perda acentua o sentimento de aversão (Baumann et al., 2010; Dholakia, 2001).

De acordo com Sirdeshmukh et al. (2002) os profissionais de atendimento tem papel fundamental na formação da confiança entre consumidor e provedor de serviço, uma estratégia que busque incrementar a lealdade dos clientes e o CLV passa eminentemente pelos profissionais de atendimento e, especificamente, pelo gerente.

Contudo, a comparação entre os grupos indica que aquele definido em função das características do produto não percebeu a mesma relevância na recomendação do gerente. Este grupo privilegia o produto, em maior nível, prescinde do profissional para orientá-lo e parece não perceber nele alguém que possa atenuar sua sensação de insegurança.

Adicionalmente, confirmando os resultados já apurados, os mais intuitivos parecem se apoiar no gerente para reduzir seu esforço cognitivo ou mesmo como forma de reduzir a possibilidade de arrependimento em caso de resultados negativos. Alguém dotado de conhecimento técnico em quem possam confiar parece ser o que estes investidores estão procurando.

Os resultados apresentados nesta seção parecem confirmar a viabilidade em se segmentar os clientes com base em sua pré-disposição em acompanhar a recomendação do gerente. Estes talvez tenham um comportamento de decisão mais emotivo, possivelmente percebam o risco menos como uma medida e mais como uma sensação e estejam mais propensos a confiar nos 
gerentes como personagens que tornam suas decisões de investimentos mais simples e menos tensas.

Finalizando este capítulo de análise dos resultados, apresenta-se, em seguida, um quadro síntese das hipóteses de pesquisa e resultados do teste estatístico correspondente.

\begin{tabular}{|c|c|c|}
\hline Grupos & Hipóteses & $\begin{array}{c}\text { Aceita } \\
\text { (A)/Rejeita(R) }\end{array}$ \\
\hline \multirow[t]{4}{*}{$\begin{array}{l}\text { Hierarquia de } \\
\text { preferência }\end{array}$} & $\begin{array}{l}H 1_{a} \text { : Existe relação monotônica entre os níveis de cada atributo de } \\
\text { decisão. }\end{array}$ & A \\
\hline & $\begin{array}{l}H_{l b} \text { : Existe diferença entre as importâncias relativas dos atributos de } \\
\text { decisão. }\end{array}$ & $\mathrm{A}$ \\
\hline & $\begin{array}{l}H_{I c} \text { : Rentabilidade e risco registram, respectivamente, as maiores } \\
\text { importâncias relativas na decisão. }\end{array}$ & $\mathrm{R}$ \\
\hline & $\begin{array}{l}H_{l d}: \text { A recomendação do gerente deve assumir peso } \\
\text { significativamente menor que rentabilidade ou possibilidade de } \\
\text { perda. }\end{array}$ & $\mathrm{R}$ \\
\hline \multirow[t]{4}{*}{$\begin{array}{l}\text { Enquadramento da } \\
\text { situação }\end{array}$} & $\begin{array}{l}H_{2 a} \text { : Em um cenário positivo a importância relativa da rentabilidade } \\
\text { é maior que a do risco. }\end{array}$ & $\mathrm{R}$ \\
\hline & $\begin{array}{l}H_{2 b} \text { : Em um cenário negativo a importância relativa do risco é maior } \\
\text { que da rentabilidade. }\end{array}$ & $\mathrm{R}$ \\
\hline & $\begin{array}{l}H_{2 c} \text { : Em um cenário negativo se registra uma inversão de } \\
\text { preferência e a importância relativa do risco passa a ser maior que a } \\
\text { da rentabilidade. }\end{array}$ & $\mathrm{R}$ \\
\hline & $\begin{array}{l}H_{2 d}: \text { Em um cenário adverso se registra uma inversão de preferência } \\
\text { e a importância relativa da possibilidade da recomendação do } \\
\text { gerente passa a ser maior que a da rentabilidade. }\end{array}$ & $\mathrm{R}$ \\
\hline \multirow[t]{6}{*}{ Aversão ao risco } & $\begin{array}{l}H_{3 a}: \text { O ganho de utilidade decorrente do aumento da rentabilidade é } \\
\text { maior para os considerados avessos. }\end{array}$ & $\mathrm{R}$ \\
\hline & $\begin{array}{l}H_{3 b} \text { : A perda de utilidade decorrente do aumento do risco é maior } \\
\text { para os considerados avessos. }\end{array}$ & $\mathrm{R}$ \\
\hline & $\begin{array}{l}H_{3 c} \text { : A importância relativa do atributo rentabilidade é maior para o } \\
\text { grupo que se considera mais avesso ao risco. }\end{array}$ & $\mathrm{R}$ \\
\hline & $\begin{array}{l}H_{3 d} \text { : A importância relativa do atributo risco é maior para o grupo } \\
\text { que se considera mais avesso ao risco. }\end{array}$ & $\mathrm{R}$ \\
\hline & $\begin{array}{l}H_{3 e}: \text { O ganho de utilidade decorrente do da recomendação do } \\
\text { gerente é maior para os considerados avessos. }\end{array}$ & A \\
\hline & $\begin{array}{l}H_{3 f} \text {. A importância relativa do atributo recomendação do gerente é } \\
\text { maior para o grupo que se considera mais avesso ao risco. }\end{array}$ & A \\
\hline
\end{tabular}




\begin{tabular}{|c|c|c|}
\hline \multirow[t]{4}{*}{ Gênero } & $\begin{array}{l}H_{4 a}: \text { A proporção de mulheres que se consideram mais avessas ao } \\
\text { risco é maior que a proporção de homens. }\end{array}$ & $\mathrm{A}$ \\
\hline & $\begin{array}{l}H_{4 b} \text { : A importância relativa do atributo rentabilidade é menor para } \\
\text { as mulheres do que para os homens. }\end{array}$ & $\mathrm{A}$ \\
\hline & $\begin{array}{l}H_{4 c}: \text { A importância relativa do atributo possibilidade de perda é } \\
\text { maior para as mulheres. }\end{array}$ & $\mathrm{R}$ \\
\hline & $\begin{array}{l}H_{4 d} \text { : A importância relativa do atributo recomendação do gerente é } \\
\text { maior para as mulheres. }\end{array}$ & $\mathrm{A}$ \\
\hline \multirow[t]{3}{*}{$\begin{array}{c}\text { Nível de } \\
\text { conhecimento }\end{array}$} & $\begin{array}{l}H_{5 a}: \text { A proporção de pessoas menos letradas em investimentos e } \\
\text { avessas ao risco é maior que as mais letradas. }\end{array}$ & $\mathrm{R}$ \\
\hline & $\begin{array}{l}H_{5 b} \text { : A importância relativa do atributo risco é maior para as pessoas } \\
\text { que se declaram menos letradas em investimentos. }\end{array}$ & $\mathrm{R}$ \\
\hline & $\begin{array}{l}H_{5 c}: \text { A importância relativa do atributo recomendação do gerente é } \\
\text { maior para as pessoas que se declaram menos letradas em } \\
\text { investimentos. }\end{array}$ & $\mathrm{R}$ \\
\hline \multirow[t]{6}{*}{ Estilo cognitivo } & $\begin{array}{l}H_{6 a}: \text { Não existe diferença significativa entre o incremento da } \\
\text { rentabilidade para os grupos mais intuitivo e menos intuitivo. }\end{array}$ & $\bar{A}$ \\
\hline & $\begin{array}{l}H_{6 b}: \text { Não existe diferença significativa entre o incremento do risco } \\
\text { para os grupos mais intuitivo e menos intuitivo. }\end{array}$ & $\mathrm{A}$ \\
\hline & $\begin{array}{l}H_{6 c}: \text { Não existe diferença entre a importância relativa da } \\
\text { rentabilidade para os grupos mais intuitivo e menos intuitivo. }\end{array}$ & $\mathrm{R}$ \\
\hline & $\begin{array}{l}H_{6 d} \text { : Não existe diferença significativa entre a importância relativa } \\
\text { do risco para os grupos mais intuitivo e menos intuitivo. }\end{array}$ & $\mathrm{A}$ \\
\hline & $\begin{array}{l}H_{6 e:} \text { Não existe diferença significativa entre o incremento da } \\
\text { recomendação do gerente para os grupos mais intuitivo e menos } \\
\text { intuitivo. }\end{array}$ & $\mathrm{R}$ \\
\hline & $\begin{array}{l}H_{6 f:} \text { Não existe diferença significativa entre a importância relativa } \\
\text { da recomendação do gerente para o grupo mais intuitivo. }\end{array}$ & $\mathrm{R}$ \\
\hline $\begin{array}{l}\text { Estilo cognitivo } \mathrm{X} \\
\text { aversão ao risco }\end{array}$ & $\begin{array}{l}H_{7} \text { : Em relação à importância relativa da recomendação do gerente, } \\
\text { ela é maior para os mais intuitivos mesmo quando se ignora a } \\
\text { aversão ao risco. }\end{array}$ & A \\
\hline
\end{tabular}

Quadro 6.1 - Síntese das Hipóteses de Pesquisa 


\section{Conclusões, Limitações e Direcionamentos Futuros}

A decisão de investimento de uma pessoa implica em que ela renuncie ao prazer presente advindo do consumo de um bem ou serviço pela expectativa de que no futuro possa adquirir algo mais dispendioso que lhe traga uma satisfação ainda maior ou por um nível mais elevado de bem estar.

É uma decisão complexa que envolve, entre outras, definir o montante possível de recursos a ser investido, quais objetivos se deseja alcançar, qual prazo para que se atinjam tais objetivos, quanto de perda é suportável, qual nível de flutuação dos retornos e qual a liquidez aceitável.

Talvez o primeiro tradeoff a ser enfrentado em uma decisão de investimento seja escolher entre o prazer certo do consumo presente ou possibilidade de algo melhor no futuro. $\mathrm{O}$ resultado é incerto. Pior que em um jogo, no mundo real dos investimentos as probabilidades são desconhecidas, no máximo modelos estatísticos conseguem estima-las. Mesmo após estar tomada a decisão de investir, outros tradeoffs devem ser encarados, tais como: maior risco em busca de maior retorno ou menor risco em busca de preservar o capital.

Os objetivos de investimento podem não ser alcançados, os retornos podem ser menores que os previstos ou menores que os produzidos pelas alternativas descartadas, Ainda pior, é possível que ocorra perda, parcial ou total, do capital investido.

A teoria da utilidade esperada (EUT) pressupõe que o indivíduo é racional, tem preferências estáveis e se utiliza de axiomas lógicos que conduzem a uma decisão que maximiza a sua utilidade ou satisfação. No caso de investimentos, dado um determinado nível de aversão ao risco, o investidor decidirá pela alternativa que apresente a melhor relação esperada de riscoretorno, aquela que para um dado nível de risco ofereça a maior taxa de retorno. Quanto maior a aversão, mais elevada deve ser a relação exigida.

Não há dúvida que, considerando tudo o mais constante, um investidor preferirá maiores taxas de retorno para dado patamar de risco. Nestas condições, sendo possível, não há motivos para que alguém aceite taxas de retorno menores. A dúvida que se coloca é se não existiriam outros fatores em atuação no momento da decisão, além da busca racional pela mais alta 
relação entre risco e retorno. Adicionalmente, a teoria de finanças define risco como resultado da variância dos retornos de um ativo. Resta, então, saber se, de fato, as pessoas encaram risco como uma medida eminentemente quantitativa.

A EUT é de orientação normativa, ela pressupõe que as pessoas se comportam conforme regras lógicas, estabelecidas, que levarão a melhor decisão. Já a teoria do prospecto é descritiva e, sendo assim, se preocupa em entender e representar o comportamento observado; ela se constitui em uma alternativa à teoria da utilidade esperada.

A teoria do prospecto advoga que as pessoas decidem em relação a um ponto de referência a partir do qual avaliam ganhos e perdas, que elas têm aversão à perda, valorizam mais as perdas do que os ganhos e se utilizam de regras simplificadoras para inferir as probabilidades dos eventos. Ela incorpora elementos de contexto à decisão e aspectos relacionados às emoções para tentar explicar o processo decisório.

Considerando a escassez de literatura sobre o comportamento do investidor individual e a contribuição que este conhecimento pode agregar para elaboração de produtos e políticas comerciais, esta tese buscou identificar se fatores emocionais não previstos pela teoria da utilidade esperada poderiam influenciar a decisão do investidor. Em especial, se o estilo cognitivo poderia resultar em diferenças significativas na formação da preferência dos investidores.

Para alcançar estes objetivos foi realizada uma pesquisa de campo, em plataforma internet, em que os respondentes foram apresentados a estímulos, produzidos pelo método conjoint based choice (CBC), que simulavam tradeoffs típicos de uma decisão real de investimento financeiro. Para confecção do questionário de pesquisa foi levada a cabo uma ampla revisão de literatura sobre fatores que poderiam afetar a decisão do investidor que foi complementada por estudo exploratório, por meio de entrevistas em profundidade, com executivos seniores do mercado de fundos de investimento que trouxeram insights valiosos para o trabalho.

A Pesquisa bibliográfica e o estudo exploratório foram responsáveis por indicar os principais fatores que os investidores levam em consideração no momento de escolher uma aplicação financeira. Estes fatores são: rentabilidade passada, possibilidade de perda (risco), liquidez, taxa de administração e recomendação do gerente. Os quatro primeiros atributos são 
característicos do produto fundos de investimento que impactam, sem dúvida, a decisão. Já a recomendação do gerente não é um atributo do produto.

A conjoint analysis é um método estatístico multivariado de decomposição da utilidade entre os atributos que determinam a decisão. Pelos preceitos da EUT, a decisão deveria ser definida no campo retorno e risco. Já a experiência dos executivos indicou que a preferência recairia principalmente sobre a recomendação do gerente.

Os insights indicaram que a relação entre cliente e gerente muitas vezes se caracteriza mais pela dependência do que pelo estabelecimento da confiança. A ignorância do investidor o levaria a precisar do gerente. Sobre a decisão do investidor, quando se considera apenas os atributos do produto, a preferência recairia sobre a rentabilidade passada e então sobre a liquidez. O risco, segundo estes executivos, é uma variável que os investidores teriam dificuldade de entender e sua melhor representação seria por meio da possibilidade de perda, usualmente inferida pelo passado. A taxa de administração ainda conta com pouca visibilidade e teria menor influência.

O objetivo da CBC foi apurar a utilidade gerada por cada atributo e sua importância relativa na decisão. A partir destes resultados buscou-se identificar a existência de fatores não previstos na EUT que ajudassem a explicar a decisão do investidor em produtos financeiros.

Como primeiro resultado da pesquisa quantitativa identificou-se que todos os atributos apresentaram a relação monotônica esperada. Ou seja, para atributos considerados positivos quanto maior o valor maior a utilidade, já no caso contrário, quanto maior o valor menor a utilidade produzida. Desta forma, quanto maior a rentabilidade e mais forte a recomendação do gerente maior a utilidade. Já os demais atributos, quanto maior o risco e a taxa de administração menor a utilidade. Em relação à liquidez, quanto maior o prazo para reaver os recursos investidos, menor a satisfação.

Em sintonia com o comportamento prescrito pela EUT, quanto mais se experimenta de algo considerado bom maior a satisfação alcançada e vice versa. Observando-se isoladamente os atributos é uma decisão racional, pois não há dúvida que o incremento de um item positivo trará mais satisfação. 
O cálculo das importâncias relativas (pesos) na decisão talvez seja o principal resultado da conjoint analysis. Os números revelaram ser a recomendação do gerente o atributo de maior relevância, respondendo por $30 \%$ da decisão do investidor. Ordenando-se os atributos em ordem decrescente, rentabilidade responde por $23 \%$ da decisão e risco por outros $21 \%$. A taxa de administração e a liquidez estão mais distantes e explicam 15\% e 11\%, respectivamente.

A precedência da recomendação do gerente sobre os demais atributos inerentes ao produto de investimento indica que as preferências não são previamente conhecidas ou mesmo estáveis. Elas estariam sujeitas a influência de outros fatores que não aos inerentes aos produtos em avaliação. Estar suscetível a opinião do gerente, ou até de outra pessoa, significa que a preferência pode se alterar conforme esta recomendação. Isto implica que, a depender da opinião do gerente, é possível que o investidor diante de alternativas idênticas tome decisões diferentes. Que algo que foi preferido antes, mantidas as mesmas condições, possa ser rejeitado depois.

Investir é complexo, exige avaliar uma série de informações específicas e, ao final, a despeito de todo esforço, ainda pode resultar em perda. O desconforto provocado por esta decisão e a aversão a perda parecem estar no centro da maior preferência atribuída ao gerente. A tensão surgida por conta desta decisão leva a buscar por alguém que possa amenizar esta sensação. $\mathrm{O}$ gerente teria este papel, de transmitir a confiança necessária para a tomada de decisão. Além disto, seria alguém com quem se poderia repartir a responsabilidade em caso de resultados aquém da expectativa e, principalmente, quando da perda. Esta discussão sugere que a decisão de investimento está envolta em emoção e, ao que parece, o gerente é a principal fator mitigador do risco percebido. Este risco se assemelha mais a uma sensação, algo difícil de descrever, mas que está associado à possibilidade de frustração decorrente de expectativas não realizadas e, especialmente, a perda, ele não parece ser o resultado da variância dos retornos ou de cálculos feitos sobre as informações do produto.

As emoções estão mais relacionadas ao estilo cognitivo conhecido como Sistema 1, que é automático, rápido, intuitivo, associativo e baseado na experiência. Fazendo o contraponto, o Sistema 2 é controlado, lento, racional, orientado por regras e baseado nas consequências. 
Como o Sistema 1 é mais ligado às emoções, investigou-se, então, a relação entre estilos cognitivos e a decisão de investimento. Foram utilizados testes de diferenças de médias, ANOVA, para verificar se haveria diferenças entre pessoas mais intuitivas e menos intuitivas. Para identificar e classificar as pessoas nestes dois grupos foi utilizado o teste cognitive reflection test (CRT), proposto por Frederick (2005), que mede o quão intuitiva é a resposta a três perguntas que naturalmente ensejam respostas que vem automaticamente a mente.

Os resultados indicaram que $34 \%$ da decisão do investidor mais intuitivo repousa sobre a recomendação do gerente contra $29 \%$ para o menos intuitivos. Sobre a rentabilidade, verificou-se o oposto, ela explica apenas $21 \%$ da decisão dos mais intuitivos enquanto os menos intuitivos atribuem $24 \%$ de peso a ela. Os percentuais mais elevados atribuídos à recomendação do gerente reforçam a ideia de que fatores emocionais atuam de forma relevante na decisão. Contudo, a inversão entre as importâncias relativas atribuídas a rentabilidade sugere que os menos intuitivos são mais propensos a avaliar as informações, construir juízos de valor e tomar suas decisões de forma mais racional, ou seja, que busque compensar maior risco com maior rentabilidade.

Considerando que o Sistema 1 é mais emocional e a importância atribuída pelos mais intuitivos à recomendação do gerente, tais resultados parecem comprovar que o gerente atua sobre as emoções trazendo mais conforto cognitivo para decisão. O Sistema 1 é perceptual, gera imagens que são associadas a, por exemplo, perigo e segurança e partir delas são tomadas as decisões.

Poderia haver alguma interação entre os efeitos do estilo cognitivo e da aversão ao risco. Em relação influência do nível de aversão, os testes indicaram haver diferença para a recomendação do gerente, com mais avessos atribuindo peso de $32 \%$ contra $29 \%$ dos menos avessos. Para risco e rentabilidade as diferenças não foram significativas. Mesmo para os mais avessos, a recomendação do gerente surge como o fator com maior poder de atenuar a sensação de risco embutida na decisão de investimento.

A sobreposição entre os grupos compostos por mais avessos e mais intuitivos é de apenas 24\%, o que já indicaria serem, estas características, distintas. Para medir o efeito da influência destes dois traços de forma isolada, descartando a interação possível, foi realizado um teste 
ANOVA de dois fatores que encontrou evidências de serem aversão ao risco e estilo cognitivo fatores que atuam de forma independente na decisão do investidor. Os resultados sugerem, inclusive, ser mais acentuada a influência do estilo cognitivo.

Os resultados levam a supor que os mais avessos se utilizam da recomendação do gerente como meio para mitigar a sensação de risco advinda dos produtos de investimento em avaliação. Já os mais intuitivos parecem buscar na recomendação do gerente o conforto necessário para a tomada de decisão evitando, assim, a tensão cognitiva associada a esta escolha.

Considerando as descobertas desta pesquisa, surgiu curiosidade em saber se seria factível agrupar os respondentes em dois grupos, um mais propenso à tomada de decisão baseada nas características dos produtos e outro cuja decisão recairia com maior intensidade sobre a recomendação do gerente. Para tanto, foi levado a cabo uma análise de cluster, utilizando o método Ward, que teve como parâmetro pré-definido a segregação em dois grupos.

Os dois grupos foram formados com sucesso, para o grupo mais influenciado pelo gerente o centroide foi definido pela recomendação que respondeu por $38 \%$ da decisão, enquanto o grupo mais ligado ao produto teve o centroide fixado em torno da rentabilidade, com valor de $28 \%$. No grupo denotado pelo gerente, $85 \%$ dos seus participantes apontaram a recomendação como sendo o fator mais importante na decisão. Já para o grupo produto, 50\% indicaram a rentabilidade como fator mais relevante e outros $35 \%$ designaram o risco.

Com objetivo de descobrir qual a importância relativa dos atributos na determinação dos grupos, foi realizada uma análise discriminante, técnica estatística que identifica as variáveis independentes que melhor discriminam a variável dependente.

Todos os atributos foram considerados bons previsores dos grupos, sendo a recomendação do gerente aquele que exerce maior influencia na discriminação dos grupos. Na sequencia, risco e rentabilidade, respectivamente, com scores semelhantes, respondem por maior parcela da discriminação dos grupos. A função discriminante alcançou $94 \%$ de assertividade na predição dos indivíduos aos grupos. 
O cruzamento das informações destes grupos com o estilo cognitivo revelou que $70 \%$ dos mais intuitivos estão no grupo formado em torno da recomendação do gerente. Aqui parece haver uma oportunidade de segmentação para bancos e distribuidores de produtos de investimento.

O estudo exploratório apontou que os bancos pretendem aprofundar estratégias de relacionamento com seus clientes que aumentem a satisfação e possam incrementar a lealdade em busca de retornos mais elevados no longo prazo. O que esta pesquisa sugere é que os clientes mais intuitivos são mais propensos à recomendação do gerente e, portanto, a valorizar um relacionamento mais próximo. Eles tendem a precisar mais do acompanhamento do gerente aumentando a possibilidade para se reforçar a lealdade. Considerando que os recursos são sempre escassos, uma segmentação que classifique os clientes em relação ao estilo cognitivo e os priorize tende a alcançar resultados mais efetivos.

Esta pesquisa buscou identificar atributos relevantes para a decisão de investimento bem como suas importâncias relativas. Para tanto, buscou-se simular decisões reais de investimento que, naturalmente, devem ter curso em meio ao ambiente econômico vigente. Neste sentido, a rápida degradação verificada nos principais indicadores macroeconômicos brasileiros entre a data de formulação do questionário e o período de sua aplicação pode ter reduzido a efetividade dos cenários, positivo e negativo, apresentados aos respondentes e que pretendiam induzir uma maior ou menor percepção de risco. Desta forma, os resultados obtidos em relação aos testes de enquadramento da decisão talvez tenham sido comprometidos.

A forma como os respondentes foram classificados em relação ao seu nível de aversão ao risco, que foi declaratória, também pode ser apontada como uma limitação. Testes de proficiência talvez pudessem ter levado a resultados mais acurados no que tange a relação entre aversão ao risco e conhecimento sobre produtos financeiros.

Esta pesquisa infelizmente não contou com informações sobre pares de risco e retorno que pudessem ajudar a entender o quanto os menos intuitivos, de fato, relacionam estas duas dimensões e decidem em função de cálculos estatísticos. Na presença destes pares, teria sido 
possível relacionar o conhecimento declarado em investimento financeiro com maior racionalidade e habilidade com cálculos nos julgamentos de risco-retorno.

A elevada concentração da amostra em pessoas com renda mensal até R $\$ 5.000,00$, a despeito de estar alinhada ao perfil de distribuição e renda da sociedade brasileira, torna oportuna a reprodução deste estudo para classes com perfil de renda mais alto. Ainda em relação à amostra, a acentuada participação das regiões nordeste e sul em detrimento da região sudeste pode ter provocado algum impacto nos resultados obtidos e, também, sugere desdobramentos para esta pesquisa.

Os resultados aqui alcançados indicam a preponderância do gerente ou especialista nas decisões de investimento, contudo, os avanços da tecnologia da informação vêm transformando a forma de atuação das empresas e mesmo a maneira como buscam se relacionar com seus clientes. Esta realidade cria oportunidades para o aprimoramento desta pesquisa no que tange aos impactos do atendimento e aconselhamento por meio de robôs e demais recursos habilitados pela tecnologia da informação na relação entre clientes e instituições financeiras. Adicionalmente, neste contexto, um volume maior de informações tende a estar acessível aos potenciais investidores, causando, assim, uma redução na assimetria de informação e talvez uma diminuição da importância do gerente.

É escassa a literatura acadêmica sobre comportamento do investidor, espera-se que esta pesquisa possa contribuir para despertar o interesse no assunto e possa estimular o surgimento de novos estudos. Como foi aqui revelado, o estilo cognitivo exerce influência relevante na decisão de investimento, aprofundar estes estudos enfocando produtos financeiros de outra natureza, tal como crédito, pode gerar um conhecimento bastante útil para o setor bancário. $\mathrm{O}$ alvo principal deste trabalho foi o estilo mais intuitivo e seu impacto na decisão, o aprofundamento destas comparações entre mais intuitivos e mais racionais pode trazer importantes contribuições para o setor financeiro. 


\section{Referências Bibliográficas}

Abdellaqui, M., Bleichrodt, H., \& Paraschiv, C. (2007). Loss Aversion Under Prospect Theory: A parameter-Free Measurement. Management Science. 53(1), 1659-1674.

Aldrighi, D. M., \& Milanez, D. Y.(2005). Finança Comportamental e a Hipótese dos Mercados Eficientes. Revista de Economia Contemporânea. 9(1), 41-72.

Alter, A. L., \& Oppenheimer, D. M. (2006). Predicting short-serm stock fluctuations by using processing fluency. PNAS Review. 103(24), 9369-9372. Recuperado em 06 de janeiro, 2015 de http://www.pnas.org/cgi/doi/10.1073/pnas.0601071103.

Alter, A. L., \& Oppenheimer, D. M. (2009) Uniting the Tries of Fluency to Form a Metacognitive Nation. Personality and Social Psychology Review. 13(3), 219-235.

Alter, A. L., Oppenheimer, D. M., Epley, N., \& Eyre, R. N. (2007) Overcoming Institution: Metacognitive Difficulty Activates Analytic Reasoning. Journal of experimental psychology: General. 136(4), 569-576.

Associação Brasileira das Instituições dos Mercados Financeiro e de Capitais (2014a). Percepção sobre as certificações ANBIMA. São Paulo.

Associação Brasileira das Instituições dos Mercados Financeiro e de Capitais (2014b). Pense no seu gerente: por que ele é importante para você. São Paulo.

Associação Brasileira das Instituições dos Mercados Financeiro e de Capitais (2015). Relatório ANBIMA de Distribuição de Produtos no Varejo. Recuperado em 20 de dezembro, 2014 http://portal.anbima.com.br/informacoes- tecnicas/estatisticas/varejo/Pages/default.aspx.

Associação Brasileira das Instituições dos Mercados Financeiro e de Capitais (2015). Ranking de Gestão de Fundos de Investimento. Recuperado em 20 de dezembro, 2014, de http://portal.anbima.com.br/informacoes- tecnicas/estatisticas/varejo/Pages/default.aspx.

Barasinska, N., Schafer, D., \& Stephan, A. (2012) Individual risk attitudes and the composition of financial portfolios: Evidence from German household portfolios. The Quarterly Review of Economics and Finance. 52, 1-14.

Barberis, N. C.. (2012). A Model of Casino Gambling. Management Science. 58(1), 33-51.

Barberis, N. C.. (2013). Thirty Years of Prospcet Theory in Economics: A Review and Assessment. Journal of Economic Perspectives. 27(1), 173-196, winter.

Baron, J. (2009). Thinking and Deciding. New York: Cambridge University Press.

Basel, J. S., \& Bruhl, R. (2013) Rationality and dual process models of reasoning in managerial cognition and decision making. European Mangement Journal. 31, 745-754.

Baumann, C., Elliot, G., \& Hamin, H. (2011) Modelling customer loyalty in financial services - A hybrid of formative and reflective constructs. International Journal of Bank Marketing. 29(3), 247-267. 
Bazerman, M. H., \& Moore, D. (2010). Processo Decisório. Rio de janeiro: Campus.

Bazerman, M. H., Loewenstein, G. F., \&White, S. B. (1992) Reversals of Preference in Allocation Decisions: Judging an Alternative Versus Choosing Among lternatives. Administrative Science Quarterly. 37(2), 220-240.

Bell, D. E. (1982). Regret in Decision Making Under Uncertainty. Operations Research. 30(5), 961-981.

Benartzi, S., \& Thaler, R. H. (1995). Myopic Loss Aversion and the Equity Premium Puzzle. The Quarterly Journal of Economics. 73-92.

Benartzi, S., \& Thaler, R. H. (1999). Risk Aversion or Myopia? Choices in Repeated Gambles and Retirement Investments. Management Science. 45(3), 364-400.

Bernoulli, D. (1954) Exposition of a New Theory on the Measurement of Risk. Econometrica. 22(1), 23-36.

Bernstein, P. L., \& Damodaran, Aswath. (Orgs). (1998). Investment Management. New York: John Wiley.

Berry, L. L. (1995). Relationship Marketing of Services - Growing Interest, Emerging Perspectives. Journal of the Academy of Marketing Science. 23(4), 236-245.

Berry, L. L. (2002) Relationship Marketing of Services - Perspectives from 1983 and 2000. Journal of Relationship Marketing. 1(1).

Bettman, J., Luce M., Payne, J. (2006), Constructive Consumer Choice Processes. In: LICHTENSTEIN, S.; SLOVIC, P. (Orgs) The Construction of Preference. New York: Cambridge University Press.

Blackwell, R. D., Miniard, P. W., \& Engel, J. F. (2011) Comportamento do Consumidor. Porto Alegre: Bookman.

Bloemer, J., Ruyter, K., \& Peeters, P. (1998) Investigating drivers of bank loyalty: the complex relationship between image, service quality and satisfaction. International Journal of Bank Marketing. 16/7, 276-286.

Bodie, Z., Kane, A., \& Marcus, A. J. (2013) Investments. New York: McGraw-Hill.

Bohm, G., \& Brum, W. (2008) Intuition and affect in risk perception and decision making. Judgment and Decision Making. 3(1), 1-4.

Bolte, A., Goschke, T., \& Kuhl, J. (2003) EMOTION AND INTUITION: Effects of Positive and Negative Mood on Implicit Judgments of Semantic Choerence. Psychological science. $14(5), 416-421$.

Brasinska, N., Schäfer, D., \& Stephan, A. (2012) Individual Risk Attitudes and the Composition of Financial Portfolios: Evidence from German Household Portfolios. The Quarterly Review of Economics and Finance. 52, 1-14. 
Byrne, K. (2005) How do consumers evaluate risk in financial products. Journal of Financial Services Marketing. 10(1), 21-36.

Camerer, C. F., \& Loewenstein, G. (2004) Advances in Behavioral Economics. New Jersey: Princetown University.

Charness, G., \& Gneezy, U. (2012) Strong Evidence for Gender Differences in Risk Taking. Journal of Economic Behavior \& Organization. 83, 50-58.

Chuah, S., \& Devlin, J. (2011) Behavioural Ecomomics and Financial Services Marketing: A Review. International Journal of Bank Marketing. 29(6), 456-469.

Cronin, J. J., \& Taylor S. A. (1992) Measuring Service Quality: Reexamination and Extension. Journal of Marketing. 56(3), 55-68.

Damodaran, A. (1998) Introduction: The Investment Process. In: Investment Management. New York: John Wiley, 1998.

Damodaran, A. (2009) Gestão Estratégica do Risco. Porto Alegre, RS: Bookman.

Desarbo, W. S. (1995) Markketing Segmentation with Choice-Based Conjoint Analysis. Marketing Letters. 6(2), 137-147.

Desarbo, W. S., Ramaswamy, V. \& Cohen, S. H. (1995) Market Segmentation with ChoiceBased Conjoint Analysis. Marketing Letters. 6(2), 137-147.

Dholakia, U. M. (2001) A motivational process model of product involvement and consumer risk perception. European Journal of Marketing. 35(11-12), 1340-1360.

Dolvin, S. D., \& Templeton, W. K. (2006) Financial Education and Asset Allocation. Financial Services Review. 15, 133-149.

Dwyer, P. D., Gilkeson, J. H., \& List, J. A. (2002) Gender differences in revealed risk taking: evidence from mutual fund investors. Economics Letters. 76, 151-158.

Ellis, C. D. (2014) The Rise and Fall of Performance Investing. Financial Analyst Journal. 70(4), 14-23.

Ellis, C. D., Bernstein, P. L., \& Damodaran, A. (1998) The Investment Setting. In: Investment Management. New York: John Wiley.

Elton, E. J., \& Gruber, M. J. (1997) Modern Portfolio Theory, 1950 to Date. Journal of Banking \& Finance. 21, 1743-1759.

Estelami, H. (2012) Marketing Financial Services. Indianapolis: Dog Ear Publishing.

Federação Brasileira de Bancos. (2011) Pesquisa FEBRABAN de Tecnologia Bancária 2014. $\begin{array}{lllll}\text { Recuperado em } & 19 & \text { dezembro, } & 2014, & \text { de }\end{array}$ https://www.febraban.org.br/7Rof7SWg6qmyvwJcFwF7I0aSDf9jyV/sitefebraban/Pesquisa\% 20FEBRABAN\%20de\%20Tecnologia\%20Bancaria\%202014.pdf 
Fellner, G., \& Maciejovsky, B. (2007) Risk Attitude and Market Behavior: Evidence from Experimental Asset Markets. Journal of Economic Psychology. 28, 338-350.

Finucane, M. L., Alhakami, A., Slovic, P., \& Johnson, S. M. (1968) The Affect Heuristic in Judgment of Risks and Benefits. Journal of Behavioral Decision Making. 13, 1

Fishburn, P. C. (1968) Utility Theory. Management Science. 14(5), 335-378.

Frederick, S. (2005) Cognitive Reflection and Decision Making. The Journal Economic Perspectives. 19(4), 25-42.

Frederick, S.; Loewenstein, G.; O'Donoghue, T. (2002) Time Discounting and Time Preference: A Critical Review. Journal of Economic Literature. 40(2), 351-401.

Gallouj, F., \& Weinstein, O. (1997) Innovation in Services. Research Policy. 26, 537-556.

Ganesan, S. (1994) Determinants of Long-Term Orientation in Buyer-Seller Relationship. The Journal of Marketing. 58(2), 1-19.

Ganzach, Y. (2000) Judging Risk and Return of Financial Assets. Organizational Behavior and Human Decision Processes. 83(2), 353-370.

Garbarino, E., \& Johnson, M. S. (1999) The Diffrent Roles of Satisfaction, Trust, and Commitment in Customer Relationships. Journal of Marketing. 63(2), 70-87.

Gigerenzer, G., \& Gaissmaier, W. (2011) Heuristics Decision Making. Annual Review of Psychology (62). $451-482$.

Gilovich, T, Griffin, D., \& Kahneman, D. (Orgs.) (2002). Heuristics and Biases: The Psychology of Intuitive Judgment. New York: Cambridge University Press.

Green, P., Krieger, A., Wind, Y. (2001) Thirty Years of Conjoint Analysis: Reflections and Prospects. Interfaces. 31(3), S56-S73.

HAIR JR., J., Babin, B., Money, A., Samouel, P. (2005). Fundamentos e Métodos de Pesquisa de Administração. Porto Alegre: Bookman.

HAIR JR., J., Black, W., Babin, B., Anderson, R., Tatham, R. (2009). Análise Multivariada de Dados. Porto Alegre: Bookman.

Hastie, R., \& Dawes, R. (2010). Rational Choice in an UncertainWorld: The Psychology of Judgment and Decision Making. California: Sage Publications.

Hausman, D. M. (2012) Preference, value, Choice, and Welfare. New York: Cambridge University Press.

Hoffmaan, D. K., Bateson, J. E. G., Ikeda, A. A., \& Campomar, M. C. (2010) Princípios de Marketing de Serviços. São Paulo: Cengage Learning.

Hogarth, R. M., Portell, M., Cuxart, A., \& Kolev, G. I. (2011) Emotion and Reason in Everyday Risk Perception. Journal of Behavioral Decision Making. 24, 202-222.

Holton, G. A. (2004) Defining Risk. Financial Analyst Journal. 60(6), 19-25. 
INVESTMENT COMPANY INSTITUTE (ICI). (2003) Understanding Mutual Funds. Washington.

INVESTMENT COMPANY INSTITUTE (ICI). (2013). Ownership of mutual funds, Shareholder Sentiment, and use of the internet. 19 (9).

Johnson, R. M. (1974) Trade-Off Analysis of Consumer Values. Journal of Marketing Research. 11, $121-127$.

Jordan, J., \& Kaas, K. P. (2002) Advertising in the mutual fund business: The role of judgmental heuristics in private investors'evaluation of risk and return. Journal of Financial Services Marketing. 7(2), 129-140.

Kahneman, D. (2003) A Perspective on Judgment and Choice. American Psychologist. 58(9), 697-720.

Kanheman, D. (2011). Rápido e devagar: duas formas de pensar. Rio de Janeiro, RJ: Objetiva.

Kahneman, D., \& Frederick, S. (2002) Representativeness Revisited: Attribute Substituition in Intuitive Judgment. In Heuristics and Bisses: The Psychology of Intuitive Judgment. New York: Cambridge University Press.

Kahneman, D., \& Riepe, M. (1998) Aspects of Investor Psychology: Beliefs,Preferences, and biases investment advisors should know about. Journal of Portfolio Management. 24 (4).

Kahneman, D., \& Tversky, A. (1979) Prospect Theory: An Analisys of Decision Under Risk. Econometrica, 47 (2), 263-92.

Kahneman, D., \& Tversky, A. (1983). Choices, Values, and Frames. American Psychologist. V. 39, n. 4, p. $341-350$.

Kahneman, D., \& Tversky, A. (Orgs) (2000). Choices, Values, and Frames. New York: Cambridge University Press.

Kahneman, D., Knetsch, J., Thaler, L., \& Richard, H. (1990) Experimental Tests of the Endowment Effect and the Coase Theorem. The Journal of the Political Economy. 98 (6), 1325-1348.

Kahneman, D., Knetsch, J., Thaler, R. (1991) Anomalies: The Endowment Effect, Loss Aversion, and Status Quo Bias. The Journal of Economic Perspectives. V. 5. N. 1, p. 193 206.

Kamakura, W., Wedel, M., Rosa, F., \& Mazzon, J. (2003). Cross-selling through database marketing: a mixed data factor analyzer for data augmentation and prediction. International Journal of Research in Marketing, 20, 45-65.

Keeney, R. L., \& Raiffa, H. (1993) Decisions With Multple Objectives: Preferences and Value Tradeoffs. New York: Cambridge University Press. 
Kimura, H. (2003) Aspectos Comportamentais Associados às Reações do Mercado de Capitais. RAE-Eletrônica. 2 (1).

Kimura, H., Basso, L. F. C., \& Krauter, E. (2006) Paradoxos em Finanças: Teoria Moderna Versus Finanças Comportamentais. RAE-Eletrônica. 46 (1).

Klos, A. (2014) Investment Decisions and Time Horizon: Risk Perception and Risk Behavior in Repeated Gambles. Disponível em: <http://www.ssrn.com/avstract=1301228>.

Klos, A., Weber, E. U., \& Weber, M. (2005) Investment decisions and time horizon: Risk perception and risk behavior in repeated gambles. SSRN. Recuperado de $\mathrm{http} / / \mathrm{ssrn} . \mathrm{com} / \mathrm{abstract}=1301228$.

Köche, C. (2002). Fundamentos de Metodologia Científica. Rio de Janeiro: Vozes.

KOTLER, P.; KELLER, K. (2012) Administração de Marketing. São Paulo: Pearson.

Kritzman, M. (1998) Risk and Utility: Basics. In Bernstein, P., \& Damodaran, A. (Orgs) Investment Management. New York: John Wiley.

Kruglanski, A. W., \& Gigerenzer, G. (2011) Intuitive and Deliberative Judgments Are Based on Common Principles. Psychological Review. 118(1), 97-109.

Kumar, V., Lemon, K. N., \& Parasuraman, A. (2006) Managing Customer Value: An Overview and Research Agenda. Journal of Service Research. 9(2), 87-94.

Las Casas, A. (2007) Marketing Bancário. São Paulo: Saint Paul Editora.

Lichtenstein, S., \& Slovic, P. (Orgs.). (2006) The Construction of Preference: An Overview. In: The Construction of Preference. New York: Cambridge University Press.

Lichtenstein, S., \& Slovic, P. Reversals of Preference Between Bids and Choices in Gambling Decisions. Journal of Experimental Psychology. 89(1), 46-55.

Lima, M. V. (2003) Um Estudo sobre Finanças Comportamentais. RAE-Eletrônica. 2(1).

Loewenntein, G. F., Weber, E. U., Hsee, C. K, \& Welch, N. (2001) Risk as Feelings. Psychological Bulletin. 127(2), 267-286.

Loewenstein, G. (Org.). (2003) Time and Decision: Economic and Psychological Perspectives on Intertemporal Choice. New York: Russel Sage Foundation.

Loomes, G., \& Sugden, R. (1982) Regret Theory: An Alternative Theory of RationalChoice Under Unvcertainty. The Economic Journal. 92(368), 805-824.

Louviere, J. J. (1988) Analysing Decision Making: Metric Conjoint Analysis. California: Sage Publications.

Louviere, J. J., \& Woodworth, G. (1983) Design and Analysis of Simulated Consumer Choice or Allocation Experiments: An Approach Base on Aggregate Data. Journal of Marketing Research. 20, 350-367, nov.

Lovelock, C., \& Wirtz, J. (2006). Marketing de Serviços. São Paulo: Pearson Prentice Hall. 
Lunenburg, F. C. (2010) Escalation of Commitment: Patterns of Retrospective Rationality. International. Journal of Management, Business, and administration. 13(1), 1-5.

Maafi, H. (2011) Preference Reversals Under Ambiguity. Management Science. 57(11), 20542066.

Magretta, J. (2012) Entendendo Michael Porter. São Paulo: HSM Editora.

Malhotra, N. (2012) Pesquisa de Marketing. Porto Alegre: Bookman.

Malkiel, B. G. (2007) A Randon Walk Down Wall Street. New York: W.W. Norton \& Company.

Markowitz, H. (1952) Portfolio Selection. The Journal of Finance. 7(1), 77-91.

Markowitz, H. (1990). Normative Portfolio Analysis: Past, Present, and Future. Journal of Economic and Business, 103, 42- 99.

Mayer, R. C., \& Davis, J. H. (1995) An Integrative Model of Organizational Trust. Academy of Management Review. 20(3), 709-734.

Mobius, M. (2007) Mutual Funds. Singapura: Wiley \& Sons.

Moorman, C., Deshpandé, R., \& Zaltman, G. (1993) Factors Affecting Trust in Market Research Relationships. Journal of Marketing. 57(1), 81-101.

Morgan, R. M., \& Hunt, S. D. (1994) The Commitment-Trust Theory of Relationship Marketing. Journal of Marketing. 58, 20-38.

Neri, M. (2011) A Nova Classe Média. São Paulo: Saraiva.

Nofsinger, J. R. (2011) The Psychology of Investing. Boston: Pearson.

Nofsinger, J., \& Varma, A. (2007) How Analytical is Your Financial Advisor?. Financial Services Review. 17, 245-260.

Novemsky, N., \& Kahneman, D. (2005) The Boundaries of Loss Aversion. Journal of Marketing Research. 42, 119-128.

Odean, T. (1998) Are Investor Reluctant to Realize Their Losses. The Journal of Finance. 53(5), 1775-1798.

Olsen, R. A. (1997) Investment Risk: The Experts' Perspective. Financial Analysts Journal. 53(2), 62-66.

Oppenheimer, D. M., \& Kelso, E. (2015) Information Processing as a Paradigm for Decision Making. Annu. Rev. Psychol. 66, 277-294.

Orme, B. K. Which Conjoint Method Should I Use? Research Paper. Sawtooth Software, Recuperado em março, 2014, de http://www.sawtoothsoftware.com/support/technicalpapers\#general-conjoint-analysis. 
Orme, B. K. (2010) Getting Started with Conjoint Analysis. Ohio: Research Publishers, LLC.

Pachur, T., Hertwig, R., \& Steinmann, F. (2012) How Do People Judge Risks: Availability Heuristic, Affect Heuristic, or Both. Journal of Experimental Psychology: Applied. 18(3), 314-330.

Parasuraman, A., Zeithaml, V. A., \& Berry, L. L. (1985) A Conceptual Model of Service Quality and Its Implications for Future Research. Journal of Marketing. 49(4), 41-50.

Pensa, P. (2006). Nomen est Omen: How Company Names Influence Short- and Long-Run Stock Market Performance. Recuperado em 11 de junho, 2015, de http://EconPapers.repec.org/RePEc:bsl:wpaper:2006/13.

Peterson, M. (2009). An Introduction to Decision Theory. Cambridge: Cambridge University Press.

Pilli, L. (2012) Julgamento e Decisão: Limites para a Racionalidade do Consumidor. (Dissertação Mestrado em Administração) - Programa de Pós-Graduação em Administração, Faculdade de Economia, Administração e Contabilidade da Universidade de São Paulo, São Paulo.

Pindyck, R. S.; \& Rubinfeld, D. L. (2010) Microeconomia. São Paulo: Makron Books.

Pinheiro, R. (2011). Comportamento do Consumidor. Rio de Janeiro: FGV.

Pompian, M. (2012) Behavioral Finance and Wealth Management. New Jersey: John Willey \& Sons.

Porter, M. (1986) Estratégia Competitiva. Rio de Janeiro: Campus.

Powell, M., \& Ansic, D. (1997) Gender differences in risk behavior in financial decisionmaking: An experimental analysis. Journal of Economic Psychology. 18, 605-628.

Qi, J., Zhou, Y., Chen, W., \& Qu, Q. (2012) Are customer satisfaction and customer loyalty drivers of customer lifetime value in mobile data services: a comparative cross-country study. Information Technology Management. 13, 281-296.

Rabin, M. (2000) Risk Averse and Expected Utility Theory: A Calibratioon Theorem. Econometrica. 68, 1281-1292.

Reilly, F., \& Brown, K. (2012) Investment Analysis Portfolio Management. Ohio: Thomson South-Western.

Reyna, V. F. (2004) How People Make Decisions That Involve Risk. Current Direction in Psychological Science. 13(2), 60-66.

Rieskamp, J. (2006) Extending the Bounds of Rationality: Evidence and Theories of Preferential Choice. Journal of Economic Literature.44, 631-661.

Rouwenhorst, G. (2004) The Origins of Mutual Funds. Yale School of Management (Working Paper). 
Rust, R.; Zeithaml, V., \& Lemon, K. (2001) O Valor do Cliente. Porto Alegre: Bookman.

Samuelson, P. (1937) A Note on Measurement of Utility. The Review of Economic Studies. $4(2), 155-161$.

Samuelson, W., \& Zeckhauser, R. (1988) Status Quo Bias in Decision Making. 1, 7-59, 1988.

Sawtooth, S. (2014) The CBC System for Choice-Based Conjoint Analysis: Version 8. Recuperado em 30 de junho, 2015, de http://www.sawtoothsoftware.com/support/downloads.

Schniter, E., Sheremeta, R., \& Sznycer, D. (2013). Building and Rebuilding Trust with Promises and Apologies. Journal of Economic Behavior \& Organization 94, 242-256.

Schoemaker, P. (1982) The Expected Utility Model: Its Variants, Purposes, Evidence and Limitations. Journal of Economic Literature. 20(2), 529-563.

Shah, A., \& Oppenheimer, D. (2007 Easy Does It: The Role of Fluency in Cue Weighting. Judgment and Decision Making, 2 (6) 94, 371-379.

Shainesh, G. (2012) Effects of trustworthiness and trust on loyalty intentions - Validating a parsimonious model in banking. International. Journal of Bank Marketing. 30(4), 267-279.

Shefrin, H. (2002) Beyond Greed and Fear: Understanding Behavioral Finance and the Psychology of Investing. New York. Oxford: University Press.

Shefrin, H., \& Statman, M. (1985) The Disposition to Sell Winners Too Early and Ride Loosers Too Long: Theory and Evidence. The Journal of Finance. 40(3), 777-790.

Shleifer, A. (2000) Inefficient Markets: An Introduction To Behavioral Finance. New York: Oxford University Press.

Shostack, L. (1977) Breaking Free from Product Marketing. Journal of Marketing. 41(2), 7380 .

Simon, H. (1955) A Behavioral Model of Rational Choice. The Quartely Journal of Economics. 69(1), 99-118.

Siqueira, J. (1997) Mensuração da Estrutura de Preferência do Consumidor: uma aplicação de Conjoint Analysis em Marketing. (Dissertação Mestrado em Administração) Programa de Pós-Graduação em Administração, Faculdade de Economia, Administração e Contabilidade da Universidade de São Paulo, São Paulo.

Sirdeshmukh, D., Singh, J., \& Sabol, B. (2002) Consumer Trust, Value, and Loyalty in Relational Exchanges. Journal of Marketing. 66, 15-37.

Sitkin, S., \& Pablo, A. (1992) Reconceptualizing the determinantes of risk behavior. Academy of Management Review. 17(1), 9-38.

Sitkin, S., \& Weingart, L. (1995) Determinants of Risky Decision-Making behavior: A test of the mediating role of risk perceptions and propensity. Academy of Management Journal. 38(6), 1573-1592. 
Slovic, P. (1982) Facts versus Fears: Understanding Perceived Risk. in Judgment Under Uncertainty: Heuristics and Biases. New York: Cambridge University Press.

Slovic, P. (1987) Percetion of Risk. Science. 236(4799), 280-285.

Slovic, P. (1999) Trust, Emotion, Sex, Politics, and Science: Surveying the Risk-Assessment Battlefield. Risk Analysis. 19(4), 689-701.

Slovic, P. (2002) The Affect Heuristic. In Gilovich, T., Griffin, D., \& Kanheman, D. (Orgs) Heuristics and Biases: the Psychology of Intuitive Judgment. New York: Cambridge University Press.

Slovic, P. (2004) Risk as Analysis and Risk as Feelings: Some Thoughts about Affect, Reason, Risk, and Rationality. Risk Analysis. 24(2), 311-322.

Slovic, P., \& Lichtenstein, S. (2006) Relative Importance of Probabilities and Payoffs in Risk Taking. In: The Construction of Preference. New York: Cambridge University Press.

Slovic, P., Peters, E. (2006) Risk Perception and Affect. Current Directions in Psychological Sciennce. 15(6), 322-325

Slovic, P., Finucane, M. L., Peters, E., \& MacGregor, D. G. (2004) Risk as Analysis and Risk as Feelings: Some Thoughts about Affect, Reason, Risk, and Rationality. Risk Analysis. 24(2), 311-322.

Slovic, P., Finucane, M., Peters, E., \& MacGregor, D. G. (2002) The Affect Heuristic. in: Heuristics and Biases: the psychology of intuitive judgment. 397-420.

Slovic, P., Fischhoff, B., \& Lichtenstein, S. (1982) Why Study Risk Perception?. Risk Analysis. 2(2), 83-93.

Slovic, P., Peters, E., Finucance, M. L., \& MacGregor, D. G. (2005) Affect, Risk, and Decision Making. Health Psychology. 24(4), 535-540.

Solomon, M. (2011). O Comportamento do Consumidor. Rio Grande do Sul: Bookman.

Soman, G. (2005) The Psychology of Intertemporal Discounting:Why Are Distant Events Valued Differently from Proximal Ones?.Markketing Letters. 347-360.

Stanovich, K. E., \& Evans, J. B. T. (2013) Dual-Process Theories of Higher Cognition: Advancing the Debate. Association for Psychological Science. 8(3), 223-241.

Stanovich, K., \& West, R. (2000) Individual Differences in Reasoning: Implications for the Rationality Debate?. Behavioral and Brain Sciences. 23, 645-726.

Starmer, C. (2000) Developments in Non-Expected Utility Theory: The Hunt for a Descriptive Theory of Choice Ubder Risk. Journal of Economic Literature. 38, 332-382.

Statman, M. (1999) Behavioral Finance: Past Battles and Future Engagement. Association for Investment Management and Research. 
Statman, M., \& Klimek, G. (2010) The Cultures of Risk Tolerance. Recuperado em 10 de janeiro, 2014, de http://ssrn.com/abstract $=1647086$.

Staw, B. (1981) The Escalation Commitment to a Course of Action. Academy of Management Review. 6(4), 577-587.

Steinkuhler, D., Mahlendor, M. D., \& Brettel, M. (2014) How Self-Justification Indirectly Drives Escalation of Commitment - A Motivational Perspective. Sbr. 66, 191-222

Svenson, O. (2006) Pre- and Post- DecisionConstructionof Preferences: Differentiation and Consolidation. In: Slovic, P., Lichtenstein, S. (Orgs), The Construction of Preference. New York: Cambridge University Press.

Takahashi, C. (2013) Investimentos: e agora José. Valor Econômico.

Thaler, R. (1980) Toward a Positive Theory of Consumer Choice. Journal of Economic Behavior and Organization. 1, 39 -60.

Thaler, R. (1985). Mental Account and the Consumer Choice. Marketing Science. v. 4, n. 3, p. 199-214.

Thaler, R. (1988). Anomalies: The Winner's Curse. The Journal of Economic Perspectives. v. 2, n. 1, p. 191-202.

Thaler, R. (1990) Gambling with the House Money and Trying to Break Even: The Effects of Prior Outcomes on Risky Choice. Management Science. 36(6), 643-660.

Thaler, R. (1993). Advances in Behavioral Finance. New York: The Russell Sage Foundation, 1993.

Thaler, R. (1999). The End of Behavioral Finance. Financial Analysts Journal. V. 55, n. 6, p. $12-17$, nov.-dec.

Thaler, R. (2000) From Homo Economicus to Homo Sapiens. Journal of Economic Perspectives. 14(1), 133-141.

Thaler, R., \& Sunstein, C. (2009) NUDGE: O Empurrão para a Escolha Certa. Rio de Janeiro: Elsevier.

THE ROYAL SWEDISH ACADEMY OF SCIENCE. Foundations of Behavioral and Experimental Economics: Daniel Kahneman and Vernon Smith. Recuperado em novembro, 2013, de http://www.nobelprize.org/ceremonies/archive/2002.

Tice, D. M., Bratslavsky, E., \& Baumeister, R. (2001) EmotionalDistress Regulation Takes Precedence Over Impulse Control: If you Feel Bad, Do It!. Journal of Personality and Social Psychology. 80(1), 53-67.

Toledo, G. (1978) Marketing Bancário. São Paulo: Atlas.

Topolinski, S., \& Strack, F. (2009) The anlysis of intuition: Processing fluency and affect in judgements of semantic coherence. Psychology Press. 23(8), 1465-1503. 
Trautmann, S. T., Vieider, F. M., \& Wakker, P. P. (2011) Preference Reversals for Ambiguity Aversion. Management Science. 57(7), 1320-1333.

Tversky, A. (1990) The Cuases of Preference Reversal. The American Economic Review. 80(1), 204-217.

Tversky, A., \& Kahneman, D. (1974) Judgement Under Uncertainty: Heuristics and Biases. Science; 211(185), 1124-1131.

Tversky, A., \& Kahneman, D. (1981). The Frame of Decisions and the Psychology of Choice. Science. V.. 211, n. 4481, 453-58.

Tversky, A., \& Kahneman, D. (1986). Rational Choice and the Framing of Decision. The Journal of Business. V. 59, n. 4, p. S251 - S278.

Tversky, A., \& Kahneman, D. (1991). Loss Aversion in Riskless Choicce: A ReferenceDependent Model. The Quarterly Journal of Economics. P. 1039 - 1061.

Tversky, A., \& Kahneman, D. (1992). Advances in Prospect Theory: Cumulative Representation of Uncertainty. Journal of Risk and Uncertainty.V. 5, p. $297-323$.

Tversky, A., \& Simonson, I. (1993) Context-Dependent Preferences. Management Science. 39(10), 1179-1189.

Tversky, A., \& Thaler, R. (1990) Anomalies: Preference Reversals. The Journal of Economics Perspectives. 4(2), 201-211.

Verhoef, P. C., \& Lemon, K. N. (2013) Successful customer value management: Key lessons and emerging trends. European Management Journal. 31, 1-15.

Von Neumann, J., \& Morgenstern, O. (1944) Theory of Games and Economic Behavior. New Jersey: Princeton University Press.

Wakker, P. (2010) Prospect Theory For Risk and Ambiguity. New York: Cambridge University Press.

Weaver, R., \& Frederick, S. (2012) A Reference Price Theory of the Edowment Effect. Journal of Marketing Research. XLIX, 696-707.

Weber, E. U., \& Milliman, R. A. (1997) Perceived Risk Attitudes: Relating Risk Perception to Risky Choice. Management Science. 43(2), 123-144.

Weber, E. U., Anderson, C. J., \& Birnbaum, M. H. (1992) A Theory of Perceived Risk and Attractiveness. Organizational Behavior and Human Decision Processes. 52, 492-523

Weber, E. U., Blais, A., \& Betz, E. (2002) A Domain-specific Risk-attitude Scale: Measuring Risk Perceptions and Risk Behaviors. Journal of Behavioral Decision Making. 15, 263-290.

Weber, M., \& Zuchel, H. (2005) How Prior Outcomes Affect Risk Attitude? Comparing Escalation of Commitment and the House-Money Effect. Decision Analysis. 2(1), 30-43. 
Weber, M., Weber, E. U., \& Nosic, A. (2013) Who takes Risks When and Why: Determinants of Changes in Investor Risk Taking. Review of Finance. 17, 847-883.

Zeithaml, V., Berry, L., \& Parasuraman, A. (1993) The Nature and Determinants of Customer Expectations of Service. Journal of the Academy of Marketing Science. 21(1), 1-12.

Zeithaml, V., Berry, L., \& Parasuraman, A. (1996) The Behavioral Consequences of Service Quality. Journal of Marketing. Vol. 60, nº 2, p. 31-46. 


\section{Anexo A - Questionário}

A seguir versão do questionário utilizado na pesquisa.

\section{Apresentação}

Esta pesquisa é realizada pelo instituto ILUMEO, em contribuição a uma tese de doutorado da FEA USP.

Primeiramente, obrigado por responder ao questionário. Sua opinião é muito importante para nós.

Se você responder até o fim, concorrerá a um vale presente da livraria cultura no valor de $\mathrm{R} \$ 100$ para gastar em qualquer produto da loja.

O questionário dura em torno de 25 minutos.

Por favor, responda com bastante atenção e dê respostas muito sinceras. Lembre se que não há resposta certa nem errada. O mais importante é a sua opinião verdadeira.

Passe para a próxima página para começar a responder.

\section{Seção I - Dados Sócio Econômicos e Perfil do Investidor}

\begin{tabular}{|l|}
\hline I.1. Dados Sócio Econômicos \\
\hline 1. Sexo \\
\hline . Masculino \\
. Feminino \\
\hline 2. Idade (informe abaixo) - (filtro: acima de 22 anos) \\
\hline . ( \\
\hline 3. Estado em que reside \\
\hline . Lista dos estados da federação \\
\hline 4. Estado civil \\
\hline . Solteiro \\
. Casado/"Mora Junto" \\
. Divorciado/Separado \\
. Viúvo \\
\hline 5. Nível máximo de educação completo \\
\hline . Fundamental \\
. Médio \\
Superior \\
. Pós-graduação \\
. Mestrado \\
. Doutorado \\
\hline
\end{tabular}




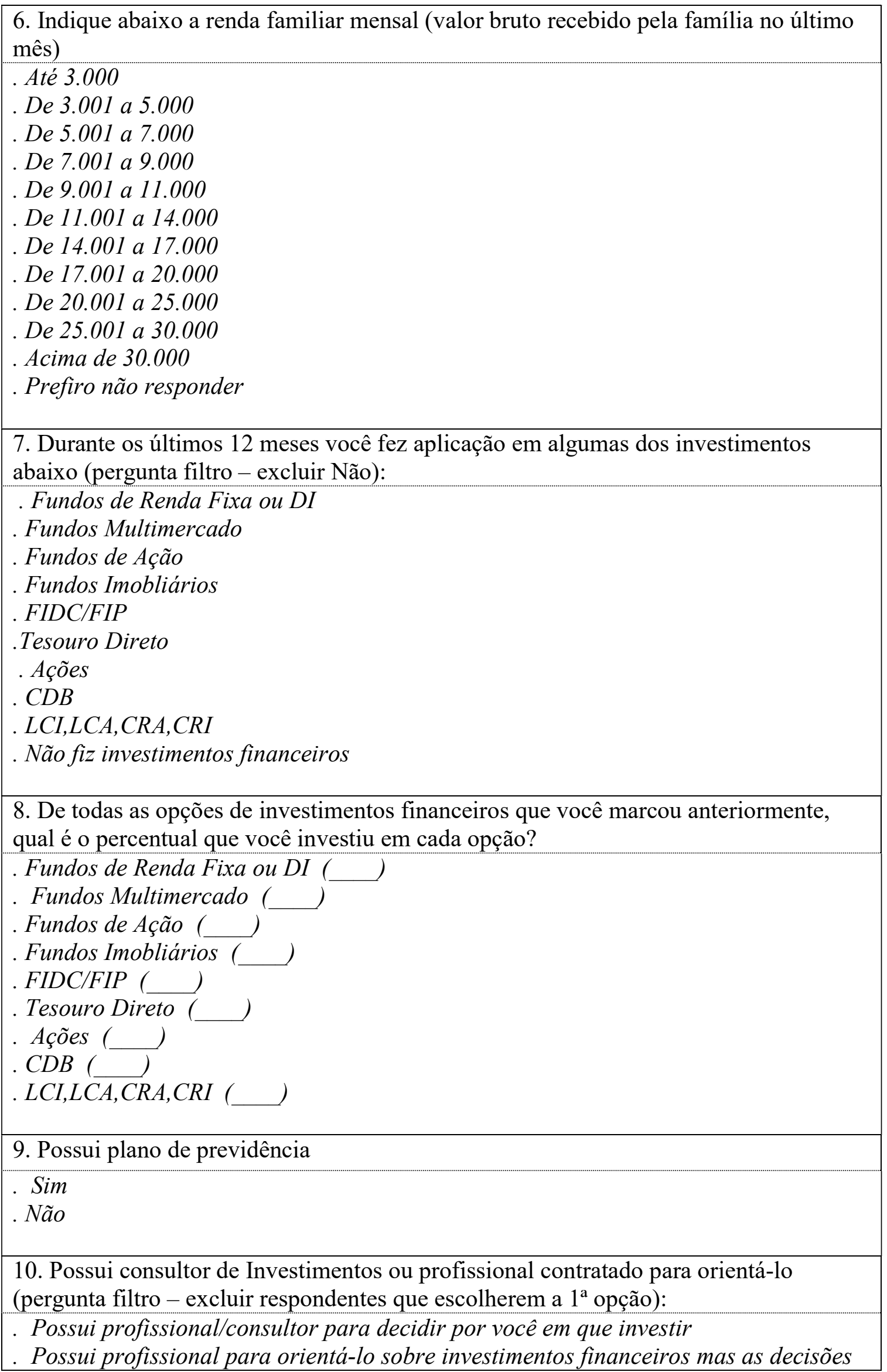


são tomadas por você

. Não possui profissional/consultor de investimentos financeiros e toma suas decisões

\section{I.2. Conhecimento sobre Investimentos}

11. Como classifica seus conhecimentos sobre investimentos

. Muito baixo

. Baixo

. Médio

. Alto

. Muito alto

12. Indique em uma escala de 1 a 7, o quão capaz você se considera para dar conselhos sobre investimentos financeiros para amigos e familiares.

De 1 a 7 (sendo 1 o menor)

I.3. Perfil de investidor (deve ser considerado um cenário em que os recursos a serem investidos estão livres, ou seja, não são necessários para pagamento de despesas ou compra de bens)

13. Indique, em uma escala de 1 a 7 , o quão avesso a risco você se considera no momento de realizar algum investimento financeiro.

De 1 a 7 (sendo 1 o menor)

14. Qual dos comportamentos abaixo melhor representa, em geral, sua disposição na hora de investir (você procura)?

. Risco substancial para ganhos substanciais

- Risco acima da média para ganhos acima da média

- Risco médio para ganho médio

Risco baixo para ganho baixo

. Nenhum risco

15. Indique, em uma escala de 1 a 7, qual a importância de cada uma das fontes de informação abaixo.

. Gerente do banco (de 1 a 7 - sendo 1 o menor)

- Especialista de investimentos do banco

. Internet (sites de bancos, corretoras ou assessores financeiros e outros

especializados) (de 1 a 7 - sendo 1 o menor)

. Amigos e parentes (de 1 a 7 - sendo 1 o menor)

. Leitura de Jornais e revista, (de 1 a 7 - sendo 1 o menor)

- Assistir TV elou ouvir rádio(de 1 a 7 - sendo 1 o menor)

. Cursos, seminários e palestras(de 1 a 7 - sendo 1 o menor)

16. Ordene do mais importante ao menos importante $(1=$ mais importante e $3=$ menos importante), os fatores que influenciam sua decisão em realizar o investimento financeiro..

- Retornos passados

. Liquidez

. A instituição responsável pelo produto 
Seção II - Escala CRT (teste)

\section{II.1 Responda a questão abaixo utilizando somente números.}

16. (1) Um bastão e uma bola custam $\mathrm{R} \$ 1,10$. O bastão custa $\mathrm{R} \$ 1,00$ a mais que a bola. Quanto custa a bola? (__ ) centavos

17. (2) Cinco máquinas levam 5 minutos para produzir 5 peças. Quanto tempo levará para 100 máquinas produzirem 100 peças? (

18. (3) Em um lago, há uma parte coberta por lírios. Todo dia esta parte dobra de tamanho. Se levar 48 dias para que os lírios cubram todo o lago, quanto tempo levaria para os lírios cubrissem metade do lago?

\section{Seção III - Opções para Escolha (Conjoint Analysis)}

\section{Cenário}

Para 1/3 da amostra é apresentado um cenário negativo, para outro $1 / 3$ um cenário positivo e para a os $1 / 3$ restantes não é apresentado qualquer cenário.

O propósito dos cenários é induzir uma percepção de maior ou menor risco para tomada de decisão e, assim, alterar o ponto de referência a partir do qual os respondentes tomarão suas decisões em relação às opções de investimento (estímulos) apresentadas a seguir. O grupo para o qual não foi apresentado cenário funciona como controle.

Ao final de cada cenário é solicitado ao respondente que avalie o cenário (manipulation check) conforme abaixo.

Em sua opinião este cenário apresentado é considerado:

. Muito ruim

Ruim

. Neutro

. Bom

. Muito bom 
Após a apresentação dos cenários, são apresentados os estímulos, exemplo a seguir.

Veja as 5 opções de investimentos financeiros mostradas abaixo levando em consideração as 5 principais características mostradas na primeira coluna. Abaixo da tabela, selecione aquela que parece ser a mais atrativa para você.

\section{Exemplo}

\begin{tabular}{|c|c|c|c|c|c|}
\hline Atributos/Fatores & Opção 1 & Opção 2 & Opção 3 & Opção 4 & Opção 5 \\
\hline $\begin{array}{l}\text { Rentabilidade } \\
\text { nominal no ano } \\
\text { anterior }\end{array}$ & $10 \%$ a.a. & $18 \%$ a.a. & $10 \%$ a.a. & $14 \%$ a.a. & $6 \%$ a.a. \\
\hline $\begin{array}{l}\text { Pior rentabilidade } \\
\text { em um mês no } \\
\text { último } \\
\text { anterior }\end{array}$ & $0,0 \%$ a.m. & $-4 \%$ a.m. & $0,0 \%$ a.m. & $-1 \%$ a.m. & $0,0 \%$ a.m. \\
\hline Liquidez & $\begin{array}{l}\text { no dia } \\
\text { seguinte }\end{array}$ & Em 90 dias & Em 30 dias & $\begin{array}{ll}\text { Em } & 30 \\
\text { dias } & \end{array}$ & $\begin{array}{l}\text { No dia } \\
\text { seguinte }\end{array}$ \\
\hline $\begin{array}{l}\text { Taxa de } \\
\text { Administração } \\
(\% \text { ao ano })\end{array}$ & $3,00 \%$ a.a. & $3,00 \%$ a.a. & $3,00 \%$ a.a. & $2,50 \%$ a.a. & $1,00 \%$ a.a. \\
\hline $\begin{array}{l}\text { Recomendado } \\
\text { pelo gerente }\end{array}$ & recomendado & recomendado & recomendado & Indiferente & recomendado \\
\hline \multicolumn{6}{|c|}{$\begin{array}{l}\text { Analisando as opções acima, qual delas você considera a mais atrativa? } \\
\text { Opção } 1 \\
\text { Opção } 2 \\
\text { Opção } 3 \\
\text { Opção } 4 \\
\text { Opção } 5 \\
. \text { Não considero as opções suficientemente atrativas, prefiro não realizar o investimento. }\end{array}$} \\
\hline
\end{tabular}




\section{Textos utilizados nos cenários}

\section{Cenário 1 (positivo)}

Após um ano de muita responsabilidade e trabalho intenso, sua empresa lhe pagou um bônus substancial como forma de reconhecimento por ter atingido as metas combinadas no ano anterior. Você não precisa desta importância para fazer frente a despesas e, neste momento, não pretende adquirir bens ou propriedades.

Sendo assim, você precisa tomar uma decisão sobre qual aplicação financeira investir este dinheiro. Considerando o cenário a seguir, qual das opções abaixo você escolheria?

$\mathrm{O}$ ano anterior foi muito bom para o Brasil e os principais analistas econômicos esperam que o ano corrente seja ainda melhor. Em relação às expectativas do mercado para este ano, estes analistas estimam que a inflação será reduzida para $4 \%$, abaixo do centro da meta, o Real (R\$) se fortalecerá e a taxa de câmbio terminará o ano abaixo de R\$ 2 reais por dólar (US\$), a taxa de juros cederá abaixo de $9 \%$ ao ano e o PIB crescerá cerca de 4,5\%, melhor resultado dos últimos anos. Este é um cenário bastante positivo que deve atrair mais investimentos e deve alavancar os níveis de renda e emprego.

\section{Cenário 2 (negativo)}

Após um ano de muita responsabilidade e trabalho intenso, sua empresa lhe pagou um bônus substancial como forma de reconhecimento por ter atingido as metas combinadas no ano anterior. Você não precisa desta importância para fazer frente a despesas e, neste momento, não pretende adquirir bens ou propriedades.

Sendo assim, você precisa tomar uma decisão sobre qual aplicação financeira investir este dinheiro. Considerando o cenário a seguir, qual das opções abaixo você escolheria?

$\mathrm{O}$ ano anterior foi muito ruim para o Brasil e os principais analistas econômicos esperam que o ano corrente seja ainda pior. Em relação às expectativas do mercado para este ano, estes analistas estimam que a inflação se elevará ao patamar de $10 \%$, mais que o dobro do centro da meta, a taxa de câmbio se deteriorará e terminará o ano acima de R\$ 3 reais por dólar (US\$), a taxa de juros subirá até $16 \%$ ao ano e o PIB sofrerá uma retração de $-2,5 \%$, pior resultado dos últimos anos. Este é um cenário bastante adverso e deve inibir os investimentos com reflexos negativos nos níveis de renda e emprego. 